\author{
UNIVERSITY OF BELGRADE \\ FACYLTY OF TECHNOLOGY AND METALLURGY
}

Abdolghane M. Torki

\title{
DYNAMIC MECHANICAL PROPERTIES \\ OF HYBRID NANOCOMPOSITE \\ MATERIALS
}

Doctoral Dissertation

Belgrade, 2012 


\section{UNIVERZITET U BEOGRADU \\ TEHNOLOŠKO-METALURŠKI FAKULTET}

Abdolghane M. Torki

\section{DINAMIČKO MEHANIČKA SVOJSTVA HIBRIDNIH NANOKOMPOZITNIH MATERIJALA}

Doktorska Disertacija

Beograd, 2012 
Supervisor:

Dr Radoslav Aleksić, full professor, University Of Belgrade Facylty Of Technology And Metallurgy

\section{Member of Committee}

Dr Petar Uskoković, full professor, University Of Belgrade

Facylty Of Technology And Metallurgy

Dr Vesna Radojević, associate professor, University Of Belgrade Facylty Of Technology And Metallurgy

Dr Milorad Zrilić, associate professor, University Of Belgrade

Facylty Of Technology And Metallurgy

Dr Irena Živković, associate researcher, BIA-Institute of Security

Date: 


\section{ACKNOWLEDGEMENTS}

It is a great pleasure for me to express my sincere gratitude to the people whose generous assistance and support this research.

First and foremost, I would like to express my sincere thanks and appreciation to my project supervisor Dr. Radoslav Aleksic, for his patient guidance. His intellectual insight, work discipline and personal strengths have had a positive influence on my research life, for which I am grateful.

I would like to acknowledge Dr. Petar Uskokovic, Dr. Vesna Radojevic, Dr. Milorad Zrilic and Dr. Irena Zivkovic, my thesis examiners for their insightful suggestions and comments on my thesis.

Special thanks to Dr. Dusica Stojanovic for her encouragements in my research life and technical support in experiments. 


\section{DINAMIČKO MEHANIČKA SVOJSTVA HIBRIDNIH NANOKOMPOZITNIH MATERIJALA}

\section{Rezime}

Predmet istraživanja ove doktorske disertacije pripada oblasti nanomateijala i nanotehnogija koja je u trendu savremenih istraživanja. Posebno su intenzivna istraživanja u oblasti polimernih nanokompozita gde tradicionalno slabe strane polimera (niske vrednosti parametara mehaničke čvrstoće i loša termostabilnost) se značajno poboljšavaju primenom malog udela nano punioca i ojačanja uz neznatan porast gustine. Razvijena je metoda dizajniranja strukture nanokompozitnih balističkih materijala sa gledišta poboljšanja njihovih svojstava otpornosti pri udarima visoke energije. Proučeni su uslovi dobijanja laminarnih kompozitnih materijala p-aramid/poli (vinil butiral). Poli (vinil butiralni) sloj nanošen je u obliku disperzije poli (vinil butirala) i nano čestica $\mathrm{SiO}_{2}$ u etil-alkoholu, pri čemu su korišćene modifikovane i nemodifikovane čestice $\mathrm{SiO}_{2}$ sa vezujućim agensom-AMEO silanom. Na taj nači je utvrđen veliki značaj modifikacije nano čestica $\mathrm{SiO}_{2}$ sa silanima na mehanička, termička i antibalistička svojstva dobijenih hibridnih nanokompozitnih materijala. Savremena istraživanja $\mathrm{u}$ ovoj oblasti usmerena su u pronalaženju mehanizama zaustavljanja rasta prsline modifikovanjem strukture na nano nivou što je i predmet ove doktorske disertacije. Proučavanja u okviru ove disertacije bila su usmerena na istraživanja mehanizama apsorpcije energije u nanokompozitima pri udarnim opterećenjima visoke energije i ponašanje nano čestica kao konstituenata u strukturi hibridnih kompozitnih materijala. Sinteza ovih nanokompozitnih materijala izvršiće se primenom koloidnih suspenzija koje se karakterišu ekstremnim porastom viskoznosti pri velikim brzinama smicanja kojima su izloženi pri udarnim naprezanjima. Originalnost ideje se ogleda što je princip hibridizacije primenjen na izradu laminatnih balističkih ploča sa laminama koje su različito nanomodifikovane a samim tim i sa različitim svojstvima. Značaj ove ideje je što različito nanomodifikovane lamine omogućavaju izradu funkcionalno gradijentnih kompozitnih materijla od nano do mikro nivoa.

Ciljevi ove disertacije su višestruki: 1) proučavanje mehanizama procesiranja nano prahova različitih oksida u različitim disperzionim sredstvima prema klasičnim metodama i savremenim metodama modifikovanja površine čestica; 2) eksperimentalna istraživanje uticaja procesnih uslova brizganja i toplog presovanja hibridnih nonokompozita sa tkaninama od aramidnih vlakana sa različitim udelom modifikovanih nanočestica na njihova dinamickomehanička svojstva (modul sačuvane i izgubljene energije i tangens gubitaka) u različitom temperaturnom intervalu pri različitim frekvencijama); 3) eksperimentalna istraživanje uticaja procesnih uslova brizganja i toplog presovanja hibridnih laminatnih nonokompozita sa 
matricom od poli (vinil butirala) sa različitim udelom modifikovanih čestica silicijum dioksida na makromehanička svojstva (Jungov modul elastičnosti, zatezna čvrstoća, prekidno izduženje); 4) eksperimentalna ispitivanja otpornosti na razaranje dobijenih hibridnih nanokompozitnih materijala na udar velikim energijama i brzinama (standardna balistička ispitivanja sa municijom u realnim uslovima).

Disperzija, stepen deaglomeracije kao i mikrografije polaznih i modifikovanih nanočestica ispitani su korišćenjem transmisione elektronske mikroskopije (TEM). Proces površinske modifikacije nanočestica praćen je metodom infracrvene spektroskopije (FTIR). Morfologija, raspodela i veličina nanočestica u polimernom kompozitu odredjena je metodom skenirajuće elektronske mikroskopije (SEM). Termička karakterizacija dobijenih nanokompozita uradjena je primenom metoda diferencijalne skenirajuće kalorimetrije (DSC). Uticaj udela ojačanja kao i jačina veze ojačanje-polimer za različite temperature i frekvencije dinamičkih naprezanja uspitan je primenom dinamičko-mehaničke analize (DMA). Zatezna mehanička svojstva nanokompozita oderdjena su koriščenjem hidrauličke kidalice sa računarskim sistemom za pracenje rezultata merenja. Udarna balistička ispitivanja velikim energijama izvršena su u standardizovanom balističkom tunelu prema najnovijoj standardizovanoj proceduri NIJ Standard 0101.04 za materijale zaštitu ljudskog tela.

Doprinos rezultata ove teze može se posmatrati sa stanovišta poboljšane modifikacije površina nanočestica kao i dobijanja nanokompozita sa znatno poboljšanim termičkim, dinamičko-mehaničkim i nanomehaničkim svojstvima u poređenju sa do sada objavljenim rezultatima. Analiza raspodele veličina deaglomerisanih nanočestica kao i mikrostrukturna analiza pokazuju da je primena navedene metode dovela do visokog stepena deaglomeracije nanočestica, preciznije, od primarnih aglomerata dimenzija preko $1 \mu \mathrm{m}$, nanosilika čestice su dovedene do dimenzija oko $60 \mathrm{~nm}$ (SEM). Takođe primena ove metode dovela je i do povećanja količine kovalentno vezanih silana kao kuplujućih agenasa i stepena pokrivenosti površine sa procentom hemisorbovanih silana.

Kljucne reči: Nanokompoziti, poli(vinil butiral), nano- $\mathrm{TiO}_{2}$, nano $\mathrm{SiO}_{2}$ dinamičkomehanička svojstva, hibridni kompoziti, laki zaštitni kompoziti

Naučna oblast: Hemija i hemijska tehnologija

Uža naućna oblast: Nauka o materijalima i inženjerstvo materijala

UDK: 66.017 


\title{
DYNAMIC MECHANICAL PROPERTIES OF HYBRID NANOCOMPOSITE MATERIALS
}

\begin{abstract}
The purpose of this dissertation is to investigate the effects of lamination and hybrid soft armor systems through ballistic impact. The investigation was carried out by using dynamic mechanical analysis and actual ballistic testing. The most important conclusions derived from this research are that lamination of the systems with very low resin content are superior to multiple non-laminated systems, and this advance could be improved further by hybrid systems using nanomodified fabric layers on the impact side and relatively tighter woven fabrics between the layers.

This dissertation reports the preparation of $\mathrm{SiO}_{2}$ and $\mathrm{TiO}_{2} /$ poly (vinyl butyral) nanocomposites with enhanced dynamic mechanical properties. Silica and titania nanoparticles were introduced in the matrix as the neat powder and as colloidal sol using the melt mixing process. Composites reinforced with colloidal sol silica and titania showed higher mechanical properties than the ones reinforced with as-received particles. When sol $\mathrm{TiO}_{2}$ particles are used, the highest increase of storage modulus of about $54 \%$ is obtained for $5 \mathrm{wt} \%$ loading, while for sol $\mathrm{SiO}_{2}$, the storage modulus increases with the addition of nanosilica with the largest increase of about $99 \%$ for 7 $\mathrm{wt} \%$ loading. In addition, nanocomposites were introduced within Kevlar/PVB composites. The addition of $5 \mathrm{wt} \%$ silica and titania colloidal sol lead to the remarkable increase of the storage modulus for about 98 and 65\%, respectively. Largest contribution of nanoreinforcements in lowering the glass transition temperature is observed for $7 \mathrm{wt} \%$ loading of $\mathrm{TiO}_{2}$ and $\mathrm{SiO}_{2}$ colloidal sol.

This study reports the manufacture of new fabric forms from the preparation of hybrid laminated multi-axial composites with enhanced thermo-mechanical properties. Thermal and dynamic mechanical analysis of polymer matrix films and fabricated hybrid composites were employed in order to determine the optimal material composition and reinforcement content for composites with improved viscoelastic properties. The introduction of $5 \mathrm{wt}$ \% silica nanoparticles in a composite of p-aramidpoly(vinyl butyral) led to significant improvements in the mechanical properties, and the addition of silane coupling agents yielded maximal values of the storage modulus
\end{abstract}


for hybrid nanocomposites. The introduction of silane led to a better dispersion and deagglomeration of SiOR2R particles and to the formation of chemical bonds between organic and inorganic constituents, or p-aramid-poly(vinyl butyral) composites. In this way, the mobility of macromolecules was reduced, which can be seen from the decreasing value of damping factor for the p-aramid-poly(vinyl butyral) composite. Analysis of the glass transition temperature of the composite with amino-functionalized silica nanoparticles revealed improved thermal stability in addition to the aforementioned mechanical properties of the tested materials.

Keywords: Nanocomposites, poly (vinyl butyral), nano- $\mathrm{TiO}_{2}$, nano $\mathrm{SiO}_{2}$, dynamic mechanical properties, hybrid composites, lightweight armor composites

Academic Expertise: Chemistry and Chemical Technology

Field of Academic Expertise: Materials Science and Engineering

UDK: 66.017 


\section{TABLE OF CONTENTS}

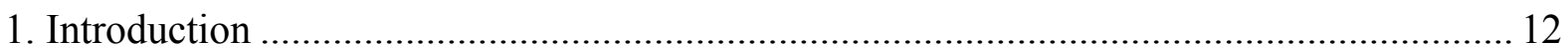

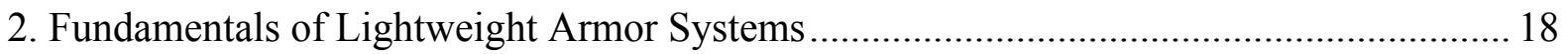

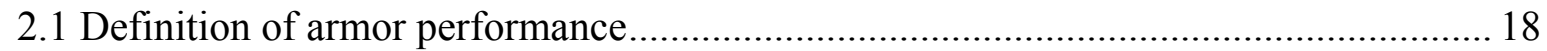

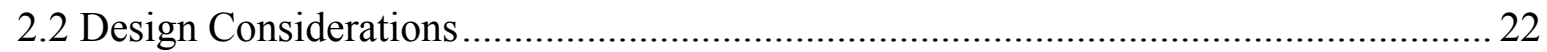

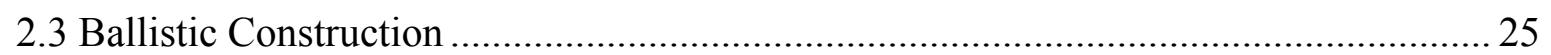

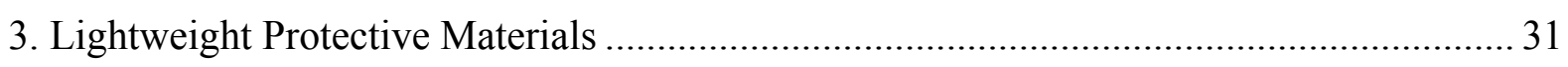

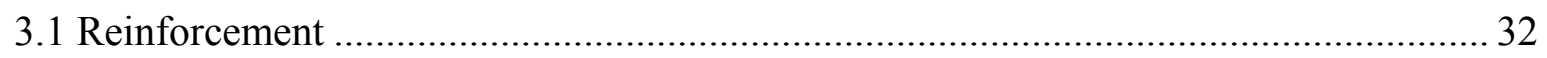

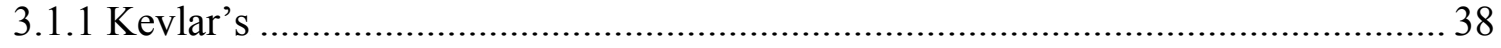

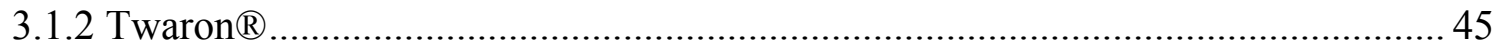

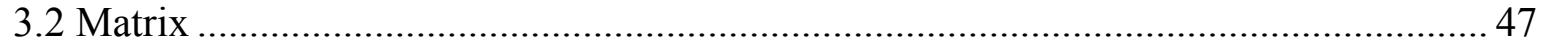

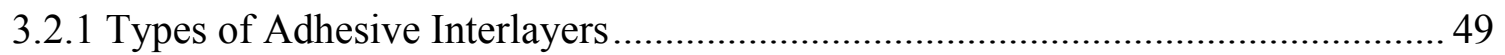

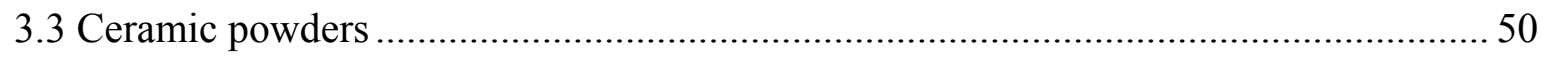

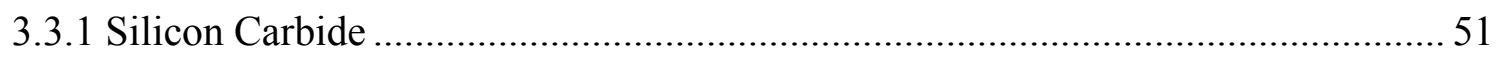

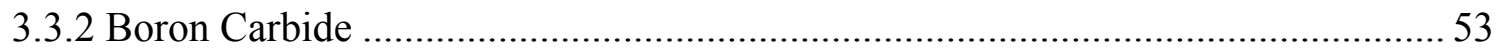

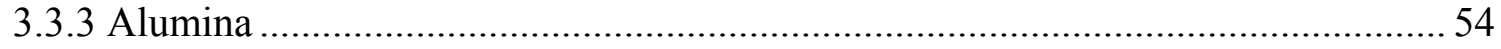

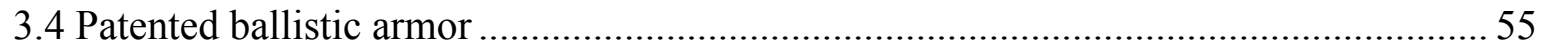

4. Polymer Protective Nanocomposites Materials................................................................. 59

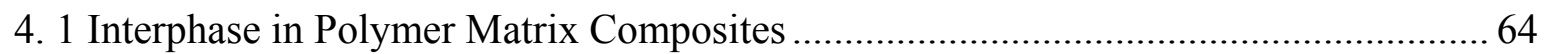

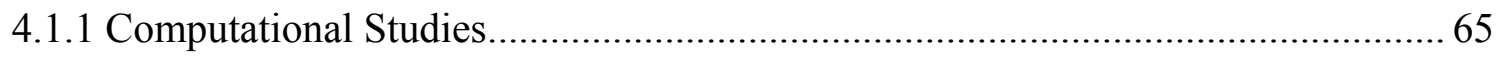

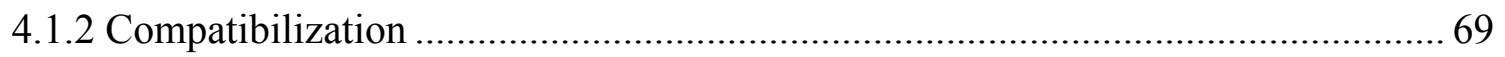

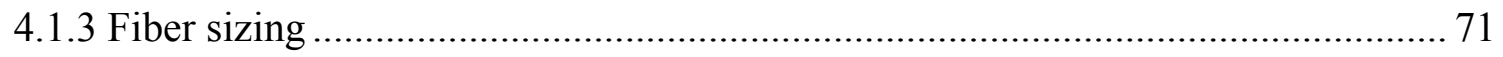

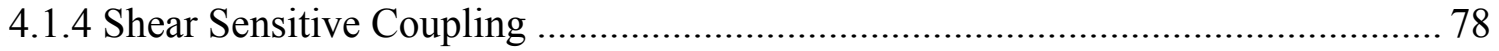

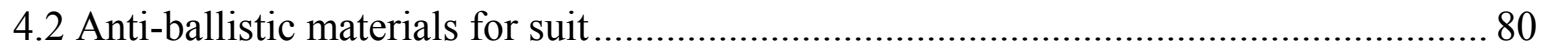

5. Failure Mechanisms of Ballistic Fabrics and Concepts for Improvement ......................... 82

5.1 Mechanisms of Penetration in Protective Materials .................................................... 82

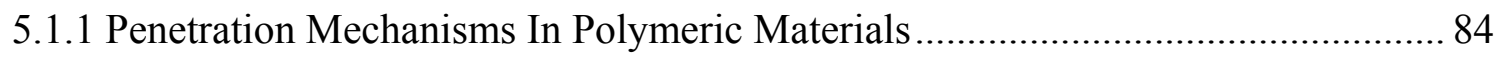

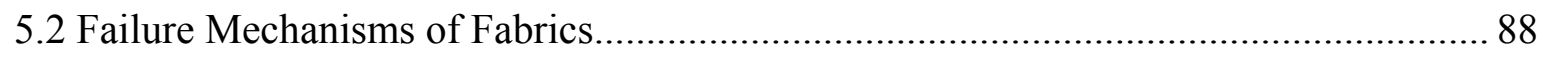

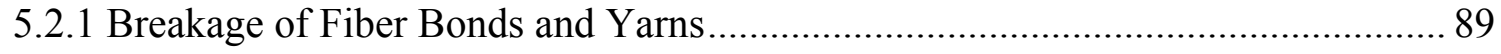

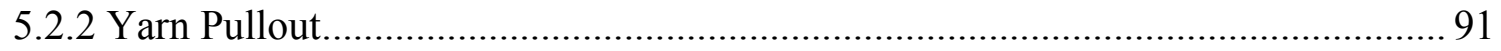




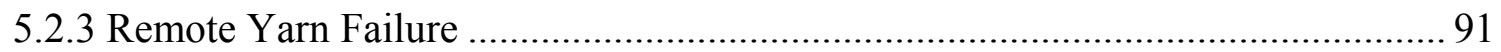

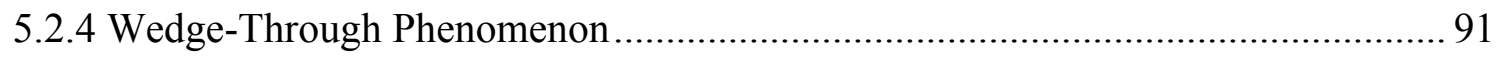

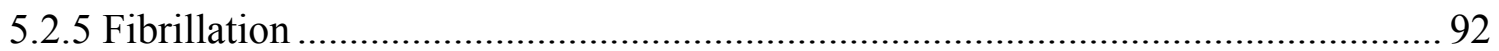

5.2.6 Effects Of Friction Between The Projectile And The Fabric, Yarns, And

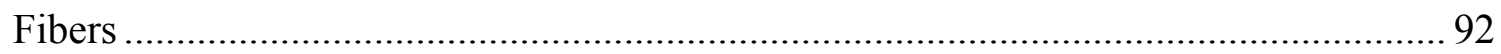

5.3 Concepts For Enhancing Ballistic Performance Of Fabrics ....................................... 93

5.3.1 Important Issues for Ballistic Performance of Fabrics ......................................... 93

5.4 Deformation And Failure Mechanisms Of Ballistic Composites............................... 96

5.4.1 Deformation And Failure Mechanisms ................................................................. 97

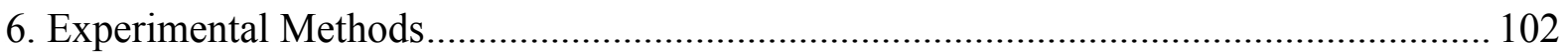

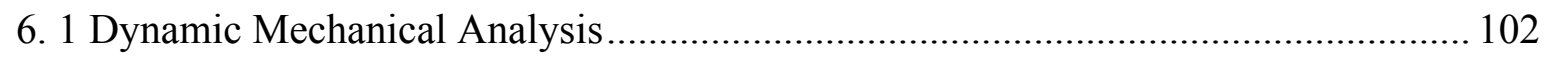

6.2 Equipment Standards for Ballistic Resistance of Personal Body Armor ................... 104

7. Dynamic Mechanical Properties Of Nanocomposites With Poly (Vinyl Butyral)

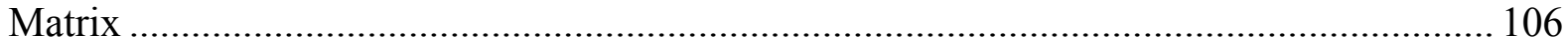

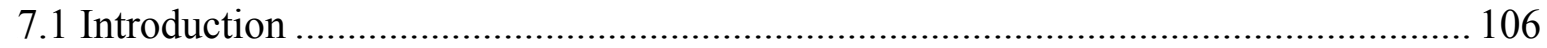

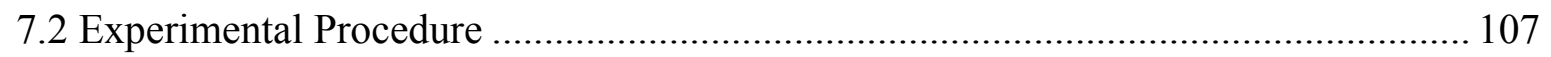

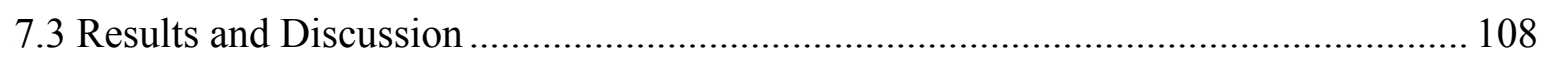

8. The Viscoelastic Properties Of Modified Thermoplastic Impregnated Multi-Axial

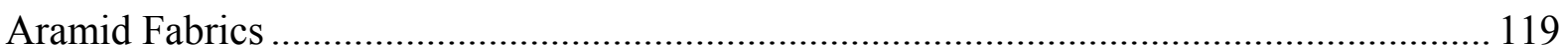

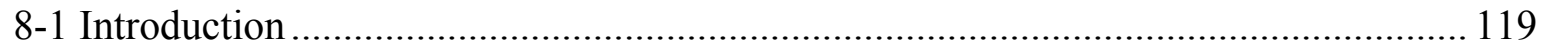

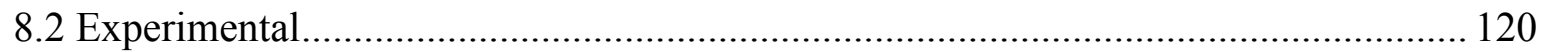

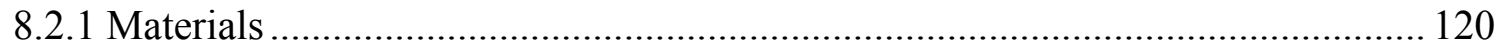

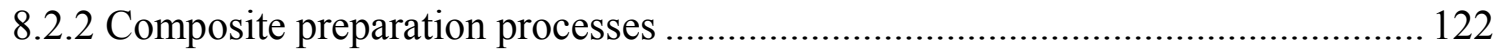

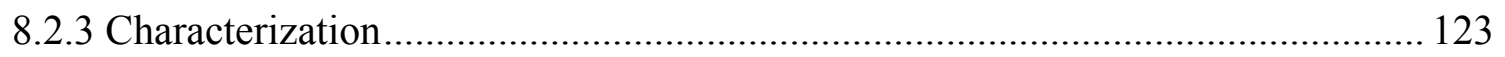

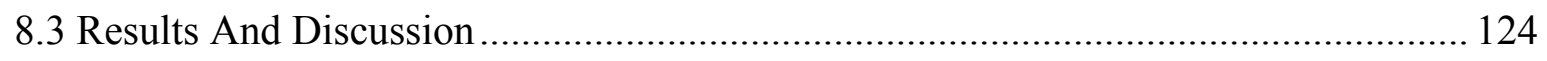

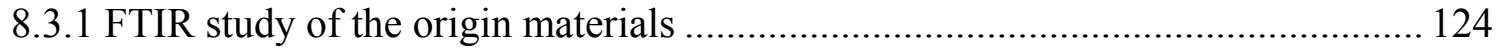

8.3.2 FTIR Analysis Of The p-Aramid Fabrics............................................................ 126

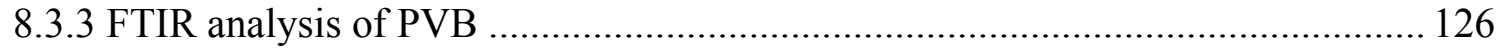

8.3.4 FTIR study of the composite materials............................................................. 127

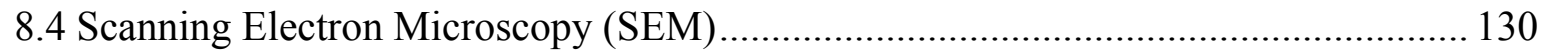

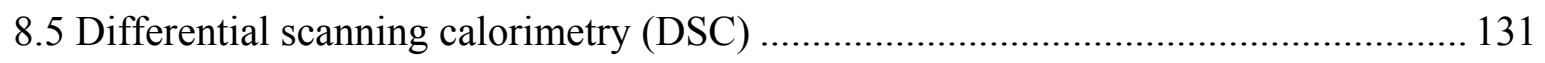

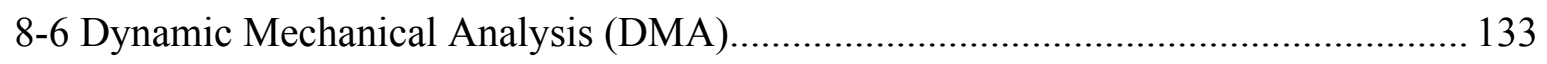


8.6.1 DMA Of Multi-Axial p-Aramid Fabric Composites With Films (Method A)..... 134

8.6.2 DMA Of The Modified p-Aramid Fabric Composites (Method B) 136

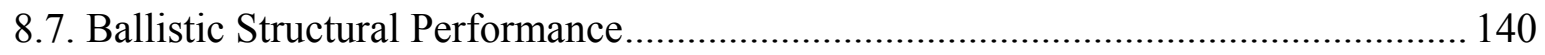

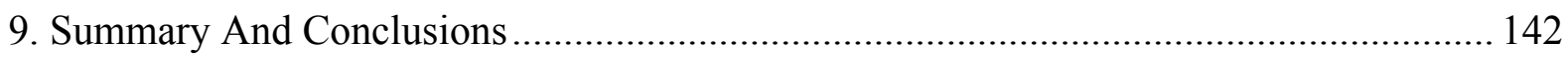

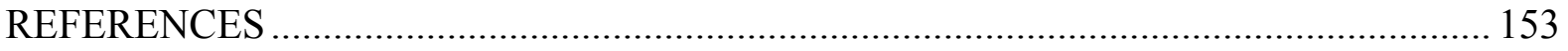




\section{Introduction}

The discovery of novel materials, processes, and phenomena at the nanoscale, as well as the development of new experimental and theoretical techniques for research provide fresh

opportunities for the development of innovative nanostructured materials. The term nanocomposites as used in this report is taken to mean polymer-based materials containing particles (equiaxed or elongated), or fibres with at least one dimension in the 1 to 200 nanometre range. The particles or fibres may be inorganic (metal or ceramic, including semiconductors) or organic (e.g. polymer). This definition excludes metal-matrix nanocomposites, and similarly ceramic-matrix nanocomposites.

The definition of nanocomposite material has broadened significantly to encompass a large variety of systems such as one-dimensional, two-dimensional, threedimensional and amorphous materials, made of distinctly dissimilar components and mixed at the nanometer scale. Nanocomposite materials which exploded in the eighty's with the expansion of soft inorganic chemistry processes not only represent a creative alternative to design new materials and compounds for academic research, but also their improved or unusual features allow the development of innovative industrial applications.

Nanostructured materials are understood to be intermediates between the classical molecular scale and microsized entities. Introduction of nanoparticles to polymer matrix ensure significant property improvements with very loading levels. Traditional microparticle additives require much higher filler concentration to achieve similar results. There are three basic reasons to see changes in properties of materials when their dimension is reduced to the nanometer level:

(1) Quantum confinement, where the energy levels of the atom, electron, or nucleus change as the size of the confined region changes; the well- known particle in a box situation. Since the quantized energy levels (En) vary inversely with the size of the box $(L)$, small changes in $L$ when that size is small amount to very large changes in the energy levels. Small changes in $L$ when $L$ is large do not result in large shifts in the energy levels. Therefore any property which depends on the value of the energy level, 
or the spacing between energy levels, will likely change when you have a material structure which will confine those particles, like electrons and atoms.

(2) High interface area, where the number of atoms at an interface becomes very large. For a polycrystalline material, when the diameter of the crystals (e. g., grains) is on the order of microns, the fraction of atoms at the interface is only on the order of a half percent. As the dimension of the grain is reduced, the fraction of atoms at the interface increases quickly. Consequently, at large grain sizes, the properties of the material will be closely related to the properties of the atoms interior to the grains. Conversely, at small grain diameters, the material properties will be related to the properties of the interface atoms.

(3) Closeness of the material lengths to the critical length scale of the property. Every property has a critical length scale associated with that property (e. g., the mean free path in electrical and thermal conductivity, diffusion length in atomic transport, wavelength in scattering behavior, penetration depth in absorption, and half-life in radioactive decay processes), and material behavior will typically change when a material length scale becomes comparable with that property length scale.

It is relevant to emphasise the difference and similarities between convectional composites (carbon-fibre and glass-fibre reinforced polymers), nanocomposites, and conventional polymers containing fillers. The dimensions of conventional carbon and glass fibres are in the micrometer range, i.e. considerably larger than the nanotubes/fibres mentioned below. While fibre dimensions are relevant in terms of manufacturing processes, what is much more relevant is the dramatic enhancement in mechanical and physical properties obtained in carbon nanotubes, and the related but less expensive nanofibres.

Many polymers are today compounded with fillers to modify their properties. This is usually done to improve mechanical properties such as stiffness, or improve environmental stability against ultraviolet degradation. In addition, various other additives can be used to modify the performance (colour, transparency, magnetic properties, reflectivity, etc) of a polymer. Some particle additives (aluminium compounds) are added to improve fire resistance. In most, if not all cases these additives are of conventional particle size, typically in the 10 to 100 micrometre range. Often relatively large volumes of additives are required to obtain the desired property, which results in density increases 
(most additives have a density much greater than the polymer host, and a reduction in flexibility and fracture toughness of the polymer.

There are usually disadvantageous side effects to using conventional additives, mainly the effect on mechanical properties. While elastic modulus may be increased, fracture toughness and tensile/bend strength are negatively affected. A major advantage of using nanoparticles additives is that mechanical properties are not negatively affected, and in fact tensile strength is usually improved, often significantly. An additional benefit of nanoparticles additions is that they can be combined with conventional carbon- and glassfibre reinforcement, and conventional process technology (resin transfer moulding, injection moulding, etc) can be used. This is not possible with conventional (micrometre-size) fillers.

In the field of materials technology there are relatively few examples of materials, including nanocomposites, which are developed specifically for defence applications. In contrast to the situation during the period of the Cold War where the need for materials for weapons systems and aerospace provided the driving force for much materials research and development, the situation today is that commercial forces almost exclusively provide the driving force. Only in areas such as signature management, where there are in principle no civilian applications, does defence needs motivate a dedicated effort.

Nanocomposites classification and design. The properties, structure and organization of nanocomposites not only depend on the chemical nature of their components, but they also rely on the synergy between them. Consequently, the nature of the interface and interactions exchanged by the organic and inorganic components has been used to categorize these organic- inorganic hybrids into two main different classes. The systems don't have covalent or iono-covalent bonds between the organic and inorganic components and the various components only exchange weak interactions (at least in terms of orbital overlap) such as hydrogen bonding, van der Waals contacts, $\pi-\pi *$ interactions or electrostatic forces, are categorized in class I composites. In class II composites, at least a fraction of the organic and inorganic components are linked through strong chemical bonds such as covalent, iono-covalent or Lewis acid-base bonds. The properties of materials depend on the atomic structure, composition, microstructure, defects and interfaces which are controlled by thermodynamics and kinetics of the synthesis. Thus, a key point for the design of new hybrids is the tuning of the nature, the extent and the accessibility of the inner interfaces, then the chemical 
pathways that are used to design a given hybrid material play the critical role regarding to this issue. These main chemical routes for the synthesis of organic-inorganic composites are.

Path $A$ corresponds to very convenient soft chemistry based routes including a) conventional sol-gel chemistry, b) using specific bridged and polyfunctional precursors and c) hydrothermal synthesis.

Path $B$ corresponds to a) the assembling or b) the dispersion of well-defined nanobuilding blocks which consists of perfectly calibrated preformed objects that keep their integrity in the final material. This is a suitable method to reach a better definition of the inorganic component

Path $C$ or selfassembling procedures including templated growth by organic surfactants, templated growth of mesoporous hybrids by using bridged precursors

Path D corresponds to the integrative synthesis,

Polymer nanocomposites are commonly defined as the combination of a polymer matrix and additives that have at least one dimension in the nanometer range. The additives can be one-dimensional (examples include nanotubes and fibres), twodimensional (which include layered minerals like clay), or three-dimensional (including spherical particles). Over the pa st decade, polymer nanocomposites have attracted considerable interests in both academia and industry, owing to their outstanding mechanical properties like elastic stiffness and strength with only a small amount of the nanoadditives. This is caused by the large surface area to volume ratio of nanoadditives when compared to the micro- and macro-additives. Other superior properties of polymer nano-composites include barrier resistance, flame retardancy, scratch/wear resistance, as well as optical, magnetic and electrical properties..

The incorporation of the organic functions have been carried out in two ways: a) by covalent binding on the inorganic walls of the material, b) by direct incorporation of the organic functions, during the synthesis process which allows a higher organic content and a more homogeneous organic distribution in the composite.

Advances in polymer and textile technology have led to the phenomenal growth in the application of coated fabrics for many diverse end uses. Coated fabrics find an important place among technical textiles and are one of the most important technological processes in modern industry. Textiles are made impermeable to fluids by 
two processes: coating and laminating. Coating is the process of applying a viscous liquid (fluid) or formulated compound on a textile substrate. Laminating is the process of bonding together a preprepared polymer film or membrane with one or more textile substrates by adhesives, heat, or pressure. Fibrous materials are also used for reinforcing polymeric materials to form composites for use in tires, conveyor belts, hoses, and so forth. The scope of this book has been restricted to coated and laminated textiles and does not include discussion of polymer fiber composites. Several methods of production are used to manufacture a wide range of coated or laminated fabrics. Broadly, they are spread coating, dip coating, melt coating, and lamination. They differ not only in the processing equipment used, but also in the form of polymeric materials used. Thus, pastes or solutions are required for spread coating; solutions for dip coating; and solid polymers, such as powders, granules, and films, for melt coating and lamination. The basic stages involved in the processes are feeding the textile material from rolls under tension to a coating or laminating zone, passing coated fabric through an oven for volatalization of solvents, and curing and gelling and cooling of the fabric before final winding up.

At present, textile fibres such as kevlar, nomex and nylon find immense applications in protective wear garments for military personnel. High strength, antiballistic, flame retardant characteristics are some of the vital properties that make these fibres uniquely suitable for defence and other hightech applications. In addition to the availability of high performance fibres, specialty chemicals and coatings enhance the performance of protective fabrics. Non-woven materials such as spun-bonded and melt-blown non-woven fabrics are mainly used for the manufacture of protective wears like barrier protection and fire-retardant fabrics. The advantages of using these fabrics, as against the conventional fabrics, lie in their low cost, improved barrier properties, impermeability to particulate matter, adequate strength, and comfort properties. Recently, there is a growing interest in the use of fine fibres such as micro- and nanofibres for specialist applications. The protective clothing made up of these fibres and their composites give high performance, functionality, comfort, and larger life span with less weight, size, maintenance and cost. Nanostructures and nanocomposites are being developed for the following defence applications:

- Lightweight protective clothing 
- Flexible antiballistic textiles

- Chemical and biological warfare protection and self-decontaminating nanofibre fabrics

- Adaptive suits like switchable fabrics for improved thermal control, switchable camouflage. Microsensors for body and brain sensing, environmental and situational awareness, integrated into a smart suit or a smart helmet.

The new design path for armor provides enhanced and closer coupling of the materials research and development community and the modeling and simulation community, resulting in significantly reduced time for development of new armor. This new approach connects the armor design process to the materials research and development community through canonical models to deal with the restricted information problem. The elements of armor system design are not themselves new, but the emphasis shifts from design-make-shoot-redesign to rapid simulation iterations, and from designing with off-the-shelf materials to designing that exploits materials for their protective properties. The feedback loop between armor system design and material design contrasts with current practice, in which a one-way flow puts new materials on the shelf to be tried in the make-shoot-look process.

The challenge for protective material developers, made clear by current military engagements, is twofold: (1) to ensure the rapid (re)design and manufacture of armor systems optimized against specific threats and (2) at the same time, ensure that these systems are as lightweight as possible. Many of the advances in the performance of lightweight armor have historically come from the introduction of new or improved materials. However, it has become increasingly difficult to produce new materials with properties that allow the design of complex new armor systems or the rapid iterations of such designs. Not only must a material be quickly identified, but it must also be reliably produced, which is not currently possible with the extensive, costly, and timeconsuming practice that is perhaps best described as "build it, shoot it, and then look at it." 


\section{Fundamentals of Lightweight Armor Systems}

\subsection{Definition of armor performance}

The complexities of armor systems make even the assessment of weight situationally dependent: What is lightweight for vehicles is extremely heavy for personnel. Thus, in assessing whether an armor system is sufficiently lightweight, one cannot look at the absolute weight of the system. Rather, because armor is used to protect a particular area, its practical weight is best described by its areal density, Ad:

$$
\mathrm{A}_{\mathrm{d}}=\frac{\text { Weight of the armor system }}{\text { Area being protected }} \quad\left(\mathrm{kg} / \mathrm{m}^{2}\right)
$$

Measurement of both partial and complete penetration by threats of the separate material composing the system and of the full armor system is key to understanding how materials are selected for use in armor systems to protect against ballistics. In the case of body armor, in addition to the ability of the armor to stop the projectile, there is another requirement-namely, that the deflection of the backside of the armor toward the wearer be small. The specifics of the tests used to qualify armor systems for field use are well documented and will not be described at length here. As an example, the very elaborate requirements for the testing of body armor are described in great detail in the National Institute of Justice (NIJ) standard ${ }^{1}$.

Although the purchase specification for body armor might seem insensitive, it allows for an "acceptable number of complete and partial penetrations," as shown in Figure 2-1. An additional parameter for body armor certification is the maximum depth of the back-face deformation for partial penetrations. Back-face deformation is the depth of the crater left by each partial penetration in the clay placed behind the armor during testing with threats. It represents the blunt force trauma inflicted on the wearer, which can contribute to injury or even death. The accepted deformation of the back face of an armor system is currently $44 \mathrm{~mm}$ or less. 


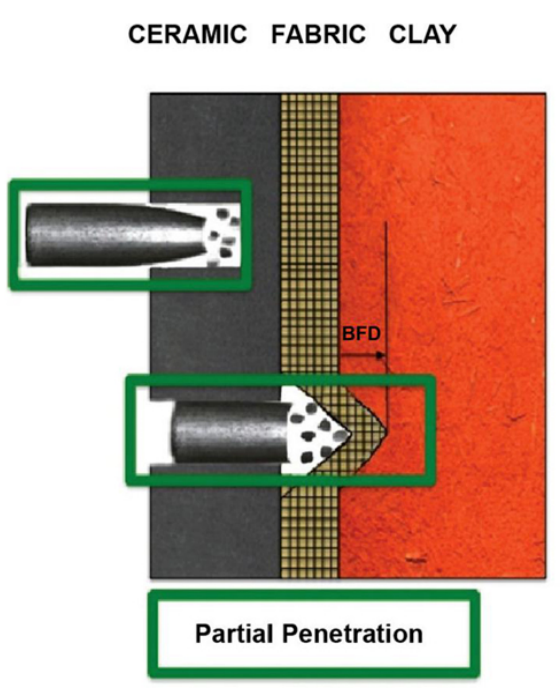

CERAMIC FABRIC CLAY

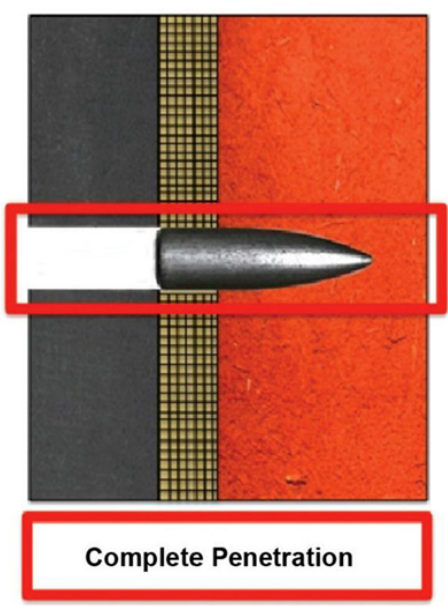

Figure 2-1 Partial and complete ballistic penetration. In a partial penetration the projectile stops within the armor structure, whereas in a complete penetration, it exits the armor structure. Note that the clay is not part of the armor structure but is placed behind the armor to record its deformation. BFD, back-face deformation. ${ }^{2}$

1

To assess the different threats against a particular armor system, two key measurements, $\mathrm{V}_{0}$ and $\mathrm{V}_{50}$, are made. $\mathrm{V}_{0}$, the ballistic limit, is "the maximum velocity at which a particular projectile is expected to consistently fail to penetrate armor of given thickness and physical properties at a specified angle of obliquity." ${ }^{3}$ If the measured $V_{0}$ exceeds the maximum velocity for a particular threat (see Table 2-1) the armor system is said to defeat that threat.

TABLE 2-1 National institute of justice (NIJ) ballistic threat standards

\begin{tabular}{|l|c|c|c|c|}
\hline \multicolumn{1}{|c|}{ Level } & Projectile & $\begin{array}{c}\text { Weight } \\
(\mathbf{g})\end{array}$ & $\begin{array}{c}\text { Velocity } \\
(\mathbf{m} / \mathbf{s})\end{array}$ & $\begin{array}{c}\text { Kinetic } \\
\text { Energy } \\
\text { (Relative }\end{array}$ \\
& & & & \\
& & & & Type IIA) \\
\hline Type IIA & $9 \mathrm{~mm}$ full-metal jacketed & 8.0 & $373 \pm 9.1$ & 1.0 \\
\hline
\end{tabular}




\begin{tabular}{|c|c|c|c|c|}
\hline & $\begin{array}{l}\text { round nose (FMJ RN) } \\
0.40 \mathrm{~S} \& \mathrm{~W} \text { FMJ }\end{array}$ & 11.7 & $352 \pm 9.1$ & 1.3 \\
\hline Type II & $\begin{array}{l}9 \mathrm{~mm} \text { FMJ RN } \\
0.357 \text { magnum } \\
\text { jacketed soft point (JSP) }\end{array}$ & $\begin{array}{c}8.0 \\
10.2\end{array}$ & $\begin{array}{l}398 \pm 9.1 \\
436 \pm 9.1\end{array}$ & 1.7 \\
\hline Type IIIA & $\begin{array}{l}.357 \text { SIG FMJ flat nose }(\mathrm{FN}) \\
0.44 \text { magnum } \\
\text { semijacketed hollow point (SJHP) }\end{array}$ & $\begin{array}{c}8.1 \\
15.6\end{array}$ & $\begin{array}{l}448 \pm 9.1 \\
436 \pm 9.1\end{array}$ & 1.5 \\
\hline $\begin{array}{l}\text { Type III } \\
\text { (rifles) }\end{array}$ & $\begin{array}{l}7.62 \mathrm{~mm} \text { FMJ, steeljacketed } \\
\text { bullets (U.S.military designation } \\
\text { M80) }\end{array}$ & 9.6 & $847 \pm 9.1$ & 6.2 \\
\hline $\begin{array}{l}\text { Type IV } \\
\text { (armorpiercing } \\
\text { rifle) }\end{array}$ & $\begin{array}{l}0.30 \text { caliber armorpiercing (AP) } \\
\text { bullets } \\
\text { (U.S. military designation M2 AP) }\end{array}$ & 10.8 & $\begin{array}{c}878 \pm \\
9.1\end{array}$ & 7.5 \\
\hline
\end{tabular}

Essentially, the qualification tests described above ensure that $\mathrm{V}_{0}$ exceeds the performance specification. However, the expense of firing and the inability to control projectile velocity exactly makes the determination of 0 percent penetration statistically problematic during the experimental phase of armor development. The determination of $\mathrm{V}_{0}$ is therefore generally reserved for the final stages of development and qualification. For research and development purposes, the use of $\mathrm{V}_{50}$, "the velocity at which complete penetration and partial penetration are equally likely to occur," is much more prevalent. These tests are done with a configuration similar to that in Figure 2-1 but without the clay, which is replaced by a "witness plate" placed at a distance behind the armor configuration. A complete penetration event takes place when a thin witness plate is fully penetrated, or perforated, by the projectile; partial (or no) penetration takes place when no perforation of the witness plate is observed. To calculate $\mathrm{V}_{50}$, the highest partial/no penetration velocities and the lowest complete penetration velocities are used, generally with at least 4 and often as many as 10 shots-enough to make sure there are at least two partial/no and at least two complete penetrations. During the development of 
armor systems, it is much more important to understand what is actually occurring during the penetration event than it is to simply measure $\mathrm{V}_{0}$ or V50. To this end, ballistic ranges are often equipped with an array of sophisticated diagnostic tools.

Although the testing and definitions described above hold for all classes of armor systems, the threats and the design philosophy are completely dependent on how the armor is used. Thus, each of the three applications focused on in this report (personnel, vehicle, and transparent armors) are treated separately. It should be noted that military armor systems are currently purchased according to performance specifications that are classified. Descriptions of threats and designs in this study are taken from the open literature and documents approved for public release. As such, they are only illustrative of current threats and designs.

There is a great deal of difference between pistol and rifle ammunition. Pistol ammunition is designed to be accurate to a range of around 40 meters, whereas rifle rounds need to be capable of hitting a target up to 1000 or more meters away. Pistol ammunition usually is straight cased. Rifle ammunition is often "bottle necked," so it can contain a larger amount of propellant. The distinction is not quite so clear, as there are pistols that fire rifle ammunition and long-barrelled weapons (including some submachine guns) that fire pistol ammunition.

There are several different sorts of bullets, such as:

Full Metal Jacket-A metal casing around a lead core.This produces a nonexpanding, deep-penetrating round that is considered very reliable.

Jacketed Hollow Point-These bullets have an exposed, hollowed lead tip that allows expansion of the round on impact. They are likely to penetrate tissue less deeply than a full metal jacket bullet but more energy is transferred to the tissue.

Soft Point-An exposed lead tip allows the bullet to expand rapidly on impact at lower velocities. A wide wound of up to $200 \%$ of original bullet diameter is produced from the round's rapid expansion.

Modern armor for personnel protection includes both body armor and combat helmets. The threats for which personnel armor is designed are small-caliber projectiles, including both bullets and fragments. The level of ballistic protection of personnel armor is taken as the total kinetic energy of a single round that the armor can stop. The 
standards set by the NIJ shown in Table 2-1 are for typical ballistic threats, although not specifically those for military body armor, which are classified. Note that a Type IV projectile has more than 7.5 times the energy of a Type IIA projectile. In addition to surviving the impact of specific projectiles, there is generally a requirement to withstand multiple hits on the same armor panel. For armor meeting NIJ Type IIA and Type III standards, panels must demonstrate the ability to survive six hits without failure. Only Type IV has no multi-hit requirements. Personnel protection armor is also often designed against fragments. Finally, for body armor, as previously mentioned, stopping penetration is not the only issue. It is also important that when stopping the projectile, the armor itself does not deflect to an extent that would severely injure the wearer. This puts an additional constraint on body armor systems.

\subsection{Design Considerations}

The design of armor for personnel protection depends on the specific threat. For fragments and lower velocity penetrators, vests are typically made from polymer fibers. Advances in fibers for personnel armor began with the use of fiberglass and nylon. These were followed in the late 1960s by polyaramid fibers (DuPont PRD 29 and PRD 49), now called Kevlar. Later, high molecular weight polyethylene fibers, made of Spectrashield and Dyneema, were also used as backing in vests. Zylon, made of polybenzobisoxazole (PBO), has also been considered. Figure 2-2 depicts how the evolution of fibers has steadily improved the performance of polymer vests. Thus, the primary factor in the design of armor for vests is the selection of the fiber. 


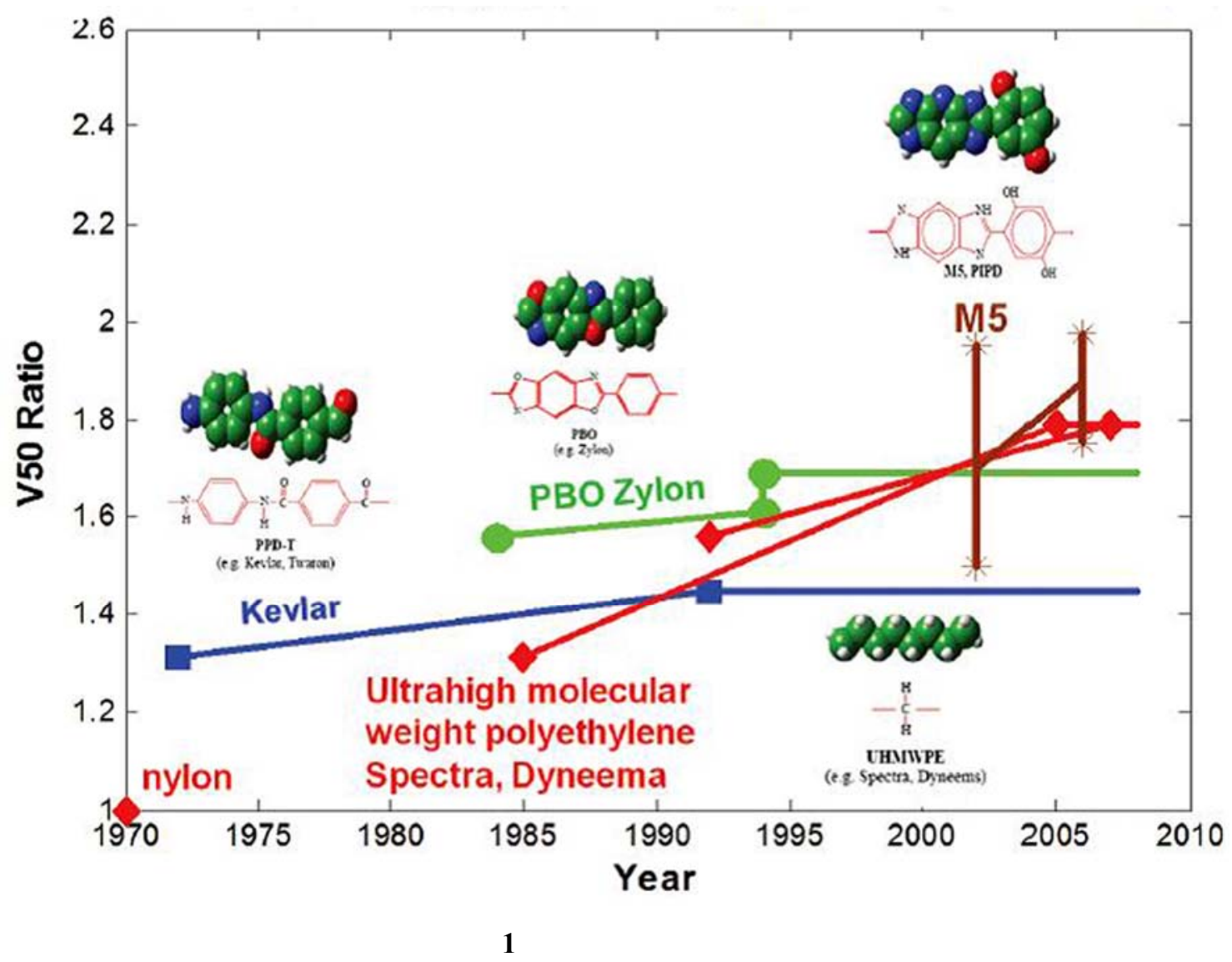

Figure 2-2 Increase in ballistic performance as a function of improved fibers.

This figure depicts how the V50 of fiber-based vests has increased as new fibers have been introduced over the years. ${ }^{4}$

When the threat increases to rife rounds, including armor-piercing projectiles (see Table 2-1, Types III and IV), ballistic fabric alone is insuffcient. Stopping these threats requires adding a ceramic plate to the outside of the vest. The hard ceramic blunts and/or erodes the projectile nose, which increases the projected area of the projectile and spreads the load across more of the fabric ${ }^{5}$ It is the combination of two independently developed materials a ceramic faceplate and a fiber fabric that constitutes the armor system and provides overall protection. The combination creates a complex system where the performance of the ceramic and the polymer backing (vest) are intimately connected.

The currently fielded body armor, the Interceptor body armor (IVA), makes use of the combination of ceramic and fiber described above and shown in Figure 2-3. ${ }^{6}$ The 
main component of this armor is the improved outer tactical vest, which provides protection against fragments and 9-mm rounds.

Enhanced small-arms protective insert (ESAPI) ballistic plates and enhanced side ballistic insert plates are inserted into plate carrier pockets in the polymeric vest. These plates can withstand multiple small-arms hits, including armor-piercing rounds. ${ }^{7}$ IVA can stop small-arms ballistic threats and fragments, thus reducing the number and severity of wounds. An improvement, the X small-arms protective insert, is designed for "potential emerging small arms ballistic threats." The deltoid and axillary protectors, an integral component of the improved outer tactical vest, extend protection tection, primary ballistic protection is also based on the performance of the fiber. against fragments and 9-mm rounds to the upper arm areas .

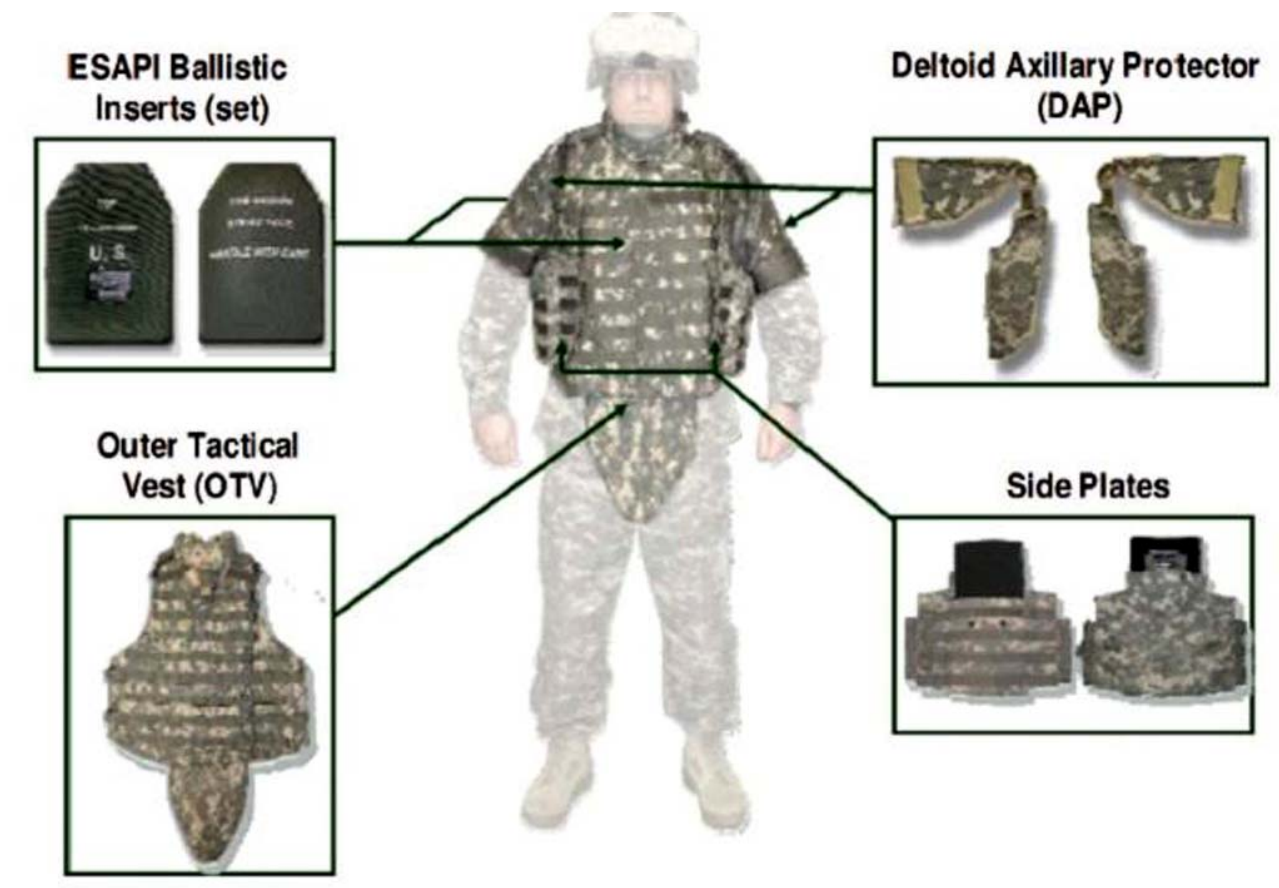

Figure 2-3 Interceptor body armor ${ }^{8}$.

The combination of ceramic inserts and polymeric fibers in the IVA vest is an example of how particular arrangements of specifc materials make up a typical armor system.

Because helmets and vests demand similar levels of pro tection, primary ballistic protection is also based on the performance of the fber. However, the currently felded 
helmet, the advanced combat helmet, must not only provide ballistic protection, but- it must also protect against blunt forces. Equally important, the helmet must provide comfort and thermal management without degrading vision or hearing and be able to interface with other equipment, including night vision goggles and weapons. Ultimately, the weight of the helmet is limited by the ability of the neck to bear weight, especially over long periods of time.

\subsection{Ballistic Construction}

The ballistic protection packages in todays vests are made of high strength artifical fibres. The fibres are spun to form a thread or yarn and this is then further processed to either a fabric or a composite lay up, Figure 2.4.

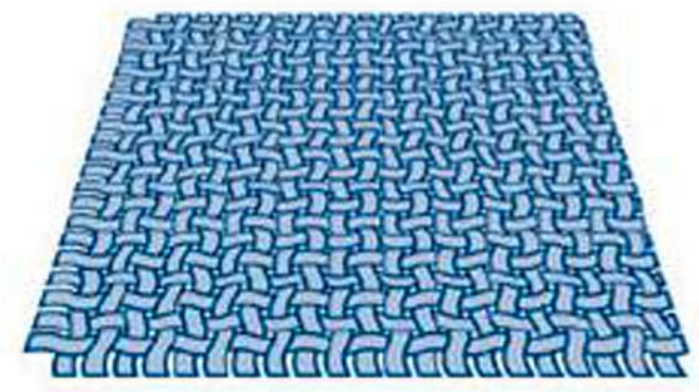

a)

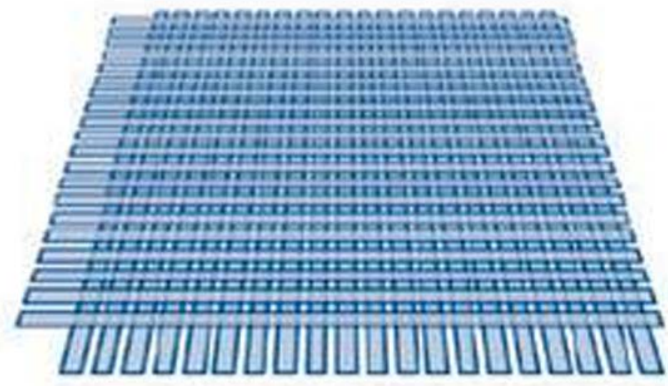

b)

Figure 2-4 a) Ballistic a) fabric, b) laminate

A ballistic protection package is made up of a certain number of layers of either fabric, Unidirectional fibres or a mix of both depending on the requirements. This is generally referred to as the soft ballistic construction.

A flexible spike and ballistics panel having a strike surface and a rear surface. The panel contains a strike face grouping and a rear face grouping, where the normalized stiffness of each strike face layer is about 3 to 50 times greater than the normalized stiffness of each textile layer. The strike face grouping contains at least two strike face layers, each strike face layer having resin and high tenacity yams, where the high tenacity yams are in an amount ofat least $50 \%$ by weight in each layer, where the high tenacity yarns have a tenacity of at least 5 grams per denier, and where the strike 
face grouping forms the strike surface of the panel. The rear face grouping contains at least ten layers of a spike resistant textile layer, each textile layer having a plurality of interwoven yarns or fibers having a tenacity of about 5 or more grams per denier, where at least one ofthe surfaces ofthe spike resistant textile layer contains about $10 \mathrm{wt} \%$ or less, based on the total weight ofthe textile layer, ofa coating comprising a plurality of particles having a diameter of about $20 \mathrm{flm}$ or less.

For increased protection, ballistic protection can be ..upgraded with additional protective plates, constructed of various layers of ballistic materials. These are pressed together, sometimes with ceramics, to form a composite. This is referred to as hard ballistic construction, Figure 2-5

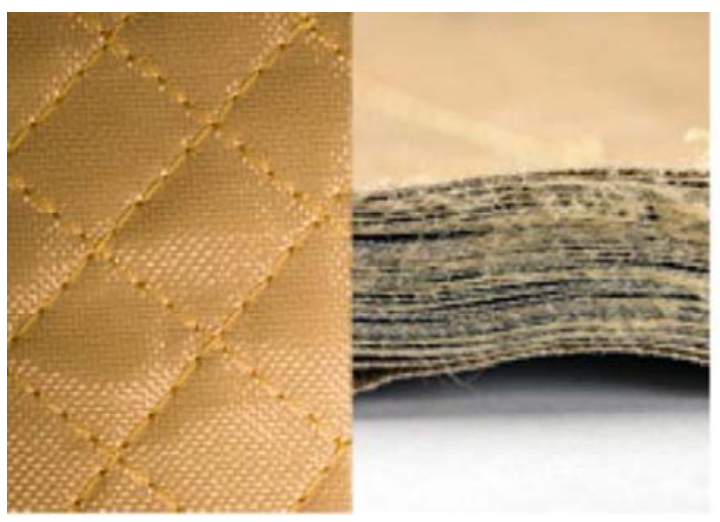

a)

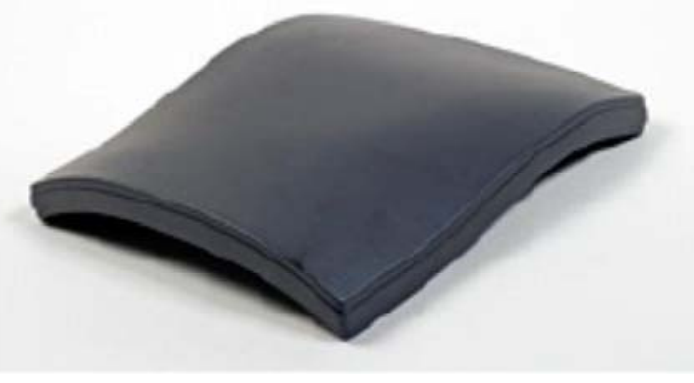

b)

Figure 2-5 a) Fabric as example for soft ballistic b) protective plate as example for hard ballistic

Regarding soft ballistic construction, it is worth mentioning the implementation of laminated fibre lay ups. The fibres are laid similiar to a standard lay up, then pressed between films to form a composite. Through the fixation of the fibres with a film and adhesive matrix, it is possible to better absorb and distribute the energy of a ballistic impact or stab, thus offering better protection. Ballistic packages made of laminates tend to be stiffer than fabric packages.

Police, correctional officers, security personnel, and even private individuals have a growing need for simultaneous protection from multiple types of penetration threats, including spike, knife and ballistic threats, in a single protective garment. Known materials that protect against knife threats typically have flexible metallic plates, metallic chain mails, or laminated, resinated, or coated fabrics. However, the flexible 
metallic components tend to increase the weight of vests and are difficult to be cut into irregular shapes to fit the body. Further, materials with laminated or resinated or coated fabrics are less satisfactory against knife and spike stab. Further, merely combining separate materials, each known to protect against one threat, with other material(s) known to protect against other threat(s) does not usually provide a flexible light weight structure comfortable for body wear with adequate protection against multiple threats. Thus, there is a need for a flexible light weight structure that resists penetration by multiple threats. .

The ballistic performance of a composite focuses on the capacity of energy absorption of structures during a high-velocity impact. For a given target-projectile combination, the ballistic limit is defined as the lowest initial velocity of the projectile that will result in complete penetration. The factors that affect ballistic performance are: material properties of reinforcement; fabric structure; matrix mechanical properties; interaction of multiple plies-number and order of layers; projectile geometry and its velocity. The majority of the kinetic energy of the projectile is transferred to the yarns that are in direct contact with the projectile as strain and kinetic energy, whereas, the contribution of the orthogonal yarns to energy absorption is small. Fibers possessing high tensile strengths and high failure strains can absorb considerable amounts of energy, thus the materials possessing high modulus and low density disperse the strain wave more rapidly from the impact point, which distributes the energy over a wider area and prevents large strain development from developing at the impact point.

"Fabric tightness factor" and "Cover factor" are names given to the density ofthe weave ofa fabric. Cover factor is a calculated value relating to the geometry of the weave and indicating the percentage ofthe gross surface area of a fabric that is covered by yarns of the fabric. The equation used to calculate cover factor is as follows: ${ }^{9}$

$$
C_{w}=\frac{d_{w}}{p_{w}} C_{f}=\frac{d_{f}}{p_{f}}
$$

$\mathrm{d}_{\mathrm{w}}$-width of warp yam in the fabric, $\mathrm{d}_{\mathrm{f}}$-width of fill yam in the fabric, $\mathrm{p}_{\mathrm{w}}$-pitch of warp

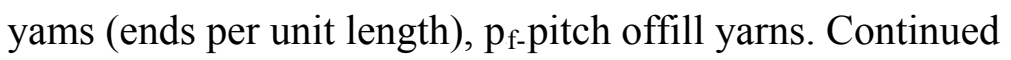




$$
\begin{aligned}
& \text { Fabric Cover Factor }=C_{f} \text { ab }=\frac{\text { total area obsured }}{\text { area enclosed }} \\
& C_{f a b}=\frac{\left(p_{w}-d_{w}\right) d_{f}+d_{w} p_{f}}{p_{w} p_{f}}=C_{f}+C_{w}-C_{f} \cdot C_{w}
\end{aligned}
$$

Depending on the kind of weave of a fabric, the maximum cover factor may be quite low even though the yarns ofthe fabric are situated close together. For that reason, a more useful indicator ofweave tightness is called the "fabric tightness factor". The fabric tightness factor is a measure of the tightness of a fabric weave compared with the maximum weave tightness as a function of the cover factor.

$$
\text { Fabric tightness factor }=\frac{\text { actual cover factor }}{\text { maximum cover factor }}
$$

For example, the maximum cover factor that is possible for a plain weave fabric is 0.75 ; and a plain weave fabric with an actual cover factor of 0.68 will, therefore, have a fabric tightness factor of 0.91 .

For ballistic applications the fabrics have plain or basket weave, with the "cover factor' ranging from 0.6 to 0.95 . Stitching multiple fabric-plies increases the ballistic impact damage tolerances of a carbon fiber/epoxy and the compression strength in ballistic impact increased by about $50 \%$. The impact property and damage tolerance of composite laminates with different laminate constitutions depends on matrix ductility. The composites thickness significantly affects the energy absorption capacity during ballistic. Thus, the most efficient hybrid composites for ballistic protection contain carbon (in the front part) and polyethylene (Dyneema $\left.{ }^{\circledR}\right)$ fibers in rigid and flexible epoxy matrices with laminates consisting of two separated types of fibers. Composites with rigid epoxy matrix have lower energy absorption capacity than those with flexible matrix, viz. ca. $30 v s .36(\mathrm{~J})$, respectively. The basket wave fabrics resulted in structures with $10 \%$ higher energy absorption than those with plain weave. With the increasing number of plies the specific energy absorption ability of the composites increased, i.e., the efficiency of the individual layers increased. It was established that glass, aramid and Dyneema ${ }^{\circledR}$ reinforcing composites structures lead to high ballistic performance, Tabela 2-2.. 
Tabela 2-2. Comparison of PPTA (Kevlar® 29) with UHMWPE (Dyneema®)

\begin{tabular}{|l|c|c|c|c|}
\hline Materials & $\begin{array}{c}\text { Modulus } \\
\text { E(Gpa) }\end{array}$ & $\begin{array}{c}\text { Density } \\
\mathbf{P}\left(\mathbf{k g} / \mathbf{m}^{\mathbf{3}}\right)\end{array}$ & $\begin{array}{c}\text { Tensile } \\
\text { strength } \\
\mathbf{( M P a )}\end{array}$ & $\begin{array}{c}\text { Failure strain } \\
\mathbf{( \% )}\end{array}$ \\
\hline Kevlar${ }^{\circledR}$ & 9 & 1160 & 450 & 9 \\
\hline PE laminate & 19.5 & 900 & 653 & 7 \\
\hline
\end{tabular}

Colakoglu et al. studied ballistic properties of two composites containing Kevlar® 29 or polyethylene (PE) fibers saturated with polyvinyl butyral (PVB). ${ }^{10}$ Even when the bullet does not penetrate the armor, the part of the body directly behind the point of impact usually receives a "hammer-like" blow as a result of the deformation of the armor from the impact of the bullet. The blow may produce bruises, lacerations of the skin and damage internal organs. Thus, the authors investigated the ballistic performances of two different polymer matrix composites. In addition to experimental tests they constructed a finite element model for the backside deformation and penetration speed. It was found that PE fiber composite had better ballistic limit, the backside deformation, and penetration speed than that of Kevlar ${ }^{\circledR} 29$. Considering the performance parameters listed in the Table 2-1, this observation was to be expected.

The US Army undergo significant equipment changes, e.g., weight reduction from $70+$ ton ground fighting vehicles $(\mathrm{GFV})$ to $<20$ tons Composite Armored Vehicle (CAV), without loss of personal protection or performance. This only may take place by designing an advanced composite armor that combines ceramics, metals and polymeric composites, using advanced materials and mathematical modeling. Previously two types of composites have been developed: (1) structural with high compressive strength and (2) ballistic with high projectile energy absorption, Figure 2-6. 


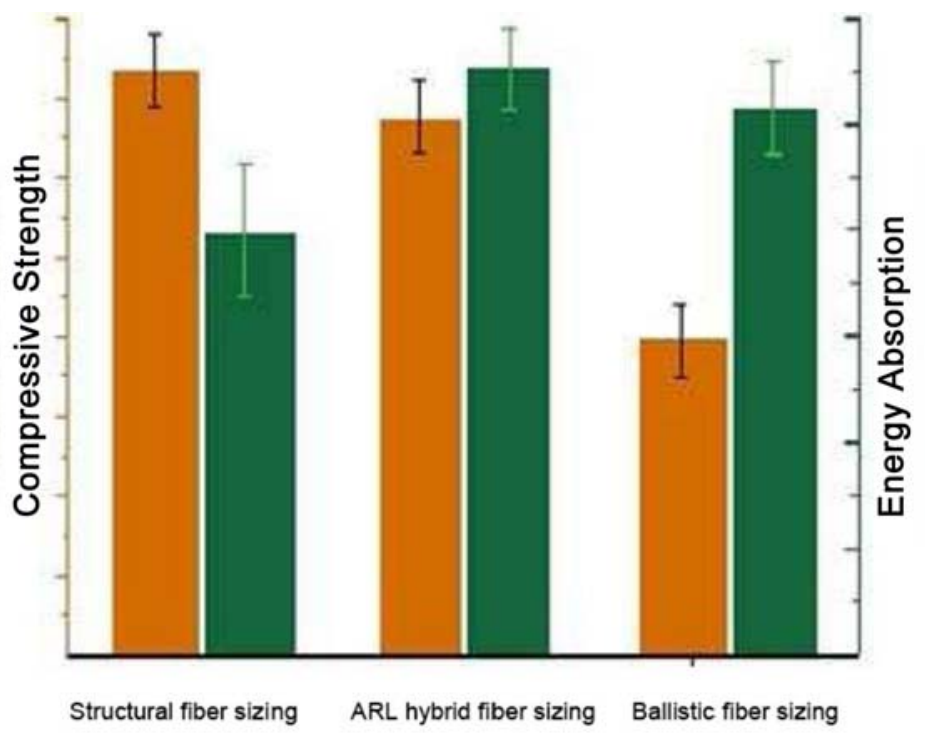

Figure 2-6 Properties of advanced composite armor ${ }^{11}$

As illustrated in the Figure 2-6, the newly-developed third hybrid type combines both functions. ${ }^{12}$ Owing to sensitivity of information, rather sketchy image emerges what has been done and how. For the new CAV, the polymeric composites contain ca. 50 vol\% of glass fibers (GF), rest being thermoset or thermoplastic polymer. The hybrid composites are designed with strong fiber-matrix interfacial adhesion at structural loading rates, and weak interfacial strength at ballistic loading rates. This is possible through innovative manipulation of the chemical and physical interactions between the matrix and fibers. 


\section{Lightweight Protective Materials}

To provide a basic understanding of current armor materials and to anticipate areas where there could be revolutionary improvements in armor materials, this chapter examines the synthesis and processing of each of the main types of materials, with particular emphasis on the resultant material structure from the atomic to the macro scale. Potential new compositions and the tailoring of microstructures to discover material behaviors that could dramatically enhance armor performance are highlighted, as are the challenges involved in achieving such advances. The schematic in Figure 3-1 depicts a notional armor structure, ${ }^{13}$ consisting of both dense and porous ceramics, fibers, environmental coatings, polymer binders, and adhesive joints.

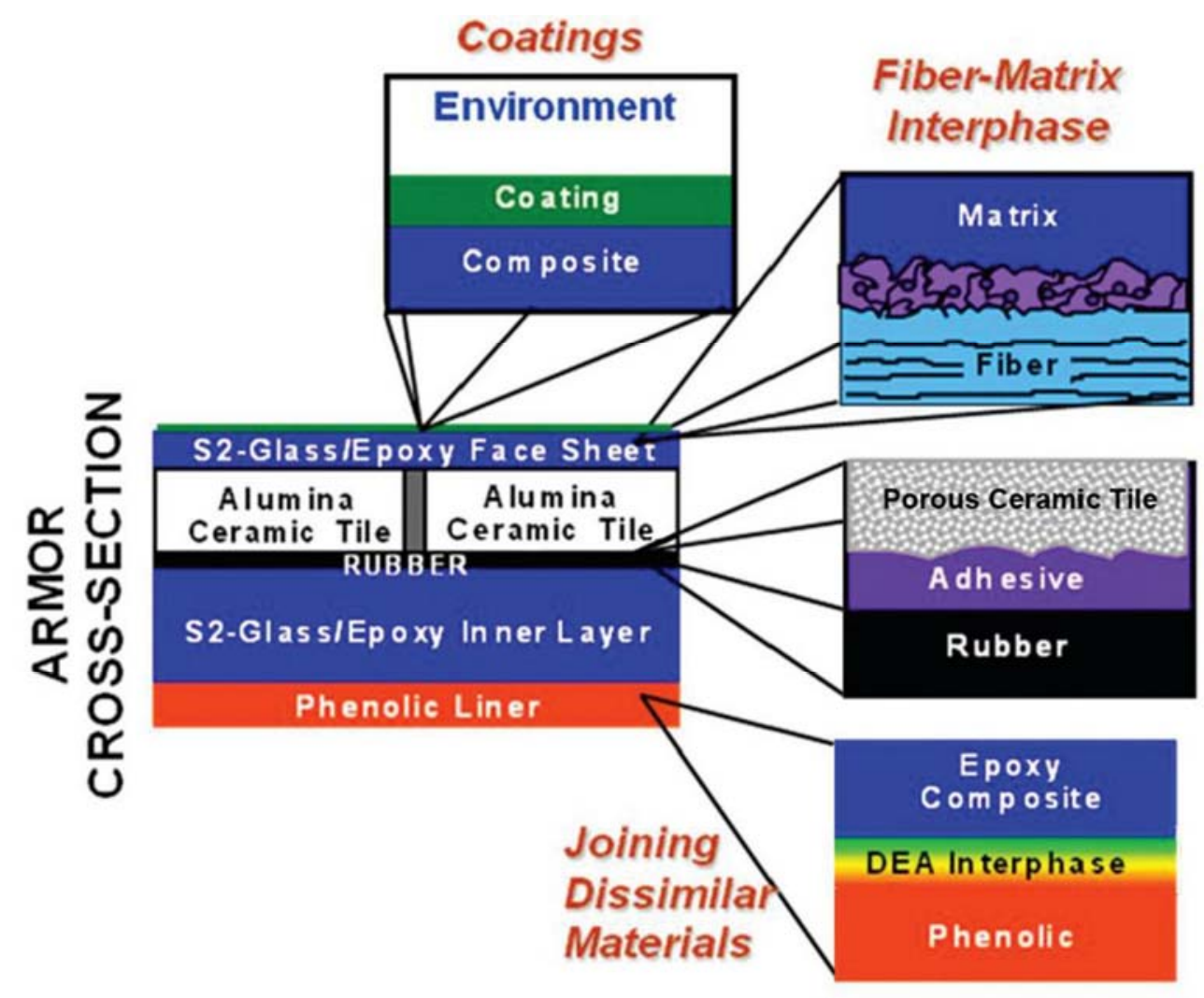

FIGURE 3-1 Schematic presentation of the cross section of an armor tile typically used for armored vehicles showing the complexity of the armor architecture.

Different classes of materials, such as dense and porous ceramics, fiber composites, thermoplastic polymers, and adhesives are used for the tile assembly. DEA, diethanolamine ${ }^{14}$ 
The complex tile architecture presented in Figure 3-1 uses several materials and different assembly methods for those materials such that the layers perform their protective functions during the projectile impact. This chapter will examine how achieving improved material behavior but also minimizing manufacturing cost requires a deep scientific and engineering understanding of the desirable structures and compositions of advanced protective materials as well as how to make and process them. That said, as explained in Chapter 2, the requisite material properties that are to be optimized cannot be measured by the usual quasi-static measures of mechanical behavior. However, even at lower strain rates, conducting mechanical tests at small scale-that is, at the microstructural level, on the order of nanometers or microns-will likely shed light on the deformation mechanisms under known loading states and can provide information that is very useful for parallel modeling efforts, keeping in mind that the ultimate goal is real-time measurements of many properties on ballistic timescales.

\subsection{Reinforcement}

Since the 1970s, several new fibers and construction methods for bulletproof fabric have been developed besides Kevlar ${ }^{\circledR}$, e.g., DSM Dyneema ${ }^{\circledR}$, Honeywell's GoldFlex $^{\circledR}$ and Spectra ${ }^{\circledR}$, Teijin Twaron ${ }^{\circledR}$, Pinnacle Armor's Dragon Skin ${ }^{\circledR}$ body armor, INNegRITY Innegra_S and Toyobo's Zylon ${ }^{\circledR}$.

The protective properties of body armor rely on the properties of the fibres implemented. The following high strength fibres are currently used in body armor, Tabela 3-1:

Tabela 3-1 Fibers for bulletproof fabrics

\begin{tabular}{|l|l|}
\hline Chemical name & Trade name \\
\hline PA & Kevlar $^{\mathrm{R}}$, Twaron $^{\mathrm{R}}$, Artec $^{\mathrm{R}}$ \\
\hline (Polyamide) & \\
\hline PE & Dyneema $^{\mathrm{R}}$, Spectra $^{\mathrm{R}}$ \\
\hline
\end{tabular}




\begin{tabular}{l|l|}
\hline $\begin{array}{l}\text { (Polyethylene) } \\
\text { PBO }\end{array}$ & Zylon $^{\mathrm{R}}$ \\
(Poly[p-phenylene bezobisoxazole] $)$ & \\
\hline $\begin{array}{l}\text { PIPD } \\
\text { (Poly2,6dimidazo[4,5-e]-pyridinylene- }\end{array}$ & $\mathrm{M}^{\mathrm{R}}$ \\
1,4(2,5-dihidroxy)phenylene]) & \\
\hline
\end{tabular}

Aramid fibers (Kevlar and Technora). Poly(p-phenylene terephthalamide), Kevlar, was first synthesized by Kwolek at DuPont in the 1960s. Kevlar is processed from sulfuric acid, with the polymer concentration at about $20 \mathrm{wt}$ percent. Surprisingly, there is a decrease in viscosity with increased polymer concentration due to local alignment of polymer molecules in the solution to form a nematic phase. Thus the solution becomes liquid crystalline, a feature that had earlier been predicted by Flory. ${ }^{15}$ The solution is extruded through an air gap into an acid solvent, such as water, where it coagulates. Removal of the approximately 80 percent acid from solution during fiber drying and tension heat treatment $\left(500^{\circ} \mathrm{C}\right)$ leads to the formation of a highly aligned, extended chain fiber. However, the coagulation process also creates undesirable defects. The number of defects can be estimated from the deviation of the actual fiber density from the theoretical crystal density of 100 percent (approximately $1.45 \mathrm{~g} / \mathrm{cm}^{3}$ versus $1.50 \mathrm{~g} / \mathrm{cm}^{3}$ ). Kevlar fiber was developed and commercialized at DuPont, originally for completely different applications than for body armor (for example, it was used for reinforcing tires). The potential of Kevlar for use in ballistic protection was realized only when the National Institute of Justice conducted ballistic testing on Kevlar fabric. Other polyaramids followed, including Technora, an aramid copolymer fiber that is produced in the Netherlands and Japan from terephthaloyl chloride and a mixture of pphenylenediamine and 3,4'-diaminodiphenylether.

Polyethylene (Spectra, Dyneema). Unlike the extended rigid-rod molecular structure of Kevlar, polyethylene (PE) is one of the most flexible polymers. Since the 1930s, fibers and films have been manufactured from PE by melt processing. The morphology of these fibers and films is semicrystalline, consisting of 60 to $70 \mathrm{vol}$ percent crystals; the remainder consists of amorphous, entangled polymer chains. Interestingly, melt-processed polyethylene contains chain-folded crystals with a 
modulus in the $1 \mathrm{GPa}$ range. Trash bags and milk jugs, having typical molecular weights of 50,000 to $200,000 \mathrm{~g} / \mathrm{mole}$, are common examples of such polyethylene products. But if PE molecules could be extended into straight chains, the carbon-carbon backbone would give outstanding properties. Indeed, after nearly half a century of process development in the field of polyethylene, a new type of spinning was invented by Smith and Lemstra in the Netherlands in early 1980s. ${ }^{16}$ Known as gel spinning, this process is able to extend the macromolecules to nearly their full length and results in a highly crystalline extended-chain polyethylene fiber exhibiting high strength and high modulus characteristics that show ballistic protection capability. Because the molecules are processed from a dilute solution, the molecular weight of the polyethylene used in gel spinning can be in excess of 3 million $\mathrm{g} /$ mole or higher, much higher than that in any other synthetic polymer. Fiber is processed from a decalin solution that typically contains less than $5 \mathrm{wt}$ percent polymer. The polymer solution is extruded at between $130^{\circ} \mathrm{C}$ to $150^{\circ} \mathrm{C}$ or so into a cold coagulant such as water. This resulting gel-like fiber, which contains more than 95 percent solvent, is typically then drawn at between $90^{\circ} \mathrm{C}$ and $130^{\circ} \mathrm{C}$ to draw ratios of 50 to 100 . The macromolecules become extended and form near-single-crystal fibers.

The theoretical density of polyethylene is $1.00 \mathrm{~g} / \mathrm{cm}^{3}$, while the density of Spectra and Dyneema fibers is about $0.97 \mathrm{~g} / \mathrm{cm}^{3}$. This underscores the fact that even today's highly extended-chain polyethylene fibers contain a significant number of defects and suggests an opportunity for even more significant gains in future development of this material.

Rigid-rod polymers (Zylon and M5). After the successful commercial development of Kevlar in the 1970s, significant research efforts were devoted to the development of other rigid-rod polymers. Rigid-rod polymers programs began in the 1960s at the U.S. Air Force Research Laboratory as well as in Russia. The U.S. program was accelerated in the 1970s, resulting in the development of poly-p-phenylene benzobisthiazole and polybenzoxazole (PBO) fibers. ${ }^{17}$ PBO fiber was further developed initially at SRI International and later at Dow Chemical Company before being commercialized by Toyobo Company (Japan) in 1998 under the trade name Zylon. Among other applications, PBO fiber was also developed for use in fire-protective clothing as well as for ballistic protection. However, in the early 2000s it became clear 
that there were environmental stability issues with Zylon fiber causing decreased fiber strength over time and negatively affecting its ballistic performance. This is attributed to poor resistance to ultraviolet radiation as well as to poor hydrolytic stability.

In an attempt to improve intermolecular interactions in rigid-rod polymers with the intent of increasing the fiber compressive strength and torsional modulus, the Akzo Nobel firm in the Netherlands synthesized and processed polypyridobisimidazole (under the name M5) fiber during the 1990s. ${ }^{18}$ The fiber was further developed by Magellan Systems International, and the technology now resides with DuPont, although the fiber has not yet been commercialized.

Similar to Kevlar, both the Zylon and M5 fibers are processed from a liquid crystalline polymer solution, except in this case the solution is one of polyphosphoric acid. Depending on the polymer molecular weight, for fiber spinning, polymer concentration in solution is again typically between 5 weight percent 15 weight percent. Like the process used to make Kevlar, the nematic solution is extruded through an air gap into an acid solvent such as water. The coagulated fiber is then heat-treated under tension up to about $500^{\circ} \mathrm{C}$.

Structure formation mechanism in the rigid-rod chains of Zylon and M5 fibers is very similar to the structure formation mechanism in Kevlar and is quite different from that of the flexible-chain gel-spun polyethylene (Dyneema and Spectra).

Intermolecular interactions in polyethylene are only van der Waals interactions, whereas in Kevlar there is hydrogen bonding in one dimension transverse to the fiber axis, and in M5 fibers there is hydrogen bonding in two transverse directions. Ranking fibers in from greatest to least, in terms of compressive and torsional properties, shows that M5 has highest compressive and torsional properties, followed by Kevlar, then Zylon, then Spectra and Dyneema, which are approximately equal.

Thermotropic liquid crystalline polymeric fibers. Thermotropic liquid crystalline polymeric fibers, developed in the 1970s, are melt processed (no solvent). These polymers exhibit liquid crystalline behavior in the melt state. Vectran, a copolyester and an example of a commercialfiber in this class, is spun at temperatures of $275^{\circ} \mathrm{C}$ or more. To further enhance mechanical properties, as-spun fiber may be further drawn and annealed below the polymer melting temperature. During this process, fiber may also undergo further solid state polymerization, resulting in a polymer of 
higher molecular weight. Unlike the liquidcrystalline-solution processing of rigid-rod polymers and the gel spinning of flexible-chain polyethylene-both of which are processed from polymer solutions containing 85 percent to 95 percent solvent (which must be removed during fiber processing)-there is no solvent to be removed in the processing of thermotropic liquid crystalline polymers.

Compared to polyethylene, however, the molecular weights (and hence the chain length) of aramids, rigid-rod polymers, and thermotropic liquid crystalline polymers are much more limited. Vectran has more applications in injection-molded products than in fiber form.

Carbon fibers. The development of modern carbon fibers dates back to the 1960s with research by Shindo in Japan, Watt in England, and Bacon at Union Carbide in the United States. Early carbon fibers were made by pyrolyzing cellulose; today, carbon fibers are made starting from petroleum pitch or from polyacrylonitrile (PAN) copolymers. Pitch-based carbon fibers can have a very high tensile modulus and high electrical and thermal conductivities but exhibit relatively low tensile and compressive strength. By contrast, PAN-based carbon fibers have high tensile strength, good compressive strength, and intermediate modulus and electrical and thermal conductivities. High-purity mesophase pitch (a liquid crystalline pitch) is melted, extruded typically at about $400^{\circ} \mathrm{C}$, and then carbonized in stages (Stage 1 at $600^{\circ} \mathrm{C}$ to $1000^{\circ} \mathrm{C}$, Stage 2 at $1100^{\circ} \mathrm{C}$ to $1600^{\circ} \mathrm{C}$, and Stage 3 at $2200^{\circ} \mathrm{C}$ to $2700^{\circ} \mathrm{C}$ ) in an inert environment. Fibers carbonized at about $2700^{\circ} \mathrm{C}$ can exhibit up to 90 percent of the theoretical modulus. The theoretical modulus of graphite along graphene planes is 1,060 $\mathrm{GPa}$, giving it a specific theoretical modulus of $469 \mathrm{~N} / \mathrm{tex}, 5$ which is equivalent to 469 $\mathrm{GPa} /(\mathrm{g} / \mathrm{cm} 3)$. PAN fibers are either wet spun or dry-jet wet spun from solutions in sodium thiocyanate and water, dimethyl acetate, dimethylsulfoxide, or zinc chloride and water. ${ }^{19}$ Depending on the molecular weight, solvent, and the copolymer composition, the polymer concentration in solution is typically 5 to $25 \mathrm{wt}$ percent. After spinning, fibers are successively drawn at several different temperatures (typically between room temperature and $175^{\circ} \mathrm{C}$ ). Drawn fibers are oxidized under tension typically between $200^{\circ} \mathrm{C}$ and $350^{\circ} \mathrm{C}$ for approximately 2 hours. Oxidized fibers are then carbonized under tension in stages, similar to the carbonization of pitch-based fiber. Fibers with the highest tensile strength are typically obtained at about $1300^{\circ} \mathrm{C}$ to $1500^{\circ} \mathrm{C}$. 
Carbon nanotube fibers. Carbon nanotube (CNT) fibers to date have been processed primarily by one of the following two techniques: (1) CNT smoke drawn directly from the chemical vapor deposition reactor in the form of aerogel fibers ${ }^{20}$ and (2) fiber processed from aqueous ${ }^{21}$ or acidic $^{22}$ dispersions of CNTs. In both cases, it is important that the CNTs be as long as possible and as perfect as possible, and they should be free of catalyst and other foreign impurities, including amorphous carbon. The tube-to-tube diameter variation should be minimized and the diameter should be relatively small. Nanotube orientation also plays a critical role with respect to mechanical properties. ${ }^{23}$ Multiwall CNTs tend to undergo telescoping, with the individual tubular shells slipping past one another, whereas single-wall CNTs are essentially the ultimate for a highstrength polymer molecule, having a theoretical strength as high as $150 \mathrm{GPa}$ and modulus values as high as 1,050 GPa, respectively. The theoretical modulus of carbon nanotubes is dependent on their diameter since their central portion is empty; however, their specific theoretical modulus is $469 \mathrm{~N} /$ tex irrespective of the diameter.

\section{Alumina, boron, silicon carbide, glass, and alumina borosilicate ceramic}

fibers. Boron fiber is processed using chemical vapor deposition on substrates such as tungsten or carbon, whereas silicon carbide fibers can be processed either by chemical vapor deposition or by a precursor method similar to the processing of carbon fibers. Alumina and alumina borosilicate fibers are typically processed using a sol-gel precursor followed by sintering. Nextel fibers (from 3M Company) are ceramic oxide fibers that belong to the category of alumina-boro-silicate. Compared to polymeric and carbon fibers, these fibers retain their mechanical properties to much higher temperatures. Although the tensile strength of these fibers is not quite as high as that of some of the polymeric fibers, their compressive strength can be comparable to or higher than that of carbon fiber having the best compressive strength. Owing to ioniccovalent bonds in all directions, these fibers are much more isotropic than are carbon and polymer fibers, which exhibit a very high degree of anisotropy. ${ }^{24}$ Glass is melt-extruded and drawn into fibers typically at $1000^{\circ} \mathrm{C}$ to $1200^{\circ} \mathrm{C}$. Fiber tensile strength is limited by defects, residual stresses, and structural inhomogeneities in the fibers. 


\subsubsection{Kevlar's}

During the 1920s and 1930s DuPont carried out fundamental research that led to the invention and commercialization of Neoprene synthetic rubber (1933), Nylon ${ }^{\circledR}$ linear polyamides (1938), Teflon ${ }^{\circledR}$ fluoro-polymer resins, Kevlar ${ }^{\circledR}$ poly-p-aramid fibers (1971), Nomex ${ }^{\circledR}$ poly-m-aramid fiber and sheets, Lycra ${ }^{\circledR}$ spandex fiber, Sontara ${ }^{\circledR}$ spun-laced fabric, Mylar ${ }^{\circledR}$ polyester film, Tyvek ${ }^{\circledR}$ spun-bonded olefin, Cordura ${ }^{\circledR}$ nylon fiber, and Corian ${ }^{\circledR}$ solid surface material, etc. ${ }^{25}$

Kevlar® is an aramid, an abbreviation for aromatic polyamide. Chemically, it is a poly p-phenylene-terephthalamide, or PPTA. The ,para" denotes that the amide groups are attached to opposite sides of the benzole ring, Figure 3-2.

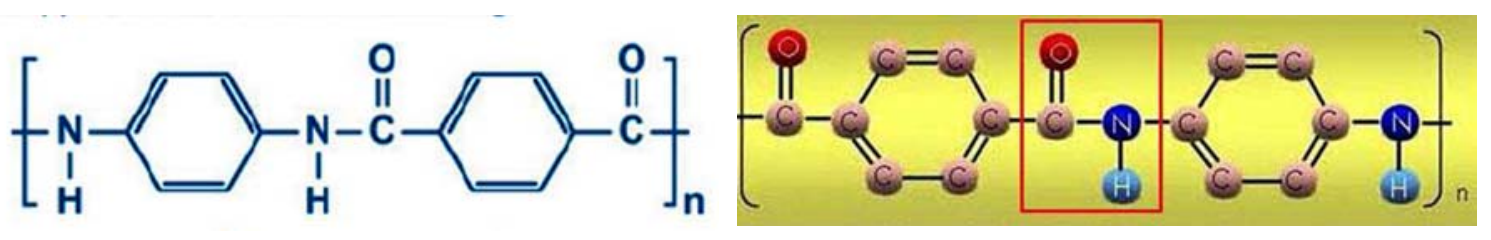

Figure 3-2 Aramide structure formula ${ }^{2}$

Stephanie Kwolek invented Kevlar ${ }^{\circledR}$ crystalline aromatic polyamide, a fiber gram-for-gram five times stronger than steel, with ca. $1 / 2$ of fiberglass density. ${ }^{26}$ The PPTA aramid stretched fibers are highly resistant to chemical attacks. Thus, the adhesion with epoxy is poorer than that with inorganic fibers. Aramid/epoxy chemical interactions are expected to be only secondary, strong enough to result in a thermodynamic fiber wetting. Fiber matrix physical interactions resulting from the thermal stress and Poisson contraction are not strong enough to improve significantly the interfacial load transfer and may even be detrimental to adhesion. Skin-core morphology of the aramid fibers may result in weaker properties in the surface region that may form a cohesive weak boundary in the fiber-matrix interphase. These observations suggest that to improve aramid-epoxy adhesion both the morphological and the physiochemical modification of the interphase must be considered. Kevlar ${ }^{\circledR}$ displays excellent dimensional stability over a wide range of temperatures for prolonged periods. Even at $160^{\circ} \mathrm{C}$ it shows essentially no embrittlement or strength loss. Kevlar ${ }^{\circledR}$ 
fiber also has excellent dimensional stability with a slightly negative coefficient of thermal expansion $\left(-0.210^{-6} /{ }^{\circ} \mathrm{C}\right)$. The fibers do not melt or support combustion and start decomposing at about $427^{\circ} \mathrm{C}$.

The aromatic rings assure Kevlar's thermal stability, while the para $(p)$ structure its crystalizability. Like PA, Kevlar ${ }^{\circledR}$ filaments are made by extruding a precursor through a spinneret. The rigid flat rod $p$-aramid molecules and the extrusion process make Kevlar® fibers anisotropic-they are stronger and stiffer in the axial than in the transverse direction, Figure 3-3.

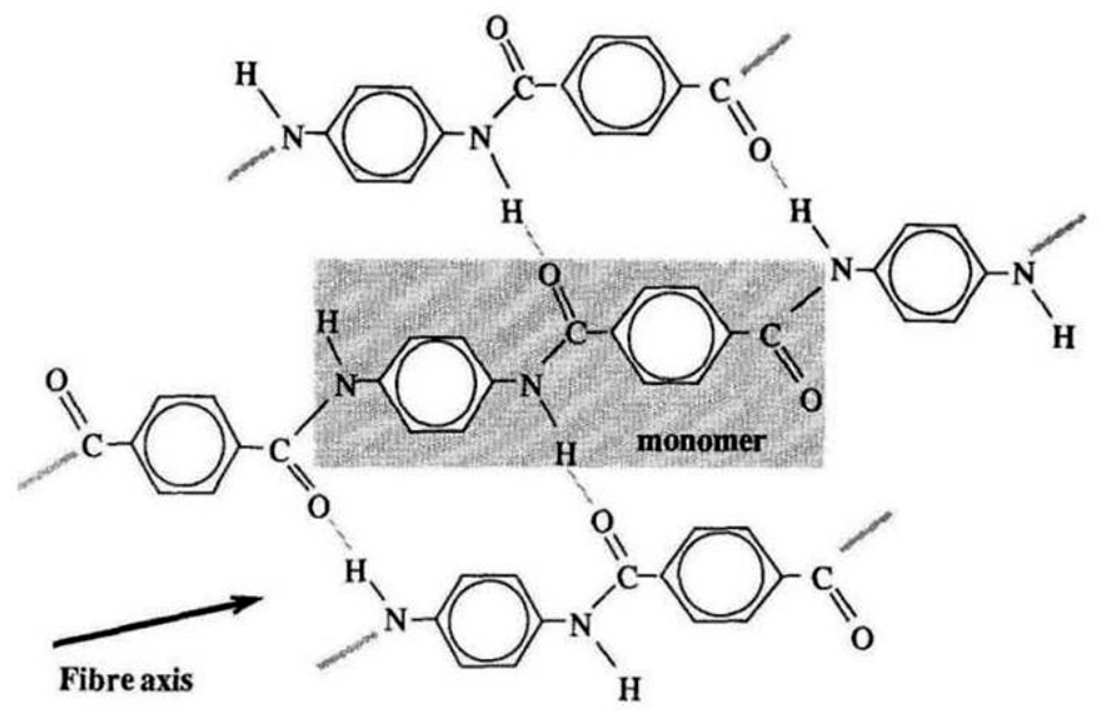

Figure 3-3. Aramide fibers structure and anisotropic properies ${ }^{2}$

The PPTA aramid stretched fibers are highly resistant to chemical attacks. Thus, the adhesion with epoxy is poorer than that with inorganic fibers. Aramid/epoxy chemical interactions are expected to be only secondary, strong enough to result in a thermodynamic fiber wetting. Fibermatrix physical interactions resulting from the thermal stress and Poisson contraction are not strong enough to improve significantly the interfacial load transfer and may even be detrimental to adhesion. Skin-core morphology of the aramid fibers may result in weaker properties in the surface region that may form a cohesive weak boundary in the fiber-matrix interphase. These observations suggest that to improve aramid-epoxy adhesion both the morphological and the physiochemical modification of the interphase must be considered. ${ }^{27}$ 
Recently Li et al. functionalized Kevlar ${ }^{\circledR} 1680$ monofilament with phosphoric acid, $\mathrm{H}_{3} \mathrm{PO}_{4}$. For the initial fictionalization of less than $40 \%$ the monofilament tensile strength was constant. For the optimal functionalization the fibers were tested in various combinations of epoxies and hardeners. The mechanical properties were well enhanced. The interfacial shear strength and inter-laminar shear strength were 76 and $79 \mathrm{MPa}$, respectively. Microstructure analysis revealed better interfacial adhesion and the suitable toughness matching between ductile fiber and toughened matrix, which resulted in high improvement of composite performance. ${ }^{28}$

From 1970 to 2005, the helmet material technology changed little. The U.S. Army ballistic helmets used woven aramids with a toughened polyvinyl butyral (PVB)/phenolic resin that often failed to meet all the criteria. The combination of mass efficient ballistic and structural materials provides a means of meeting the spectrum of performance specifications. Several helmet prototypes with alternate design methods have been produced, e.g., stiffening the core ballistic shell. Walsh et al. presented a preliminary normalized performance data on hybrid structures, demonstrating the improved mass efficiency. A series of Kevlar ${ }^{\circledR}$ KM2 structures has been hybridized using secondary structural materials, such as graphite-reinforced polyolefin/polyamide. The specimens have been characterized ballistically and structurally. The conclusion has been that thermoplastic based systems can yield a 10 to $25 \%$ weight reduction over the conventional thermoset (PVB/phenolic) materials, maintaining equivalent protection levels. The practical manufacturing methods for producing these systems have been identified and preliminary prototypes of these new material and system designs have been fabricated at relatively low pressures. ${ }^{29}$

There are several grades of Kevlar® available for ballistic applications: ${ }^{30} 313233$

Kevlar ${ }^{\circledR} 29 \& 129$ are tough yarns which are well suited for ballistic protection and are used both in soft body armor applications such as ballistic vests and as robust reinforcements for variety of hard armor applications, helmets, spall panels, ballistic blankets and electronic housing protection. These Kevlar's have been also used in industrial-type applications.

The thermal treatment of Kevlar® 29 fibers enhances its performance through two mechanisms: (1) free-radical formation within the external skin region, resulting in the formation of interchain crosslinks; and (2) hydrogen-bond disruption resulting in the 
destruction of the highly ordered, pleated sheet configuration within the core region. Interchain covalent crosslinks improve the compressive strength of the aramid fiber by augmenting its rigidity. Disruption of hydrogen-bond within the core region slightly disorient the crystals and enhances the compressive properties of Kevlar® by disrupting nearly perfect molecular alignment. ${ }^{34}$

The tensile modulus and strength of Kevlar® 29 is comparable to that of glass ( $\mathrm{S}$ or E), yet its density is almost $1 / 2$. Thus, Kevlar ${ }^{\circledR}$ may be substituted for glass where lighter weight is desired.

Kevlar® 49 or 149 cut the weight even further when the higher strength is accounted for. Tensile properties of the three "standard" Kevlar's are presented in Table $3-2$.

Table 3-2. Tensile properties of common grades of Kevlar® PPTA

\begin{tabular}{|c|c|c|c|c|}
\hline Grade & $\begin{array}{c}\text { Density } \\
\left(\mathbf{k g} / \mathbf{m}^{\mathbf{3}}\right)\end{array}$ & $\begin{array}{c}\text { Modulus } \\
\mathbf{( G P a )}\end{array}$ & $\begin{array}{c}\text { Strength } \\
\mathbf{( G P a )}\end{array}$ & $\begin{array}{c}\text { Elongation } \\
\mathbf{( \% )}\end{array}$ \\
\hline 29 & 1440 & 83 & 36 & 4.0 \\
\hline 49 & 1440 & 131 & $3.6-4.1$ & 2.8 \\
\hline 149 & 1470 & 186 & 3.4 & 2.0 \\
\hline
\end{tabular}

Kevlar® KM2, is $p$-aramid fiber made in 400, 600 and 850 denier (denier is the total weight in grams of $9 \mathrm{~km}$ of a filament). This high performance product was designed for ballistic applications in soft and hard military products, e.g., for fragmentation protection. DuPont created $\operatorname{Kevlar}{ }^{\circledR}$ KM2 to achieve the performance goals defined by casualty reduction testing.

The transverse compressive behavior of the Kevlar® KM2 fibers is nonlinear and pseudo-elastic. The original loading and unloading path is totally different, provided the maximum deformation during these cycles does not exceed the maximum deformation the specimen has experienced in the first loading cycle. The original loading and unloading cycle leaves a large residual strain in the fiber of absorbed energy. Furthermore, KM2 fibers keep their mechanical properties in their longitudinal direction 
despite of large residual strain in the transverse. Their transverse compressive behavior is insensitive to loading rates, but the longitudinal tensions can stiffen the transverse behavior at large deformations. To estimate the transverse Young's modulus, a relation was derived between transverse compressive load and deflection based on a classical stress solution to this plane strain problem and the constitutive relation for transversely isotropic materials. At low deformation the transverse compressive Young's modulus was estimated at $1.34 \pm 0.35 \mathrm{GPa}^{35}$

Helmets and vests made with KM2 provide enhanced bullet and fragmentation resistance while remaining comfortable and breathable. Its excellent thermal stability at temperature extremes, water repellency, chemical stability, as well as inflammability and resistance to petroleum products has made KM2 a high asset to the military. The KM2 fiber is a transversely isotropic.

Its tensile stress-strain response in the axial direction is linear and elastic until failure. However, the overall deformation in the transverse directions is nonlinear and inelastic, although it can be treated linearly and elastically at low strains. For a linear, elastic, and transversely isotropic material, five material constants are needed to describe its stress-strain response. ${ }^{36} 37$

Kevlar ${ }^{\circledR}$ LT is a new yarn used in development of the lightest weight body armor products for the market, to be mainly used in the civilian police products, providing comfortable, high level protection.

Kevlar ${ }^{\circledR}$ K-159 was developed for correctional institutions as the first stab resistant fabric. This new fiber, is 4 times thinner than typical ballistic yarns and used for an ultra-dense weave that maintains a strength value five times stronger than steel on an equal weight basis.

Kevlar ${ }^{\circledR}$ Mark IV was recently developed for the use in hybrid personal protection and armoring solutions. ${ }^{38}$ Mark IV is being evaluated by the U.S. Army in the Enhanced Combat Helmet $(\mathrm{ECH})$ program.Kevlar ${ }^{\circledR}$ Mark IV is combined with a thermoplastic matrix, which provides more protection per weight than existing aramidphenolic composites. It can help to improve performance and reduce helmet thickness and cost of ECH or other emerging military helmet, including the Next Generation Helmet. 
Kevlar XP. Kevlar ${ }^{\circledR}$ XPTM is the newest innovation from DuPont. With it, you can create NIJ III A vest designs that provide superior ballistic performance and reduce back face deformations by approximately $15 \%$ or more. This new Kevlar ${ }^{\circledR}$ XP'M S300 technology offers more flexibility in designing body armor for specific end-user requirements in addition to NIJ, such as standards that focus on $9 \mathrm{~mm}$ threats (e.g., SK1). This extension compliments the existing DuPont ${ }^{\mathrm{TM}}$ Kevlar ${ }^{\circledR}$ XP ${ }^{\mathrm{TM}}$ S102.

When a bullet strikes a standard bullet-resistant vest, the resulting backface deformation could cause serious ballistic or trauma injuries. Kevlar ${ }^{\circledR}$ XPTM decreases the impact, reducing backface deformations by approximately $15 \%$ or more.* It's also able to maintain its performance in extreme field conditions that officers face, including heat, humidity and mechanical wear. Tests show that Kevlar® XP'M typically stops bullets within the first three layers of a vest designed with a total of 11 layers. The remaining layers of Kevlar ${ }^{\circledR}$ XP $\mathrm{XP}^{\mathrm{TM}}$ absorb the energy of the bullet, resulting in less trauma to the vest wearer. Kevlar® ${ }^{\circledR} \mathrm{XP}^{\mathrm{TM}}$ features a patented new woven fabric technology that enables vests to weigh at least $10 \%$ less than those made with other commercially available technologies, while still being made of all Kevlar® material.

The high toughness thermoplastic resin matrix of Kevlar ${ }^{\circledR}$ XР ${ }^{\text {TM }}$ H170 increases ballistic performance over current aramid phenolic systems, while the exceptional performance of Kevlar ${ }^{\circledR}$ KM2 Plus fiber provides maximum strength. In addition, the broad processing capability of Kevlar ${ }^{\circledR}$ XPTM $\mathrm{H} 170$ allows for co-processing with existing high performance thermoplastic and existing Kevlar ${ }^{\circledR}$ phenolic systems.

KEVLAR ${ }^{\circledR}$ CORRECTIONAL ${ }^{\text {TM}}$. DuPont's ongoing commitment to provide technology solutions that first anticipate - then meet - the needs of its customers led to the development of KEVLAR ${ }^{\circledR}$ CORRECTIONAL ${ }^{\mathrm{TM}}$, a new KEVLAR ${ }^{\circledR}$ fiber that is four times thinner than typical ballistic fibers (for an ultradense weave) and five times stronger than steel on an equal weight basis. Personal body armor made with this innovative technology uses this unique, superfine fiber. It is woven so tightly together, that when struck by sharp, handmade instruments, such as spikes, awls or shanks, the fiber absorbs and dissipates the energy of the puncture or penetration.

M5® fiber is not polyaramid (thus it is not Kevlar), but it is being developed by Magellan Systems International (where DuPont is majority owner) using DuPont high performance fiber technology. $M 5 \AA$ is the polyhydroquinone-diimidazopyridine, 
developed by Sikkema at Akzo Nobel. Potentially it is an ultra-high strength, ultrahigh thermal and flame resistant alternative to the existing advanced fibers. Its future applications may include soft and hard ballistics protection, fire protection, nonstructural composites, and a host of others. M5 is stronger than aramids (Kevlar ${ }^{\circledR}$, Twaron) or UHMWPE (Dyneema $\left.{ }^{\circledR}\right)$, it is the most fire resistant organic fiber (better than Nomex $\left.{ }^{\circledR}\right)$, less brittle than carbon fiber and will yield when stretched. The US Army is experimenting with it in new, advanced composites for lighter and more effective protection of vehicle and body armor.

M5 fibers are prepared by a condensation of tetra-amino pyridine with dihydroxy terephthalic acid using di-phosphorus pentoxide as a dehydrating agent. Then, the polymer mixture is heated and extruded to form brightly blue fibers, which are extensively washed with water and an alkaline removing the residual phosphoric acid, $\mathrm{H}_{3} \mathrm{PO}_{4}$. Finally, the fiber is heated and stretched, aligning its macromolecules to optimal configuration. Its crystalline structure is different from all other high strength fibers. The macromolecules have covalently bonded backbone with a hydrogen-bonded network in the lateral dimensions. M5 fibers have an average tensile modulus of 310 GPa (i.e., higher than $95 \%$ of the carbon fibers), and average ultimate tensile strength $\leq$ 5.8 GPa (higher than Kevlar ${ }^{\circledR}$ or Twaron ${ }^{\circledR}$, and on a par with Zylon® ${ }^{\circledR}$ PBO fibers). The ballistic impact performance of composites prepared from relatively poor M5 fibers (ultimate tensile strength $=3.9 \mathrm{GPa}$, elongation at break $=1.4 \%$, and modulus $=271$ GPa) was slightly inferior to aramid armor systems, Table 3-3. However, M5 armor systems based on these fibers have been shown to provide performance almost as good as the best composite materials ever prepared for fragmentation protection. Thus, at the same level of protection the fragmentation protective armor systems based on M5 might require $40-60 \%$ smaller areal density than that based on Kevlar ${ }^{\circledR}$ KM2 fabric. ${ }^{39}$ 
Table 3-3. Advanced Fiber Mechanical Properties

\begin{tabular}{|c|c|c|c|c|}
\hline $\begin{array}{l}\text { Fiber/ } \\
\text { (denier) }\end{array}$ & $\begin{array}{c}\text { Strength }(\sigma) \\
(\mathrm{GPa})\end{array}$ & $\begin{array}{l}\text { Failure Strain } \\
\text { (ع) }(\%)\end{array}$ & $\begin{array}{l}\text { Modulus }(E) \\
(\mathrm{GPa})\end{array}$ & $\begin{array}{l}\text { Strain wave velocity } \\
(\mathrm{m} / \mathrm{s})\end{array}$ \\
\hline PBO & 5.20 & 3.10 & 169 & 813 \\
\hline Spectra $^{\oplus} 1000$ & 2.57 & 3.50 & 120 & 801 \\
\hline Kevlar ${ }^{\oplus}$ KM2/600 & 3.40 & 3.55 & 82.6 & 682 \\
\hline Kevlar $^{\oplus}$ KM2/850 & 3.34 & 3.80 & 73.7 & 681 \\
\hline Kevlar $129 / 840$ & 3.24 & 3.25 & 99.1 & 672 \\
\hline Kevlar $^{\oplus}$ 29/1500 & 2.90 & 3.38 & 74.4 & 625 \\
\hline Kevlar $^{\oplus}$ 29/200 & 2.97 & 2.95 & 91.1 & 624 \\
\hline Kevlar $^{\oplus} 29 / 1000$ & 2.87 & 3.25 & 78.8 & 621 \\
\hline Kevlar $^{\oplus} 49 / 1140$ & 3.04 & 1.20 & 120 & 612 \\
\hline Carbon fiber & 3.80 & 1.76 & 227 & 593 \\
\hline E-Glass & 3.50 & 4.7 & 74 & 559 \\
\hline Nylon & 0.91 & N/A & 9.57 & 482 \\
\hline M5 ${ }^{\circledR}$ Conservative & 8.50 & 2.5 & 300 & 940 \\
\hline $\mathrm{M}^{\circledR}{ }^{\circledR} \mathrm{Goal}$ & 9.50 & 2.5 & 450 & 1043 \\
\hline M5 ${ }^{\circledR}$ (2001 Sample) & 3.60 & 1.4 & 271 & 583 \\
\hline
\end{tabular}

Potential Army applications of the M5® fiber include fragmentation vests and helmets, composites for use in conjunction with ceramic materials for small arms protection and structural composites for vehicles and aircraft, for body armor of soldiers and police, heat-resistant coats for fire fighters, and engineered composites for satellite struts and aircraft wings. Only after meeting those critical markets will the company turn to consumer products such as golf club shafts, bicycle frames and tennis rackets. As the Table 3-4 above shows, there is large difference between the performance obtained in 2001 for M5® and the goal. Depending on the application, M5® could be interwoven with other fibers to boost their performance. M5 ${ }^{\circledR}$ doesn't degrade with exposure to waters, acids or ultra-violet light, and its ability to adhere to resins allows it to be used in composites. Competitors' fibers may compete on the basis of individual attributes, but none combine all its characteristics. ${ }^{40}$

\subsubsection{Twaron®}

Twaron ${ }^{\circledR}$ 1000, 2040 are high performance $p$-aramid fibers supplied by Teijin Aramid $\AA$. In the last 15 years of Twaron ${ }^{\circledR}$ being in the marketplace, many improvements in properties have been made. ${ }^{41}$ Developments of finer filaments, 
uniquely combined with higher tensile properties, resulted in the patented Twaron Microfilament ${ }^{\circledR}$ and have led to the newest types of Twaron $\AA$ yarns well adapted to the specific demands of hard and soft ballistic applications.

Twaron ${ }^{\circledR}$ LFT AT is based on 930 dtex $p$-aramid fibers from Teijin Twaron Ballistic Engineering in 2006. It shows excellent performance using laminating technology for hard armor applications. The high tenacity Twaron ballistic fabrics were combined with an impact-resistant polypropylene composite for soft armor application. However, there was a long way to go from the initial idea to the final product. Countless runs followed by ballistic tests were required before launching Twaron ${ }^{\circledR}$ LFT AT. The new plain weave, laminated material is capable distributing deformation energy of a bullet over a larger area, thus reducing hematomas. Teijin also developed a composite called Curv, consisting of an extended thin polypropylene ribbon, which is woven and then laminated into a composite structure joined with Twaron woven fabric, CT 707, in a specially developed pressing procedure. Its application is for hard shell suitcases, under-seal of cars, shin protection in sports equipment, etc. For the ballistic application the goal was reinforcement of the rather brittle Curv so that it is able to distribute the energy of the impact over a larger area. Two layers of LFT AT reduced the bruises to the body by almost $40 \%$. The real aim was a compromise between maximum protection for the wearer and portability of the vest. The LFT AT is more economical and lighter in comparison with shock absorbers manufactured from neat aramid-laminates. Patents are pending. ${ }^{42}$

Heracron ${ }^{\circledR}$ polyaramid fibers from a Korean company, Kolon Inc. It has high strength, thermal and chemical resistance, thus it may be used in ballistics.

Twaron ${ }^{\circledR}$ LFT GF is a recent (2010) soft ballistic unidirectional laminate of 4 layers of Twaron (orientation 0 and $90^{\circ}$ ) between two PE films, designed for the use in bullet resistant vests. For helmets Twaron fabrics: CT 736 (2x2 basket weave; 1680 dtex; $410 \mathrm{~g} / \mathrm{m} 2$ ), or T750 (plain weave; $3360 \mathrm{dtex} ; 460 \mathrm{~g} / \mathrm{m}^{2}$ ) are recommended by Teijin. $^{43} 44$

Innegra $^{\text {TM }}$ S Fibers are highly Kolon developed Heracron ${ }^{\circledR}$ technology during 1979 to 1994 period, accumulating 25 related patents. Global commercialization of Heracron ${ }^{\circledR}$ (filament and pulp) started in 2005. 
Making fabrics. Hexcel is the largest weaver of high performance yarns in the US for over 25 years. Hexcel fabrics are woven from Kevlar ${ }^{\circledR}$, Spectra ${ }^{\circledR}$, Twaron ${ }^{\circledR}$ and other high performance fibers that offer unmatched resistance to bullets, fragments, cuts, stabs and abrasions, while offering lightweight strength and comfort. Police forces exposed to relatively high-mass/low-velocity bullets will use a different fiber and different weave than military, which encounter relatively low-mass/highvelocity bullets and fragments. The high strength fabrics woven from these fibers provide ballistic and blunt trauma protection which has saved thousands of lives. Kevlar ${ }^{\circledR}$ fabric displays excellent dimensional stability over a wide range of temperatures for prolonged periods. $^{45}$

Kevlar® KM2, made in 400, 600 or 850 denier, is a high performance product designed for use in ballistic applications.

Kevlar ${ }^{\circledR}$ K-159 was developed for correctional institutions as the first stab resistant fabric. This new fiber, which is 4 times thinner than typical ballistic yarns, is used for an ultra-dense weave but still maintains a strength value that is five times stronger than steel on an equal weight basis.

$\operatorname{Kevlar}{ }^{\circledR}$ XLT is one of the newest yarns developed for body armor. This new yarn is available to licensed companies through Du Pont.

$\operatorname{Kevlar}^{\circledR}$ A-200 and LT are new yarns that are used in the development of the lightest weight body armor products. These new yarns are used in the civilian police products to provide comfortable, high level protection.

Kevlar ${ }^{\circledR}$ Mark IV is a new poly( $p$-aramid) yarn in a thermoplastic resin matrix material, used in the helmet design, being evaluated by the U.S. Army's Enhanced Combat Helmet $(\mathrm{ECH})$ program. It provides more protection per weight than existing $p$ aramid-phenolic composites. ${ }^{46}$

\subsection{Matrix}

The synthetic thermoplastic polymers are divided into three categories: ${ }^{47}$

1. Commodity resins (PE's, PP, styrenics, acrylics, PVC),

2. Engineering resins (PA, PEST, PC, POM, PPE), and 
3. Specialty resins (PSF, PPS, PES, PAE, PEK, PEEK, PEKK, PI, PEI, PAI, PAr, PARA, PEA, LCP, PHZ, etc.).

The five large-volume commodity polymer families are: polyethylenes (PE), polypropylenes (PP), styrenics (PS), acrylics (PMMA), and vinyls (PVC). They represent $71 \%$ of all plastics and their world market share remains stable.

Thermoset polymers constitute ca. $13 \%$ of the plastics mass.

The five engineering polymer families are: polyamides (PA), thermoplastic polyesters (PEST), polycarbonates (PC), polyoxymethylene (POM or acetal), and polyphenyleneether (PPE). They constitute about $13 \%$ by volume and $34 \%$ by value of the plastic's consumption.

The specialty polymers are characterized by high mechanical properties and high continuous use temperature $150 \leq \mathrm{CUT}\left({ }^{\circ} \mathrm{C}\right) \leq 500$; their consumption amounts to about $3 \%$. Th ey are expensive, produced in relatively small quantities either for specific applications or expecting a market niche. Their glass transition temperature, $\mathrm{Tg}>200^{\circ} \mathrm{C}$ and modulus $>3 \mathrm{GPa}$. To this category belong: polysulfone (PSF), polyphenylsulfide (PPS), polyethersulfone (PES), polyarylethers and ketones (PAE, PEK, PEEK, PEKK), polyimides (PI, PEI, and PAI), polyarylates (PAr), polyarylamides (PARA), polyetheramide (PEA), liquid crystal polymers (LCP), polyphosphazene (PHZ), and several others. PEEK was the polymer of choice in body armor patent US Pat 7,413,809. Excellent properties were reported for PEEK with nanoparticles, such as tungsten disulfide ( $\leq 2 \mathrm{wt} \% \mathrm{WS} 2$ ) fullerene, fly ash (maximum strength for about $20 \mathrm{wt} \%$ ) or mica (best for ca. $10 \mathrm{wt} \%)^{48} 49$

Evidently, in addition to neat polymers there are numerous blends prepared to address some specific lacunae of the basic resin. Polyamides (PA-, followed by the number of carbons in a di-amine and dicarboxylic acid, e.g., PA-66 patented in 1937 by Carothers, commercialized by du Pont two years later as Nylon ${ }^{\mathrm{TM}}$, an aggregate of New York and LONdon. PA-11 was commercialized in 1955, PA-12 in 1966, PA-612 in 1970, and PA-46 in 1987. Liquid crystal aromatic polyamides (PARA), poly(metaphenylene isophthalamide), Nomex ${ }^{\mathrm{TM}}$, and poly(p-phenylene terephthalamide), Kevlar TM-49, were commercialized in 1961 and 1965, respectively. 
Amorphous aromatic polyamide, Trogamid ${ }^{\mathrm{TM}}$, was introduced in 1969, and polyphthalamide, Amodel ${ }^{\mathrm{TM}}$, in 1991.

PA's are characterized by the presence of amide groups (-CO-NH-). They may be divided into three categories: aliphatic (such as PA-6 or PA-12), semi-aromatic (e.g., PA-63T), and aromatic (i.e., polyaramids such as Kevlar ${ }^{\circledR}$ or Nomex ${ }^{\circledR}$ ) where the amide linkages, R-CO-NH-R, are directly attached to two aromatic groups. Depending on the regularity of structure, PA's may be either crystalline or amorphous- the latter being transparent and susceptible to solvent attack. ${ }^{50}$

Polyamides are tough, strong, and impact resistant, have low friction coefficient and abrasion resistance, are easy to process, and have fair resistance to solvents and bases. However, they also suffer from several drawbacks, out of which the moisture absorption and susceptibility to hydrolysis (especially by acids) is a major one. The molecular weight of the attacked polymer decreases and then cracks are formed. PA-6 is affected by moisture more than more hydrophobic higher PA's, such as PA-12. High temperatures may also degrade the polymer. Furthermore, PA's are susceptible to oxidation and UV degradation; hence stabilization is required. Another disadvantage is a large, in-mold shrinkage caused by crystallization.

\subsubsection{Types of Adhesive Interlayers}

Thermoplastic Polyvinyl Butyral. Developed in the late 1930s and commonly used in automotive glass applications, thermoplastic polyvinyl butyral (PVB), which is generally plasticized, has been the workhorse of polymeric adhesive interlayers. Examples are Saflex (Solutia, Inc.), Butacite (DuPont), Trosifol (Kuraray Europe), SLEC (Sekisui Chemical), and KB (GlasNovations). Positive features of PVB include good optical transparency when bonded to glass, controllable adhesion to glass, resistance to elongation when struck with a projectile, and good UV stability. ${ }^{51}$

Thermoplastic Polyurethanes. Thermoplastic polyurethanes (TPUs) come in two broad categories, aliphatic or aromatic, depending on the precursor from which they are synthesized. Examples are Dureflex (Bayer Material Science), IM800 (and others from Inter Materials), Deerfield 4700 (and others from Deerfield Urethane), and Huntsman 399. Aliphatic TPUs are generally preferred for transparent armor 
applications because of their superior clarity compared to aromatic TPUs. TPUs are sometimes preferred to PVB since they do not contain plasticizer, which can chemically attack other polymers such as acrylics and polycarbonate. ${ }^{52}$ TPUs are typically extruded and rolled in sheet form. The composite is formed by layering the materials, which are then sealed in a bag that is then evacuated of air and autoclaved to consolidate the layers.

Thermosets. Other cross-linkable polyurethanes may be used for adhesive interlayer materials. One such example uses a poly(urethane urea) elastomer. ${ }^{53}$ Blends of mercaptans with epoxies have shown improved performance. ${ }^{54}$ Epoxies for use as adhesives in nontransparent composite armor have also been studied. ${ }^{55}$

\subsection{Ceramic powders}

For ballistic-scale operations, $\mathrm{SiC}$ and $\mathrm{B} 4 \mathrm{C}$ powders are produced by the arbothermic reduction of a silicon oxide or boric oxide in contact with a carbon source. The resultant powder has large grains and must be comminuted to produce the micronto submicron-sized particles required for ceramic processing. As a consequence, process-related impurities are introduced or process-induced changes occur within the particles, requiring extraordinary cleaning processes to remove impurities and a greater understanding of the changes that take place during processing. ${ }^{56}$

Aluminum nitride powder is primarily produced by carbothermal nitridation of alumina $\left(\mathrm{Al}_{2} \mathrm{O}_{3}\right)$ in contact with carbon in a nitrogen atmosphere. Oxygen content can dramatically affect the structure of AlN, so large-scale Acheson-type furnaces cannot be employed. Typically, pusher-type furnaces are employed to provide improved control in the moving-bed furnace. Impurities condense near cold zones, which can lead to variable chemistry powders. Also, like SiC, AlN must be comminuted to achieve micron-sized powders, leading to process-related impurities that must be cleaned. ${ }^{57} 58$

Alumina is by far the most widely used ceramic powder, being a precursor to aluminum smelting. As a result, worldwide availability for commodity-grade $\mathrm{Al}_{2} \mathrm{O}_{3}$ has changed with the economic conditions in recent years. Across-theboard production cuts and future uncertainty have been prevalent. This has dramatically reduced the availability of low-soda, high-purity ( $>99.99$ percent) $\mathrm{Al}_{2} \mathrm{O}_{3}$. 
Spinel and aluminum oxynitride (AlON) are specialty materials typically produced in very small volumes for transparent crystalline ceramics. AlON powder is not commercially available but is typically prepared by a vertically integrated ceramic producer. Common methods for forming $\mathrm{AlON}$ are either direct reaction of $\mathrm{Al}_{2} \mathrm{O}_{3}+$ AlN or reduction nitridation of $\mathrm{Al}_{2} \mathrm{O}_{3}+\mathrm{C}+(\mathrm{Al}$ or $\mathrm{H} 2)$ in nitrogen or ammonia. The latter process is the most widely utilized, although with this process it tends to be difficult to remove all residual carbon. As with $\mathrm{AlN}$ and $\mathrm{SiC}$, this process results in powders that must be reduced in size by comminution. Consequently, these powders must be carefully milled to avoid particulate contaminations. $^{59}$

Spinel powder is produced by direct reaction of magnesium and aluminum salts that are subsequently calcined to produce the powders. Spray pyrolysis has also been used for very high purity powders. There is one source, Baikowski International Corp. (France), of commodity spinel worldwide. As a result, the cost of spinel powder is high. Variability in chemistry, particle size, and degree of aggregation has led to challenges in producing transparent ceramics. ${ }^{60} 6$ The current cost of spinel, at $\$ 60 / \mathrm{kg}$ to $\$ 80 / \mathrm{kg}$, is much too high to

expect widespread use for transparent armor. There is a need for research to be conducted to determine whether a more affordable, uniform, ceramic-grade powder can be produced.

\subsubsection{Silicon Carbide}

Silicon carbide $(\mathrm{SiC})$ is not found in any appreciable quantities in nature but is one of the most widely used synthetic technical minerals. The market for $\mathrm{SiC}$ focuses on its hardness and refractoriness, but $\mathrm{SiC}$ is also used as a source of silicon in the metallurgical processing of iron. SiC's hardness and high-temperature stability make it as widely used as alumina as an abrasive grain. For higher-performance applications, the higher-purity (green) SiC powder is used, and for lesser requirements the lowerpurity (black) SiC powder is used. For advanced ceramic applications such as armor, 
only the high-purity green materials are used. Other applications of high-purity $\mathrm{SiC}$ include space-based mirrors, semiconductor processing equipment, wire-impregnated saws for silicon wafer cutting, and automobile catalysts. These markets have driven the world supply of green $\mathrm{SiC}$ to more than 1 million tons per year. Armor ceramics make up less than 1 percent of the world market for high-purity $\mathrm{SiC}^{61}$

There are many methods for producing $\mathrm{SiC}$, including carbothermic reduction of silica, chemical vapor-phase reactions, and electrothermal techniques. The Acheson process, which dates from 1893, places electrodes into a graphite core laid within a mixture of reactant carbon, salt, and sand. The electric current resistively heats the graphite and in turn the surrounding reactants, resulting in the formation of a hollow cylinder of $\mathrm{SiC}$ and the evolution of carbon monoxide (CO) gas. ${ }^{62}$ The chemical reaction that Acheson described for the manufacture of SiC from silica sand and carbon is as follows:

$$
\mathrm{SiO}_{2}+3 \mathrm{C} \rightarrow \mathrm{SiC}+2 \mathrm{CO}
$$

Within the ceramic-grade zone, both green $\mathrm{SiC}(>99$ percent $\mathrm{SiC})$ and black $\mathrm{SiC}$ (95-98 percent $\mathrm{SiC}$ ) can be found, with metallurgical $\mathrm{SiC}$ (80-94 percent $\mathrm{SiC}$ ) making up the remainder of the reaction zone. The boundary between unreacted materials and the reaction zone is marked by a layer of condensed impurities. This layer is discarded, but the unreacted precursors can be used again.

The exact kinetics of the reaction are highly dependent on carbon source, particle size, mixing uniformity, and packing of the silica and the carbon. During the heating of the graphite core, silica can react with carbon at temperatures as low as $1527^{\circ} \mathrm{C}$ to create $\beta$-SiC. At temperatures about $1900^{\circ} \mathrm{C}$, the $\beta$-SiC converts to $\alpha$-SiC. The various polytypes formed are dependent not only on temperature but also on the presence of impurities. For example, for $\alpha$-SiC the $6 \mathrm{H}$ polytype is most prevalent. However, in the presence of aluminum, either intentionally or as an impurity, the $4 \mathrm{H}$ polytype becomes dominant. This change in polytype alters not only the shape of the resultant particles but also the microhardness, with the $4 \mathrm{H}$ being less hard. ${ }^{63}$

Work by Choi et al. ${ }^{64}$ indicated that $\mathrm{SiC}$ sintered with $\mathrm{AlN}$ and oxide additives could have a marked effect on the mechanical properties of the resulting SiC. Zhou et 
al. ${ }^{65}$ showed the strong influence of rare-earth additions and resulting intergranular properties on the mechanical properties of SiC. Thus a better understanding of the role of intergranular phases could be used to engineer high-performance armor materials.

\subsubsection{Boron Carbide}

Worldwide, 1,000 to 2,000 metric tons of boron carbide are produced annually. The boron carbide market is driven by the use of boron carbide based on selected properties, such as its hardness-for example, as an abrasive grit or powder; its neutron absorption capacity (for use as control rods and shielding in pressurized water nuclear reactors, among other applications); and its specific hardness-as an armor ceramic, for example. ${ }^{66}$ Boron carbide is a solid solution containing 10 percent to 20 percent carbon. The exact chemistry of boron carbide powders depends on the particular powder synthesis route. The carbothermic reduction processes provide the largest quantities of boron carbide powders produced. ${ }^{67}$ Magnesiothermic reduction and vapor-phase reactions, while producing high-quality fine-grain powders, are very expensive $(>\$ 500 / \mathrm{kg})$ and are not discussed here.

Carbothermic reduction of boron carbide utilizes a Higgins or an electric arc furnace. Here, a water-cooled crucible is insulated with a packed wall of the mixed boric oxide and carbon precursors. An electric arc is used to generate temperatures between approximately $2500^{\circ} \mathrm{C}$ and $2800^{\circ} \mathrm{C}$. Mixed precursor powders are added where they slowly melt, near the highest temperature areas. Because the melt is highly viscous and evolved $\mathrm{CO} 2$ must be allowed to escape, materials are gradually added and the electrode height is changed. When sufficient materials have been reacted, the electrodes are withdrawn and the melt is cooled. The result is an ingot that weighs between $25 \mathrm{~kg}$ and $1,000 \mathrm{~kg}$. The outer edges of the ingot are covered with unreacted precursor powders, which must be manually removed and are typically recycled. The ingot then undergoes a series of crushing operations, and the powder grain is milled to size. Depending on the manufacturer, metallic impurities derived from the crushing and milling equipment can be eliminated through a series of acid leaching steps. ${ }^{68}$

The carbothermic method is a very high temperature operation having large temperature variations across the crucible, and the stoichiometry of the product boron 
carbide is typically rich in carbon, commonly $\mathrm{B}_{4-\mathrm{x}} \mathrm{C}$. A few percent of essentially pure carbon is typically found in the powder, resulting from unreacted graphite, graphite originating from the electrode, decomposed $\mathrm{B}_{4} \mathrm{C}$, or vapor-phase condensates of $\mathrm{CO} / \mathrm{CO} 2$. Direct carbothermic reduction has been demonstrated on a pilot scale, where boric oxide and carbon are reacted in a vertical tube furnace at between $1973^{\circ} \mathrm{C}$ and $2073^{\circ} \mathrm{C}$. Although this method produces a fine-grained $(0.5-5 \mu)$ and very controlled stoichiometric boron carbide, its yield is lower than that of the arc-melted grain method and at present it is not considered a viable option. ${ }^{69}$

\subsubsection{Alumina}

In 1887, Bayer discovered that aluminum hydroxide precipitated from alkaline olution was crystalline and could be more easily filtered and washed than that precipitated from acid medium. The process was a key to the development of modern metallurgy, since aluminum hydroxide is the raw material for the electrolytic aluminum process that was invented in 1886. The process that Bayer invented has remained essentially the same and produces nearly all of the world's alumina as an intermediate in aluminum production. The Bayer process can be considered in three stages: (1) extraction, (2) precipitation, and (3) calcination.

The aluminum-bearing minerals in bauxite are dissolved in a solution of sodium hydroxide (caustic soda) to selectively extract them from the insoluble components (mostly oxides). Then the ore is milled to make the minerals more available for extraction and to reduce the particle size. It is then combined with the process liquor in a heated pressure digester. Temperature and pressure within the digester reflect the type of ore. Temperatures vary between $140^{\circ} \mathrm{C}$ and $240^{\circ} \mathrm{C}$ and pressures vary up to $35 \mathrm{~atm}$. After the aluminumcontaining components dissolve, the insoluble residue is separated from the liquor by settling. Crystalline aluminium trihydroxide (ATH) is then precipitated from the digestion liquor:

$$
\mathrm{Al}(\mathrm{OH})_{4}+\mathrm{Na}^{+} \rightarrow \mathrm{Al}(\mathrm{OH})_{3}+\mathrm{Na}^{+}+\mathrm{OH}^{-}
$$


The ATH crystals are then classified into size fractions and fed into a rotary kiln at temperatures greater than $1050^{\circ} \mathrm{C}$ for calcination. The $\mathrm{ATH}$ is calcined to form alumina, which can be directly used for aluminum processing or can be used for ceramic applications. If the ATH is to be used for ceramics, it can undergo multiple washing steps to reduce the ionic sodium to less than 0.01 percent. The particle size of the calcined powder is reduced in size, depending on specifications determined by the end user.

\subsection{Patented ballistic armor}

Number of ballistic-resistant constructions for hard or soft armor articles is described in several U.S. Patents, viz. 4,403,012, 4,457,985, 4,613,535, 4,623,574, $4,650,710,4,737,402, \quad 4,748,064, \quad 5,552,208, \quad 5,587,230, \quad 6,642,159, \quad 6,841,492$, $\mathbf{6 , 8 4 6 , 7 5 8}, 7,700,503,7,727,914,7,762,175$, and others. These usually describe sandwich structures made off high strength fibers, felts or fabrics.

For example, patents $\mathbf{4 , 6 2 3 , 5 7 4}$ and $\mathbf{4 , 7 4 8 , 0 6 4}$ disclose composite structures comprising high strength fibers embedded in an elastomeric matrix. Patent 4,650,710 discuses a flexible article manufactured from several flexible layers, including high strength, extended chain polyethylene, polypropylene, polyvinyl alcohol, and extended chain polyacrylonitrile $(\mathrm{PAN})$ fibers coated with a low modulus $\left(<41 \mathrm{MPa}\right.$ at $\left.23^{\circ} \mathrm{C}\right)$ elastomeric material. ${ }^{70}$

Patents 5,552,208 and 5,587,230 disclose articles comprising at least one network of high strength fibers and a matrix composition that includes a vinyl ester and di-allyl phthalate. ${ }^{71}$ Preferably, the article is made from at least one prepreg which includes at least two layers of the high strength fiber network in the vinyl estercontaining matrix composition. The prepreg element is made by applying a peroxidecurable mixture of epoxy vinyl ester, di-allyl phthalate and a carbon-carbon saturated solvent (an alcohol that contains 1 to 5 carbon atoms) to the high strength fiber network.

Patent 6,162,746 discloses a composite designed to be impact resistant to knife and ice pick stabs, which comprises a number of woven layers selected from the group consisting of extended chain polyethylene, aramid and polybenzoxazole (PBO) or 
polybenzothiazole fabrics with a tightness factor of at least 0.75 , and a number of layers of a network fiber. ${ }^{72}$ Pats. No. 6,642,159 and later 7,762,175 discloses an impact resistant rigid composite having multitude of fibrous layers with elastomeric layers there between. The composite is bonded to a hard plate to increase protection against armor piercing projectiles.

Patent 7,700,503 describes a ballistic-resistant material composed of several layers: 1. first exterior layer formed of a ballistic-resistant non-woven textile, 2. a second exterior layer formed of a ballistic-resistant non-woven textile, and 3. an interior layer of ballistic-resistant woven tight weave textile arranged between 1 and $2 .^{73}$ Pat.Stress is on the well-performing needled felt: ArmorFeltTM [50\% $p$-aramid, 50\% extended chain UHMWPE, e.g., 50\% 1.5 denier Kevlar ${ }^{\circledR}$ K29 + 50\% 3.6 denier Spectra ${ }^{\circledR} 1000$ with extra 30\% performance over the average]. As shown below, on impact Kevlar ${ }^{\circledR}$ fibrillates while UHMWPE deforms. The projectile energy is efficiently dissipated by destabilization of its path.

Pat 7,727,914 also discusses flexible, penetration resistant articles comprising a number of layers including continuous filament yarns, having an areal density of less than about $4.4 \mathrm{~kg} / \mathrm{m}^{2} .{ }^{74}$ At least one of these layers should have a fiber with tenacity $>3$ $0 \mathrm{~g} / \mathrm{dtex}$ and a continuous filament yarn having a linear density of less than about 1100 dtex. The first layers may be made from polybenzoxazole, polybenzothiazole, polyareneazole, polypyridazole, or poly(pyridobismidazole) fibers, while the continuous filament yarns are selected from the group comprising polyamide, polyolefin, polybenzoxazole fibers, polyareneazole, polypyridazole, polypyridobisimidazole fibers, and mixtures thereof.

US Pat. 7,762,175 describes lightweight, ballistic resistant armor incorporating two or more connected but spaced apart, ballistic panels, having superior impact and ballistic performance at a light weight. ${ }^{75}$ The panels are spaced by air or by an intermediate material. When a high speed projectile hits the first panel, the projectile is deformed, redirected and slowed down before reaching the second panel, where it is either slowed down further, or stopped. The spacing reduces the back-face deformation compared to a configuration where multiple panels are bonded together. The improved ballistic resistance allows weight reduction. 
For example, the first panel comprises a number of consolidated fibrous layers, each made of fibers having a tenacity of $>7 \mathrm{~g} /$ denier or and a tensile modulus of $>150$ g/denier. The fibers are coated with a polymer. The fibrous layers are united into a monolithic structure by the application of heat and pressure, to form the single, consolidated composite of fibers and the matrix polymer. The second panel, connected to the first one, also comprises a number of consolidated fibrous layers, each made of many fibers with a tenacity of $>7 \mathrm{~g} /$ denier or and a tensile modulus of $>150 \mathrm{~g} / \mathrm{denier}$. The fiber surface is coated with an elastomeric or rigid polymer. The two (or more) panels are connected and spaced apart by about 6 to $13 \mathrm{~mm}$ from each other. The spacing is achieved by placing a frame between the panels with air vents, or a layer of open-cell foam of PU or PVC. Excellent ballistic resistance is achieved when individual fibrous layers are cross-plied such that the fiber alignment direction of one layer is rotated at an angle with respect to the fiber alignment direction of another layer, e.g. 0/45/90/45/0o (see also: U.S. Pats. 4,457,985; 4,748,064; 4,916,000; 4,403,012;

\section{$4,623,573$; and $4,737,402$ ).}

Each panel comprises a combination of fibers and a matrix. For sufficient ballistic resistance, the fiber content preferably ranges from about 65 to $85 \mathrm{wt} \%$ plus the optional polymeric matrix composition. The matrix may include additives such as fillers and reinforcements. The number of layers in a single panel depends on the ultimate use. For example, in armor vests with the areal density of $4.9 \mathrm{~kg} / \mathrm{m}^{2}$, a total of at 22 layers may be used.The preferred ballistic composite comprises: (a) a network of fibers having a tensile modulus of at least about $500 \mathrm{~g} /$ denier and an energy-to-break of at least about $22 \mathrm{~J} / \mathrm{g}$; and (b) a matrix consisting essentially of an elastomer, which substantially coats each of the individual fibers and has a tensile modulus (at 25oC) of $\leq 41 \mathrm{MPa}$. The high tensile modulus fibers include extended chain polyolefin fibers (UHMWPE, Spectra and Armor), and ultra-high molecular weight polypropylene fibers or types (UHMWPP), $p$ aramid fibers (Kevlar $\AA$, Twaron $\AA$, Heracron $\AA$, and Rusar), polyamide fibers, polyethylene terephthalate fibers, polyethylene naphthalate fibers, extended chain polyvinyl alcohol fibers, extended chain polyacrylonitrile fibers, polybenzazole fibers (PBO, Zylon) and polybenzothiazole fibers, and liquid crystal copolyester fibers.

Ballistic composite test packages were assembled from Spectra ${ }^{\circledR}$ Shield II SR 3124, where one layer includes four plies of non-woven consolidated fibers (adjacent 
plies cross-plied at 0 and 90o) and water-based Kraton ${ }^{\circledR}$ block copolymer latex, the resin comprising about $16 \%$ of the 4-ply layer. The assembled test packages were tested against 17 grain fragment simulating projectiles (FSP) to determine the $V_{50}$ of the molded panels. Excepting single example where plywood was used as a spacer, air or foam spacing did not enhance the performance. Better results were obtained for panels touching each other compared to a single molded panel of equivalent weight. The ballistic performance of two panels with 1/4" air gap was slightly better (the first panel deformed and destabilized the bullet), but four half as thick panels kept 1/4" apart did not deform the bullet and was less effective than even a monolithic panel. 


\section{Polymer Protective Nanocomposites Materials}

With the highly promising expectations of nanotechnology for new innovative products, materials and power sources it is evident that nanotechnology can bring many innovations into the world. The unique properties of nanotechnology originate from: a) small dimensions, enabling high speed and high functional density (nanoelectronics, lab-on-chip), small and lightweight devices and sensors (smart dust), high sensitivity (sensors, nanowires) and special surface effects (such as lotus effect); b) very large surface area, providing reinforcement and catalytic effects; c) quantum effects, such as highly efficient optical fluorescent quantum dots; d) new molecular structures, with new material properties: high strength nanotubes, nanofibers and nanocomposites.

The polymer nanocomposites (PNC) are 30 years old. ${ }^{76}$ The two principal components of PNC are the polymeric matrix and nano-sized particles. Virtually all polymers (thermoplastic, thermoset and elastomer) have been modified by addition of nano-particles. Of the latter the most frequently used are clays and more recently nanotubes. The key for the PNC performance is the random distribution of individual nano-particles throughout the matrix - possible ONLY at low concentration; for most commercial clays it ranges from 1.1 to $3.6 \mathrm{wt} \%$ inorganic content.

Ostermayer et al. tested PA-6 based PNC for the ballistic impact protection using commercially available materials, Ube 1015B (PA-6 matrix) and 1015C2 PA-6 with ca. $2 \mathrm{wt} \%$ MMT. The velocity at which $50 \%$ of $0.22 \sim$ cal. fragment simulator projectiles penetrated the unmodified PA- 6 and $0.5 \mathrm{~mm}$ aluminum witness plate was $\mathrm{V}_{50}=436$ while that of PNC was $338 \mathrm{ft} / \mathrm{s}$. Thus, incorporation of organoclay reduced the impact resistance of PA-6. ${ }^{77}$ Reports from different branches of science suggest that reduction of particle size leads to enhanced, not reduced STF. For example, the recent article reported that nano-crystalline metals show $>10$-fold increase of strain-rate sensitivity in comparison to the conventional coarse-grained counterparts. This unexpected effect (tensile modulus of $1015 \mathrm{C} 2 \mathrm{G}=4.1$ while that of $1015 \mathrm{~B} \mathrm{G}_{\mathrm{o}}=2.7$ $\mathrm{GPa}$ ) is most likely caused by $\mathrm{C} 12$ paraffinic chain attaching PA-6 macromolecules to MMT. On high velocity impact the paraffin may act as a lubricating plasticizer. 
Reports from different branches of science suggest that reduction of particle size leads to enhanced, not reduced STF. For example, the recent article reported that nanocrystalline metals show $>10$-fold increase of strain-rate sensitivity in comparison to the conventional coarse-grained counterparts. ${ }^{78}$ The effect may originate in the increased specific surface area, $A \mathrm{~s}$, thus stronger interactions between nano-particles (for MMT $A \mathrm{~s}$ $\left.=750-800 \mathrm{~m}^{2} / \mathrm{g}\right)$.

As in 2004 Savage wrote, there are few examples of PNC used in defense applications - these materials development rely on commercial forces with little support from the defense establishments. ${ }^{79}$. The author collected numerous examples of the possible applications of nanotechnology in defense, viz. carbon fibers and nanotubes in electrically conductive and energy storage applications, solid lubricants, chemical sensors, nano-foams in shock absorbers, microwave absorbers, UV resistant coatings, fire retardants, etc. The review compressed the use of nanoparticles for ballistic protection to $1 / 2$ of a page. An interesting suggestion was the use of electro-spun fibers as a replacement of the traditional high performance fibers/fabrics such as Kevlar ${ }^{\circledR}$. The only practical use of nano-particles (?) in ballistic protection mentioned in the report was the STF system developed in Wagner's laboratories.

Nanotechnology has a promising future in the area of protective clothing, due to their extraordinary physical, chemical, mechanical, and electrical properties. Thilagavathi et al.summarized the applications of nanotechnology in producing lightweight and comfortable protective clothing for the military personnel as well as in sensor, energy storage, conductivity, and decontaminant fabrics. ${ }^{80}$ The review focuses on fibers and fabrics with emphasis on micro- and nano-fibers. The protective clothing made up of these fibers and their composites give high performance, functionality, comfort, and larger life span with less weight, size, maintenance and cost. Nanostructures and nanocomposites are being developed for the following defense applications:

- Lightweight protective clothing with STF, as described by the Wagner group

- Flexible antiballistic textiles

- Chemical and biological warfare protection fabrics 
- Adaptive suits from switchable fabrics for improved thermal control and camouflage.

- Micro-sensors for body and brain sensing, environmental and situational awareness, integrated into a smart suit or a smart helmet

- Wearable and/or flexible displays for visual feedback auxiliary supports: flexible/rigid textiles for additional strength, exoskeletons, and robotics to assist the human tasks.

Recently, Gordeyev and Crawley summarized the EU situation as far as the Personal Protective Equipment (PPE) for first responders (military, police, firefighters, and bio-chem responders) are concerned. ${ }^{81}$ The estimated EU market is about €9.5-10 billions. Protective textiles have been identified as one of six lead markets for Europe with technological and market developments offering the opportunity to renew the traditional industry. The protective materials market is driven by developing standards to improve the effectiveness of PPE in response to emerging security threats and challenges.

The technological assessment of nano-enabled technologies in the PPE sector has been divided into four sub-sectors: (1) detoxification and decontamination; (2) protection from impact such as knives, ballistic projectiles, and firearms; (3) fire resistance/retardancy; and (4) integration of information and communication technologies (ICT) devices. In these materials the nano-enabled functionality may offer superior qualities over existing technologies. Examples include:

- Prototype protective vests made using carbon nanotube yarns and inorganic fullerenes with superior ballistic protection yet at a fraction of the thickness (and therefore weight) of current materials;

- Quantum Tunneling Composites offering "smart" functionalities such as a flexible control interface allowing the user to illuminate sections of clothing for high visibility purposes;

- Magnesium oxide nanoparticles loaded into nano-fibers providing effective detoxification and decontamination coupled with ability to be incorporated into cloths; 
- Use of nanoparticles in shear thickening and electro-rheological fluids providing advanced 'liquid' amours changing their rigidity when required.

Despite considerable progress in nanomaterials and nanotechnologies for security applications, the majority of experts involved in preparation of the report concurred that significant effort is still required for these results to become technically and commercially viable.

Protection from impact requires light weight gear allowing for extreme mobility, a high degree of protection, increased breathability and user comfort. Current technologies such as aramids (Kevlar $\left.{ }^{\circledR}\right)$, PBO $\left(\right.$ Zylon $\left.{ }^{\circledR}\right)$ and UHMWPE (Dyneema ${ }^{\circledR}$, Spectra $\left.{ }^{\circledR}\right)$ fibers and ceramics despite their high theoretical strength do not provide sufficient impact resistance, which depends mainly on distribution of defects in bulk materials. For example, Zylon ${ }^{\circledR}$ vests were used in the US in the late 1990's but experienced continued failures, ultimately resulting in the death of a police officer. At present UHMWPE seems to take over a major part of the market currently covered by the aramid fibers. The experimental M5 fiber seems promising as well. Nevertheless, there is a market opportunity for new technologies to enhance performance of the existing solutions.

Since 2004, the inorganic fullerenes, IF, (boron carbide and silicon carbide fullerenes are five times stronger than steel) became the promising shock absorbing materials. ApNano,

commercialized the inorganic fullerene material technology and supposedly they are developing body armor under the name 'NanoArmor'. ${ }^{82}$ Tungsten and molybdenum $d i$ sulfite, $\mathrm{WS}_{2}$ and $\mathrm{MoS}_{2}$ nanotubes are ultra-strong impact resistant materials for the production of bullet proof vests, helmets, car bumpers, high strength glues and binders. These unique nanotubes are up to 4-5 times stronger than steel and about 6 times stronger than $\operatorname{Kevlar} \AA$. The nanotubes have high aspect ratio (length $L \approx 150,000$ and diameter $D \approx 30-180 \mathrm{~nm}$ mean that $p \approx 833-5000$ ), which gives them their unique tensile strength $(21 \mathrm{GPa})$ and chemical properties. Zhu from the University of Nottingham subjected a sample of the ApNano material to shocks generated by a steel projectile traveling at velocities of up to $1.5 \mathrm{~km} / \mathrm{s}$. The material withstood the shock 
pressures generated by impacts of up to 250 tons $/ \mathrm{cm}^{2}$. The material proved to be so strong that after the impact the samples remained essentially identical compared to the original. A study by Martin from École Central de Lyon tested the new material under isostatic pressure and found it to be stable up to at least 350 tons $/ \mathrm{cm}^{2}{ }^{83}$

At an early stage of development, researchers in Australia examine the theoretical potential of carbon nanotubes $(\mathrm{CNT})$ in anti-ballistic applications. ${ }^{84}$ They concluded that ballistic resistance capacity is greater when a bullet hits the centre of a single nanotube and that those with a larger radius can withstand a higher bullet speed. They theorize that body armor made from six layers of $100 \mu \mathrm{m}$ carbon nanotube yarns (ca. $600 \mu \mathrm{m}$ thick), may bounce off a bullet with muzzle energy of $320 \mathrm{~J}$. Extending this theory they suggested that CNT body armor could have a constant ballistic resistance even when bullets strike at the same spot; the studied CNTs withstood a bullet at almost the same speed as the first impact after a short time interval.

Yarns of multi-walled carbon nanotubes (MWNT) with promising mechanical properties have been produced on an experimental scale for making bullet proof vests as strong as existing products, in addition offering 48\% reversible damping and much higher thermal, creep and chemical resistance. Despite considerable concerns regarding practical implementation of CNT and IF ballistic and dynamic properties they appear to be the most promising materials for the 10 years distant future. The introduction of improved conventional ballistic fibers and/or ceramic whiskers could lead to an important breakthrough in the field of ballistic protection on a shorter timescale. Socalled 'liquid' armor with STF may provide such functionality for low end of ballistic velocities required for applications such as protective helmets, boots/footwear, gloves and face protection (such as goggles, masks, and shields). ${ }^{85}$

The European review on the role of nanoparticles in protective equipment ends with the outlook for the near future. Electro-rheological fluids which change their rigidity in response to an electric charge have also been suggested for protection applications. ${ }^{86}$ Research needs for assessing the bullet impact on CNT under different loading conditions has been identified for applications such as bullet proof vests and explosion blankets. Research areas in protective clothing for impact protection should include: inorganic fullerenes, shear thickening fluids, electrorheological fluids, and carbon nanotubes for ballistics. 


\section{1 Interphase in Polymer Matrix Composites}

The goal of this review is for improved performance of armour materialsimprovement in the sense of better protection and durability at lowest weight and cost. One desires a tough construction that would not shatter on low speed impact, but under high velocity bullet or shrapnel become more rigid, more energy absorbent. Thus, the composite should have some rate sensitivity. After the brief review of the matrix and reinforcing materials, the next part will focus on the interphase between these two materials, including the methods that offer rate sensitive response.

In any bi-phase system there are three phases! For example, in immiscible polymer alloys and blends (PAB) the interphase thickness ranges from 2 (highly immiscible) to $60 \mathrm{~nm}$ (reactively compatibilized). Similarly in PNC's, the crystalline clay solidifies the first $6 \mathrm{~nm}$ of the matrix, and reduces segmental mobility for up to 120 nm. ${ }^{87}$

Thermodynamics requires that surface energy be minimized, thus the highly mobile, low molecular weight fractions and contaminants migrate to the interphase reducing its energy, which in turn reduces the interphasial adhesion and strength. To compensate for this effect, one must provide a mechanism strengthening the interphase - either by chemical or physical means.

The chemical method relies on the chemical reaction that create covalent, ionic or hydrogen bonding interphase between the two principal ones. Compatibilization of $\mathrm{PAB}$ or PNC is accomplished chemically either by addition of reactive compatibilizer or by adding low molecular weight reactive species that in-situ create compatibilizing macromolecules. Fiber "sizing" is also a form of compatibilization where specific fiber is chemically treated to make it more compatible with the matrix and more resistant to degradation during the lifetime of the composites (e.g., making glass fiber, GF, hydrophobic to prevent the degrading moisture attack).

The physical methods of compatibilization may involve roughening of fibers, adsorption and solidification of matrix segments on highly surface active crystalline solid, on epitaxial crystallization, on the use of strain-sensitive systems, etc.

The discussion on the interphase will be divided into four sections:

- Computational studies 
- Compatibilization

- Fiber sizing

- Shear sensitive coupling

\subsubsection{Computational Studies}

During the last two decades the understanding of the solid/polymer interactions expanded due to the advancement of the simulation techniques via the Monte Carlo (MC) or molecular dynamic (MD) methods, as well as the rapid progress of the nuclear magnetic resonance (NMR) techniques. ${ }^{88}$ Computations (and experiments) show that macromolecules are greatly affected by the solid surface energy-their molecular arrangements, conformations and dynamics are strongly perturbed with respect to the isotropic bulk. MC has also been used for simulation of tensile impact of unidirectional composites. ${ }^{89} \mathrm{MC}$ simulations have been carried out on or off the lattice. On-lattice computations, with polymeric chains represented as random, self-avoiding walks, are more economic, but not as realistic as the out-of-lattice methods. ${ }^{90} \mathrm{MC}$ and MD simulation have been used in studies of static and dynamic properties of composites. For example, mathematical modeling of organoclays and PNC has been used to describe structure and energetics of organic molecules in the vicinity of 1:2 layered silicates. ${ }^{91} 92$ Vacatello $^{93}$ carried out MC simulations for dense polymeric melt with solid, spherical nanoparticles. The model incorporated off-lattice approximation and conformational distribution of the simulated chains, similar to that of real polymer, with the LennardJones 6-12 potential. The results showed that at the interface the polymer segments are densely packed in form of ordered shells around the nanoparticles, analogous to the layer formation near planar solid surface. The thickness of the shells was approximately $1.35 \mathrm{~nm}$. According to a MD model, the mechanical reinforcement originated in the formation of long-lived transient polymer-particle networks composed of macromolecular loops and bridges. The interphase volume should be smaller than that of the bulk phase and that the reinforcement-polymer interactions must be strong. The reinforcement originates in the volume expansion of reinforcing phase caused by tension of the compatibilizing molecules. ${ }^{94}$ 
These calculations well simulate the structure and dynamics of the polymer/solid surface system. The results, determined by topology and entropy, are applicable to diverse situations. The presence of preferential interactions between polymer and a solid should not significantly change the computed structure, the order of interface shells, or the macromolecular conformation.

During the last few years the MC/MD computation was extended to simulation of the mechanical properties of composites. The multi-scale procedure starts with (1) atomic/molecular dynamics modeling of the particles and their interactions; (2) construction of a representative volume element (RVE); and (3) computation of macroscopic behavior of the composite from RVE, using either classical continuum expressions or a finite element method (FEM). Originally Odegard et al. applied this approach to systems containing carbon nanotubes. ${ }^{95}$ Later, the model was used for analyzing the mechanical properties of polyimide (PI) with dispersed silica particles, whose radius ranged from $r=1 \mathrm{~nm}$ to $1 \mu \mathrm{m} .{ }^{96}$ Sheng et al. ${ }^{97}$ applied the multi-scale modeling strategy to clay-containing polymeric nanocomposites (CPNC). (1) At nanoscale the interactions between matrix and nano-particles were computed; (2) At micronscale, the clay particles were considered either exfoliated or intercalated, forming stacks; (3) At a length scale of millimeters, the structure was assumed to be of a matrix with dispersed in it high aspect ratio particles. The new model correctly predicted the elastic moduli for CPNC with MXD6 or PA-6 matrix. More recently, 3D FEM was used to predict variation of the relative modulus with the orientation and volume fraction of clay platelets. ${ }^{98}$

Multi-scale modeling was also applied to damage in ceramic and polymeric composites. $^{99}$ The fracture behavior in fully exfoliated CPNC was recently modeled using MD. ${ }^{100}$ The MC/MD findings might be confirmed by the The system was subjected to tension in the z-direction. The simulation indicated that addition of clay platelets may improve the polymer fracture strength. The effect depends on the magnitude of polymer/clay interactions, the relaxation time of polymer chains, and the polymer glass transition temperature, $\mathrm{Tg}$. For CPNC with the matrix $\mathrm{Tg} \leq \mathrm{RT}$ (room temperature), addition of clay enhances the mechanical properties. However, when the matrix $\mathrm{Tg}$ is above RT (e.g., vitreous epoxy or polystyrene), clay addition does not 
toughen the polymers, thus creation of a stress relaxation mechanism might be necessary. For example, this might be accomplished by the use of elastomeric intercalant, or by addition of a compatibilizer/coupling agent.

There are several computational studies of the behavior of fiber-reinforced composites under load. One important aspect that emerges from the high velocity deformation studies is the coupling of the mechanical response with the temperature rise and resulting local changes in material properties. For example, under the ballistic velocity of $V=1.1 \mathrm{~km} / \mathrm{s}$ impact of a tungsten projectile onto an aluminum (Al) block the temperature reached $1800 \mathrm{~K}$ (confirmed experimentally). ${ }^{101}$

In a standard helmet tests the velocities are not as high, but at the same time the thermal conductivity of $\operatorname{Kevlar}{ }^{\circledR}$ composites is significantly lower than that of Al, viz., $2 \pm 1$ vs. $250 \mathrm{~W} / \mathrm{mK}$, respectively. Thus, this aspect may be important when selecting the material.

Recently, Phoenix et al. proposed a new interference model for the ballistic response of a hybrid, two-layered, flexible body armor. ${ }^{102}$

The new model predicts the ballistic response of a hybrid, two-layered, flexible body armor system, where the individual layers are not bonded together and differ considerably in their mechanical properties. Such systems are used in body armor for public safety officers and security personnel as well as in airline cockpit doors, helicopters, and the doors of automobiles and light trucks. It has been postulated that placing the stiffer and lighter fibrous polyethylene layer on the strike face led to an interference effect whereby the naturally occurring impact cone of the polyethylene layer clashed with that of the Kevlar® layer. This would result in impact cone interference and a shift in load from $\operatorname{Kevlar}{ }^{\circledR}$ to the top polyethylene. The paper introduces a new version of the single-layer model that responds instantaneously (in terms of material inflow velocity) to the changing tension around the projectile edge as it decelerates and it applies the new version to the two-layer, interfering system to study analytically the negative effects of such interference on $V_{50}$ performance and back-face deflection.

Since the stacking order of layers that has different mechanical properties affects the $V_{50}$ limit velocity for penetration, the authors applied the analysis to a two-layer system consisting of fabrics of Kevlar ${ }^{\circledR} 29$ and Dyneema ${ }^{\circledR}$. Early experimental results 
of 1992 showed the difference in the $\mathrm{V}_{50}$ by about factor of two for the two possible stacking orders. The new model extends previous work by addressing interference factors in terms of instantaneous material inflow to the impact cone using a convolution over current local strain around the projectile edge during its deceleration. The current model is more complete and produces velocity, strain, and deformation histories either to perforation or to halting the projectile. In the new model, $V_{50}$ differences with stacking order and with layer bonding versus no bonding are even larger. However, back-face deflections turn out to be minimally affected. Calculations are fast and postprocessing figures may be obtained in less than a minute using MATLAB on a laptop.

The most important result is that the model predicts properties for a hybrid system, allowing it to be largely expressed in terms of a single-layer problem and thus greatly reducing the number of needed independent parameters, but allowing for detailed calculation of ply strains from the effective property solution depending on true material wave-speed ratios. Note that effective parameters are considerably different among cases of layers strongly bonded together versus interfering layers, noninterfering layers, and systems based on just one of the materials at the same overall fabric areal density. Future work will extend the model to stacked biaxial fabrics and to the systems with small air gaps between layers which reduce $V_{50}$ as the spacing increases.

The Jones review of the interphase design and formation in fiber-reinforced composites provides a suitable closure to this section. ${ }^{103}$ Time-of-flight secondary ion mass spectrometry The author discusses carbon and to a lesser extent the glass fiber surface treatment and coating as the mechanism of interphase formation. dsorption of sizing polymers is a key part for securing good interaction between reinforcing fiber and polymeric matrix. (ToF-SIMS) imaging was used to analyze solid surfaces and to identify the locus of failure and confirm the nature of the interphase. In the case of glass fibers the hydrolysis of the silane coupling agent is critical.

The surface chemistry of the glass controls the degree of polymerization of the polysiloxane and hence the interaction with the matrix polymer whether it be thermoplastic or thermoset. For completeness a brief review of the surface treatments of advanced polymer fibers was included. 
The role of the interphase in the micromechanics of the failure of composites is also modeled and discussed in an attempt to provide design guidelines for the composite manufacture. The micromechanical modeling showed that the thermomechanical properties and thickness of the interphase have a major impact on the stress transfer between fiber and resin, even when the thickness of an interphase is only $5 \mathrm{~nm}$. The well-designed interphase should match the matrix mechanical properties, but have a slightly lower yield stress so that energy is absorbed by elastic-plastic deformation, not debonding.

\subsubsection{Compatibilization}

The strongest bond is that between carbon-carbon atoms, thus the crystalline form of $\mathrm{C}$ has the highest modulus. Accordingly, providing a direct covalent bond across the interphase may lead to the strongest, most rigid, but brittle composite. Macromolecules in the melt are entangled and may crystallize on solidification, thus analysis of their tensile behavior at the atomic level is difficult. However, the stressstrain of a single polystyrene (PS) chain in a solvent has been measured. ${ }^{71}$ The macromolecule $\left(M_{\mathrm{w}}=100 \mathrm{kD}\right.$, degree of polymerization DP $\left.=918\right)$ had a contour length of $284 \mathrm{~nm}$. While stretched by the ends, it first uncoiled with little resistance than upon stretching it deformed elastically by about $21 \%$ before breaking. The elastic deformation originated mainly from changes of the internal $\mathrm{C}-\mathrm{C}$ bond angles, not from their elongation. The bonds, each about $0.14 \mathrm{~nm}$ long, break when stress exceeds a critical value with little (is any) effect of the deformation rate. Thus, if the stress hardening of a system is desirable, uniformly strong covalent bonding across the interphase is not.

Evidently, for covalent bonding both the matrix and the reinforcement must be reactive. Kalantar and Drzal offer an early review of Kevlar-epoxy matrix bonding. ${ }^{104}$ The authors concluded that in spite of a considerable number of publications on aramid fiber composites and extensive efforts for improving aramid-epoxy adhesion, up to date, the efforts grossly failed. One reason for it is the highly conjugated nature of the PPTA molecules, the others: presence contaminating salts and the skin-core fiber morphology, Figure 4-1, created during filament spinning from $20 \mathrm{wt} \%$ PPTA solutions in a 
concentrated $\mathrm{H}_{2} \mathrm{SO}_{4}$. Lack of sulfonation during the process by itself indicates chemical inertness of PPTA. Thus, promising coupling agents for PPTA are not easily found.

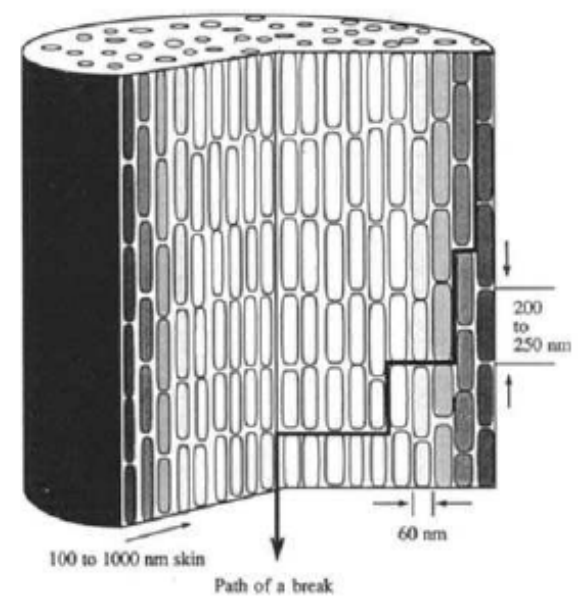

Figure 4-1 Skin-core aramid fiber morphology ${ }^{11}$

Three methods of PPTA surface treatment are possible: (1) radio frequency plasma treatment, (2) bromination, and (3) phosphoric acid treatment.

Allred et al. reported that $\operatorname{Kevlar}{ }^{\circledR}$ fibers treated with radio frequency (r.f.) plasma in the presence of $\mathrm{NH}_{3}$, resulted in a two-fold increase in the interlaminar peel strength of treated Kevlar® 49-epoxy composites with failure mode changing from interface failure to mixtures of fiber and matrix failure. ${ }^{105}$

$\mathrm{Wu}$ and Tesoro investigated selected reagents and conditions for surface-control led heterogeneous reactions on Kevlar ${ }^{\circledR}$ filaments and fabrics. They used a wet chemistry approach, brominating $\operatorname{Kevlar}{ }^{\circledR}$ fibers, subjecting them to ammonolysis, nitration, and then reduction to amine functional groups on the fiber surface. Modification of filaments has been attained without impairment to fiber properties. The presence of amino groups improved peel strength and apparent interlaminar shear strength in epoxy laminates, suggesting a significant role of covalent bonding in improving adhesion between PPTA and the matrix. Chemical treatment of aramid surface was also carried out by chloro-sulfonation. ${ }^{106}$

Li et al. functionalized Kevlar ${ }^{\circledR} 1680$ fibers (diameter, $12 \mu \mathrm{m}$, monofilament strength, $2.0 \mathrm{GPa})$ with phosphoric acid $\left(\mathrm{H}_{3} \mathrm{PO}_{4}\right)$ at different concentration. The monofilament tensile strength was constant up to $40 \mathrm{wt} \% \mathrm{H}_{3} \mathrm{PO}_{4}$, but the maximum of 
oxygen functional groups was obtained using $20 \mathrm{wt} \% \mathrm{H}_{3} \mathrm{PO}_{4}$. Composites prepared from optimally functionalized fibers, and various combinations of epoxy/hardener were studied. ${ }^{107}$ The mechanical properties were further enhanced when $40 \mathrm{wt} \%$ DGEBF (diglycidyl ether of bisphenol F, epoxy value 0.54) was added to DGEAC (diglycidyl ester of aliphatic cyclo, epoxy value 0.85) and reacted with 4,4'diaminodiphenylmethane (DDM) hardener and DETDA (a mixture hardener of two diethyl toluene di-amines). The improvement was attributed to the interfacial adhesion between functional groups of the matrix polyamide and those of the functionalized PPTA fibers, as well as to a good match of toughness of fiber and matrix. The interfacial shear strength (IFSS) and interlaminar shear strength (ILSS) were 76 and 79 $\mathrm{MPa}$, respectively, and the fiber strength conversion ratio of Naval Ordnance Laboratory (NOL) Rings reached 95\%. The microstructure analysis revealed that the increased concentration of polar functional groups on the fiber surface, enhanced interaction between resin matrix and $\mathrm{H}_{3} \mathrm{PO}_{4}$-functionalized fibers, what in turn resulted in greatly improved mechanical properties. Compared to various combinations of epoxy and hardener, Kevlar ${ }^{\circledR}$ fiber composite of DGEAC/DGEBF/DDM/DETDA system exhibited excellent mechanical properties.

\subsubsection{Fiber sizing}

Sizing refers to deposition of a specific substance on a fiber to modify its surface properties and protect it during processing. Sizing is used in papermaking, textile manufacturing, composite production and other domains. For example, yarn sizing reduces its breakage, thus assures production without stops of the weaving machine. Sizing improves the strength, abrasion resistance and the hairiness. Several types of water soluble polymers are used for textile sizing, viz. modified starch, polyvinyl alcohol (PVA), carboxy-methyl cellulose (CMC), acrylates, etc. Usually, in addition wax is added for reduction of the abrasiveness of the warp yarns.

It is noteworthy that frequently sizing agent is extracted before product goes to market or before it enters the production line, thus it does not bond covalently to the fiber. Even in cases when is not to be removed (see below) it forms a protective layer 
that offers additional resistance in standard pull-out tests, but does not exceeds the tensile strength of the fiber.

Sizing is essential for the manufacture of glass fibers (GF) as well as for improved performance of their composites. GF are abrasive and without sizing would turn each other to dust. Furthermore, without sizing it would be difficult to make glass rovings and virtually impossible for anyone to use it. GF sizing agents are mixtures of several chemicals comprising: (1) film-formers, (2) coupling agents and (3) other functional chemicals. Often the film-former is chemically similar to the matrix polymer. It is designed to protect and lubricate fibers and hold them together before processing, and then facilitate their separation when contacted by resin, thus ensuring good filament wetting. The GF coupling agent (usually an alkoxy silane) bonds the fiber to the matrix. In addition, sizing may include lubricating and antistatic agents as well as other additives. Optimized sizing works well with a specific resin, e.g., the one designed for polypropylene (PP) will not work for PA. Similarly, the one for anhydride-cured epoxy should not be used for amine-cured epoxy composites. Frequently glass manufacturers offer "tri-compatible" products (e.g., polyester, vinyl ester and epoxy), or even "multicompatible" sizing agents. Optimized sizing is essential for the recently developed long fiber-reinforced thermoplastic (LFRT) composites with PP matrix, to be used for automotive applications. ${ }^{108}$

Early studies on the interphases properties of composites discuss E-glassfiber/epoxy-amine systems. For example, Tanoglu et al. used a new dynamic microdebonding method at displacement rates in the range of 230 to $2450 \mu \mathrm{m} / \mathrm{sec}$. ${ }^{109}$ The data reduction related the force vs. displacement response to interphase shear stress/strain response. The obtained curves and interphase shear moduli were determined for the average shear rates of 215-3278 (1/s). The results showed that the interphase shear modulus depend on the sizing agent and strain rate, but it always was lower than the matrix modulus. The two sized fiber systems exhibited the highest strain rate sensitivity, with modulus increasing about threefold over the range studied. Using the dynamic mechanical analysis and the time-temperature superposition principle, the master curves of flexural storage modulus vs. strain rate were constructed.

From the cumulative damage principle, Tang et al. derived a fatigue model for predicting the lifetime of fiber reinforced polymeric composites. ${ }^{110}$ The model 
parameters are: applied maximum stress, stress amplitude, loading frequency, residual tensile modulus, and material constants. The residual modulus for a given maximum applied load after $N$ loading cycles may be predicted for the three environments combined. Fatigue data for glass fiber/vinyl ester composites were used for verification of the model. The specimens at $30^{\circ} \mathrm{C}$ were subjected to tension-tension stress at four levels and two frequencies. In freshwater and saltwater the vinyl ester/E-glass fiber composite lost 25 and $30 \%$ of tensile strength, and $15 \%$ and $11 \%$ of tensile modulus, respectively. Thus, the loss in residual tensile strength and modulus in freshwater and saltwater was similar, but larger than that in air. Numerical analysis was applied for determining the material constants. The fatigue model agrees well with the experimental data and it may be used to predict the fatigue life-time and the residual tensile modulus of the polymeric composites subjected to an applied load in different environments.

The cyclic fatigue resistance of a silane-bonded epoxy/glass interface in moist air was studied using the double cleavage drilled compression test (see the reference for the method details). ${ }^{111}$ The properties of two epoxies with similar chemical structures were controlled by varying the molecular weight between cross-links, $M_{c}$. Two rubbertoughened epoxies with different nominal rubber particle sizes (10-40 and 1-2 $\mu \mathrm{m})$ were used. The changes of $M_{c}$ had little effect on the cyclic fatigue resistance of the epoxy/glass interface, but incorporation of rubber particles significantly improved the resistance. Incorporation of rubber particles smaller than the plastic zone size found ahead of the propagating crack gives a significant improvement in the cyclic fatigue resistance of the interfaces through the additional energy absorbing mechanisms of cavitation and shear yielding. Smaller particles gave the greatest improvement of fatigue resistance ( $75 \%$ improvement) compared to non-modified epoxy. Adjustment of the number of silane bonds between the neat epoxies and the glass had little effect, suggesting that the energy dissipated through the breaking of the interface bonds accounts for only about $10-15 \%$ of the total energy necessary to drive the crack. Therefore, this term is negligible compared to the energy dissipated though plastic deformation and other inelastic mechanisms.

Jensen et al. developed a multicomponent GF sizing formulations for pultruded vinyl ester/E-glass composites. The composites were designed for Composite Integral Armour (CIA) in the Future Combat Systems (FCS). The authors stressed that 
the interphase may control CIA performance, viz. strength, durability, fatigue life, as well as the micromechanical energy absorbing capability during a ballistic event. Immediately after drawing the E-glass fibers (16.9 $\mu \mathrm{m}$ diameter) the sizing was deposited from aqueous emulsion comprising $4.4 \mathrm{wt} \%$ film former and $0.6 \mathrm{wt} \%$ propyl-tri-methoxy-silane coupling agents (methacryl-, amino-, and gycidox- or MPS, APS and GPS). The film formers were thermoset systems: $d i$-glycidyl ester of bis-phenol-A (DGEBA) epoxies, unsaturated bis-phenol-A vinyl ester and polyesters. The emulsion was stabilized by Pluronic surfactant. The sized fibers were formed into tows each having 2052 filaments, dried and spun into bundles of 38 tows. Next, the cylindrical pultruded rods were formed with $50 \mathrm{vol} \%$ of GF in vinyl ester/styrene thermoset matrix.

For determining the void content the specimen density was measured by immersion method, the interlaminar shear strength (ILSS) was calculated from the ASTM short beam shear test, the dynamic-mechanical temperature scans were conducted on dry and wet samples for determining "durability" (i.e., the ratio of wet-todry ILSS). The conclusion was based on the ILSS and durability data as the moisture resistance was judged to be of crucial importance. From the many combinations of silane and the film-former the most important conclusion was that both of them must have chemical reactivity with the vinyl ester matrix.

During GF manufacture a multicomponent sizing is applied to the fibers for protection against damage during processing. Conventional sizing incorporates silane coupling agents, which enhance adhesion between GF and the matrix and durability of the composite. The silane forms a nanometer sized interphase that surrounds GF. This structure is essential to composite performance, but poorly understood and not optimized for static and dynamic responses. Yet, there is new information that sizing may be tailored for high-energy absorption by designing weak fiber-matrix interfacial interactions and for structural performance by strong fiber-matrix interactions.

The_Army Research Laboratory (ARL) searched for the fundamental understanding of GF sizing that could suggest a new class of sizing agents with ratesensitive bonding. The resulting strategy comprises two elements:

1. Mixed organo-functional silane coupling agents are employed to vary the chemical reactivity toward the polymeric matrix and produce bond strengths dependent 
on the viscoelastic properties of the interphase. This "viscoelastic switch" yields strong fiber-matrix interactions at low strain rates (structural) and weak fiber-matrix interactions (ballistic) at high strain rates.

2. The GF surface was modified using an inorganic-organic sol-gel compound that not only acts as a silane-based, glass-fiber sizing, but also increases GF surface roughness.

The result is an increased friction coefficient between fiber and matrix during the fiber pullout stages of composite failure, further resulting in enhanced energy absorption in the composite during ballistic events. These results were first documented mechanically on micro-scale model composite specimens. Subsequently, the experimental inorganic-organic hybrid fiber sizing were scaled-up and applied using commercial manufacturing equipment to demonstrate their behavior in composites, Figure 4-2.

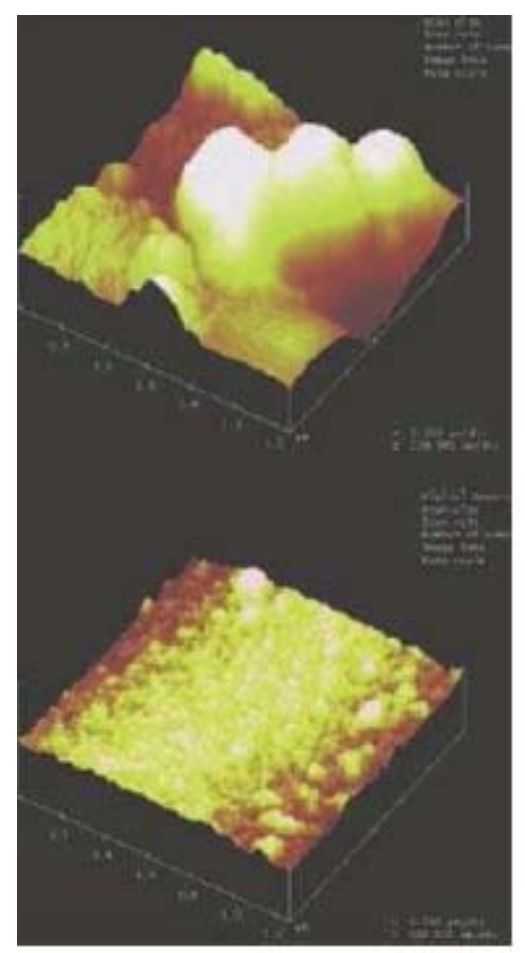

Figure 4-2 Atomic force microscopy (AFM) micrographs - top: the nanotextured GF surfaces produced on a commercial scale; bottom: a "standard" fiber. ${ }^{11}$

The fabrics made from these textured fibers were used in manufacturing reinforced composites. A $40 \%$ increase in the energy absorption of composites 
fabricated with no loss in structural properties enables the use of PMCs at reduced cost in ballistic applications where they have not been used previously.

Also carbon fibers (CF) are sized for better processability and composite performance. CF sizing is applied to the fiber tow (ca. 12,000 filaments) to prevent abrasive contact damage. In a recent patent from Mitsubishi Rayon, CF sizing agent comprised of water-soluble thermoplastic resin (e.g., PVA, PA, PU, polyacrylamide, acrylamide-vinyl acetate copolymer, polyacrylic ester or methyl cellulose) and alkylimidazoline-based betaine-type_amphoteric surfactant in a weight ratio ranging from 6/1 to $1 / 3$. Both sizing components should be water-soluble in a wide $\mathrm{pH}$ range, and impart adequate coverage to $\mathrm{CF}$, forming stable chopped carbon fibers, superior workability and satisfactory uniform tow dispersibility in water over a wide $\mathrm{pH}$ range. ${ }^{112}$

Recently Gan reviewed the interface of advanced composites. ${ }^{113}$ Nanostructuring the composite interface by introduction of nanopores and nanofibers has the key role in determining the behavior. A nonlinear damage model for characterizing deformation of the polymeric nanocomposites (PNC) was developed and its application to carbon nanotubes (CNT)-reinforced and reactive graphite nanotubereinforced epoxy composites was presented. Formation of nanopores on metal surface may increase bonding strength of the metal/polymer interface. Surface treated CNT are used in preparing nanoreinforced matrices. The nanofiber reinforced epoxies containing reactive graphitized $\mathrm{CNT}$ as new adhesives can help to alleviate the residual stress problem because they are more ductile than the conventionally used epoxy adhesives. The progressive damage of interfaces in composites may also be evaluated by nonlinear models.

For at least 20 years aramid fibers have been commercially sized. The composition of the coating is considered confidential, but some information might be found in the literature. For example, de Lange et al. analyzed Twaron ${ }^{\circledR} 2200$ (1680 dtex, f1000) fibers. Three forms were studied: without any finish (HM), with a standard finish (HMF) and with an adhesion activation treatment (HMA). The standard finish consists of deposition of a non-ionic ethylene oxide and propylene oxide that facilitates fiber processability and can easily be removed with alcohol. The adhesion-active finish is based on an epoxy-amine system, e.g., glycerol diglycidyl ether as epoxy and piperazine as amine, in the mass ratio of 9:1. This finish (which also contains some oil) 
is to improve processability and performance of epoxy composites. After application $\left(0.3 \mathrm{wt} \%\right.$ epoxy-amine, based on yarn weight) and drying $\left(2 \mathrm{~s}, 70^{\circ} \mathrm{C}\right)$, the adhesion active finish was cured on the yarn by drawing it over a hot metal plate $\left(240^{\circ} \mathrm{C}\right)$ for $5 \mathrm{~s}$. Since Soxhlet extraction with ethanol easily removed the standard finish, ethylene and propylene oxides did not chemically bonded to PPTA. Indeed, the bundle pull-out adhesion test from an epoxy matrix indicated that HM and HMF fibers had similarly low adhesion to matrix. However, in such test HMA performed better by ca. $40 \%{ }^{114}$

More recently, Twaron ${ }^{\circledR} 2200$ adhesion to epoxidized natural rubber (ENR) was enhanced by dipping the activated HMA fiber in resorcinol-formaldehyde latex (RFL). ${ }^{115}$ The authors used the micro-bond pull-out test, mechanical characterization and scanning electron microscope (SEM) in studies of the interphase properties. It was found that surface treatment is important for the adhesion of aramid fibers to ENR. The interfacial shear strength between fiber and the matrix was improved by morphological modification of its surface. By contrast with the de Lange et al. findings ${ }^{116}$ the tensile and impact strength of the Twaron/ENR composite showed that without RFL treatment the HM and HMA fibers show a similar, poor adhesion to matrix, i.e., the standard modification of the fiber surface and epoxy activation did not improved the composite performance. However, HM or HMA treatment with RFL resulted in higher tensile and impact strength, caused by improved dispersion and interactions between Twaron ${ }^{\circledR}$ and ENR. The authors suggested that both, the epoxy-based standard adhesion activation and RFL coating should be used in the PPTA/ENR composites.

A closing note on sizing should include at least a mention of the emerging nanotechnology application for the enhancement of ballistic performance of composites.

Siddiqui et al. studied the tensile strength of glass fibers sized with CNT-epoxy nanocomposite coating. ${ }^{117}$ The main idea was to create a self-healing interphase that would reduce the stress concentrations and to improve reinforcing efficiency. Coatings made from neat epoxy and CNT were deposited onto the individual GF or their rovings. Already at the level of $0.3 \mathrm{wt} \%$ CNT in epoxy there was a significant increase in tensile strength of the single fiber for all gauge lengths over the standard epoxy coating. The results on rovings also evidenced beneficial effects of nanocomposite impregnation in tensile tests, viz. higher and more uniform strength. The authors concluded: (i) The single fibers coated with the $0.3 \mathrm{wt} \%$ CNT-epoxy exhibit strength improvement over 
fibers with a neat epoxy coating, suggesting that incorporation of CNT to epoxy sizing enhances the crack healing. (ii) The effective crack length coefficient (obtained from the crack length vs. gauge length) is inversely proportional to the fiber critical strength, thus incorporation of CNT reduced the crack length indicating larger healing effect. (iii) The degree of nanoparticles dispersion in the polymer coating strongly affects the healing effect. (iv) The glass fiber bundles impregnated with CNT-epoxy nanocomposite led to much higher tensile strength than those with neat epoxy coating, with accompanied change in the failure mode. The enhancement of interfacial adhesion arising from the amino-functionalized CNT's was partly responsible for the beneficial effect of the nanocomposite on tensile strength of bundle fibers

Modern techniques are required for creating interphase regions, with which the performance of unidirectional fiber composites can be improved. Gas phase plasma polymerization is a potential new sizing approach, since the interlaminar shear strength properties can be adjusted by careful control of interphase thickness and properties. The method may cause less damage to fibers than the laser ablation assisted interphase formation. $^{118}$

\subsubsection{Shear Sensitive Coupling}

Rheology recognizes that all materials are time and rate of deformation sensitive, each within a specific range of temperature $(T)$ and pressure $(P)$, determined by their chemical nature. Thus, material sheared at constant speed may become less (thixotropy) or more (rheopexy) viscous. Similarly, when sheared at increasing rate of deformation the material may became less (pseudoplastic) or more (dilatant) viscous. This rheological terminology applies to liquid systems, single or multiphase ones. In the literature there are two other nomenclatures. The first evolved from the measurements of elongational viscosity, where entangled molecules dramatically stiffen at high strains - the effect is known as strain hardening (SH). Its opposite, the strain softening (SS), has only been recorded for filled polymers. The onset of SH or SS limits the linear viscoelastic behavior. In another nomenclature the pseudoplastic and dilatant terms are replaced by "shear softening fluid (SSF)" and "shear thickening fluid (STF)", respectively. The three terminologies are only approximately equivalent as the rheology 
speaks in terms of rate of deformation in shear or elongation, the SH/SS system in terms of strain, whereas the last one is concerned with "shear", what may mean shear stress or the total shear strain.

Deformation of a solid material may also show diverse behavior. For example, the stress-strain curves may show only elastic behavior and brittle fracture, or elastic and plastic with ductile or strain hardening performance. For given external conditions of $T$ and $P$, one is able to identify a polymer showing any of these three characteristics, e.g., at ambient conditions PS would be brittle, PA-6 ductile and PEEK strain hardening (SH). ${ }^{119}$

Biermann et al. patented an impact resistant flexible body vest, comprising a flexible support matrix and energy absorbing elements connected to the matrix. ${ }^{120}$ The elements were made off at least one ceramic material and at least one strain rate sensitive polymer. The impact resistant device was to be worn as a body armor protecting the wearer from high velocity projectiles. Each impact resistant element comprised ceramic layers alternated with $\mathrm{Fe}_{3} \mathrm{Al}$ alloy. The ceramic layers were made off yttrium stabilized zirconium oxide whose crystal structure is stable at toom temperature by addition of yttrium oxide, $\mathrm{Y}_{2} \mathrm{O}_{3}$. In addition to ceramic and metal layers, the impact resistant element comprised a strain rate sensitive polymer with modulus $\geq 3$ $\mathrm{GPa}$ at a strain rate of $1000(1 / \mathrm{s})$. PEEK was the preferred polymer not only as an internal part of the multilayer elements, but also covering and protecting their surface. The vest was made of two overlapping layers of interconnected energy absorbing elements, affixed to ballistic aramid or polyethylene fabrics.

The present day technology rarely relays on a single-component or single-phase materials. Thus, the rheological behavior, which reflects the material structure, in practice shows a more complex behavior, where for example, a suspension at increasing deformation rate may be Newtonian, then pseudoplastic, dilatant, pseudoplastic, finally reaching the lower Newtonian plateau. The multi-phase systems are also know for their yield behavior, which make the material double-sensitive to strain and to stress. 


\subsection{Anti-ballistic materials for suit}

Thanks to the technological advances in high-strength polymer fibers such as carbon, aramide and Dyneema, the performance of anti-ballistic suits has been improved considerably over the last 20 years, with subsequent reduction in weight $(30 \%)$. These suits with integrated or inserted composite fiber structures are quite effective and are being successfully applied for ballistic protection of the body. The composite structures, however, are not sufficiently flexible to be used for protection of the body extremities such as arms, legs and neck. At present, injuries of these extremities have become the dominant factor in casualties, especially from bombings and subsequent shatter, resulting in loss of military power and high costs of medical treatment. In view of this, several concepts for flexible armour have been proposed and are now in development such as:

- magneto-restrictive fluid: a nanoparticle filled flexible medium that can be electrically activated to become rigid (active system, MITISN)

- shear-thickening fluid: a nanoparticle-filled binder for highstrength textile that is flexible under low shear rate and that becomes rigid under high shear rate impact (passive system, ARL). This nanoparticle-filled system inhibits deformation and sliding of the high-strength fibers in the fabric at high shear rate.

- silliputty-type of elastomers in combination with ceramic armour: elastomer system which is deformable and elastic at low shear rate and stiff at high shear rate. Similar to shear thickening fluids, but up until now less effective in anti-ballistics (passive system, e.g. D3O material).

The shear-thickening fluid system seems quite promising: it is passive, there's no need for electrical powering and it has already a reasonable performance. It needs, however, further development and optimization.

To develop this concept further, a technology development program has been defined aiming at flexible lightweight armour for ballistic protection of body extremities. 
The program will cover development and optimization of a nanocomposite binder in combination with a high-strength fiber fabric and will demonstrate this technology in prototyped armour suits. Ideally the future combat suit gives a basic protection against debris, shatter and smaller caliber bullets and gives the combat soldier a high degree of freedom.

This can be realized by using present fiber systems such as the Dyneema fiber and combining this with a filler, or impregnating with filled liquid or another binder consisting of a polymer material filled with nanoparticles (platelets, cubicles, zeolytes, carbon nanotubes, nanofibers etc.). Key function of the nanopolymer material in, around or in between the microfibers is to keep the fibers together at bullet hits and to limit tissue damaging. The aim is to create a flexible body armour system which is basically a lightweight augmented Kevlar system and comes closer in performance to ceramic plating. 


\section{Failure Mechanisms of Ballistic Fabrics and Concepts for Improvement}

\subsection{Mechanisms of Penetration in Protective Materials}

In designing armor, materials high in hardness, strength, and toughness have traditionally been sought, since common sense would dictate that such materials should be most resistant to attack by a projectile. However, according to Shockey et al. ${ }^{121}$, ballistic tests often show that the best-performing armor material is not necessarily the strongest, the toughest, or the hardest. Are there other properties that reliably offer guidance in choosing and developing armor materials, if such conventional bulk properties do not? Does ballistic behavior depend on some vague or unknown property or combination of properties, and, if so, how can they be identified, measured, and even enhanced? Can the chemistry and processing

of materials be manipulated to achieve microstructures that exhibit nonconventional mechanical properties once they have been identified? Can such manipulation improve penetration resistance?

To answer these questions, armor development should be looked at not from the perspective of conventional bulk material properties but from that of micromechanical mechanisms. An understanding of the mechanisms operating in a target during a penetration event can suggest microstructures-including those that characterize the chemical and phase composition of the building blocks-that are more resistant to penetration and that will lead to protective materials with better performance. Moreover, by identifying penetration-induced failure mechanisms and quantifying their activity, mathematical damage models can be developed that may allow what is termed computational armor design.

The nucleation, growth, and coalescence of cracks and shear instabilities in metals and ceramics could be suppressed by manipulating the grain structure or by adding second phase particles. The size, shape, and orientation of the grains could be configured to disrupt failure mechanisms. The mechanical properties of the grain boundaries can, moreover, dictate a transgranular or intergranular failure mode. And the 
chemical and phase composition of the grains themselves and their crystalline structure can be specified to affect deformability, mode of deformation (dislocation activity, twinning, phase changes), and propensity to rupture. Likewise, the size, shape, orientation, crystal structure, spatial distribution, and mechanical properties of secondphase particles as well as the strength of particle and matrix interfaces can be manipulated to deter failure mechanisms. Second-phase particles such as coherent nanocrystallites have been shown to improve the ballistic performance of glasses, although there is not yet a detailed understanding of their effect on failure mechanisms. Pores can also inhibit cracks, and judicious open-architecture geometries may provide a lightweight solution to a penetration or blast problem.

Microstructural variables in polymers include chemical makeup, length and degree of branching of molecular chains, degree of alignment and entanglement, and extent of cross-linking. The types and strengths of bonds in the chains and between chains affect polymer strength and deformability (for instance, in thermosets versus thermoplastics) and can be expected to affect failure mechanisms.

Penetration mechanisms are perhaps best revealed by post-test examination of penetrated targets. Ejected or otherwise separated target material contains telltale signs of the failure modes that operated during penetration, as does the material in the vicinity of the penetration cavity. The collection of loose material and the sectioning of penetrated material, followed by unaided visual inspection and inspection under a microscope, show the damage features, helping to uncover the mechanisms of material failure. In situ, real-time, high-speed dynamic observations can in principle provide even better indications of failure modes. However, it is difficult to simultaneously achieve both high spatial and high temporal resolution. Future advances in instrumentation will bring new insights to the complex interplay of deformation and failure mechanisms during penetration. Partially penetrated targets are particularly useful for determining failure mechanisms. A close examination of areas where the damaged material remains in place and of polished cross sections taken on a plane containing the shot line demonstrates how damage varies with distance from the side and distance ahead of the penetrating object. Such observations also suggest how damage evolves, thereby providing notions for equations describing damage development. The next section illustrates the failure mechanisms invoked by a 
penetrator by presenting damage observations in penetrated and partially penetrated targets of metals and alloys, ceramics and glasses, and polymeric materials. This is followed by a short discussion on the damage mechanisms in cellular materials invoked by blast loads.

\subsubsection{Penetration Mechanisms In Polymeric Materials}

Polymers such as polycarbonate are often used in armor systems as backing plates (spall shields), as intermediate layers in a laminated glass or ceramic system, as a scratchtolerant front plate, or as a matrix to embed strong fibers.

Because the material failure mechanisms are sensitive to boundary conditions, they are somewhat determined by the application. Real-time observation with highspeed cameras shows that the penetration of polycarbonate plates by cylindrical projectiles occurs by elastic dishing, petalling, cone cracking, and plugging. ${ }^{122}$

The fragmentation and cracking patterns suggest that material ahead of the projectile is loaded, damaged, and displaced in three successive steps under consecutive tensile-, shear-, and compression-dominated stress states (Figure 5-1). A material element in the path of an advancing penetrator initially experiences tension and develops closely spaced cone cracks running at acute angles to the penetration direction. Subsequent lateral cracks break up the material between adjacent cone cracks. As the projectile moves closer, a local volume (about the size of the projectile nose) of the cracked material is overrun by a low-confinement field of high shear and is comminuted into fine fragments. Third, the projectile imposes high pressure and extrudes the comminuted material into the cracked and coarsely fragmented tunnel and to the sides of the projectile nose. 


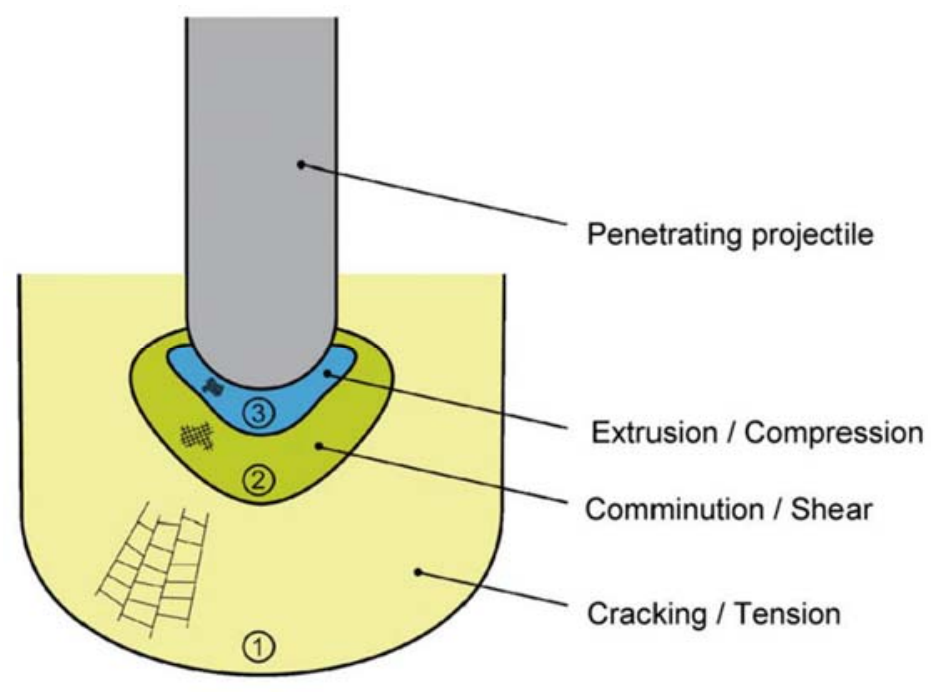

Figure 5-1 Three material processing zones and three stress states experienced by a material element in the path of an advancing penetrator. ${ }^{123}$

The projectile initially indents the surface of the plate, causing the distal plate surface to bulge and shear yielding around the impact site. As the penetrator advances, cracks form ahead of it. Depending on the projectile nose shape, plate perforation occurs by petalling or by plugging-that is, by pushing a cylinder of material ahead of the projectile through the distal plate surface. Evidence of melting has been observed. Material failure mechanisms may include tensile failure by nucleation, growth, and coalescence of planar cracks, spherelike voids, and shear instabilities. In glassy polymers, crazing, or the formation of oriented fibrils and intervening voids, is a common precursor to crack formation and tensile failure.

Polymer fibers are used in ballistic materials and as reinforcing elements in composite materials. A careful and detailed study of nanoscale failure phenomenology would be most useful in developing fibers with better ballistic performance. Figure 5-2 shows a fabric after it has been impacted by a platelike projectile. ${ }^{124}$ 

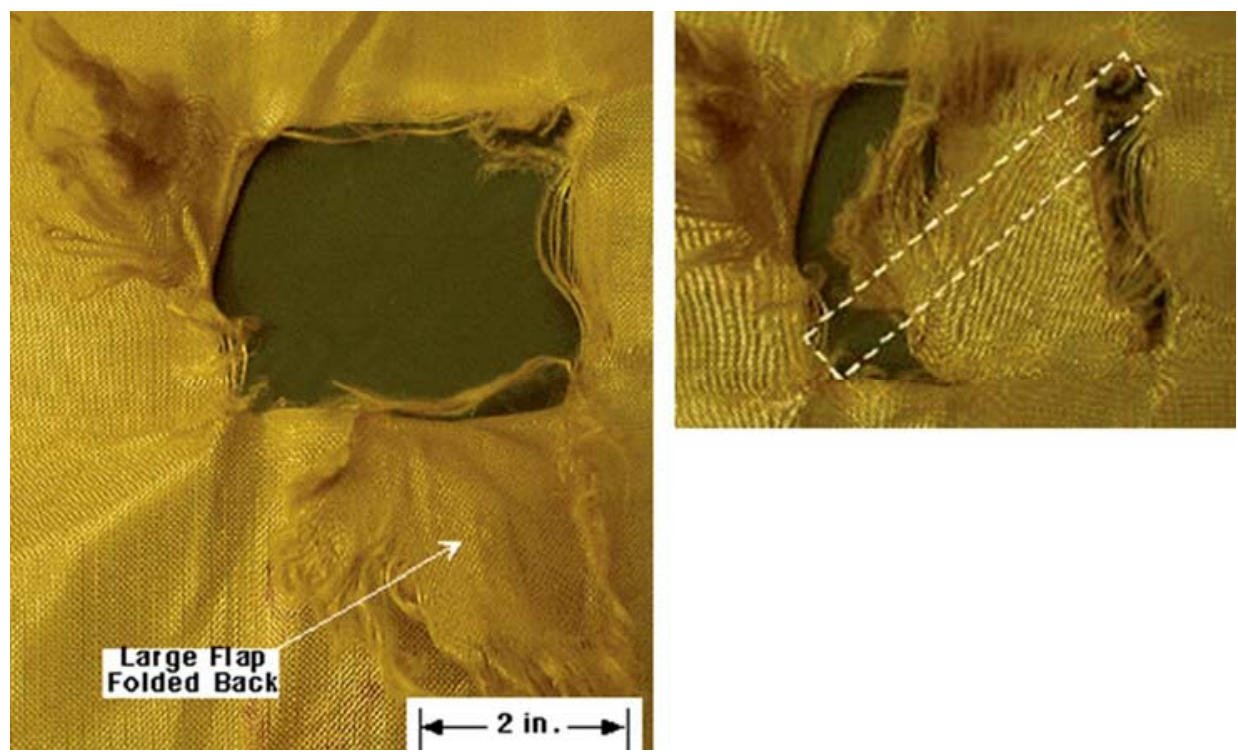

Figure 5-2 Post-test observation of fabric damage from a platelike projectile showing yarn breakage characteristics (left); the projectile size is shown with the fabric flap in its original position (right). ${ }^{125}$

The failure mechanisms of polymer fibers can be determined by examining the severed fiber ends with a scanning electron microscope (SEM). ${ }^{126}$ For example, the internal structure of a 20- $\mu$-diameter polypphenylene benzobisthiazole (PBZT) fiber consists of large length-to-width, ribbonlike fibrils typically $1 \mu$ wide, which in turn are made up of microfibrils of similar geometry but only a few nanometers wide (Figure 5$3)$. 


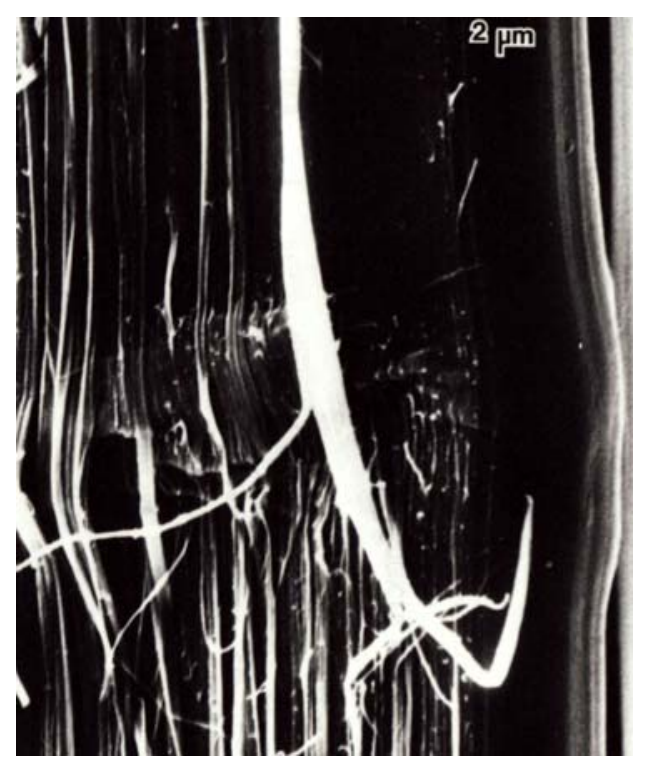

Figure 5-3 SEM micrograph revealing fibrillar microstructure in an as-spun PBZT fiber ${ }^{127}$

Figure 5-4 indicates that tensile fracture first occurred at defects such as voids and kinks and was assisted by the residual stresses that arose during processing. ${ }^{128}$
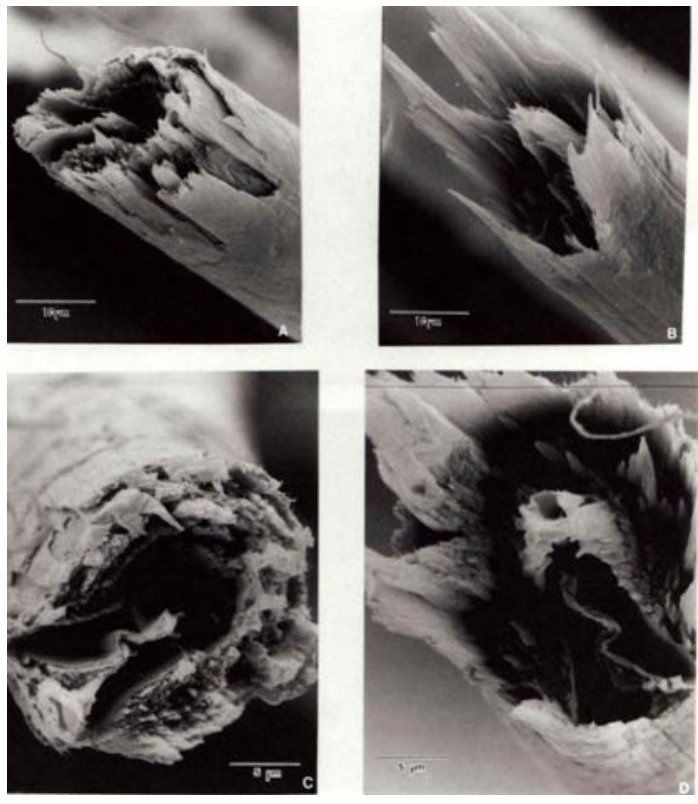

Figure 5-4 SEM side views (A,B) and endon views (C,D) of matching fracture ends of a tensile-fractured PBZT fiber. ${ }^{127}$ 
While the details of the tensile failure mechanism are not well known, high magnification shows that the fibrils in the fibers are stretched, suggesting tensile failure analogous to that seen in tensile tests of metals. Fiber material very likely undergoes homogeneous plastic deformation and localized plastic deformation in much the same way as metals; failure may also occur by the nucleation of voids, cracks, and shear bands.

It is not understood how the material microstructure at this level (the nano level) influences the deformation, localization, and failure behavior of the material. Failure initiators are thought to originate in material defects such as tiny voids, foreign particles, and chain entanglements resulting from chemical inhomogeneities or processing procedures.

Fiber failure modes other than tensile failure are also observed. For example, a projectile's impact on fabric backed with a stiff plate of ceramic compresses the fabric against the backing and causes transverse loads on the yarns and fibers that can result in deformation and failure. When compressed fibers are examined by SEM, they and the fibrils show flattening, kinking, and buckling.

The influence of the nano- and microstructure of polymeric materials on the deformation, localization, and failure behavior of the materials is not well understood, especially at high strain rates and high pressures.

Closing the large gap between the currently attainable and the theoretical strengths of fibers would benefit greatly from studies of ballistically (and quasistatically) failed fibers at the nano- and micro levels to determine the mechanism(s) of material failure and identify the nanostructural features initiating the failure process or otherwise assisting it.

\subsection{Failure Mechanisms of Fabrics}

When a projectile hits the individual fiber or yarn, ${ }^{129}{ }^{130}$ longitudinal and transverse waves propagate from the impact point. Most of the kinetic energy transfers from the projectile to the principal yarns (those that come directly into contact with the projectile); the orthogonal yarns, which intersect the principal yarns, absorb less energy. The transient deformation within the fabric was simulated by Grujicic et al. ${ }^{131}$ The 
transverse deflection continuously increases until it reaches the breaking strain of the fibers and causes failure. Specific failure mechanisms including these:

- Breakage of fiber bonds and yarns,

- Yarn pullout,

- Remote yarn failure,

- Wedge-through phenomenon (hole smaller than the diameter of projectile),

- Fibrillation, and

- Effects of friction between the projectile and the fabric, yarns, and fibers.

\subsubsection{Breakage of Fiber Bonds and Yarns}

As in all materials, when a force is applied to the fiber or yarn or fabric, a set of competing deformation processes can take place, depending on the loading rate, stress state, temperature, and other factors. Polymer fibers are normally highly crystalline and highly anisotropic due to the high molecular orientation and the covalent bonds along the fiber axis versus van der Waals or hydrogen bonding in the transverse directions. However, glass and ceramic fibers can be essentially isotropic due to their multidirectional ioniccovalent bonds. The assembly of fibers into yarns and yarns into a fabric with a given architecture or geometry leads to different overall symmetries for the actual armor.

When a molecular bond is excited beyond its activation energy, bond breakage occurs. The activation energies for shear and interchain slip are lower than for covalent bond rupture and are strongly affected by ambient temperature, pressure, and the polymer's intrinsic glass transition temperature. When a projectile hits the fabric, the fiber is stretched along the axial direction owing to the longitudinal stress wave. Also, penetration of the projectile leads to shearing across the direction of the fiber thickness. Normally in the contact area of projectile and fabrics, if induced strain is larger than the failure strain of the fibers, the fiber will break. For polymer regions that are in a rubbery state (the noncrystalline component of which may be above its $\mathrm{Tg}$ ), shear yielding is expected to occur before fracture. However, under a very high strain rate, as is the case 
for ballistic impact, the time interval that a stressed bond spends at a certain stress level is shortened and there is a lower probability for bond breaking at that level; thus, strength increases with the increase of strain rate. Termonia et al. ${ }^{132}$ calculated the strain-rate dependence of strength of perfectly ordered polyethylene (PE) and found that the maximum strength may increase from 1.5 GPa to $21 \mathrm{GPa}$ for PE with a molecular weight of $2.2 \times 10^{4} \mathrm{~g} / \mathrm{mol}$ when strain rate increases from $10^{-1} \mathrm{~min}^{-1}$ to $105 \mathrm{~min}^{-1}$. Also, at low strain rate, before bond breakage, molecular slippage occurs and plastic deformation is observed. By comparison, at the higher strain rates observed in ballistic impact, bond breakage and molecular slippage may occur simultaneously, or the primary bond breakage may even become predominant. ${ }^{133}$ Although the tensile properties of fibers such as aramid and carbon fibers are relatively less sensitive to the strain rate, fibers such as Spectra are sensitive to strain rate, and their failure strain and mechanism at high strain rate may be distinctly different from that at low strain rate. There are relatively few studies of the strain-rate dependence of tensile behavior, and more efforts are needed to fully characterize the strain-rate dependence. $\mathrm{Gu}^{134}$ observed that strength/modulus increased from $2.4 \mathrm{GPa}$ and $62 \mathrm{GPa}$ to $2.75 \mathrm{GPa}$ and $72 \mathrm{GPa}$ for Twaron [poly(paraphenylene terephthalamide)] and from $1.19 \mathrm{GPa}$ and $20.3 \mathrm{GPa}$ to 1.85 GPa and 51.2 GPa for Kuralon (a polyvinyl alcohol), when the strain rate increased from $10^{-2} \mathrm{~s}^{-1}$ to $10^{3} \mathrm{~s}^{-1}$. Wang and $\mathrm{Xia}^{135}$ tested Kevlar in the strain-rate range from $10^{-4}$ $\mathrm{s}^{-1}$ to $10^{3} \mathrm{~s}^{-1}$ and observed that the strength of Kevlar 49 increased from $2.34 \mathrm{GPa}$ to 3.08 GPa and its modulus from $97 \mathrm{Gpa}$ to $125 \mathrm{GPa}$. Zhou et al. ${ }^{136}$ studied the strain-rate dependence of mechanical properties of T-300 and M40J carbon fibers in the range $10^{-3}$ $\mathrm{s}^{-1}$ to $1.3 \times 103 \mathrm{~s}^{-1}$ and observed that these fibers were strain-rate-insensitive materials. Wang and $\mathrm{Xia}^{137}$ observed that for Kevlar 49 fiber, at a fixed strain rate, the initial tensile modulus decreased and elongation at break increased with the increase in test temperature. 


\subsubsection{Yarn Pullout}

If yarn is not well gripped at its ends, the ends may be pulled out from the fabric mesh. In this case, yarn pullout may occur and none of the fibers inside this portion of the yarn break. The pullout force is dependent on interyarn friction and pre-tension. The interyarn friction is related to friction efficiency and interyarn contact area. Yarn pullout may be the major energy dissipation path only when fabric is ungripped or not well gripped.

\subsubsection{Remote Yarn Failure}

Yarn failure may happen away from the impact area but between the impact point and the gripping boundary. Shockey et al. ${ }^{138}$ observed remote yarn failure during Zylon tensile testing. The remote yarn failure occurs in tests of both transverse load (perpendicular to the yarn direction) and cylindrical load (along the yarn direction). The remote yarn failure may be hard to detect, as broken fibers may be buried inside the fabric mesh. Remote yarn failure will not affect the load on the projectile until friction force on the yarns decreases to a value that cannot sustain additional remote yarn failure. Since remote yarn failure involves yarns in a large area of fabric target, it may significantly increase the energy absorbance. Remote yarn failure has been observed in penetration by a blunt projectile in both two-edge-gripped and four-edge-gripped fabric targets.

\subsubsection{Wedge-Through Phenomenon}

The wedge-through phenomenon occurs when the formed hole is smaller than the diameter of the projectile. The phenomenon is more predominant in the back side of a multi-ply system. When a projectile hits the fabric, the transverse movement of the yarns locally expands the mesh and increases the space between woven yarns. For a projectile with a small cross-section and a fabric with only a few layers, the projectile may push the yarns aside and slip through the hole. There is a greater possibility of a wedge-through projectile phenomenon in loosely woven fabric than in tightly woven 
fabric, as has been observed by many researchers. ${ }^{139} 140$ The wedge-through phenomenon is affected by projectile geometry, fabric structure, and mobility of yarns, which is correlated to frictional behavior of the yarns.

\subsubsection{Fibrillation}

Anisotropic fibers are subject to splitting along their axial direction.10 Highstrength fibers with highly oriented and extended polymer chains may fail in compression at very low strains, normally less than 1 percent; kinking and microbuckling are major failure responses. ${ }^{141}$ When polymer chains are highly aligned in a fiber, the tensile modulus along the fiber axis is very high, whereas the shear modulus is relatively low. Fibrillation can occur during compression and results in high energy absorption during failure, which will be useful for the ballistic performance. ${ }^{142}$ Fibrillation was found in para-aramid fibers ${ }^{143}$ after ballistic impact, and its level was found to increase at low impact energy as compared to high impact energy. Fibrillation is caused by the abrasion of a projectile with yarns in the lateral direction to the fiber axis. Flat head projectiles with less possibility of penetration do not promote much fibrillation. ${ }^{144} 145$

\subsubsection{Effects Of Friction Between The Projectile And The Fabric, Yarns, And Fibers}

During impact, the friction between projectile, fabric, yarns, and filaments may cause heat generation and lead to temperature increase. This is more of an issue for thermoplastic polymer fibers such as PE and nylons than for aromatic heterocyclic backbone fibers such as Kevlar due to the vastly higher melting points of the latter type of fiber. Carr ${ }^{146}$ observed the melting of fibers after the high energy impact of Spectra fabrics. Prosser et al. ${ }^{147}$ observed a temperature increase on the back surface of a ballistic panel containing 40 layers of nylon fabrics to as high as $76.6^{\circ} \mathrm{C}$ after perforation by a .22 caliber projectile. 


\subsection{Concepts For Enhancing Ballistic Performance Of Fabrics}

In carbon-nanotube-reinforced composites, polymers such as poly(paraphenylene terephthalamide), poly(benzobisoxazole), poly(diimidazo pyridinylene [dihydroxy] phenylene), ultrahigh-molecular-weight PE, polyurethane, and so on can be used as a matrix system, with the carbon nanotube as the reinforcing entity. Similarly, carbon nanotube- reinforced fibers can also be made from metals, ceramics, and glasses, wherein during high-temperature processing there exists the probability of compound formation and new types of interfacial bonds.

\subsubsection{Important Issues for Ballistic Performance of Fabrics}

As discussed, the ballistic performance of fabrics depends on many factors, including the structure of the fabrics, the projectile, friction, temperature, and moisture. This section discusses the main factors and reviews related studies.

Fiber Properties. Although the tensile properties of fibers, including tensile strength, modulus, and strain at failure, are important to the ballistic performance of fibers, single-fiber properties do not determine it. For example, Kevlar yarn is less tough than nylon, but its ballistic performance is better; high-strength polypropylene is approximately 50 percent stronger than nylon, but its ballistic performance is worse. To understand relative ballistic fabric performance based on single-fiber mechanical properties, Cunniff ${ }^{148}$ developed a parameter $U^{*}$ to evaluate the ballistic performance of fibers. $U^{*}$ is the product of fiber-specific toughness and strain wave velocity and is given by

$$
U^{*}=\frac{\sigma \varepsilon}{2 \rho} \sqrt{\frac{E}{\rho}}
$$

where $E$ is Young's modulus, $\sigma$ is fiber ultimate tensile strength, $\varepsilon$ is ultimate strain, and $\rho$ is density. $U^{*}$ can be used to predict $\mathrm{V}_{50}$ rankings of fibers. The mechanical properties of some high-performance fibers (e.g., UHMWPE) are strain-rate dependent while those 
of other fabrics (e.g., carbon and PPTA fibers) are much less so, which is not accounted for in the expression for the parameter $U^{*}$. Test methods that can provide fiber tensile property at strain rates greater than $10^{3} \mathrm{~s}^{-1}$ are needed. Since the mechanical behavior of polymers is pressure sensitive-for example, UHMWPE has a relatively low melting point $\left(140^{\circ} \mathrm{C}\right)$-the effects of pressure and temperature on materials behavior at high rates also need consideration.

Fabric Architecture. Normally fibers are twisted to form yarn. Farris et al. ${ }^{149}$ investigated the influence of twist on the strength and modulus and found that all the fiber yarns exhibit the best tensile strength at an optimum twist angle of about $7^{\circ}$. In ballistic applications, the most common weave patterns are plain and basket weaves. Cunniff et al. ${ }^{150}$ observed that loosely woven fabric or unbalanced weave led to poor ballistic performance. Shockey et al. ${ }^{151}$ studied single-ply Zylon fabrics and observed that absorbed energy was proportional to fabric areal density but that ballistic effectiveness was not strongly dependent on mesh density or weave tightness. Chitrangad ${ }^{152}$ observed that the cover factor (the ratio of the area covered by the yarns to the whole area of the fabric) of fabrics in the range of 0.60 to 0.95 is suitable for ballistic applications. Lower value fabrics become too loose, and at higher cover factor values, degradation occurs during weaving. The $\mathrm{V}_{50}$ of composite fabrics with higher elongation in weft yarns and lower elongation-to-break in warp yarns was greater than that of fabrics made from a single material, which may be due to the lesser influence of yarn crimp. By considering yarn crimp in modeling, Tan et al. ${ }^{153}$ obtained more accurate results. The number of fabric plies also affects the ballistic performance (note that typically there may be $20-50$ plies). Shockey et al. ${ }^{154}$ observed increased specific energy absorbed for multi-ply targets owing to the friction forces between layers. The influence of interply distance on ballistic performance has also been investigated. ${ }^{155} 156$ The influence of projectile geometry also becomes less important with the increased number of plies. ${ }^{157}$ A three-dimensional woven structure was studied in a fabric composite ${ }^{158}$ designed to provide greater through-thickness direction reinforcement than in conventional two-dimensional woven fabrics; this structure showed higher ballistic performance and led to fewer penetrated layers under impact.

Projectile Characteristics and Fabric Damage. The geometry of a projectile will strongly affect its penetration ability. A sharp-edged or pointed projectile perforates 
the fabric more easily than a blunt-faced projectile, shearing yarns across their thickness direction and leading to a smaller specific energy absorbed. ${ }^{159} 160161$ Tan et al. ${ }^{162}$ investigated the effects of projectile shape, including ogival, conical, hemispherical, and flat-headed, on the ballistic performance of single-ply Twaron fabrics; they observed the sequence hemispherical $>$ flat-headed $>$ ogival $>$ conical when projectile velocity is 100 $600 \mathrm{~m} / \mathrm{s}$. Conical and ogival projectiles caused the least yarn pullout, which suggests that they were able to wedge through the fabrics.

The velocity of the projectile will also affect the performance of fabrics. In lowvelocity impact, the transverse wave has a longer time to propagate and more fabric area is involved, which leads to higher energy absorption. Also, yarn pullout becomes the predominant failure mode. At high-velocity impact, some types of fibers become stiffer and stronger owing to their viscoelastic properties, and primary bond failure becomes the predominant failure mechanism. ${ }^{163}$

Fabric Boundary Conditions. When fabrics are impacted by a projectile, the size of the target and gripping conditions are important. For instance, a longer yarn can absorb more deformational energy than a shorter one before failure; thus a larger target area will lead to higher energy dissipation. However, this is not true when the velocity of the projectile is very high compared to the velocity of the shock wave in the fibers since then only a small portion of the target can dissipate the kinetic energy of the projectile. The boundary conditions of the target also play an important role. Shockey et al. ${ }^{164}$ observed that a two edge gripped fabric absorbs more energy than a four-edge gripped fabric, and fabrics with free boundaries absorb the least energy. Chitrangad ${ }^{165}$ observed that when pre-tension is applied on aramid fabrics, their ballistic performance is improved. Zeng et al. ${ }^{166}$ observed that for four-edge gripped fabrics, energy absorbed is improved if the yarns are oriented at $45^{\circ}$ relative to the edge.

Friction. Frictional effects between a projectile and a fabric are observed at lowvelocity impact but diminish at a higher velocity. ${ }^{167}$ A quantitative study on Kevlar yarn friction was conducted by Briscoe et al. ${ }^{168}$ The yarn pullout force increases with an increase in interyarn friction, and the increase in effective yarn modulus is attributed to the increase in interfilament friction. Fabrics with high friction and lower effective modulus can dissipate more energy than those with lower friction. Duan et al. ${ }^{169}$ modeled the effects of interyarn friction and found that it accounts for only a small 
portion of energy dissipation during impact. Friction does help maintain the integrity of local fabrics in the impact region by allowing more yarns to be involved in the impact, and it increases energy absorption by increasing yarn strain and kinetic energy. Dischler $^{170}$ applied a thin polymeric film on Kevlar (20-ply), which increased the coefficient of friction from 0.19 to 0.27 ; he observed a 19 percent improvement in ballistic performance in stopping a flechette.

\subsection{Deformation And Failure Mechanisms Of Ballistic Composites}

Polymer matrix composites (PMCs) consist of a polymer resin reinforced with fibers, an example of which is the combat helmet. PMCs can be subdivided into two categories, based on whether the fiber reinforcement is continuous or discontinuous. PMCs with discontinuous fibers (less than $100 \mathrm{~mm}$ long) are made with thermoplastic or thermosetting resins, whereas PMCs with continuous fibers usually employ thermosetting resins. The most common design for PMCs is a laminate structure made of woven fabrics held together by a polymer resin. Fabrics are incorporated in order to take advantage of their high strength and stiffness and to improve energy absorption and distribute the kinetic energy laterally. Owing to their highly engineered structures, PMCs are lightweight with high specific strength and high specific stiffness.

Commonly used reinforcement materials include carbon, glass, aramid, and polyethylene fibers. PMCs can be manufactured by wet and hand lay-up; molding (compression, injection, and transfer); vacuum bag molding; infusion molding; vacuumassisted resin transfer molding; prepreg molding; and other common fabrication techniques. Unlike common structural composites, which typically contain up to about 60 vol percent fibers, ballistic PMCs contain a higher volume fraction of fibers or fabrics (up to about 80 vol percent). The effect of this variation in structure on the ballistic protection properties of PMCs has not been thoroughly investigated.

PMCs respond to ballistic impact in ways that depend on their particular structure and thus are different from other protective materials. Unlike fabrics, with PMCs only the material in the neighborhood of the impact position shows a response; 
thus the response is completely governed by the local behavior of the material and unaffected by boundary conditions. Additionally, the penetration mechanism is dependent on the thickness of the composite. For thin composites the deformation across the thickness direction does not vary with depth, whereas for thick composites it does. ${ }^{171}$ Ballistic performance initially increases linearly with the increased thickness; however, as the composite becomes thicker the marginal protective gain incurred by increasing the thickness becomes smaller,3,4 although the rate at which the weight increases is maintained.

\subsubsection{Deformation And Failure Mechanisms}

When a PMC is subjected to high-velocity impact, the kinetic energy is transferred from the projectile to the PMC. The existence of two components, the fabric and the matrix, and their interface, makes the energy absorption mechanism more complex than that of ballistic fabrics. The commonly recognized energy absorption and failure mechanisms are discussed here.

Cone Formation on the Back Face. As with ballistic fabrics, the mode of impact response known as cone formation has also been observed in PMCs. Guoqi et al. ${ }^{172}$ observed the formation of a cone-shaped $\sigma_{f}(\varepsilon, \dot{\varepsilon}, T)$ deformation zone in the back surface of Kevlar/polyester laminates during the ballistic impact of a blunt projectile; using high speed photography, Morye et al. ${ }^{173}$ documented the temporal evolution of this response for the ballistic behavior of nylon fabric preimpregnated with a matrix of a 50:50 mixture of phenol formaldehyde resin and polyvinyl butyral resin. 


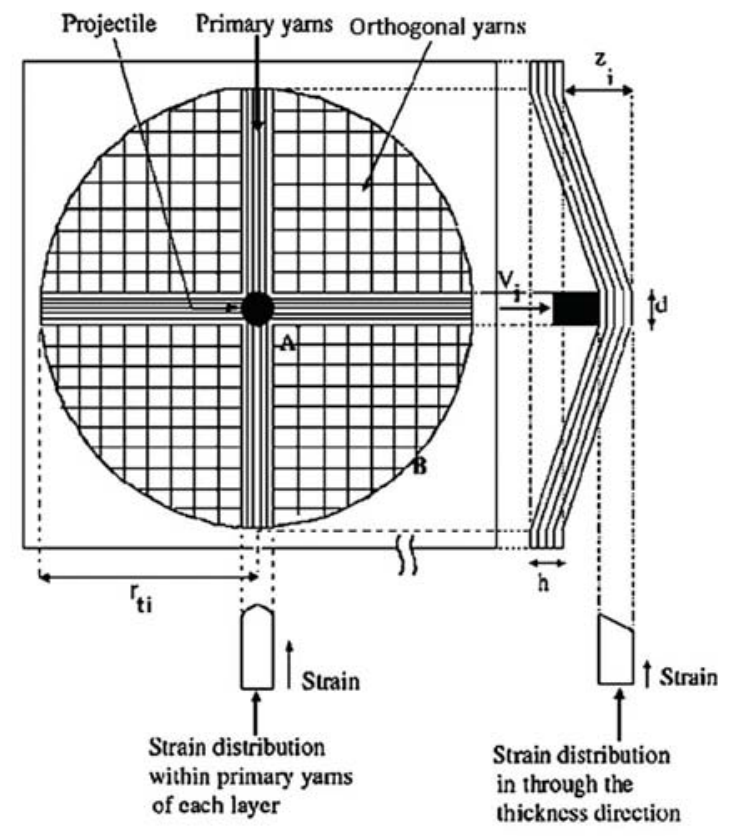

Figure 5-5 Cone formation during ballistic impact on the back face of the composite target ${ }^{174}$

Figure 5-5 shows the scheme of cone formation in two-dimensional woven fabric composites during projectile impact. The yarns that the bullet directly contacts are called primary yarns; these yarns resist penetration and undergo deformation due to cone formation. The longitudinal compressive stress wave generated upon impact propagates outward along the yarn direction, forming a quasi-circular shape. The conical portion moves backward and stores kinetic energy by its motion.

Deformation of Yarns and Failure. When a PMC undergoes ballistic impact, the primary yarns deform and resist projectile penetration. The other yarns (called orthogonal yarns) also deform, but to a lesser extent due to primary yarn deformation; this process stores kinetic energy. During cone formation, strain is highest along the middle primary yarns in each layer of the composite. The highest overall strain is at the point of impact, and the strain falls off along the radial direction. After the cone forms, the top layers of the PMC are compressed, leading to an increase in the tensile strain of the yarns there. A linear relation between strain and depth along the thickness direction can be assumed; see Figure 5-5. Once the strain is beyond the failure strain, sequential 
breakage will occur beginning at the top layer. This yarn failure absorbs additional kinetic energy.

Delamination and Matrix Cracks. During ballistic impact, transverse and longitudinal waves are formed. The geometry of the deformation influences the terminology used to describe the deformation. The waves that move out in the lateral direction (having both longitudinal and transverse polarization) from the point of impact are called transverse, and the waves propagating along the direction of the incident projectile are called longitudinal. A cone of deformation, quasi-lemniscate in shape, is formed due to transverse waves. ${ }^{175}$ As the longitudinal waves propagate along the yarns, attenuation occurs, leading to strain variations radially from the impact site in the target. The matrix has mechanical properties different from those of the yarns, but it must carry the same deformation lest delamination or slippage occur due to weak adhesion between the yarn and the matrix; there may be damage if the yarn strain is higher than the strain at failure in the matrix.

As the material deforms, cracking and delamination will continue until total perforation occurs. ${ }^{176}$ Research has shown ${ }^{177}$ that initiation and propagation of delamination occur more frequently along the warp and fill directions than along other directions. Compared to conventional materials, composite materials contain numerous interfaces between the matrix and the fibers, providing multiple locations for cracking to occur. Energy absorption occurs through a combination of cracking, delamination, and shear banding (the latter is dependent on the plasticity of the matrix and possibly of the fibers). Typical shapes of delaminated regions after impact are shown in Figure 5$6 ;{ }^{178}$ the noncircular shape is attributed to the anisotropic nature of these materials (different paths of the stress waves, hence different distances that the stress information must travel). 


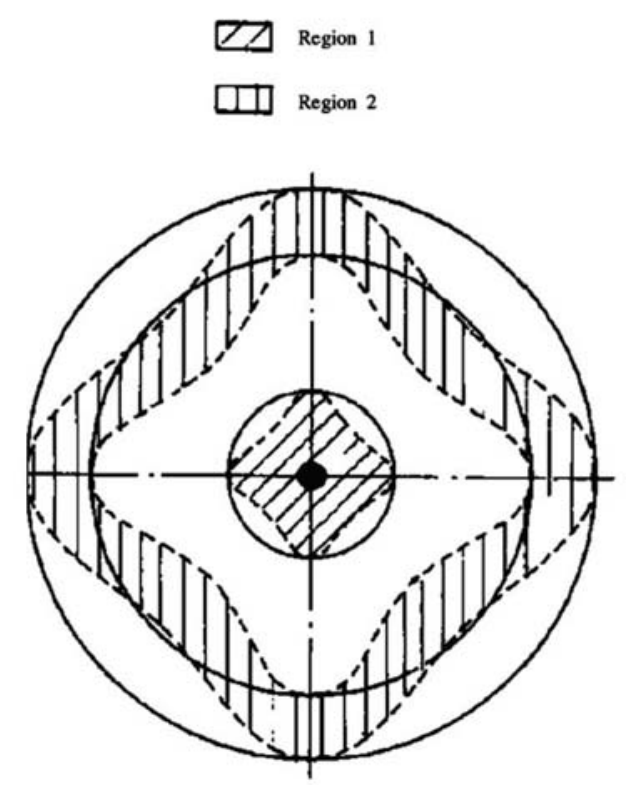

Figure 5-6 Schematic shape of delaminated regions observed in impact experiments. Region 1: area damage in the first time interval after impact;

Region 2: area damaged in the $(i+1)$ time interval. ${ }^{174}$

Shear Plugs. During impact experiments on conventional carbonfiber-reinforced plastic laminates, it was observed ${ }^{179}$ that a small area of the laminate was sheared off by the projectile during impact and that a distinct conical-shaped zone was formed. The schematic is shown in Figure 5-7.

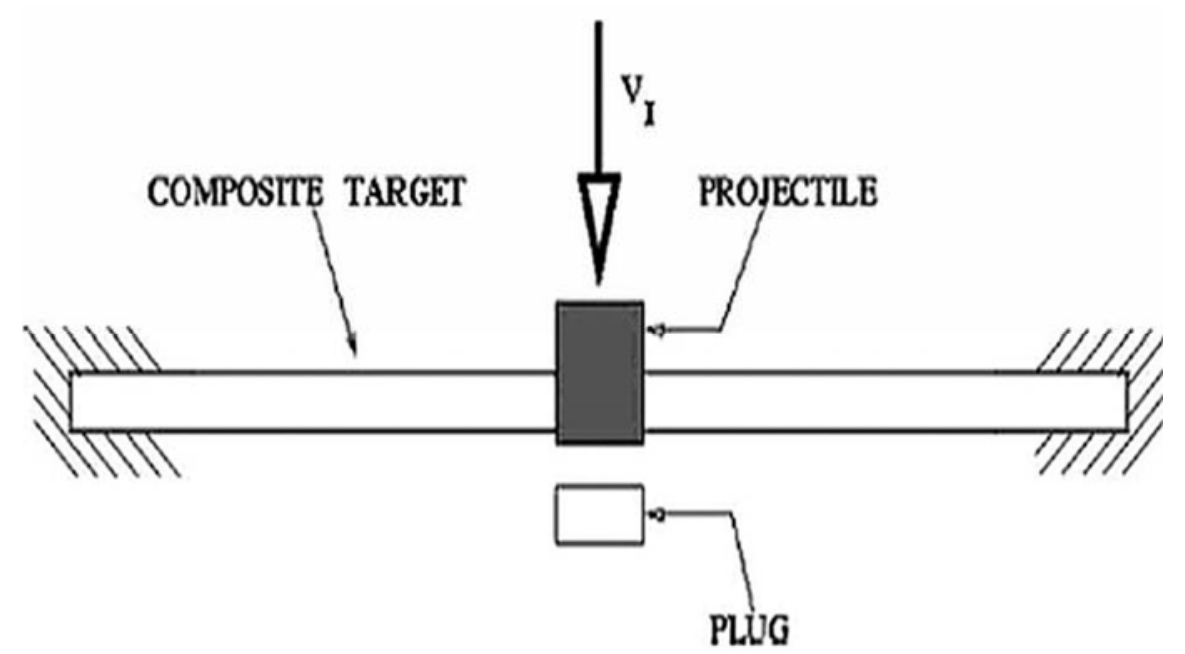

Figure 5-7 Schematic showing plug formation ${ }^{174}$ 
The shear plug phenomenon has never been observed in glass-fiber reinforced composites, which may be due to the much higher failure strain of glass fibers compared to that of carbon fibers at high strain rates.

Friction and Hole Enlargement. In contrast to the complex frictional forces present in neat fabrics (including friction between yarns, between the projectile and the yarn, and between the individual fibers), the only friction present in PMCs during impact occurs between the projectile and the laminate. After the yarns and the fabrics fail, friction between the damaged laminates dissipates some of the kinetic energy from the projectile. Goldsmith et al. ${ }^{180}$ calculated the frictional work by using the friction efficiency between projectile and laminate measured by the quasi-static method. They found that the friction resistance depends on the shape of the projectile and that it increases with increasing composite thickness. Additionally, they calculated the energy dissipated when the projectile enlarges the hole and found that this process also contributes to energy dissipation. Although the energy absorbed due to friction is much larger than that due to hole enlargement, neither of these modes is the major energy absorption mechanism.

The Contribution of Different Types of Energy Absorption Paths. Naik and Shrirao ${ }^{181}$ analyzed the ballistic impact behavior of woven fabric composites under a flat head projectile using wave theory and presented an analytical formulation for each energy absorption mechanism. The calculation is based on the material properties at high strain rate, and analytical prediction shows a good match with experimental results. During the ballistic impact, the moving area of the cone increases, leading to an increase in the kinetic energy of the cone even though the speed of the projectile is reduced. Next, as the moving speed decreases significantly, the kinetic energy of the cone decreases and becomes zero when the projectile's speed reaches zero. The kinetic energy of the cone is the major energy absorption factor, followed by deformation of the orthogonal yarns and tensile breakage of primary yarns; delamination and cracking provide only a small fraction of the energy absorption. The calculations assume a relatively thin and flexible PMC system; for thicker systems, the variation of deformation as a function of thickness changes the relevant material behavior and requires a consideration of friction. 


\section{Experimental Methods}

\section{1 Dynamic Mechanical Analysis}

Theory. Dynamic mechanical analysis (DMA)-is a thermal analysis technique that measures the properties of materials as they are deformed under periodic stress. Specifically, in DMA a variable sinusoidal stress is applied, and the resultant sinusoidal strain is measured. If the material being evaluated is purely elastic, the phase difference between the stress and strain sine waves is $0^{\circ}$ (i.e., they are in phase). If the material is purely viscous, the phase difference is $90^{\circ}$. However, most real-world materials including polymers are viscoelastic and exhibit a phase difference between those extremes. This phase difference, together with the amplitudes of the stress and strain waves, is used to determine a variety of fundamental material parameters, including storage and loss modulus, tan d, complex and dynamic viscosity, storage and loss compliance, transition temperatures, creep, and stress relaxation, as well as related performance attributes such as rate and degree of cure, sound absorption and impact resistance, and morphology. The diagram in Figure 6-1 shows the relationship between several of these parameters.
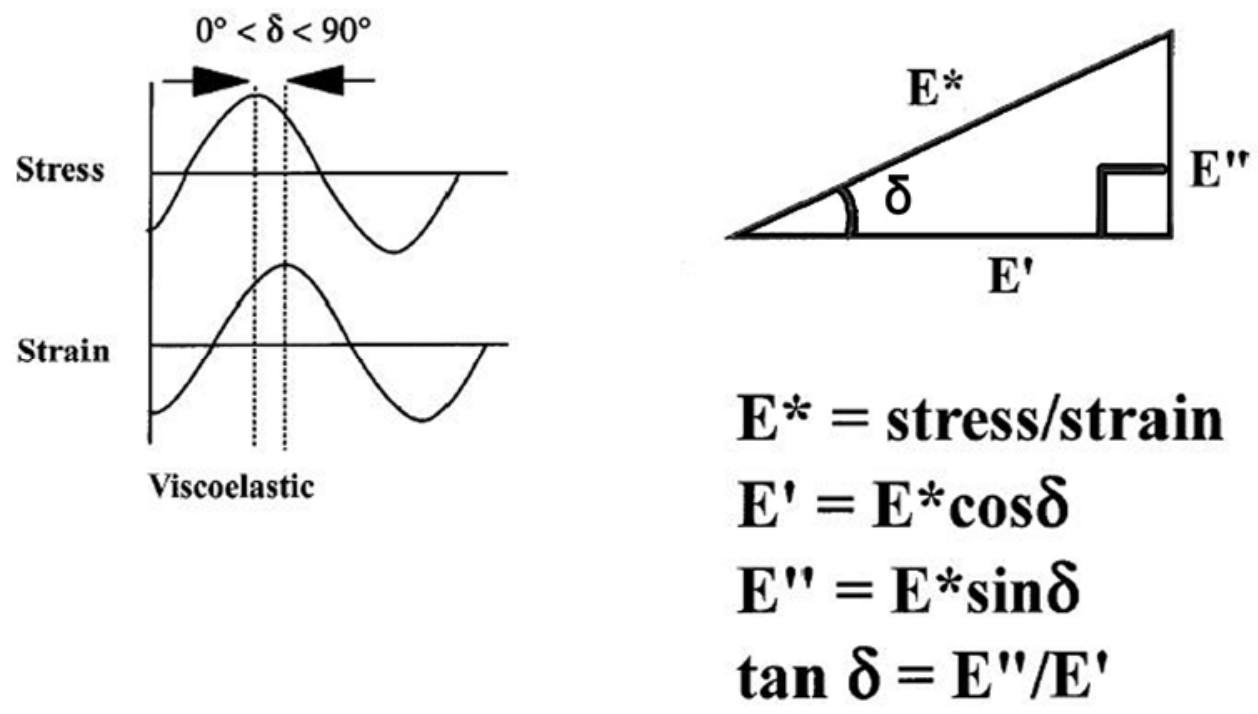

Figure 6-1 Viscoelasticity and complex modulus 
Most DMA measurements are made using a single frequency and constant deformation (strain) amplitude while varying temperature. Measurements, where the amplitude of deformation is varied or where multiple frequencies are used, provide further information.

Instrumental considerations. There are several components that are critical to the design and resultant performance of a dynamic mechanical analyzer. Those components are the drive motor (which supplies the sinusoidal deformation force to the sample material), the drive shaft support and guidance system (which transfers the force from the drive motor to the clamps that hold the sample), the displacement sensor (which measures the sample deformation that occurs under the applied force), the temperature control system (furnace), and the sample clamps. The DMA 800 dynamic mechanical analyzer (TA Instruments, Inc., New Castle, DE) (Figure 6-2) is based on a patentpending design that optimizes the combination of these critical components.

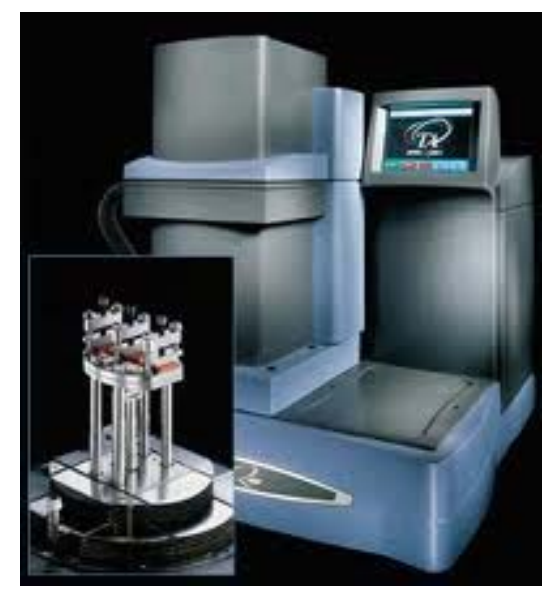

Figure 2 DMA 800 dynamic mechanical analyzer

Specifically, the analyzer incorporates a noncontact direct drive motor to deliver reproducible forces (stresses) over a wide dynamic range of $0.001-18 \mathrm{~N}$; an air bearing shaft support and guidance system to provide frictionless continuous travel over $25 \mathrm{~mm}$ for evaluating large samples (e.g., fibers as long as $30 \mathrm{~mm}$ ) or for evaluating polymers at large oscillation amplitudes $( \pm 0.5-10,000 \mathrm{~mm})$; an optical encoder displacement sensor to provide high resolution (one part in 25 million) of oscillation amplitude, which 
results in excellent modulus precision $( \pm 1 \%)$ and tan $\mathrm{d}$ sensitivity $(0.0001)$; and a bifilar-wound furnace complemented by a gas cooling accessory to allow a broad temperature range $\left(-150\right.$ to $\left.600{ }^{\circ} \mathrm{C}\right)$ to be covered. The DMA 2980 also features a variety of clamping configurations to accommodate rigid bars, fibers, thin films, and viscous liquids (e.g., thermosets) in bending, compression, shear, and tension modes of deformation.

\subsection{Equipment Standards for Ballistic Resistance of Personal Body Armor}

The Office of Law Enforcement Standards (OLES) of the National Institute of Standards and Technology (NIST) developed NIJ Standard 0101.04 as an equipment standard for "Ballistic Resistance of Personal Body Armor" that is produced as part of the Law Enforcement and Corrections Standards and Testing Program of the National Institute of Justice (NIJ). NIJ Standard 0101.04 specifies the performance requirement that equipment should meet to satisfy the needs of criminal justice agencies for high quality service. The purpose of the standard is to establish minimum performance requirements and test methods for the ballistic resistance of personal body armor intended the torso against gunfire. ${ }^{182}$

This standard classified personal body armor into seven categories according to their level of ballistic performance. The ballistic threat posed by a bullet depends on its composition, shape, caliber, mass and impact velocity. The test conditions specified in this standard represent general, common threats to law enforcement officers.

Ballistic resistant body armor suitable for full time wear during an entire shift of duty is available in classification Types I, IIA, II, and IIIA, indicated as in Table 3-1, which provide increasing levels of protection from handgun threats. Type IIIA armor is suitable for routine wear in many situations and provides the highest level of protection from high velocity $9 \mathrm{~mm}$ and 44 Magnum ammunition.

Baseline Ballistic Limit. The ballistic limit is an indication of a projectile's ability in defeating a target. It is defined as the velocity at which $50 \%$ of the impacts 
result in complete penetrations and $50 \%$ in partial penetrations according to the protection ballistic limit. Briefly, it is a statistical measure of the velocity at which penetration just occurs.

Penetration. Penetration of the projectile occurs in two forms: complete and partial penetrations. In the complete penetration $(\mathrm{CP})$ form: perforation of an armor sample or panel by a test bullet or by a fragment of the bullet or sample itself, as evidenced by the presence of that bullet or fragment (armor or bullet) in the backing material, or by a hole which passes through the armor and/or backing material. In the second case, partial penetration (PP) form determined any impact that is not a complete penetration.

Backface Signature (BFS). The depth of the depression made in the backing material, created by a nonpenetrating projectile impact, measured from the plane defined by the front edge of the backing material fixture. For armor tested on built up or curved backing material, the BFS is measured from the plane defined by the top edges of the depression or pyramid formed by the impact. Complete penetration or any designated depth measurement of BFS in the backing material greater than $44 \mathrm{~mm}$ constitute a failure. 


\section{Dynamic Mechanical Properties Of Nanocomposites With Poly (Vinyl Butyral) Matrix}

\subsection{Introduction}

Poly (vinyl butyral) (PVB) is a flexible and industrially important polymer, which is manufactured by condensation of poly (vinyl alcohol) (PVA) with nbutyraldehyde in an acid medium. ${ }^{183}{ }^{184}$ It is widely recognized for its high impact strength at low temperatures, excellent adhesive properties with a variety of materials such as glass, metals, plastics and wood. Thus, PVB is widely used as paint, an adhesive agent and a printing paste. ${ }^{185}$ The main use of PVB is in safety glass laminates, particularly in automotive, aerospace and architectural glass. Worldwide $65 \%$ of all PVB is used in automotive applications. ${ }^{186}$

Addition of reinforcements at nanoscale level to polymer matrix lead to composites with significantly improved mechanical properties in comparison to pure matrix material. ${ }^{187}$ It is expected that the addition of nanoparticle reinforcements could lead to the enhancement of the mechanical properties of the body armor material mainly

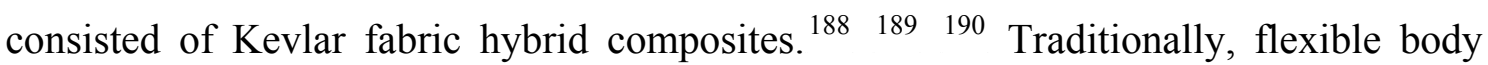
armor has been developed by using a mixture of silica and polyethylene glycol (PEG) impregnated with Kevlar. In the approach reported by Mahfuz et al. ${ }^{191}$, $30 \mathrm{~nm}$ crystalline and $7 \mathrm{~nm}$ amorphous silica were dispersed directly into a mixture of PEG and ethanol through a sonic cavitation process.

Nano- $\mathrm{SiO}_{2}$ particles display a range of specific properties, which contribute to their wide use and potential novel materials such as composites, biomaterials, sensory materials and coatings. Our previous work reports the enhancement of viscoelastic and nanomechanical properties of poly (methyl methacrylate) matrix by introducing silane coated nano- $\mathrm{SiO}_{2}$ using supercritical carbon dioxide. ${ }^{192} \mathrm{Nano}^{-\mathrm{TiO}_{2}}$ particles are used in composites for the increase of optical, mechanical and electrical properties, among others, to mention the work by Chau et al. ${ }^{193}$ 
This study reports the preparation of $\mathrm{SiO}_{2}$ and $\mathrm{TiO}_{2} / \mathrm{PVB}$ nanocomposites with enhanced dynamic mechanical properties. Additionally, Kevlar fabric/PVB composites were treated with $\mathrm{SiO}_{2}$ and $\mathrm{TiO}_{2}$ nanocomposites. Dynamic mechanical analysis of fabricated nanocomposites and hybrid composites was employed in order to analyse the optimal nanoparticle preparation and content for composites with the improved viscoelastic properties.

\subsection{Experimental Procedure}

The $\mathrm{SiO}_{2}$ and $\mathrm{TiO}_{2}$ nanoparticles with an average diameter of 7 and $25 \mathrm{~nm}$ (A380 and P25 Evonik, Degussa) were used as received and designated as $\mathrm{SiO}_{2}$ and $\mathrm{TiO}_{2}$ and in sol state designated as $\mathrm{SiO}_{2}$ sol and $\mathrm{TiO}_{2}$ sol. Thin poly (vinyl butyral) (PVB) (Saflex ${ }^{\circledR}$ - Monsanto) films were used as a matrix in the composite material.

Silica and titania powders were mixed with ethanol (5\%) and then ultrasonically treated for 15 minutes. PVB nanocomposites were prepared by melt mixing at $190{ }^{\circ} \mathrm{C}$ and $120 \mathrm{rpm}$ for $10 \mathrm{~min}$ in a Laboratory Mixing Molder (Atlas LMM). Hybrid composte samples were additionally produced with aramid fabric Kevlar 129 (Spörl GMBH) with superficial mass of $280 \mathrm{~g} / \mathrm{m}^{2}$. Weight fraction of aramid fabric was held to be $65.8 \mathrm{wt} \%$ in the composites, which were produced by lay-up of 8 layers of fabric bonded with neat PVB and PVB with introduced silica and titania nanoparticles. Lay-up was subsequently hot pressed (Mashpriborintorg P-125) under $200{ }^{\circ} \mathrm{C}$ for 30 min under the pressure of $148 \mathrm{MPa}$.

A dynamic mechanical analysis (DMA) was conducted in a single-cantilever mode at $1 \mathrm{~Hz}$ frequency using TA Instruments Q800. Sample dimensions for DMA testing were $35 \times 12 \times 3 \mathrm{~mm}$ and at least two scans were performed per sample. Transmission electron microscopy (TEM) was performed on a TECNAI-FEG F20 electron microscope at $200 \mathrm{kV}$. The samples were prepared by dispersion in ethanol and dropping the suspension on holey carbon grids. 


\subsection{Results and Discussion}

Viscoelastic properties of nanocomposites and Kevlar reinforced composites were studied using two different inorganic fillers, $\mathrm{SiO}_{2}$ and $\mathrm{TiO}_{2}$, as neat powders and as colloidal sol. Figure 7-1 shows TEM images of silica and titania nanoparticles. It is hypothesized that the addition of colloidal $\mathrm{SiO}_{2}$ and $\mathrm{TiO}_{2}$ sol could contribute to the dynamic mechanical properties of the polymer matrix via enhanced dispersion of nanoparticles while the use of nanoparticles in powder form could result in aggregated particles in the PVB matrix.
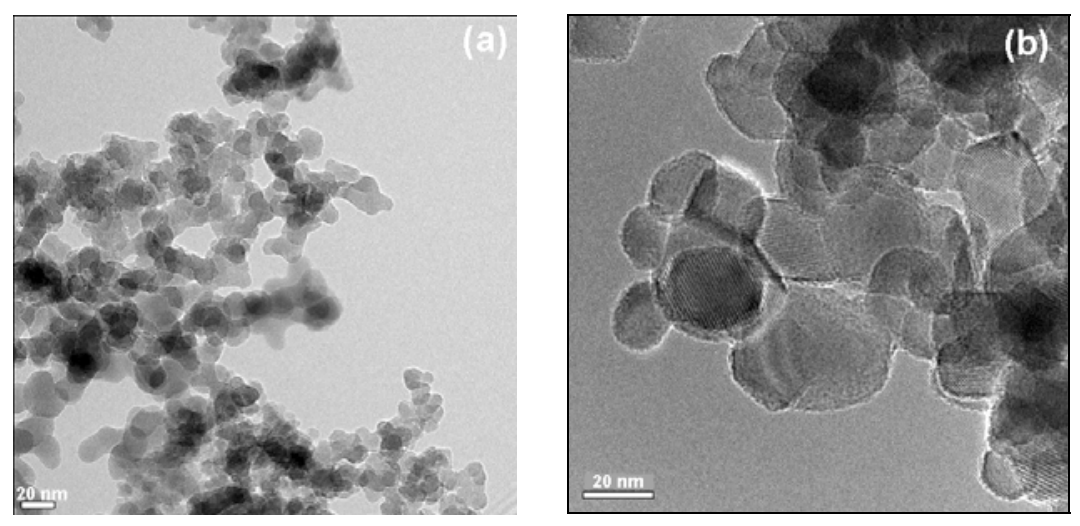

Figure 7-1. TEM images of: a) silica and b) titania nanoparticles; bar length is $20 \mathrm{~nm}$.

For the DMA testing, composite samples were produced with various content and the method of treatment (neat and sol) of silica and titania nanoparticles. Figures 7-2 up to 7-5 show nanocomposite storage modulus and damping ratios in dependence of reinforcing particle contents. The storage modules (E') and loss factor (Tan Delta) were determined as a function of temperature ranging from room to $100{ }^{\circ} \mathrm{C}$. The applied amplitude was $15 \mu \mathrm{m}$, and the heating rate was fixed for $3{ }^{\circ} \mathrm{C} / \mathrm{min}$. The glass transition $\left(\mathrm{T}_{\mathrm{g}}\right)$ temperature was deduced from the damping ratio using standard calculation method. Storage modulus trend reveals that the addition of nanoparticles influences the mechanical properties of PVB, while at the same time the glass transition temperature shows no observable trend. In order to enable more detailed discussion, results of DMA testing are compiled in Table 7-1. 


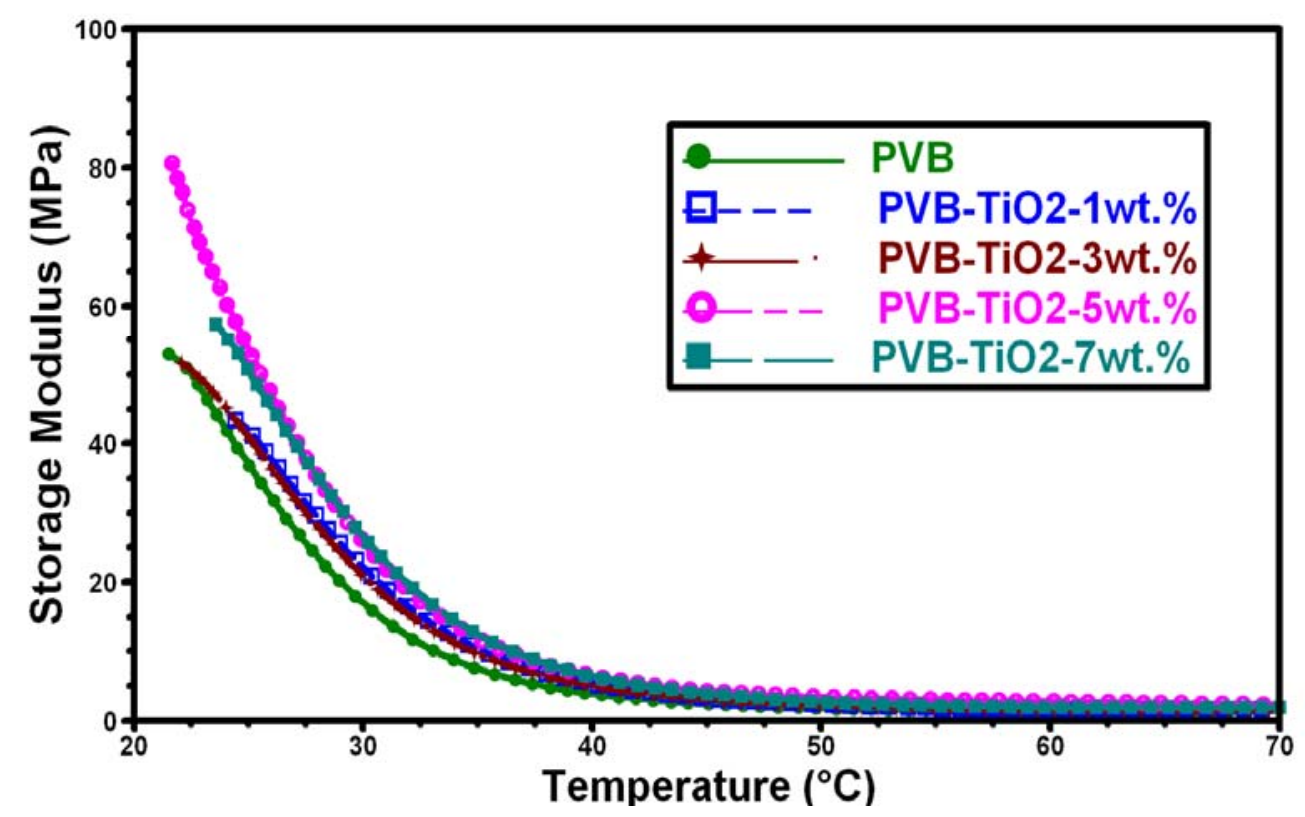

a)

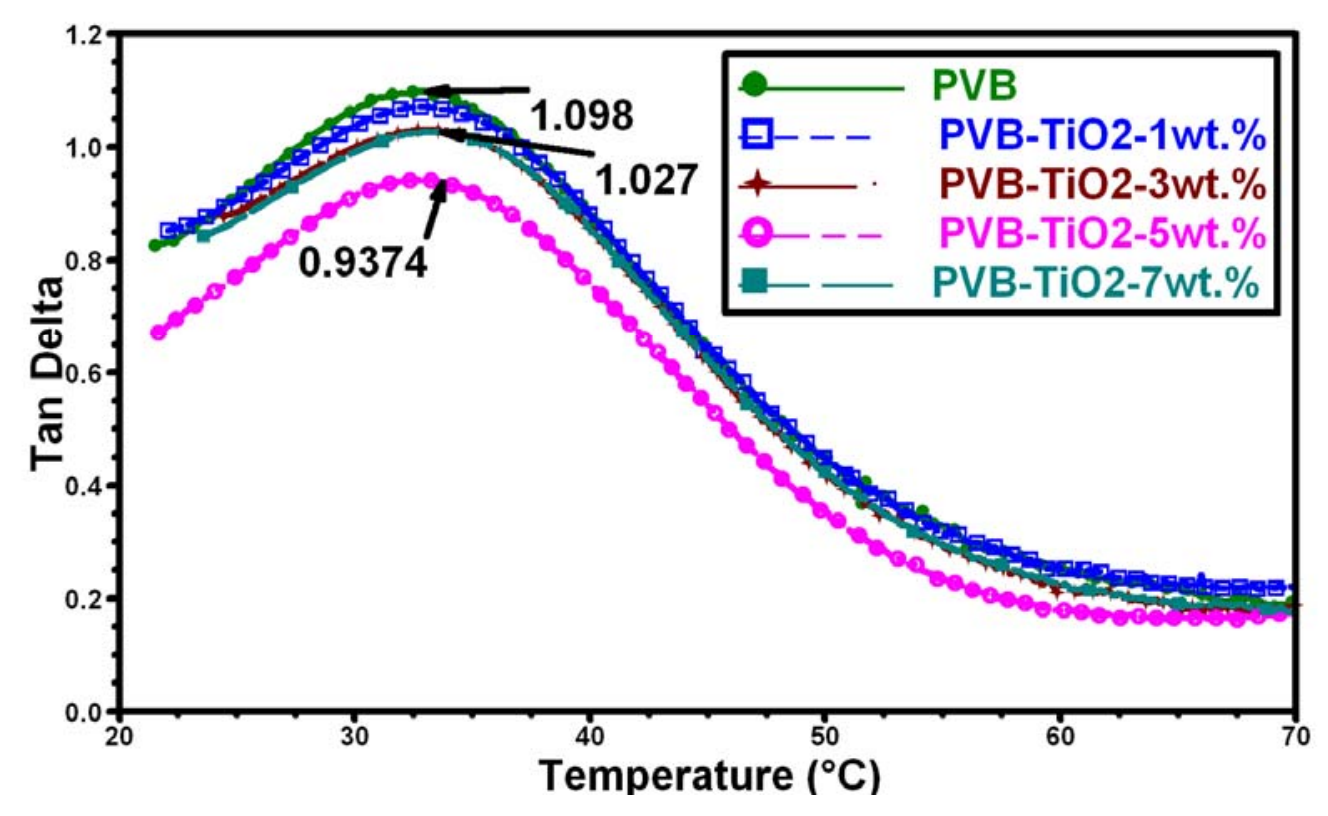

b)

Figure 7-2 Dynamic mechanical properties of nanocomposite containing colloidal $\mathrm{TiO}_{2}$ a) storage modul and b) Tangen delta. 


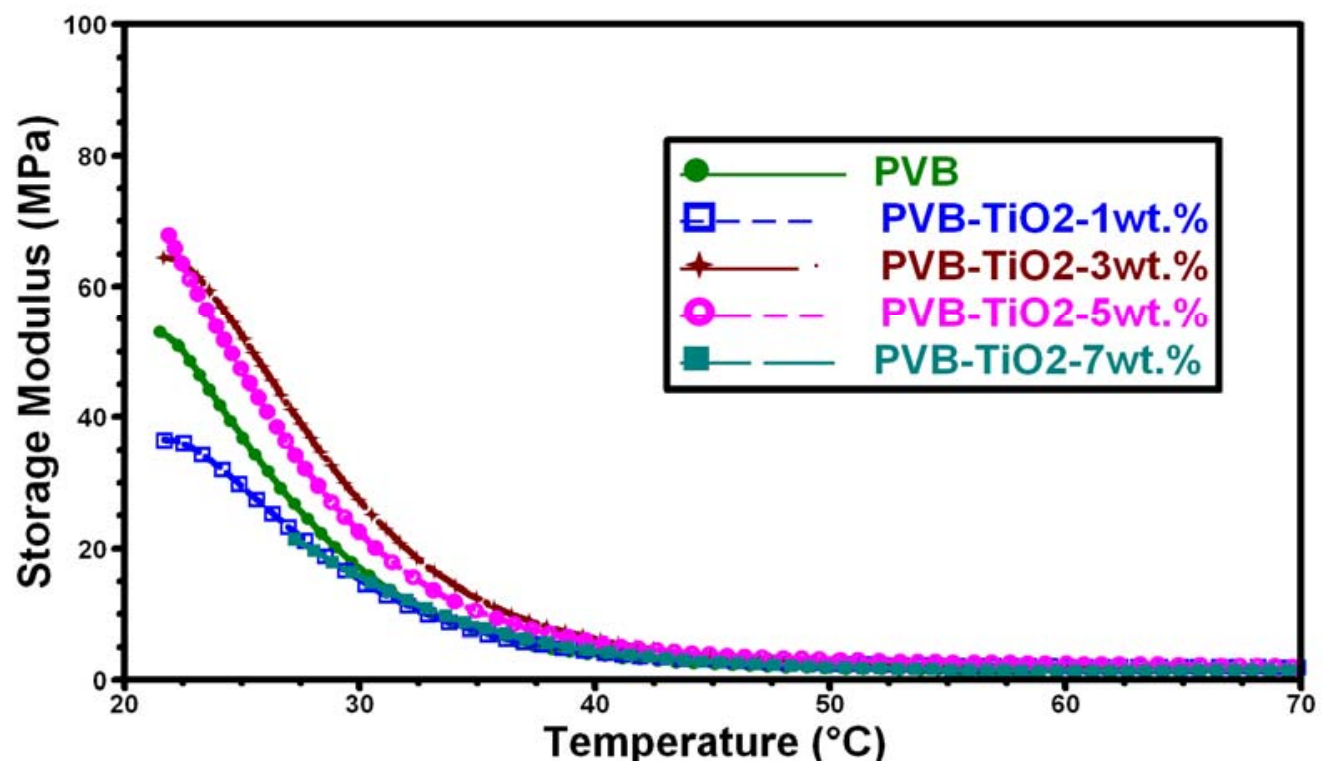

a)

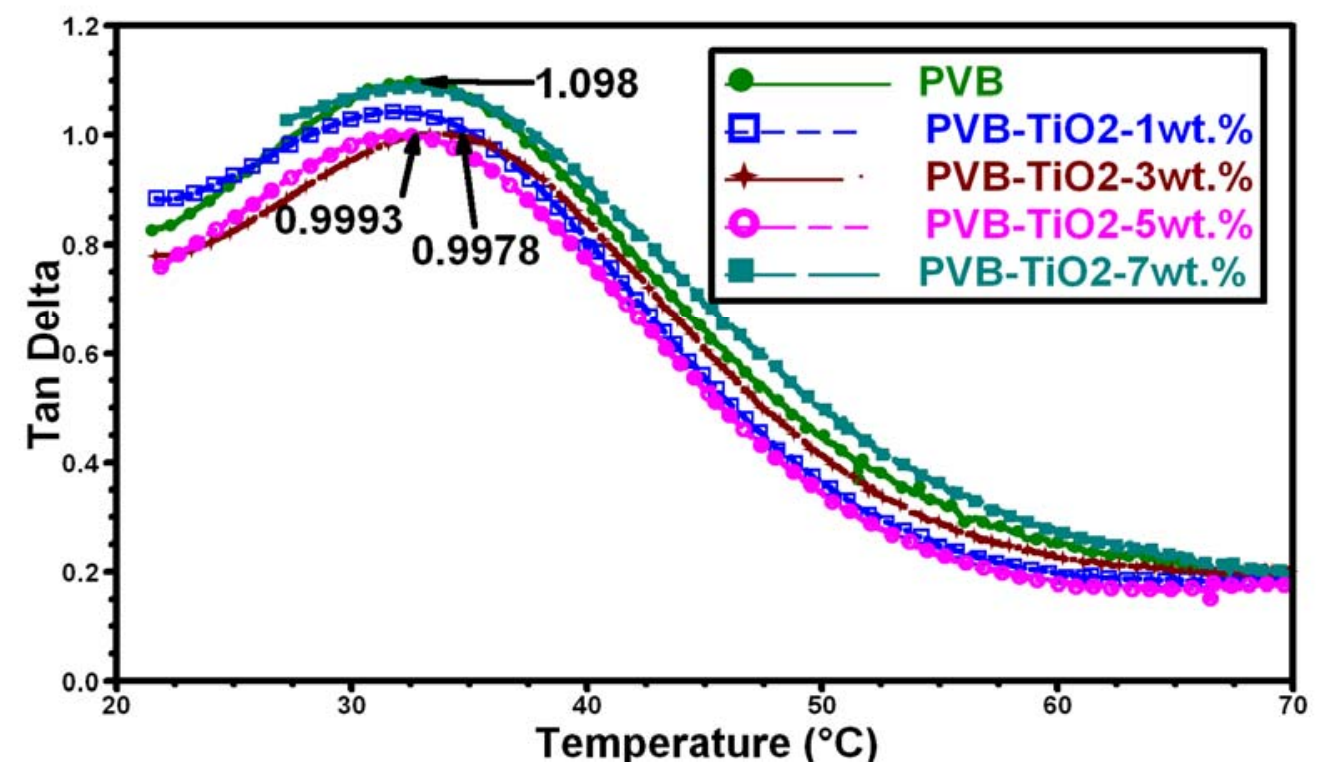

b)

Figure 7-3. Dynamic mechanical properties of nanocomposite containing $\mathrm{TiO}_{2}$ powder: a) storage modul and b) Tangen delta. 


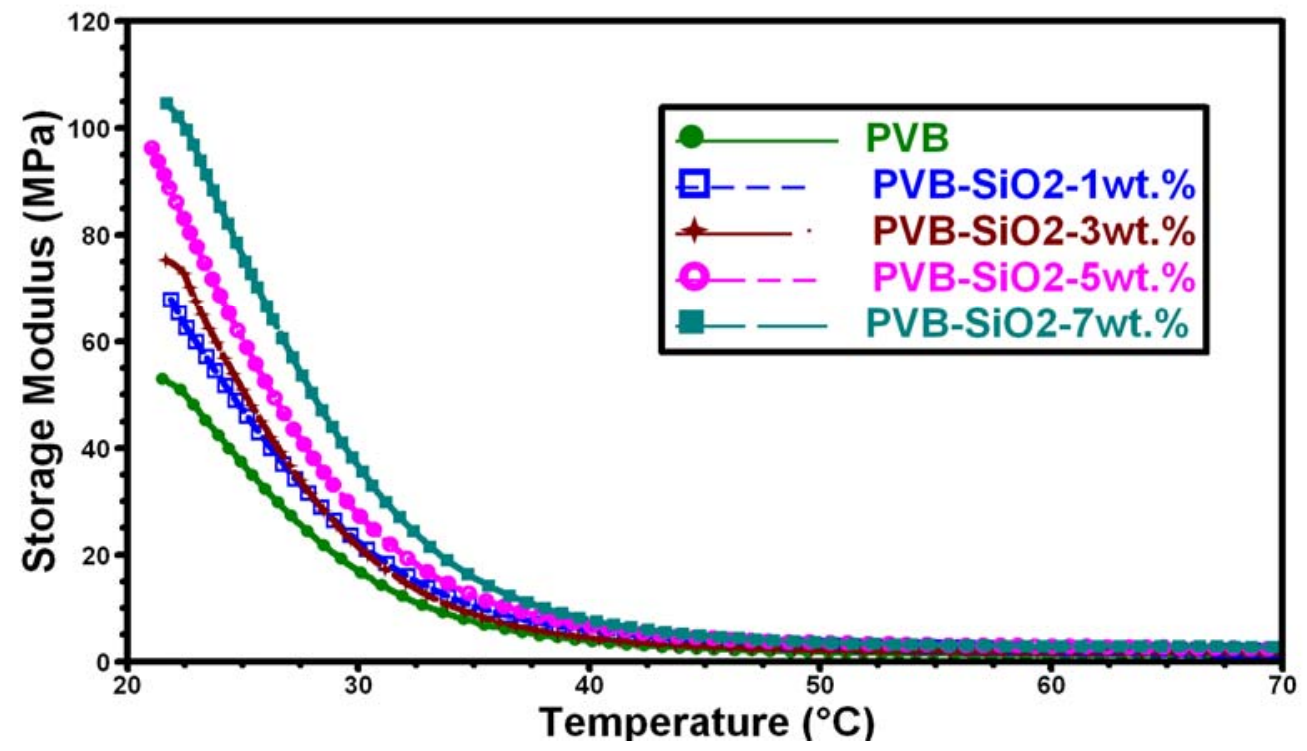

a)

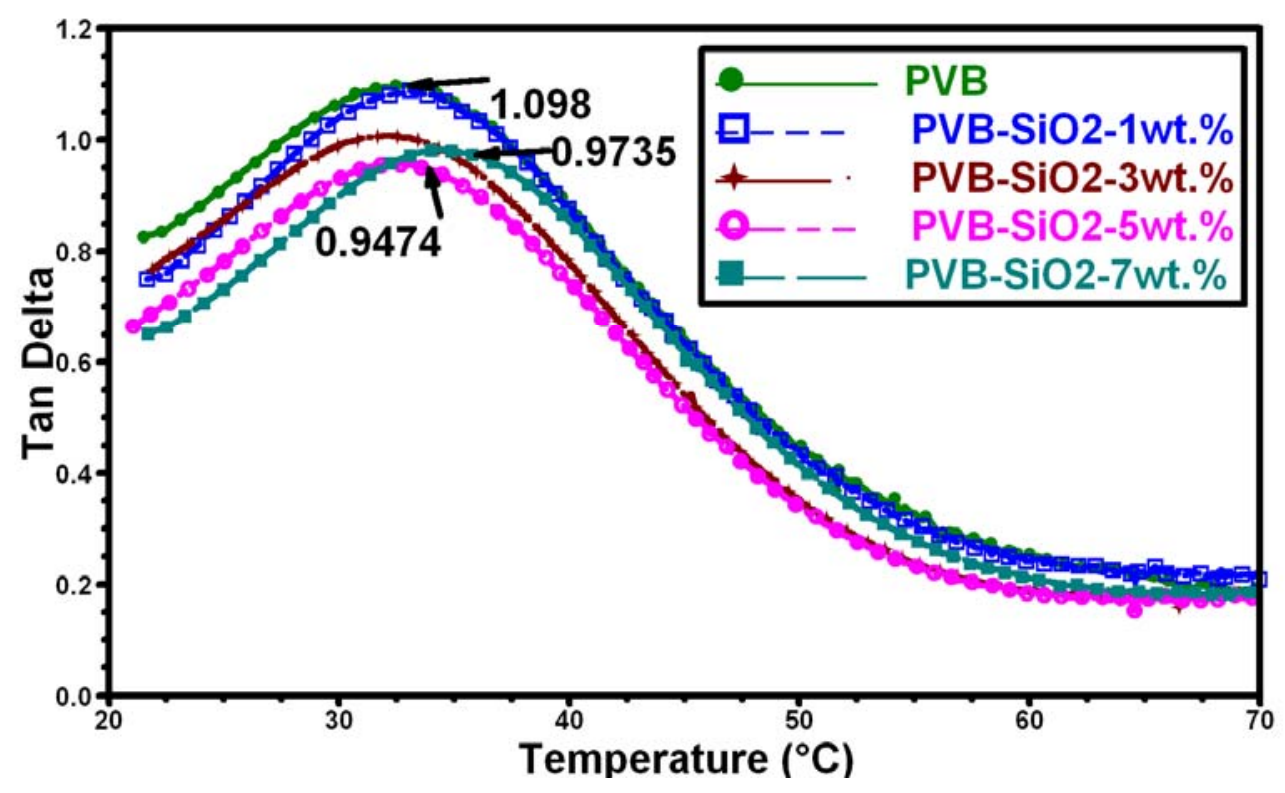

b)

Figure 7-4. Dynamic mechanical properties of nanocomposite containing colloidal $\mathrm{SiO}_{2}$ a) storage modul and b) Tangen delta. 


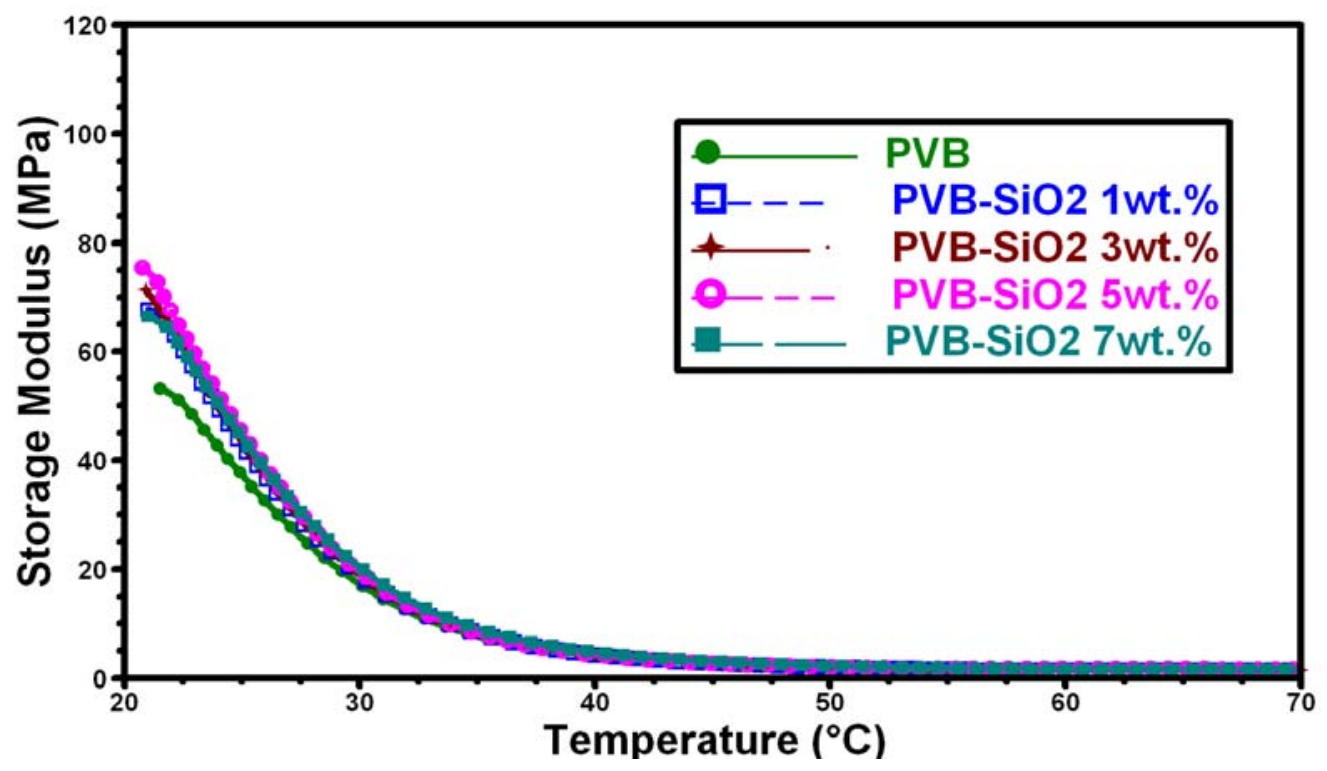

a)

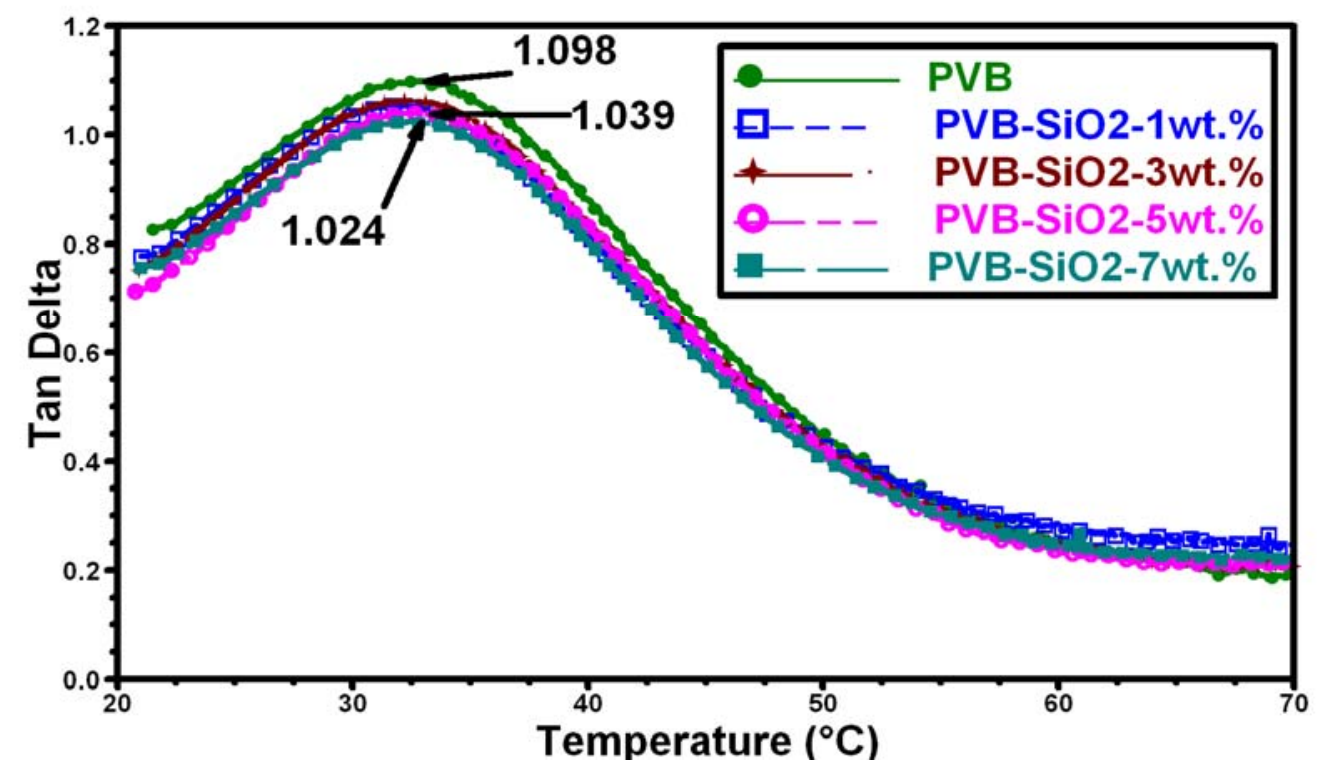

b)

Figure 7-5. Dynamic mechanical properties of nanocomposite containing $\mathrm{SiO}_{2}$ powder: a) storage modul and b) Tangen delta. 
The ratio of loss and storage modulus (Tan Delta) can be thought of as a standardized molecular mobility term called tangent delta (loss tangent). A high tangent delta indicates higher molecular mobility in the material. As temperature increases and the material approaches the rubbery state, the tangent delta value and the molecular mobility increase. From Figures. 7-2 up to 7-5 it is obvious that the addition of silica and titania lead to small Tan Delta reduction, with a slight higher decrease in sol silica and titania. This implies that dissolving the PVB in ethanol and dispersing the nanoparticles in ethanol contributes to higher storage modulus and lower Tan Delta of composites.

Table 7-1. DMA results for PVB and nanocomposite materials

\begin{tabular}{|c|c|c|}
\hline Sample & $E^{\prime}{ }_{22^{\circ} \mathrm{C}}(\mathrm{MPa})$ & $\mathrm{T}_{g}\left({ }^{\circ} \mathrm{C}\right)$ \\
\hline PVB & 51.22 & 31.73 \\
\hline \multicolumn{3}{|c|}{$\mathrm{TiO}_{2}$ powder } \\
\hline PVB-TiO $2-1 w t \%$ & 36.42 & 33.90 \\
\hline PVB-TiO $2-3 w t \%$ & 64.23 & 34.66 \\
\hline PVB-TiO $2-5 w t \%$ & 65.57 & 32.62 \\
\hline $\mathrm{PVB}-\mathrm{TiO}_{2}-7 \mathrm{wt} \%$ & 27.33 & 34.35 \\
\hline \multicolumn{3}{|c|}{$\mathrm{TiO}_{2}$ sol } \\
\hline $\mathrm{PVB}-\mathrm{TiO}_{2}-1 \mathrm{wt} \%$ & 53.73 & 33.39 \\
\hline $\mathrm{PVB}-\mathrm{TiO}_{2}-3 \mathrm{wt} \%$ & 59.62 & 34.44 \\
\hline $\mathrm{PVB}-\mathrm{TiO}_{2}-5 \mathrm{wt} \%$ & 78.66 & 35.32 \\
\hline 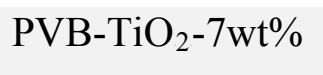 & 65.14 & 36.20 \\
\hline \multicolumn{3}{|c|}{$\mathrm{SiO}_{2}$ powder } \\
\hline $\mathrm{PVB}-\mathrm{SiO}_{2}-1 w \mathrm{t} \%$ & 66.02 & 32.50 \\
\hline $\mathrm{PVB}-\mathrm{SiO}_{2}-3 \mathrm{wt} \%$ & 66.73 & 33.40 \\
\hline PVB-SiO ${ }_{2}-5 w t \%$ & 71.29 & 34.01 \\
\hline $\mathrm{PVB}-\mathrm{SiO}_{2}-7 \mathrm{wt} \%$ & 65.35 & 32.49 \\
\hline
\end{tabular}




\begin{tabular}{|c|c|c|}
\hline PVB-SiO $2-1 w t \%$ & 67.91 & 32.92 \\
\hline $\mathrm{PVB}-\mathrm{SiO}_{2}-3 w \mathrm{t}^{\%} \%$ & 75.16 & 33.76 \\
\hline PVB-SiO $2-5 w t \%$ & 94.83 & 34.13 \\
\hline $\mathrm{PVB}-\mathrm{SiO}_{2}-7 \mathrm{wt} \%$ & 99.40 & 36.10 \\
\hline
\end{tabular}

The addition of $\mathrm{SiO} 2$ and $\mathrm{TiO} 2$ in the powder form leads to higher modulus in comparison to the neat PVB with the maximal increase in storage modulus of about 39 and $28 \%$ for the nanocomposites with $5 \mathrm{wt} \%$ of nanoparticle loading. When sol $\mathrm{TiO} 2$ particles are used, the highest increase of storage modulus of about $54 \%$ is achieved for $5 \mathrm{wt} \%$ particle loading, while for sol $\mathrm{SiO} 2$, the storage modulus increases with the addition of nanosilica with the largest increase of about $99 \%$ observed for $7 \mathrm{wt} \%$ loading. This increase is certainly not only the consequence of favorable dispersion of sol silica but also is due to the low softing point of PVB films enabling the fully wetting of reinforcing particles. Due to the fact that titania particles (neat) were not treated, the low value for $7 \mathrm{wt} \%$ loading titania is attributed to the inability of the processing route to disperse highly agglomerated particles. When $\mathrm{TiO} 2$ sol is used as reinforcement, modulus values are higher showing that the applied procedure is more appropriate for nanoparticle dispersion. The contributing factor could be the dimensions of the primer particles which were lower for nanosilica powders. By comparison of the results for neat and sol nanoparticles, i.e. in both cases sol have higher properties than the neat powders, it is interesting to observe that the influence of the nanopowder preparation procedure is more detrimental to the storage modulus than the starting dimensions of nanoparticles.

As mentioned, PVB is manufactured by condensation of polyvinyl alcohol with n-butyraldehyde in an acid medium. The condensation reaction produces 1,3-dioxane rings but it is not taken to completion leaving some non-reacted hydroxyl groups which promote good adhesion to the glass substrate on lamination. Since polyvinyl alcohol is produced from the hydrolysis of poly (vinyl acetate) (PVAc) there is a limited amount of acetate groups also present, which could slightly differ in dependence on the selected manufacturer. This process does not lead to complete conversion to poly (vinyl butyral), 
but, instead, results in a multifunctional polymer containing residual acetate and hydroxyl groups:, Figure 7-6

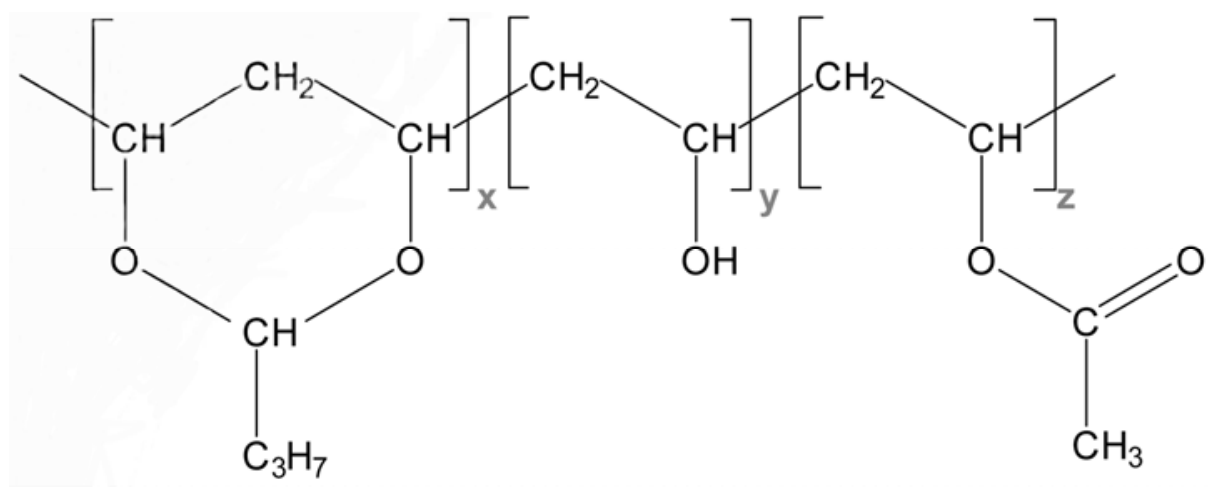

Figure 7-6 Structural formula poly (viny1 butyral)

The composition of commercial grade PVB is typically: $\mathrm{x}$ (acetal content) > $75 \%$, y (residual PVA content $)=18-22 \%$, and $\mathrm{z}$ (PVAc content $)<3 \%$. PVB adheres to inorganic oxides through interactions between oxide surfaces and polymer hydroxyl groups. In addition, the carbonyl oxygens of acetate groups present in PVB can interact with oxide surfaces through hydrogen bonding with surface hydroxyls.194 This could contribute to the assumption that $\mathrm{SiO} 2$ colloidal sol, with an excess of hydroxyl groups will have promoted adhesion with the matrix due to non-reacted hydroxyl groups, thus leading to the improved mechanical properties of nanocomposites with PVB matrix.

Addition of nanoparticles could tune and enhance the mechanical properties of PVB recycled from glass lamination in the glass recycling industry, since it is a waste of an expensive, valuable and non-renewable commodity as well as energy and land. Another possible implementation of such produced PVB nanocomposites could be in the addition to composites reinforced with Kevlar for body armor materials. In the next part of the study, the colloidal sol of $\mathrm{SiO} 2$ and $\mathrm{TiO} 2$ were added to $\mathrm{PVB}$ and subsequently the formed nanocomposite was interlayered with the PVB-Kevlar fabric layers to produce hybrid composites. Figure 7-7 shows photographs of neat PVB, nanocomposites with sol titania and silica as well as hybrid nanocomposite sample ( $\mathrm{SiO} 2 \mathrm{sol})$ with Kevlar reinforcement. 


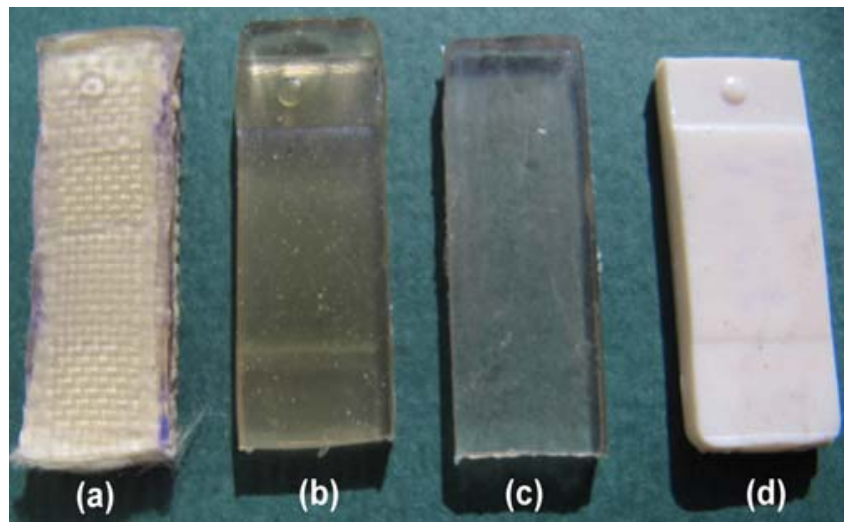

Figures 7-7. Photographs of selected samples: a) hybrid nanocomposite; b) nano$\mathrm{SiO}_{2} / \mathrm{PVB}$; c) neat PVB; d) nano- $\mathrm{TiO}_{2} / \mathrm{PVB}$.

Figure 7-7 shows storage modulus and Tan Delta of PVB, PVB-Kevlar fabric and nanocomposite reinforced PVB-Kevlar versus the nanoparticle content and method of preparation. Table 7-2 presents DMA results for PVB, composite with Kevlar fabric and composite with the introduction of nanocomposite.

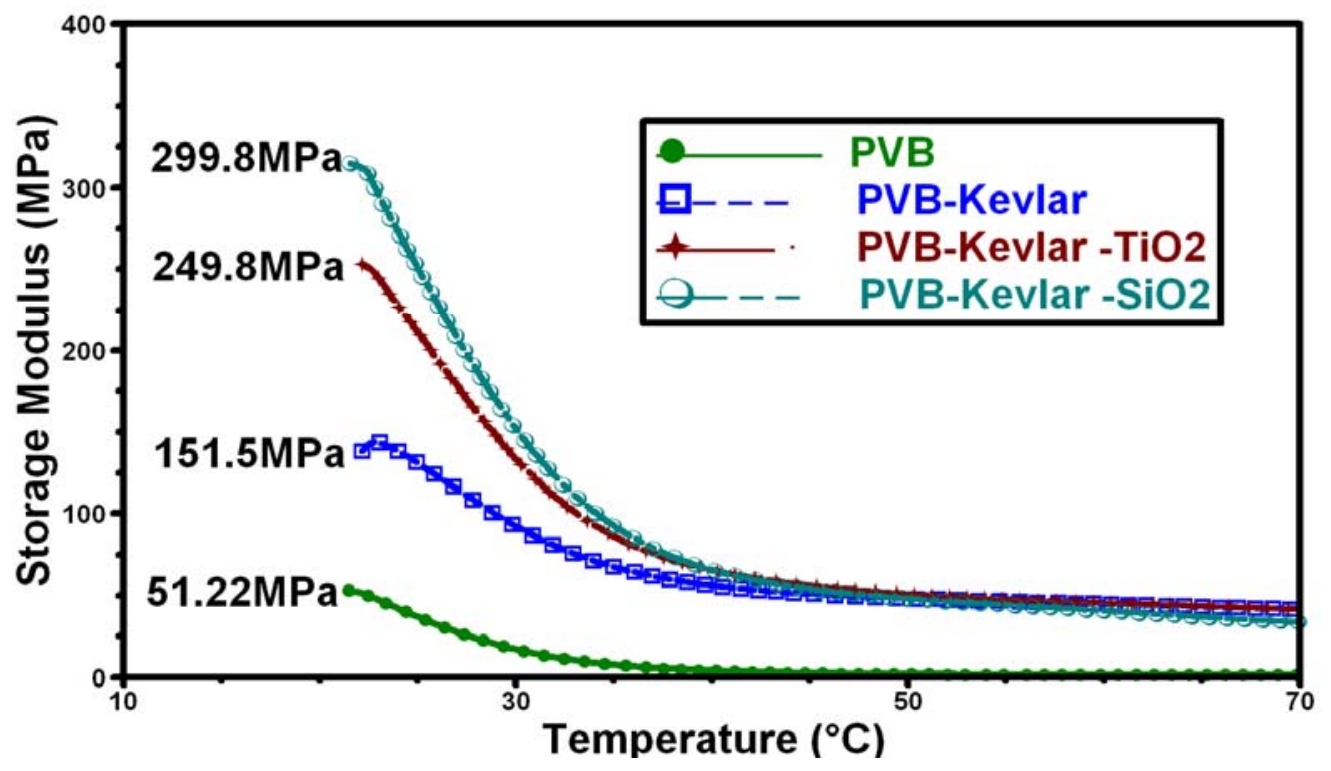

a) 


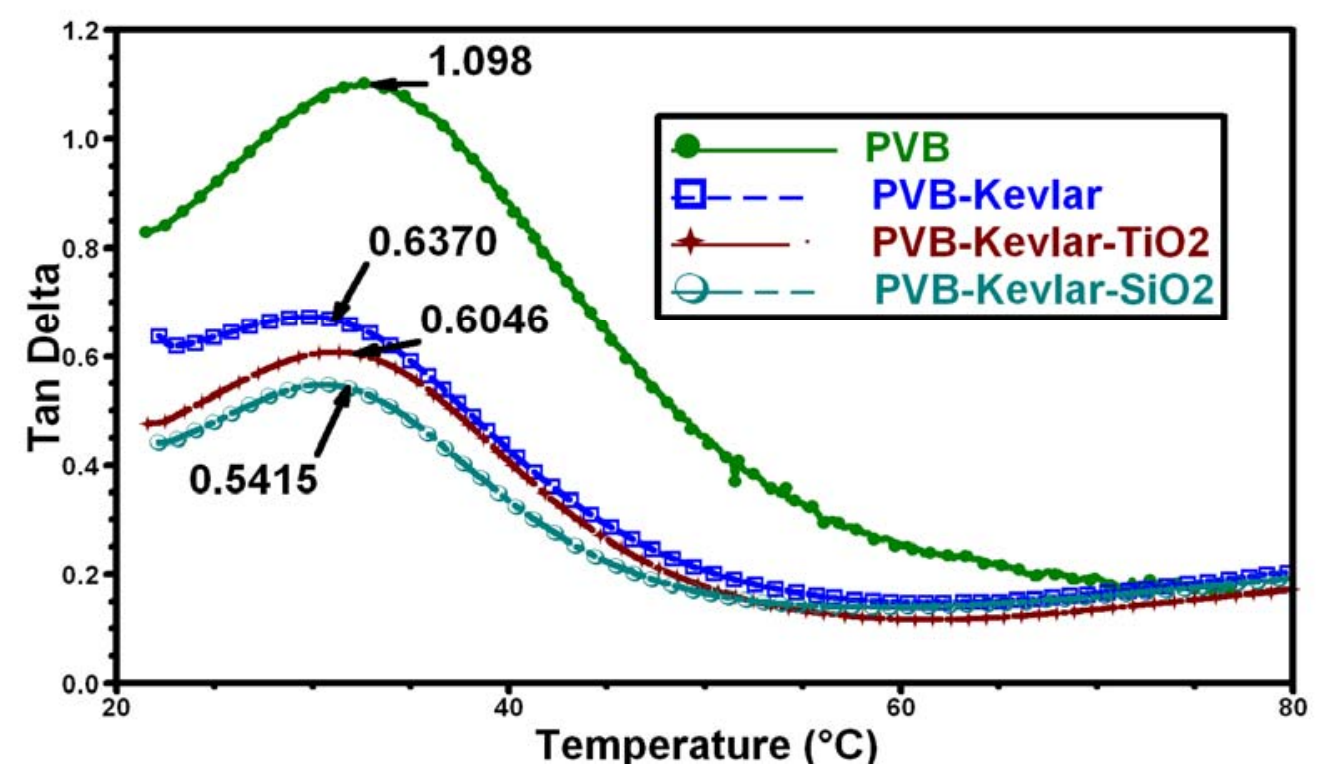

b)

Figures 7-8. Dynamic mechanical properties of neat PVB, neat PVB-Kevlar and nanocomposite reinforced PVB-Kevlar: a) storage modul and b) Tangen delta.

Table 7-2. DMA results for pure PVB, neat PVB-Kevlar and nanocomposite reinforced PVB-Kevlar.

\begin{tabular}{|c|c|c|}
\hline Sample & $E^{\prime}{ }_{22^{\circ} \mathrm{C}}(\mathrm{MPa})$ & $\mathrm{T}_{g}\left({ }^{\circ} \mathrm{C}\right)$ \\
\hline PVB & 51.22 & 31.73 \\
\hline PVB-Kevlar & 151.5 & 31.80 \\
\hline PVB-Kevlar- $\mathrm{TiO}_{2}$ & 249.8 & 31.06 \\
\hline PVB-Kevlar-SiO ${ }_{2}$ & 299.8 & 32.74 \\
\hline
\end{tabular}

Nanocomposites have significantly improved the storage modulus and have just a slight influence on the glass transition temperature of the Kevlar fabric reinforced 
composites. Addition of $5 \mathrm{wt} \%$ sol silica and titania lead to the remarkable increase of modulus for about 65 and 98\%, respectively (Figres 7-8 and Table 7-2). The improvement of $\mathrm{Tg}$ was almost negligible in Kevlar reinforced composites, while the slight improvement could be observed with the addition of nanoparticles. Largest contribution of nanoreinforcements in lowering the $\mathrm{Tg}$ was observed for $7 \mathrm{wt} \%$ loading of $\mathrm{TiO} 2$ sol and $\mathrm{SiO} 2$ sol. Tan Delta for neat PVB is 1.098 while the values for tested composites exhibit a significant decrease, i.e. for PVB-Kevlar 0.6370 and for titania and silica sol nanocomposite with PVB-Kevlar 0.6046 and 0.5415 , respectively. This implies that the molecular mobility is significantly decreased in tested hybrid composites. 


\section{The Viscoelastic Properties Of Modified Thermoplastic Impregnated Multi-Axial Aramid Fabrics}

\section{8-1 Introduction}

In recent years, multi-axial fabrics have found increased implementation in the construction of various composite structures. These fabrics consist of one or more layers of long fibers held in place by a secondary non-structural stitching thread, which is usually a polyester due to their combination of appropriate fiber properties (for binding the fabric together) and cost. The stitching process allows a variety of fiber orientations, beyond the simple $0 / 90$ of woven fabrics, to be combined into one fabric. The two key improvements with stitched multi-axial fabrics over woven types are: (a) better mechanical properties, primarily from the fact that the fibers are always straight and non-crimped, and that more orientations of fibers are available from the increased number of layers of fabric; (b) improved component build speed based on the fact that fabrics can be made thicker and with multiple fibers orientations so that fewer layers need to be included in the laminate sequence. The use of flexible resins with fabrics woven from high performance fibers to fabricate composite armor panels has been the subject of much research and many patents. ${ }^{195} 196197198199$

The general consensus of these patents is that, the more flexible the resin system used in the fabrication of the composite is, the better will be the ballistic properties of the resulting panel. Poly(vinyl butyral), PVB, was added instead of a phenolic resin to a helmet composite in order to introduce elongation and flexibility into the resin to improve the ballistic properties while maintaining the rigidity required for a helmet ${ }^{200}$.

The addition of nanoscale reinforcements to polymer matrices leads to composites with significantly improved mechanical properties in comparison to the pure matrix material 201202203 . It is expected that the addition of nanoparticle reinforcements could lead to an enhancement of the mechanical properties of body armor material, mainly consisting of Kevlar®-DuPont fabric hybrid composites. 
Traditionally, flexible body armor has been developed by using a mixture of silica and ethylene glycol (EG) or poly(ethylene glycol) (PEG) impregnated with Kevlar ${ }^{\circledR}$ fabrics. In 2003, Lee et al., reported on the ballistic impact characteristics of Kevlar® fabrics impregnated with spherical nano-sized silica particles (120 or $450 \mathrm{~nm}$ diameter, concentration of about $40 \mathrm{wt} . \%$ dispersed in ethylene glycol) with a flexible and penetration-resistant composite ${ }^{204}$. In the approach reported by Mahfuz et al., $7 \mathrm{~nm}$ amorphous- and $30 \mathrm{~nm}$ crystalline-silica were dispersed directly into a mixture of PEG and ethanol through a sonic cavitation process (55 wt. \% $\mathrm{SiO} 2$ in PEG). For improved bonding between the silica and PEG, the particles were treated with aminopropyltrimethoxy silane, which significantly improved the performance of the composites ${ }^{205}$. Hassan et al. prepared Kevlar and Nylon soaked in shear thickening fluid, STF/ethanol solution, to make an STF/fabric composite with 40 wt. \% of SiO2 particles. The results showed that the STF-impregnated fabrics had better penetration resistance, as compared to the neat fabrics, without affecting the fabric flexibility ${ }^{206}$. Tan et al. investigates the ballistic performance of Twaron CT615 plain-woven fabric impregnated with a silica colloidal water suspension. Results show that systems with 40 wt. \% SiO2 particle concentration yield the highest ballistic limit for single, double and quadruple ply systems, with the double ply system showing the greatest improvement. ${ }^{207}$ A new multi-axial aramid fabric mat, manufactured from p-aramid fibers, was introduced in the processing of hybrid laminated multi-axial composites with the addition of a low content of nanosilica particles by dispersion of the particles in a PVB solution. Dynamic mechanical analysis of fabricated multi-axial composites and hybrid multi-axial nanocomposites was employed in order to determine the optimal composition and content of materials for composites with improved viscoelastic properties.

\subsection{Experimental}

\subsubsection{Materials}

Multi-axial aramid fabrics (Martin Ballistic Mat, Ultratex, Serbia) were used with p-aramid fiber type Twaron (1000 dtex: $1680 \mathrm{f} 1000$ twist: 0) (TEIJIN ARAMID BV). "Weave and Stitch" is the basic way of manufacturing multi-axial fabrics, whereby the $+45^{\circ}$ and $-45^{\circ}$ layers could be weaved by weft unidirectionals and then 
skewed to $45^{\circ}$. A warp or weft unidirectional could also be used unskewed to form $0^{\circ}$ and $90^{\circ}$ layers. If both $0^{\circ}$ and $90^{\circ}$ layers are present in a multi-layer stitched fabric, then this can be provided by a conventional 0/90 woven fabric. Due to the fact that heavy rovings can be used to make each layer, the weaving process is relatively fast, as is the subsequent stitching together of the layers via a simple stitching frame.

In order to produce a quadraxial (four-layer: $+45,0,90,-45$ ) fabric by this method, a weft unidirectional was woven and skewed in one direction for the $+45^{\circ}$ layer, and $-45^{\circ}$ layer. The $0^{\circ}$ and $90^{\circ}$ layers would appear as a single woven fabric. These elements were then stitched together on a stitching frame to produce the final four-axis fabric (Figure 8-1 (a)). These fabrics contained four layers of fibers with varying orientation stitched together with a lightweight polyester thread (Korteks, Turkey).

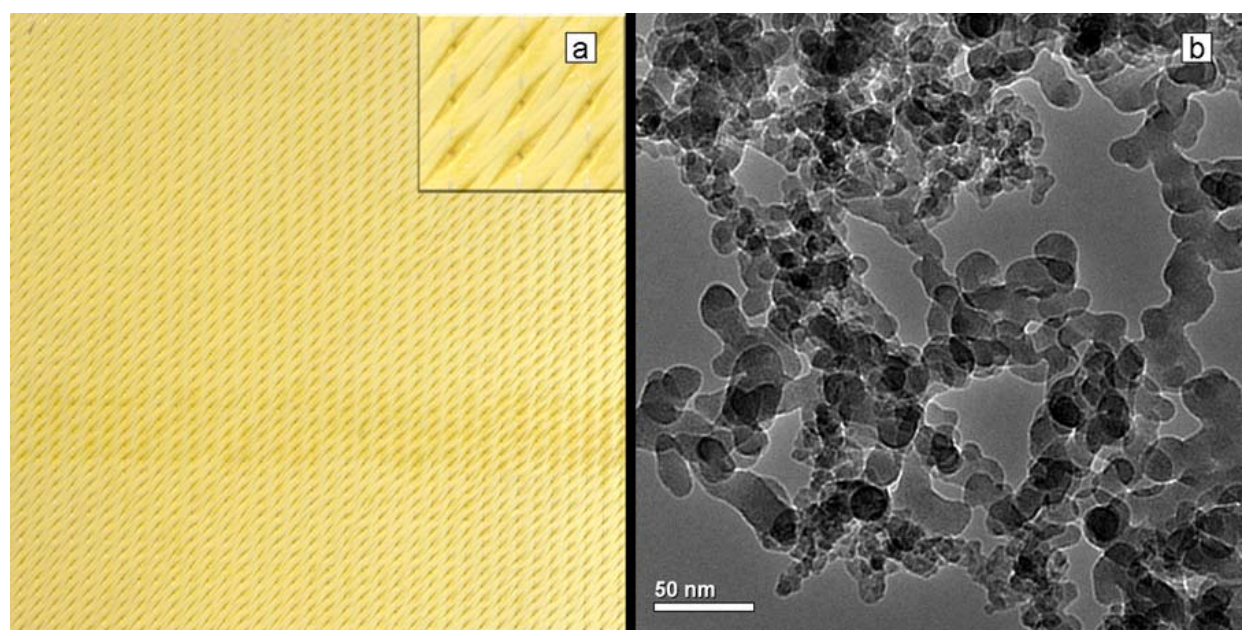

Figure 8-1. (a) Multi-axial aramid fabrics (Martin ballistic mat) and (b) Aerosil 380

Figure 8-1 (b) shows transmission electron microscopy (TEM) photo of the asreceived silica nanoparticles with an average particle diameter of about $7 \mathrm{~nm}$ (EvonikDegussa AG, Aerosil 380). The silica nanoparticles were heated in vacuum at $120{ }^{\circ} \mathrm{C}$ for $24 \mathrm{~h}$ to remove adsorbed compounds and then cooled to room temperature.

Three types of polymer matrix foils were used for this study. Thermoplastic adhesive film is a polyester-based thermoplastic polyurethane TPU (Desmopan, Bayer, Germany), with a density of $1.18 \mathrm{~g} / \mathrm{cm}^{3}$, melting range $100-130{ }^{\circ} \mathrm{C}$ and a minimal bondline temperature of $135{ }^{\circ} \mathrm{C}$. Modified milky white PVB film (PVB/PE) based on polyolefins with a melting range $115-130{ }^{\circ} \mathrm{C}$ was donated by Zhejiang Lifeng Plastic \& Rubber Co, China. PVB modified phenol resin (PVB/PH) was used for ballistic resin 
films FT 2102 (SGL GROUP-The Carbon Company, Germany) with the cure cycle properties: pressure: $20 \mathrm{bar}$, temperature: $150-170{ }^{\circ} \mathrm{C}$ and cure time $10-60 \mathrm{~min}$.

Additionally, a polymer powder, as the fourth matrix type for this study, PVB (Mowital B75H, Kuraray Specialities Europe), which is manufactured by condensation of poly(vinyl alcohol) with n-butyraldehyde in an acid medium. The condensation reaction produces 1,3-dioxane rings but has not been completed thus leaving some nonreacted hydroxyl groups, which promote good adhesion to the glass substrate on lamination. Since poly(vinyl alcohol) is produced from the hydrolysis of poly(vinyl acetate) (PVAc), there is a limited amount of acetate groups, which could slightly differ depending on the selected manufacturer. ${ }^{208}$ This process does not lead to complete conversion to poly(vinyl butyral), but, instead, results in a multifunctional polymer containing residual acetate and hydroxyl groups (Figure 8-2):

(a)

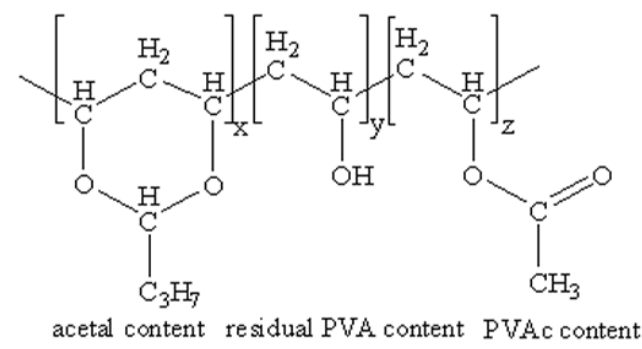

\begin{tabular}{|lll|}
\hline $65-88$ wt. $-\%$ & $11-27$ wt. $-\%$ & $1-8$ wt. $-\%$ \\
\hline
\end{tabular}

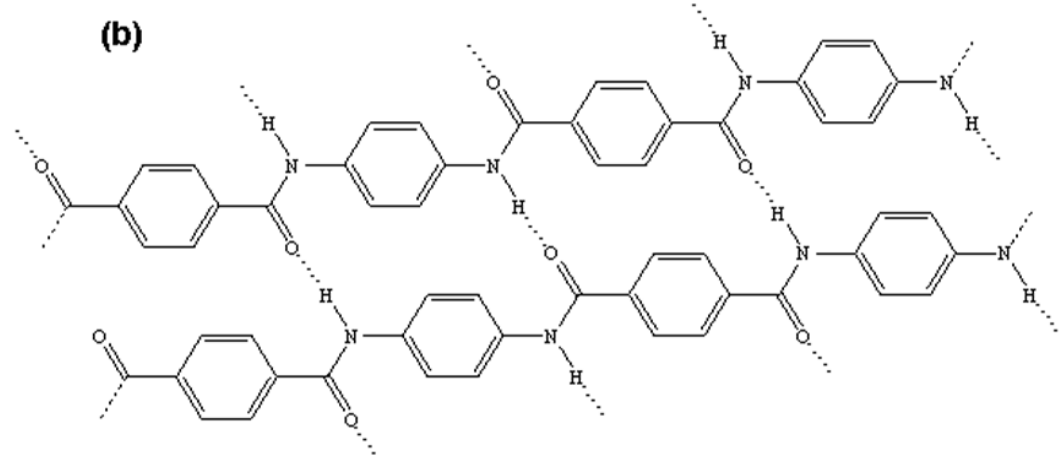

Figure 8-2. Chemical structure of (a) PVB ${ }^{\circledR}$ Mowital B75H [14] and (b) p-aramid fiber, Twaron $^{209}$

\subsubsection{Composite preparation processes}

Preparation of multi-axial p-aramid fabric composites with films (method a). Composite samples with different modified thermoplastic films (PVB/PH, PVB/PE and TPU) were prepared and denoted as $p$-aramid/PVB/PH, $p$-aramid/PVB/PE and $p$ - 
aramid/TPU. For this study, three multi-axial fabrics with modified thermoplastics films were produced (the contents of modified thermoplastic films in fabricated composite samples were 6.34 wt. \%, 4.89 wt. \% and 5.34 wt. \%, with only one film between the $p$ aramid fabrics). Thermoplastic commercial films (foils) had different thickness, which induced their various content in the aramid fabric reinforced composite.

\section{Preparation of modified multi-axial p-aramid fabric composites (method b).}

The modification procedure of silica nanoparticles using $\gamma$-aminopropyl triethoxysilane (AMEO) is derived from the surface area of the Aerosil nanoparticles $\left(380 \mathrm{~m}^{2} / \mathrm{g}\right){ }^{210}$ Based on the fact that one gram of silane covers a surface area of $353 \mathrm{~m}^{2}$, silane was added to a 95 wt. \% ethanol - 5 wt. \% water mixture to yield a 2 wt. \% final concentration of silane. Around $10 \mathrm{~min}$ was allowed for hydrolysis and silanol formation. After addition of the nanoparticles, the solution was homogenized with a magnetic mixer for $30 \mathrm{~min}$ in order to break up the major agglomerates. After $3 \mathrm{~h}$ sonication, the particles were allowed to settle at the bottom of the beaker and the supernatant was carefully decanted. The particles were rinsed with ethanol $(3 \mathrm{x})$ and dried in an oven at $110^{\circ} \mathrm{C}$. Further, a new method for nanocomposite preparation is introduced in that the functionalized silica nanoparticles were then dispersed in a mixture of 95 wt. \% ethanol and PVB (5 wt. \%) previously stirred overnight with a magnetic stirrer and the mixture was used to permeate 4 layers of multi-axial aramid fabric cut in dimensions of $29.7 \mathrm{~cm} \times 21 \mathrm{~cm}$. The impregnated fabric was then let to stand for about 24 hours whereby the ethanol evaporated. The processing conditions were the same for all impregnated fabrics. Thus, the hybrid laminated composite samples were hot pressed using N 840 D Hix Digital Press (Hix, Corp., USA) at a temperature of $170{ }^{\circ} \mathrm{C}$ for $30 \mathrm{~min}$ under a pressure of 4 bar.

\subsubsection{Characterization}

Fourier Transform Infrared (FTIR) spectra of unmodified, modified silica nanoparticles and AMEO silane in $\mathrm{KBr}$ pellets were obtained in transmission mode between 400 and $4000 \mathrm{~cm}-1$ with a resolution of $4 \mathrm{~cm}^{-1}$ using a BOMEM spectrophotometer (Hartmann \& Braun, MB-series).

The functional groups on the surfaces of pure PVB, the p-aramid fabrics and the modified p-aramid fabrics were analyzed by attenuated total reflection FTIR (ATR- 
FTIR) spectroscopy. For this purpose, the FTIR spectrometer was coupled with an ATR model Smart Orbit Nicolet 5700. Thirty-two scans with $4 \mathrm{~cm}^{-1}$ resolution were performed for each case in the reflection mode.

The thermal properties of the films were examined in a nitrogen atmosphere from room temperature to $200-300^{\circ} \mathrm{C}$ at a heating rate of $10^{\circ} \mathrm{C} / \mathrm{min}$ using a differential scanning calorimeter (DSC, Q10 TA Instruments, USA). Samples (5-10 mg) were hermetically sealed in an aluminum pan and placed in the DSC cell together with an empty aluminum pan as the reference and heated with a continuous nitrogen purge at a flow of $50 \mathrm{ml} / \mathrm{min}$.

Dynamic mechanical analysis (DMA, Q800 TA Instruments, USA) was conducted in a dual cantilever mode at a frequency of $1 \mathrm{~Hz}$. The temperature ranged from $30^{\circ} \mathrm{C}$ to $170{ }^{\circ} \mathrm{C}$ with a heating rate of $3{ }^{\circ} \mathrm{C} / \mathrm{min}$ for the determination of the storage modulus (E') and loss tangent $(\tan \delta$ ). The samples size was approximately $60 \mathrm{~mm} \times 13$ $\mathrm{mm} \times 3 \mathrm{~mm}$.

Transmission electron microscopy (TEM) was performed on a TECNAI-FEG F20 electron microscope at $200 \mathrm{kV}$. The unmodified and functionalized silica samples were prepared by dispersion in ethanol and dropping the suspension on holey carbon grids. The fabrics and fractured samples (composites) were gold-coated and observed under a scanning electron microscope (JSM 5800 FESEM). Particle distribution in goldcoated fractured composite surfaces were observed using FESEM (Tescan Mira 3).

\subsection{Results And Discussion}

\subsubsection{FTIR study of the origin materials}

The FTIR spectra of unmodified silica nanoparticles (a), amino-functionalized silica nanoparticles (b) and the AMEO silane coupling agent (c) are shown in Figure 8-3. The stretching vibration at $1103 \mathrm{~cm}^{-1}$ and bending vibration at $472 \mathrm{~cm}^{-1}$, originating from $\mathrm{Si}-\mathrm{O}-\mathrm{Si}$ groups, are specific bands for silica nanoparticles. The spectrum of Figure 8-3 (a), silica before modification, shows a broad band at $3431 \mathrm{~cm}^{-1}$ due to the presence of hydroxyl groups on the surface (stretching mode), and three absorption bands at 1635, band-shoulder at 954 and $800 \mathrm{~cm}^{-1}$ because of the presence of moisture 
in the sample ${ }^{211}$. Surface hydroxyl groups could participate in hydrogen bonding with proton-donor and proton-acceptor sites at the polymer matrix and could contribute significantly to a better dispersion of the nanosilica filler.

An appropriate modification of silica particles by AMEO silane assumes that the hydrolysis of silane by the loss of alkoxy groups provides for concomitant chemical reaction with the hydroxyl groups at the silica surface. In the FTIR spectrum of the amino modified silica, Figure 8-3 (b), in addition to the bands originating from $\mathrm{Si}-\mathrm{O}$ vibrations, the weak bands at $2933 \mathrm{~cm}^{-1}$ and $2875 \mathrm{~cm}^{-1}$ were assigned to the asymmetric, vas, and symmetric, vs, stretching modes of $\mathrm{CH} 2$ groups. The peaks at 1593 and 796 $\mathrm{cm}^{-1}$ are attributed to $\delta \mathrm{NH}$ in-plane and out-of-plane deformation vibrations of the $\mathrm{NH} 2$ groups, respectively, which is in agreement with the data reported in the literature. ${ }^{184}$ The broadening of the signal centered at about $3425 \mathrm{~cm}^{-1}$ in Figure 8-3(b) was attributed to overlapped signals of $v \mathrm{OH}$ of the adsorbed water, silanol and $v \mathrm{NH}$ group vibrations. These results indicate that silane was successfully grafted onto the silica surface, thus providing free amino groups which could be reactive sites for chemical reaction with the PVB ester group or physical interaction.

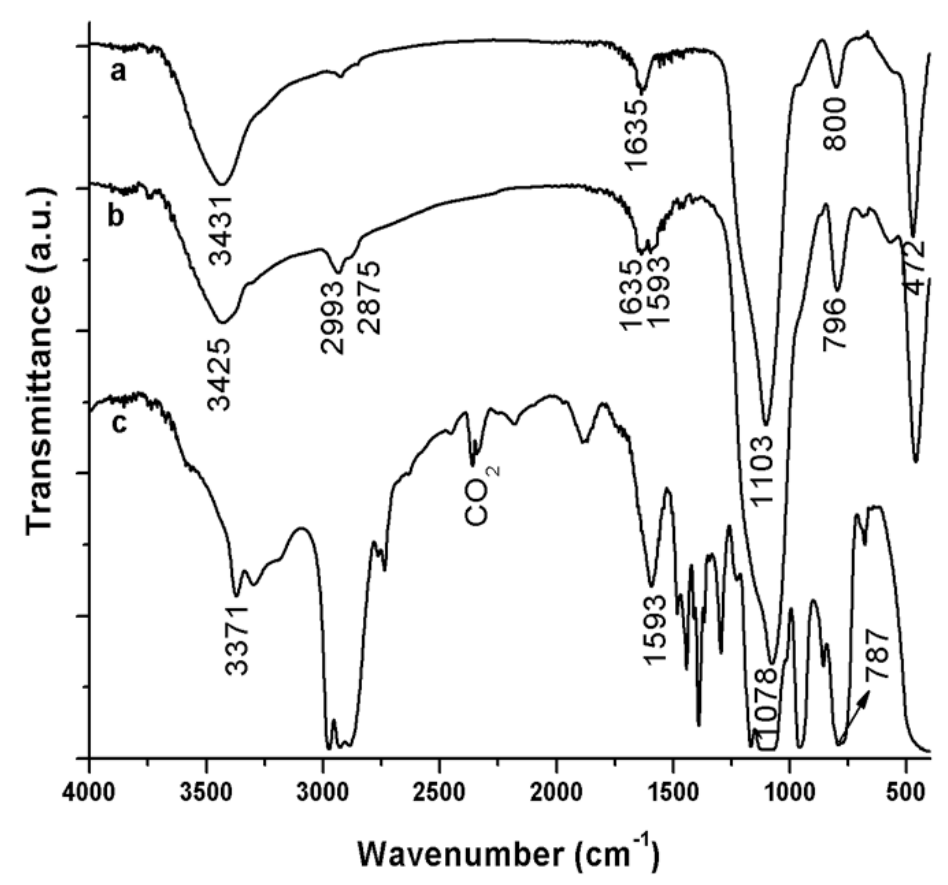

Figure 8-3. FTIR spectra of (a) unmodified silica nanoparticles, (b) aminofunctionalized silica nanoparticles and (c) AMEO silane 


\subsubsection{FTIR Analysis Of The p-Aramid Fabrics}

The FTIR spectrum of the p-aramid fabric is presented in Figure 8-4 (a). The band, appearing at $3305 \mathrm{~cm}^{-1}$, corresponding to the $v \mathrm{NH}$ stretch, was shifted slightly to a lower frequency due to hydrogen bonding between the highly oriented polymer chains along the fiber axis. The peak position was significantly affected by the transconfiguration of the amide group in poly(p-phenylene terephthalamide), which enabled strong hydrogen bonding between the carbonyl oxygen and the $\mathrm{N}-\mathrm{H}$ amide hydrogen. The peaks, corresponding to amide group vibrations were identified as follows: the first peak located at $\approx 1638 \mathrm{~cm}^{-1}$ is related to the $\mathrm{C}=\mathrm{O}$ stretching vibration (usually designated as the amide $\mathrm{I}$ band) overlapped with the $\mathrm{C}=\mathrm{C}$ stretch, the second at $\approx 1535$ $\mathrm{cm}^{-1}$ is related to the combined motion of the $\mathrm{N}-\mathrm{H}$ in-plane bending and $\mathrm{C}-\mathrm{N}$ stretching (amide II), and the last at $1301 \mathrm{~cm}^{-1}$ is related to the $\mathrm{C}-\mathrm{N}$ valence vibration coupled with $\mathrm{N}-\mathrm{H}$ vibrations (amide III). The band at $820 \mathrm{~cm}^{-1}$ corresponds to out-of-plane $\mathrm{C}-\mathrm{H}$ vibrations in an aromatic ring (aromatic para substitution).

\subsubsection{FTIR analysis of PVB}

As shown in Figure 8-4 (b), the FTIR spectrum of PVB reveals a peak at 3470 $\mathrm{cm}^{-1}$, assigned to $\mathrm{OH}$ group stretching modes. However, the broad band shape of the $3470 \mathrm{~cm}^{-1}$ peak indicates different kinds of hydrogen bonding between the $\mathrm{O}-\mathrm{H}$ moieties at the polymer chains. Hydrogen bonding affects $\mathrm{OH}$ group environment which is reflected in vibration frequency of the $\mathrm{O}-\mathrm{H}$ moieties causing a distribution of intensities in the frequency range $3000-3700 \mathrm{~cm}^{-1}$. On the other hand, free $\mathrm{O}-\mathrm{H}$ groups, absent from hydrogen bonding, resonate in narrow frequency regions and are characterized by sharp peaks. The bands at $2961 \mathrm{~cm}^{-1}$ and $2872 \mathrm{~cm}^{-1}$ corresponded to the asymmetric and symmetric stretching vibration of $\mathrm{CH} 2$ and $\mathrm{CH} 3$ groups, respectively. The absorption bands observed at $1736 \mathrm{~cm}^{-1}$ correspond to the ester $\mathrm{C}=\mathrm{O}$ stretching vibration, while the bands at 1248 and $1144 \mathrm{~cm}-1$ correspond to the vas and vs valence vibrations of the ester $\mathrm{C}-\mathrm{O}$ overlapped with the cyclic ether (backbone). An 
additional peak which corresponds to the $\mathrm{C}-\mathrm{OH}$ stretching vibration was observed at $1000 \mathrm{~cm}^{-1}$.

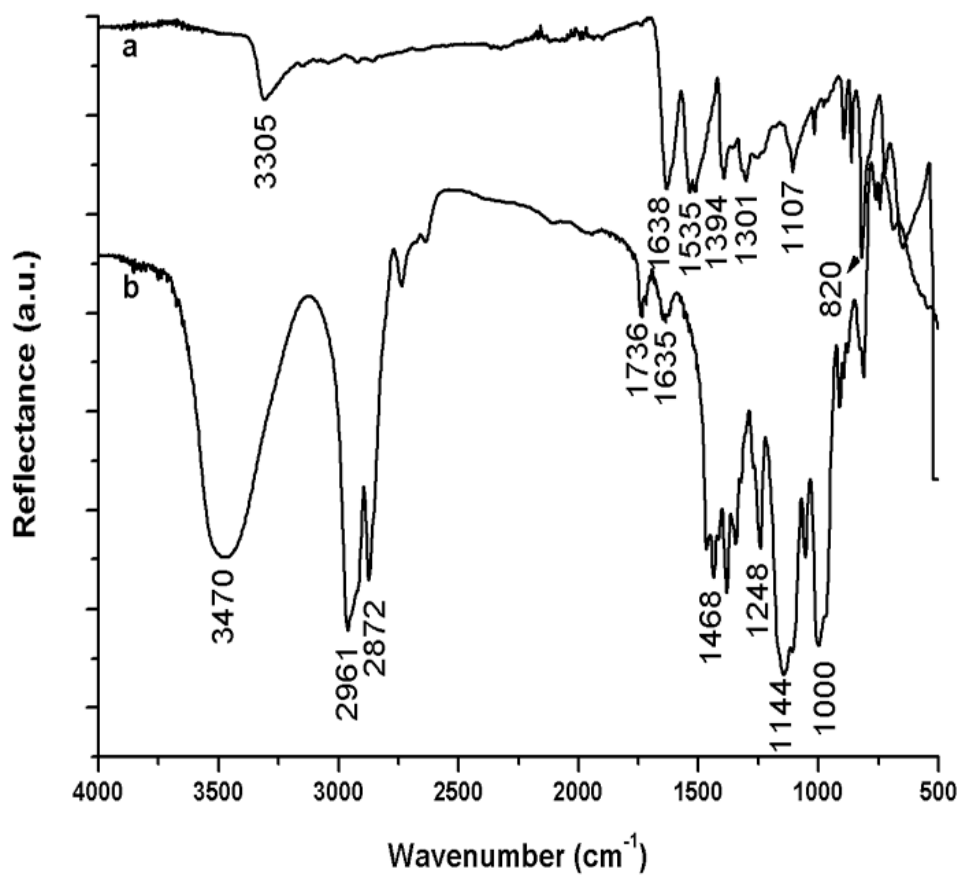

Figure 8-4 FTIR spectra of (a) the $p$-aramid fabric and (b) PVB

FTIR studies of the original components and their appropriate compositions could aid in obtaining insight into the strength of the interaction between composite components. Such a step-by-step approach could enable a good structure-properties composite to be obtained by considering the nature of the interface. It is important to emphasize that p-aramid fiber under the applied processing condition is a discrete building block in the final composite with limited possibility of chemical interaction and preferentially physical interactions (van der Waals, electrostatic and $\pi$-stacking interactions).

\subsubsection{FTIR study of the composite materials}

The FTIR spectra for the p-aramid/PVB/PH (a) p-aramid/PVB/PE (b) and paramid/TPU (c) composites are compared in Figure 8-5. 
In the p-aramid/PVB/PH FTIR spectrum, except for the characteristic bands of the original materials, bands associated with substituted aromatic rings at 1240 and 820 $\mathrm{cm}^{-1}$ could be observed. Other differences between the original components and the cured polymer composite were the appearance of three additional peaks at $1020 \mathrm{~cm}^{-1}$, $1480 \mathrm{~cm}^{-1}$ and $1730 \mathrm{~cm}^{-1}$, which were assigned to the characteristic vibrations of arylO-alkyl bonds, $\mathrm{C}-\mathrm{H}$ deformation ${ }^{212}$ and carboxyl groups, respectively. The FTIR spectrum of a p-aramid/PVB/PE composite material is presented in Figure 8-5 (a). Characteristic bands of the original polyethylene film: valence vibration (stretching) $(\mathrm{CH} 2)$ of the methylene group, vas at $2918 \mathrm{~cm}-1$ and vs at $2851 \mathrm{~cm}-1$, asymmetric deformation vibration of $\mathrm{CH} 2$ in plane (scissoring) at $1467 \mathrm{~cm}-1$ and symmetric at 1374 $\mathrm{cm}-1$, and deformation vibration of $\mathrm{CH} 2$ group at $719 \mathrm{~cm}-1$ (rocking) could be observed. Except for these bands, the spectra of $p$-aramid/PVB and $p$-aramid/PVB/PE are quite similar, indicating that the former composite material and PE were not compatible. $^{213}$

In the FTIR spectrum for the p-aramid/TPU composite, Figure 8-5 (c), the peak at $1726 \mathrm{~cm}^{-1}$ represents the non-hydrogen bonded carbonyl stretch and is probably associated with carbonyl group in the TPU polyester soft block. The small shoulder at around $1700 \mathrm{~cm}-1$ represents the carbonyl stretch resonance for hydrogen-bonded urethane groups. Bands corresponding closely to the original spectrum of the TPU film could be observed, from which a better compatibility of TPU film and p-aramid could be expected. This probably originates from the hard-block formed between the aromatic sequence of the polyurethane film and additional $\mathrm{H}$-bonding between the $\mathrm{N}-\mathrm{H}$ and urethane carbonyl, providing an ordered structure. 


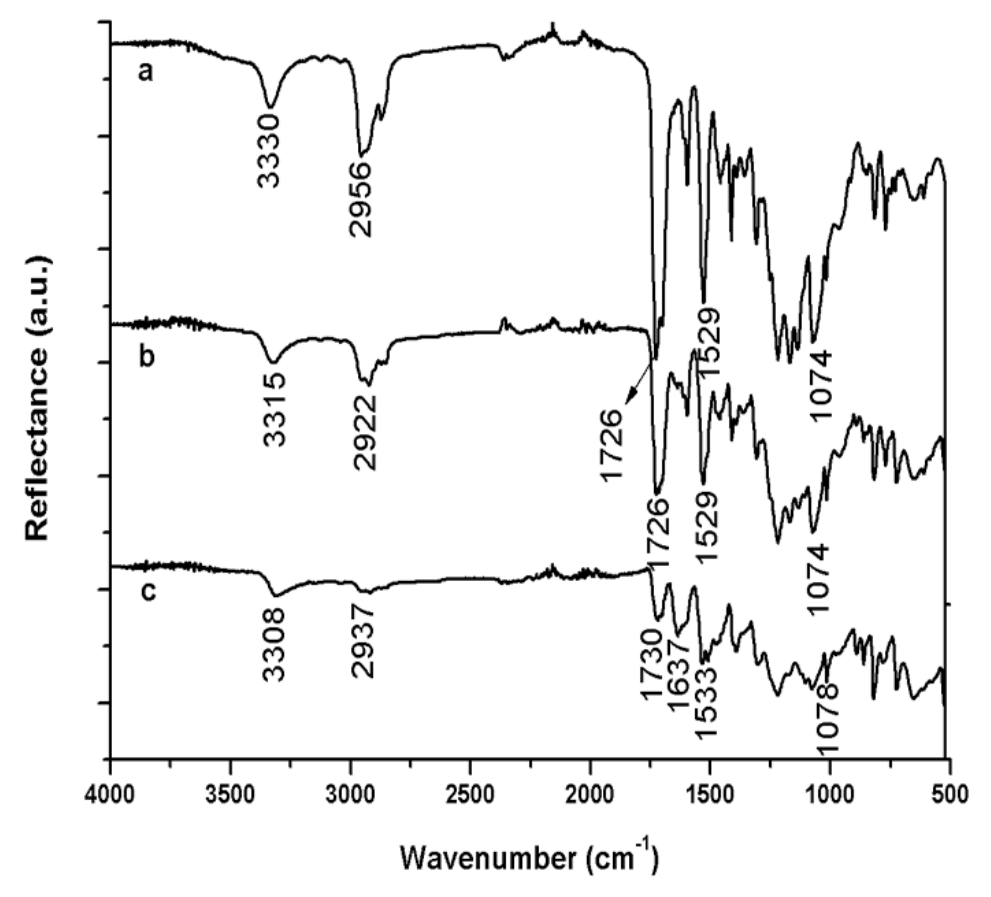

Figure 8-5. FTIR spectra of (a) p-aramid /PVB/PE, (b) p-aramid/TPU composites and (c) $\mathrm{p}$-aramid/PVB/PH

The chemical structure of the p-aramid-nanosilica composite was characterized by FTIR spectroscopy. Figure 8-6 shows the FTIR spectra of p-aramid/PVB composite (a) and the p-aramid/PVB/5wt.- $\% \mathrm{SiO}_{2}$ (b) and p-aramid/PVB/AMEO-5wt.- $\% \mathrm{SiO}_{2}$ nanocomposites (c). In the p-aramid/PVB/5wt.- $\% \mathrm{SiO}_{2}$ composite material, the interaction between the nanosilica and the p-aramid/PVB polymer chains causes small shifts of appropriate absorption bands because of the low silica loading and the relatively small contribution of weak physical interaction between functional group at the silica surface and the polymer chains. The introduction of compatible silica leads to a better $\mathrm{SiO}_{2}$ dispersion and to the formation of physical bonds, preferentially hydrogen bond, thus preventing mobility of the polymer chains, causing changes in the mechanical properties of the $\mathrm{p}$-aramid/PVB matrix.

However, the FTIR spectrum of p-aramid/PVB/AMEO-5wt.-\%SiO2 composite shows all characteristic bands of the components but it is not a simple combination of the associated FTIR spectra. In addition, the absorption representing the carbonyl vibration is slightly different in the pure PVB from that of the composite. The peak of 
the $\mathrm{C}=\mathrm{O}$ stretching vibration shifts from $1728 \mathrm{~cm}^{-1}$ in the $\mathrm{p}$-aramid/PVB/5wt.- $\% \mathrm{SiO} 2$ composite to $1734 \mathrm{~cm}^{-1}$ in the composite because of the effect of chemical and intermolecular hydrogen bonding between the nanosilica and the matrix. From the differences in the FTIR spectra between the three spectra in Figure 8-6, it could be concluded that inter-molecular chemical bonding tethered the AMEO-nanosilica and p$\operatorname{aramid} /$ PVB matrix.

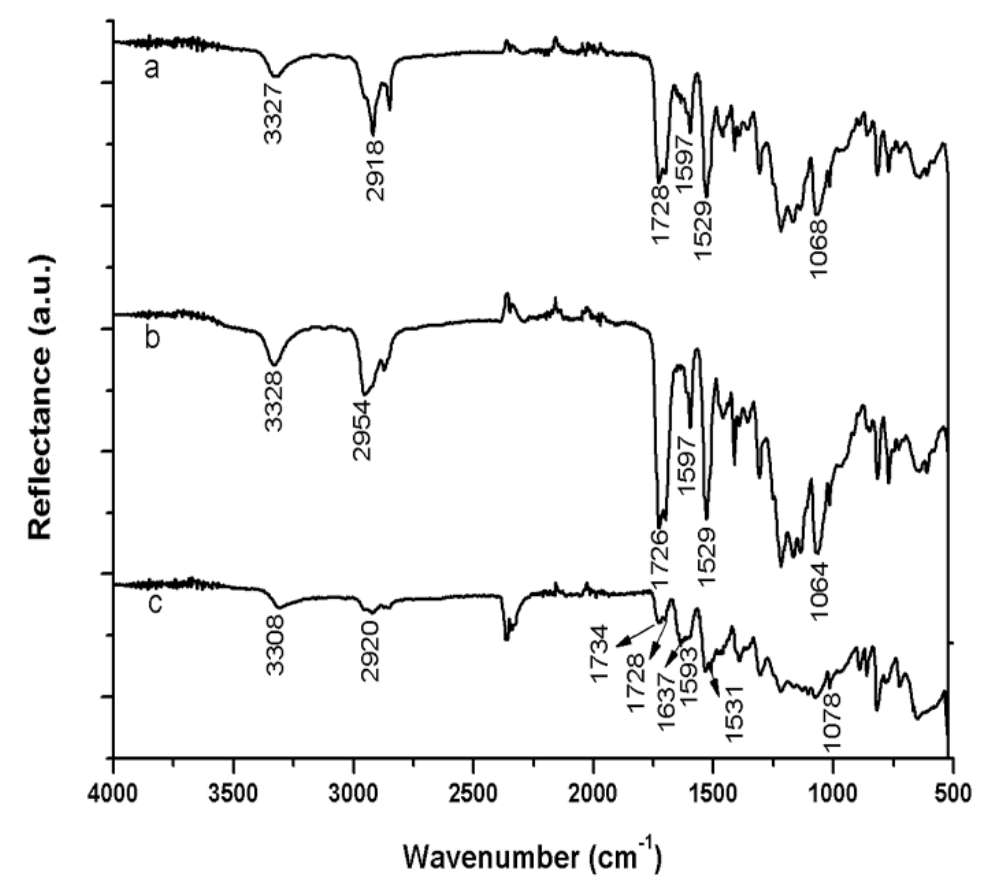

Figure 8-6. FTIR spectra of (a) p-aramid/PVB composite (b) p-aramid/PVB/5wt.$\% \mathrm{SiO} 2$ and (c) p-aramid/PVB/AMEO-5wt.-\%SiO2 nanocomposites

\subsection{Scanning Electron Microscopy (SEM)}

The SEM micrographs presented in Figure 8-7 (a-d) show microphotographs of neat paramid fabrics and p-aramid composite samples at different magnifications. Figure 8-7 (a) shows the fracture surface of neat p-aramid fabric without the addition of PVB. The SEM images presented in Figure 8-7 (b) show the plane surface of p-aramid PVB fabric composites without silica reinforcement, while the plane surface p-aramid PVB fabric with neat and AMEO-modified silica are shown in Figure 8-7 (c and d, respectively). 
Comparison of the images in Figure 8-7 (c, d) reveal that the nanoparticles cover the aramid fibers, but with the AMEO-modified ones, the dimensions are smaller, indicating better de-agglomeration. Larger magnification of particles in samples shown in Figures 8-7 $\mathrm{c}$ and $\mathrm{d}$ are presented in Figures 8-7 $\mathrm{c}_{1}$ and $\mathrm{d}_{1}$ with the smaller particle agglomerates revealed in Figure 8-7 d1.
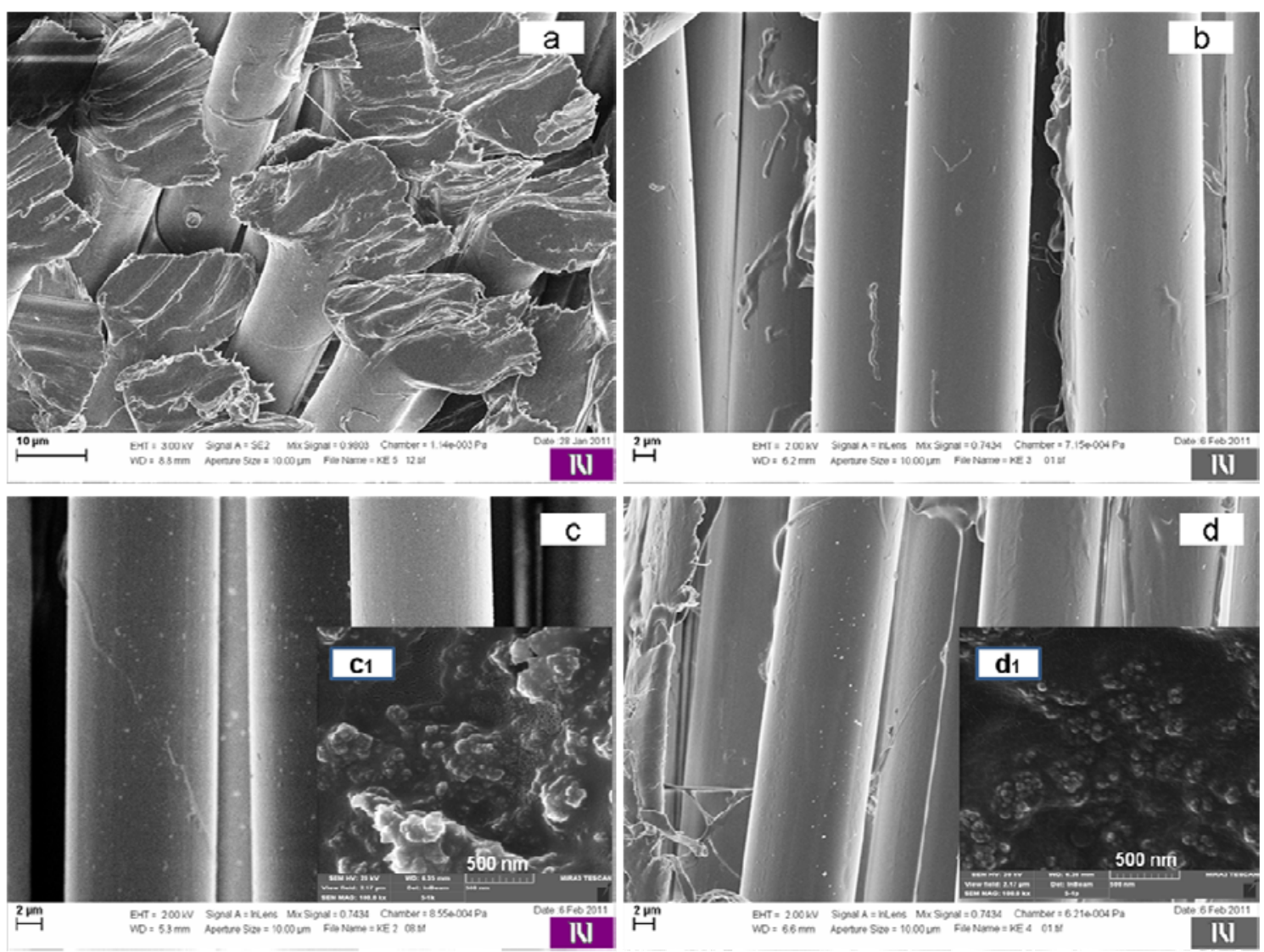

Figure 8-7. SEM images for (a) the neat p-aramid fabric and p-aramid fabric composites (b) p-aramid/PVB, (c) p-aramid/PVB/5wt.- $\% \mathrm{SiO}_{2}$, (c1) larger magnification of the sample revealing particle agglomerates, (d) p-aramid/PVB/AMEO-5wt.- $\% \mathrm{SiO}_{2}$ and (d1) larger magnification of the sample revealing particle de-agglomerates

\subsection{Differential scanning calorimetry (DSC)}

DSC traces of the modified thermoplastic films are shown in Figure 8-8. Trace (a) shows that the as-received ballistic films (PVB/PH) (without heat treatment at $170{ }^{\circ} \mathrm{C}$ ) exhibited only the glass transition temperature of the PVB polymer at $48.5{ }^{\circ} \mathrm{C}$. Thermoplastic polyurethanes (TPU) are thermoplastic elastomers, which consist of 
linear segmented block copolymers composed of polyester soft segments and crystallizable urethane hard segments. Trace (b) shows that the as-received TPU films (at temperatures from 20 to $200{ }^{\circ} \mathrm{C}$ ) had two endotherms, with a first peak at around $66{ }^{\circ} \mathrm{C}$ (this endothermic peak has been associated with the interaction between hard and soft segments) and a second one around at $129^{\circ} \mathrm{C}$ (endotherm peak corresponding to the melting temperature $\mathrm{T}_{\mathrm{m}, \mathrm{h}}$ of the hard urethane segment in the thermoplastic polyurethanes; $\mathrm{T}_{\mathrm{m}, \mathrm{s}}$, the melting temperature of the soft segment in the polymer is below $20{ }^{\circ} \mathrm{C}$ ) ${ }^{214}$. TPUs and other thermoplastic films are stable, even at high temperatures (up to $200{ }^{\circ} \mathrm{C}$ ). Trace (c) reveals that the as-received film based on the thermoplastic polyolefin was crystalline and had a melting temperature of $120.8{ }^{\circ} \mathrm{C}$ and the first temperature at about $38{ }^{\circ} \mathrm{C}$ is the glass transition temperature of PVB.

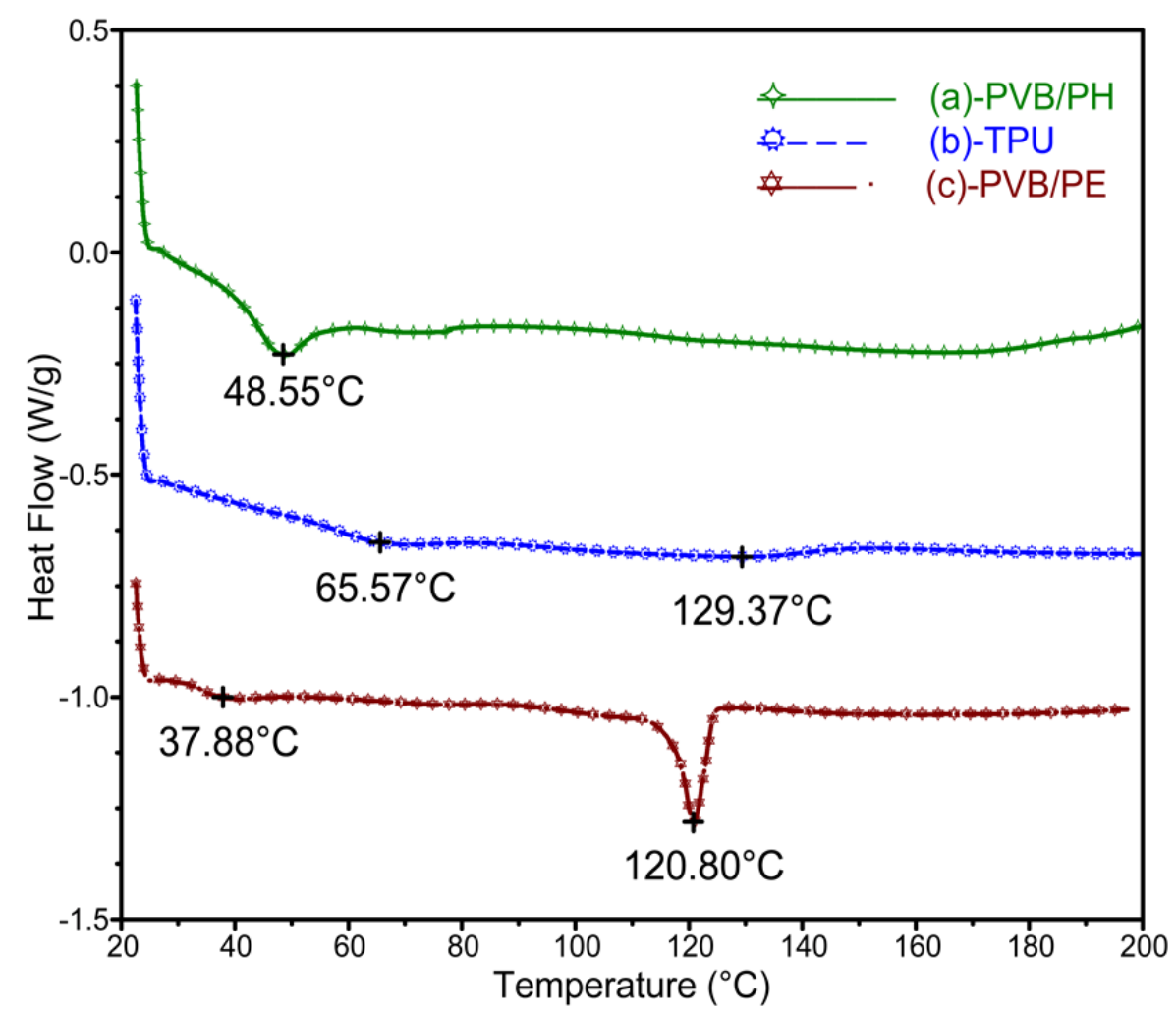

Figure 8-8. DSC traces of the polymers used as matrix materials for the investigated composites

The glass transition temperature ( $\mathrm{Tg}$ ) of Mowital $\mathrm{B} 75 \mathrm{H}$ grades decreases as the number of acetal groups increases and the degree of polymerization decreases and as 
can be seen in Figure 8-9 trace (a), the Tg of the employed PVB was $\approx 74{ }^{\circ} \mathrm{C}$. The dynamic viscosity (acc. to Hoppler, DIN 53 015) measured in a 5 wt. \% solution in 95 wt. \% ethanol at $20{ }^{\circ} \mathrm{C}$ was $50-75(\mathrm{mPa} \cdot \mathrm{s})$ and the softening temperature (ring and ball method, DIN ISO 4625 ) $>200{ }^{\circ} \mathrm{C}$. From Figure 8-9 trace (b) of the p-aramid-Martin ballistic fabric, a melting temperature was registered at $109.5^{\circ} \mathrm{C}$, even though only a small concentration of polyester yarn was present and also the thermal stability of the fabrics in the temperature range up to $300{ }^{\circ} \mathrm{C}$ was confirmed.

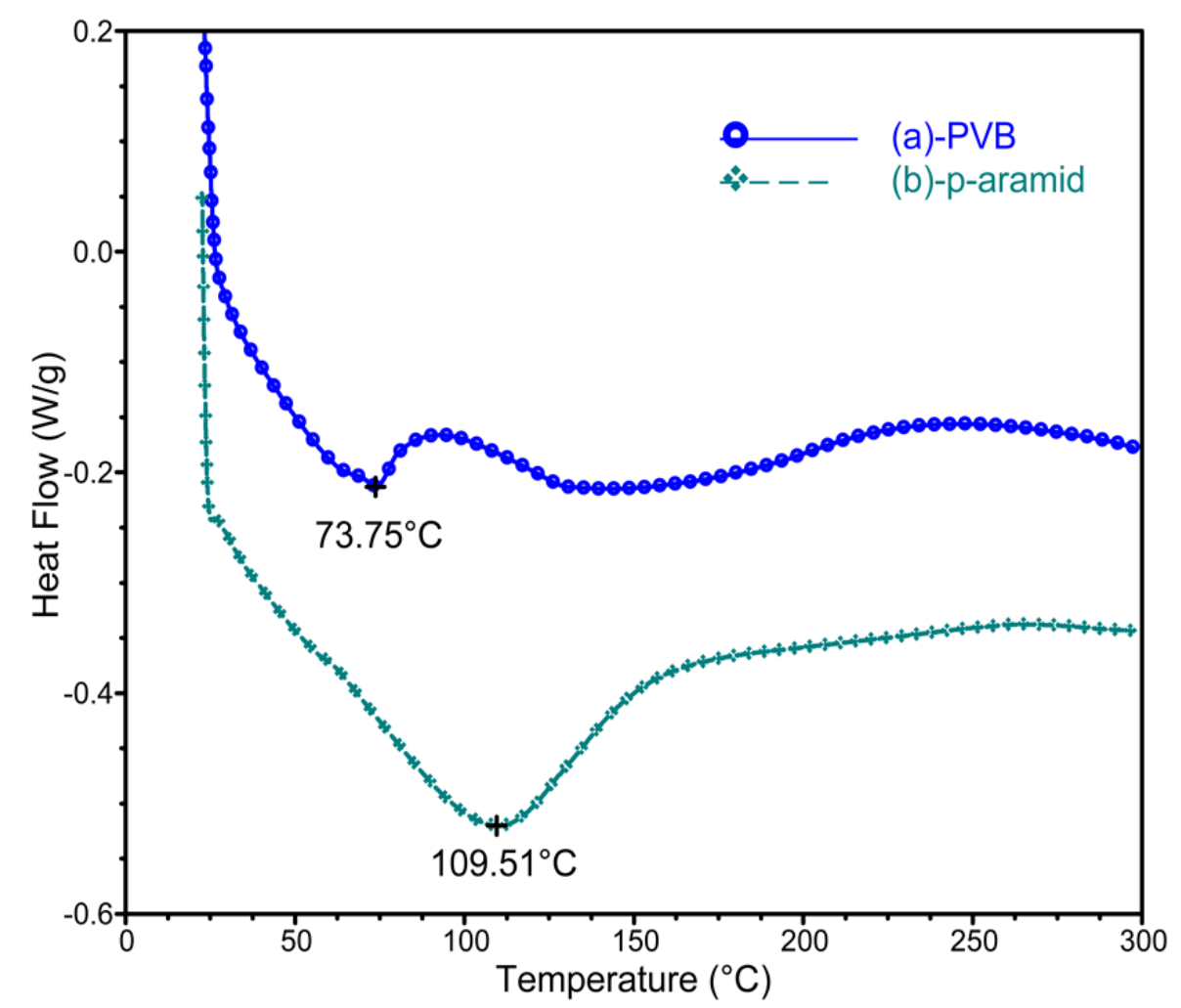

Figure 9. DSC traces of the $p$-aramid fabric and PVB Mowital

\section{8-6 Dynamic Mechanical Analysis (DMA)}

The viscoelastic properties of prepared composites were studied by dynamic mechanical analysis. DMA allows different types of transitions and relaxations to be detected and related to the structure and morphology of composites. The composites displayed dynamic mechanical behavior in the range of transitions and relaxations characteristic for thermoplastics. Generally, the thermal stability of the p-aramid fiber reinforced plastics was limited by the thermal stability of the polymer matrix. The 
storage modulus $\left(\mathrm{E}^{\prime}\right)$ and loss tangent $(\tan \delta)$ as a function of temperature are shown in Figures 8-10 and the data for the thermal transitions are also collected in Tables 8-1 and 8-2 for the materials fabricated by methods a and $b$, respectively.

\subsubsection{DMA Of Multi-Axial p-Aramid Fabric Composites With Films (Method A)}

In general, Figure 8-10 shows the temperature dependence of the storage modulus for multi-axial aramid fabrics with films. The most favorable mechanical properties were shown with the modified phenol-formaldehyde resin, PVB/PH. The composite $\mathrm{p}$-aramid/PVB/PE showed the lowest values of the storage modulus as a consequence of the weak interface effect between the multi-axial fabric and the matrix, which is consistent with the results of the FTIR analysis.

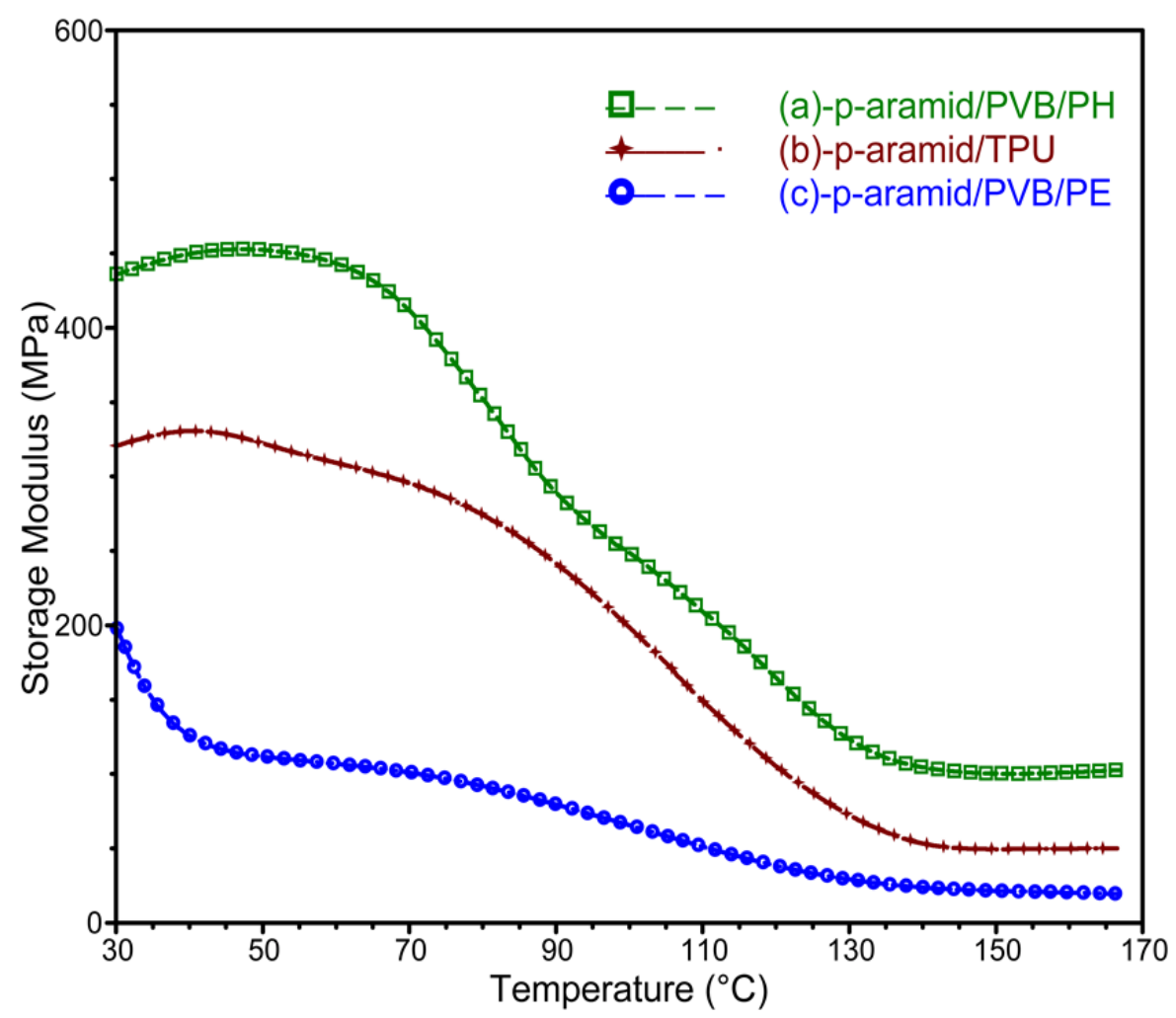

Figure 8-10 Storage modulus of $p$-aramid fabrics with various films

The plots of $\tan \delta$ as a function of temperature are shown in Figure 8-11 (a-c). The three components in the resin system could be expected to yield three different values of $\mathrm{T}_{\mathrm{g}}$. However, the $\tan \delta$ peak at the lower temperature originates from PVB $\left(\mathrm{T}_{\mathrm{g} 1}\right)$, while another $\tan \delta$ peak originating from overlapping transitions of the phenolic 
and polyester yarn $\left(\mathrm{T}_{\mathrm{g} 2}\right)$ is visible at higher temperatures for sample a. The loss peak at about $80{ }^{\circ} \mathrm{C}$ coincides approximately with the maximum loss peak for PVB in the composite, and hence this peak may be due to the second-order transition of PVB, which appears in a heterogeneous state in the composite. Another peak, found at about $131{ }^{\circ} \mathrm{C}$, may be attributed to grafting or crosslinking between the phenolic resin and the PVB, resulting from chemical reaction between the two materials during the curing process (at $170{ }^{\circ} \mathrm{C}$ ), which was confirmed by Takahashi. ${ }^{215}$ For sample $\mathrm{b}$, there is no tan $\delta$ peak at lower temperatures. The peak of the transition temperatures for the hard urethane segments and stitched polyester yarn $\left(\mathrm{T}_{\mathrm{g} 2}\right)$ is visible at higher temperatures, while for sample $\mathrm{c}$, the maximum peak of PVB $\left(\mathrm{T}_{\mathrm{g} 1}\right)$ and the other appearing peak emerges from the overlap of the polyolefin and the small content of polyester $\left(\mathrm{T}_{\mathrm{g} 2}\right)$. Measured parameters for DMA analysis are provided in Table 8-1.

Table 8-1. DMA multi-axial $p$-aramid fabrics composite with films (method a)

\begin{tabular}{|c|c|c|c|c|c|}
\hline Sample & $\begin{array}{c}\mathrm{E}^{\prime}(\mathrm{MPa}) \text { at } \\
30^{\circ} \mathrm{C}\end{array}$ & $\operatorname{Tg}_{1}\left({ }^{\circ} \mathrm{C}\right)$ & $\mathrm{Tg}_{2}\left({ }^{\circ} \mathrm{C}\right)$ & $\operatorname{Tan} \delta_{1}$ & $\operatorname{Tan} \delta_{2}$ \\
\hline $\mathrm{p}$-aramid/PVB/PH & 436.1 & 80.4 & 131.4 & 0.16 & 0.26 \\
\hline p-aramid/TPU & 320.8 & l & 138.6 & l & 0.30 \\
\hline p-aramid/PVB/PE & 196.7 & 30.5 & 138.8 & 0.48 & 0.30 \\
\hline
\end{tabular}

The variations of the loss tangent modulus show that better fiber-matrix interfacial bonding was found for fabrics impregnated with $\mathrm{PVB} / \mathrm{PH}$ film relative to the composites with the modified TPU film and PVB/PE, which was confirmed by the FTIR analysis. 


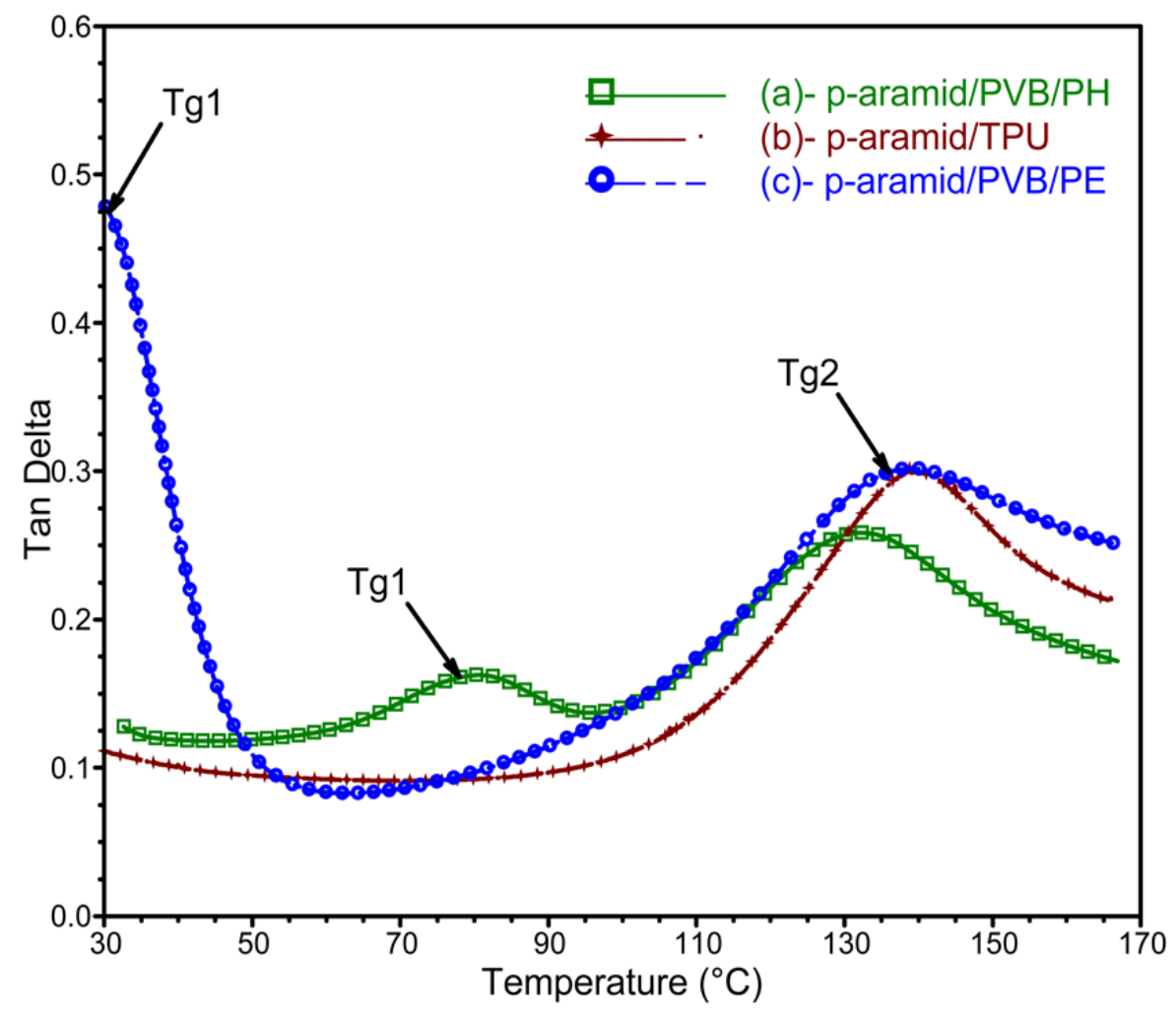

Figure 8-11. Tan Delta $(\tan \delta)$ of the $p$-aramid fabrics with various films

\subsubsection{DMA Of The Modified p-Aramid Fabric Composites (Method B)}

In this study, the dynamic mechanical properties of four hybrid composites, namely, p-aramid/PVB, p-aramid/PVB (5 and 10wt.- $\% \mathrm{SiO}_{2}$ ) and p-aramid/PVB/AMEO (5wt.-\%SiO2) were investigated. The parameters measured in the DMA analysis are provided in Table 8-2. In all samples, the synthesis reaction of PVB has been completed, thus forming residual acetate and hydroxyl groups. The interaction of PVB with inorganic oxides was achieved between the surface oxide and the hydroxyl groups of the polymers. In addition, the carbonyl oxygens of the acetate groups present in the PVB can react with the hydroxyl groups on the oxide surface, thereby establishing hydrogen bonds. This can contribute to the assumption that the hydroxyl groups of $\mathrm{SiO}_{2}$ improved their adhesion to PVB, which led to improvements in the mechanical properties of the nanocomposites p-aramid/PVB-5,10wt.- $\% \mathrm{SiO}_{2}$, resulting in small differences in the loss tangent $(\tan \delta 1)(0.20$ to 0.23$)$. Modification of the nanoparticles with AMEO silane enabled the formation of chemical bonds between the $\mathrm{SiO} 2$, 
polymers and p-aramid fibers, thus yielding significant increases in the mechanical properties of the composite p-aramid/PVB/AMEO-5wt.- $\% \mathrm{SiO}_{2}$. The storage modulus vs. temperature dependencies for the series of composite samples with $p$-aramid/PVB multi-axial fabric and different constituents are shown in Figure 8-12.

The elasticity theory confirms the presumption that the addition of $\mathrm{SiO}_{2}$ nanoparticles would improve the mechanical properties of nanocomposites. The value of the storage modulus for $\mathrm{p}$-aramid/PVB composites at a temperature of $30^{\circ} \mathrm{C}$ is 1466 $\mathrm{MPa}$, and for $\mathrm{p}$-aramid/PVB/5wt.- $\% \mathrm{SiO}_{2}$, it is $2183 \mathrm{MPa}$, stressing that the addition of $\mathrm{SiO}_{2}$ led to a $49 \%$ increase in the modulus. The addition of amino-modified nanoparticles and impregnation of p-aramid fibers maximized the storage modulus of $\mathrm{p}$ aramid/PVB/AMEO-5wt.- $\% \mathrm{SiO}_{2}$ composites, for which the value of the module was $2892 \mathrm{MPa}$, i.e., an increase of $97 \%$ in comparison to the storage modulus of $\mathrm{p}$ aramid/PVB composites. Neat silica nanoparticles tend to agglomerate and the addition of silane led to an improvement of dispersion of the silica particles and, consequently, to improved mechanical properties of the composite material.

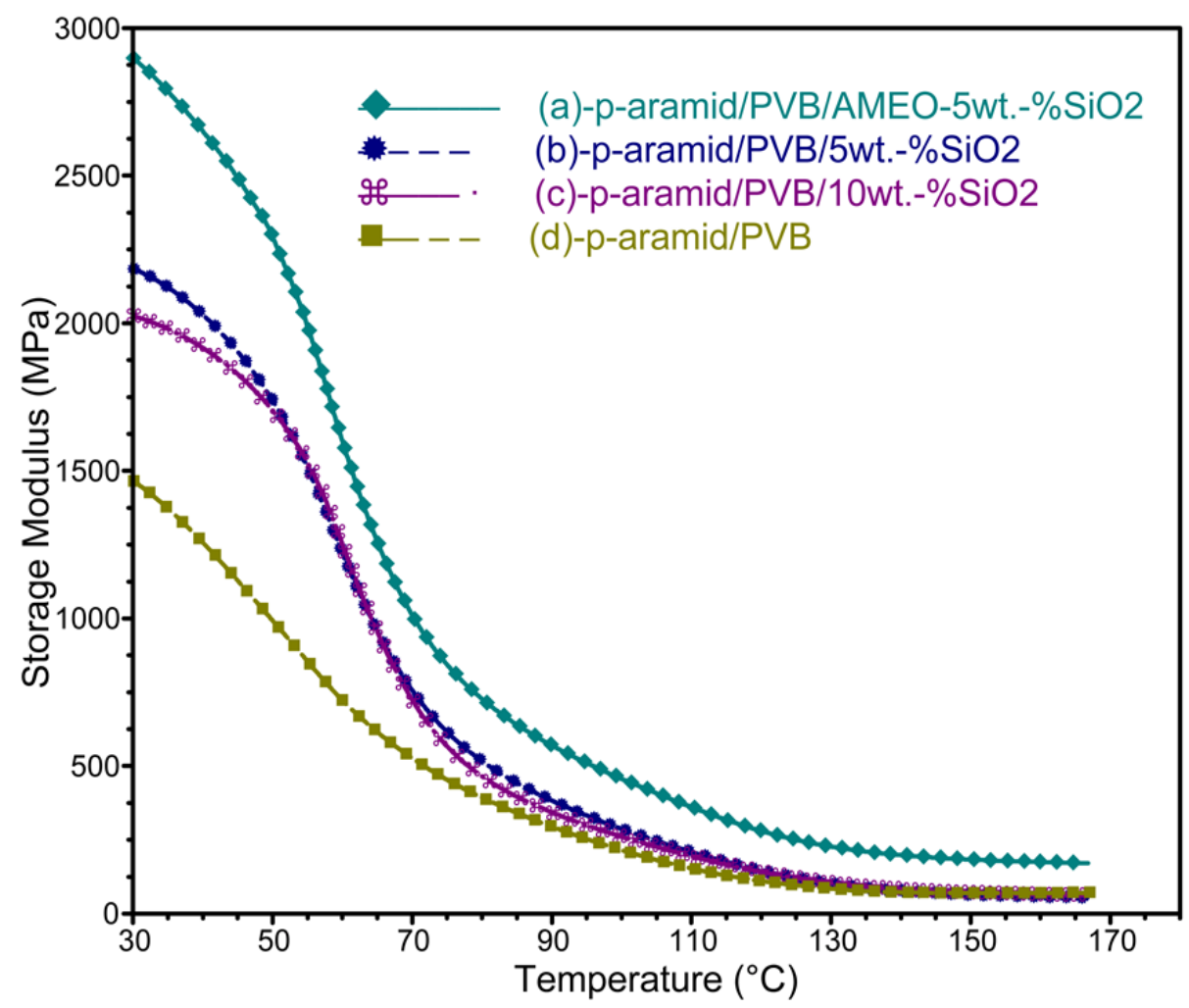

Figure 8-12 Storage modulus of the modified $p$-aramid fabric composites 
The high values of damping factor indicate high mobility of the polymer macromolecules. With increasing temperature, the polymer approaches the rubbery state, also increasing the damping factor and the mobility of the macromolecules. Two glass transitions can be seen in Figure 8-13; $\mathrm{T}_{\mathrm{g} 1}$ is derived from $\mathrm{PVB}$ and $\mathrm{T}_{\mathrm{g} 2}$ from the polyester stitched yarns. The peak in the loss tangent at the lower temperature stems from PVB $\left(\tan \delta_{1}\right)$, while the overlapping peaks from the polyester stitched yarns ( $\tan$ $\left.\delta_{2}\right)$ are seen at higher temperatures.

From Figure 8-13, it can be seen that the $\tan \delta$ maximum corresponding to $\mathrm{T}_{\mathrm{g} 1}$ for the sample modified with AMEO silane is at $67.2{ }^{\circ} \mathrm{C}$, while the one for the initial sample of $\mathrm{p}$-aramid/PVB is at $64.9^{\circ} \mathrm{C}$. There is also an increase in $\mathrm{T}_{\mathrm{g} 2}$, from $135.3{ }^{\circ} \mathrm{C}$ for the initial p-aramid/PVB sample to $140.8{ }^{\circ} \mathrm{C}$ for the sample modified with AMEO silane. This means that the addition of $\mathrm{SiO}_{2}$ nanoparticles, in particular the addition of AMEO silane, resulted in increased thermal stability of the composites; additionally, the storage modulus also increased. Increasing the glass transition temperature $\left(T_{g}\right)$ can be attributed to better interface interactions between the polymer and the modified nanoparticles.

The $\tan \delta 2$ value for the p-aramid/PVB/AMEO-5wt.- $\% \mathrm{SiO}_{2}$ was significantly decreased to 0.26 , compared to the values of the other composites $(0.44$ and 0.43$)$. This can be rationalized by the reduced mobility of macromolecular chains with the addition of $\mathrm{SiO}_{2}$ and silane because chemical bonds were established between the $\mathrm{p}$-aramid/PVB and $\mathrm{SiO}_{2}$ by the introduction of silane. 


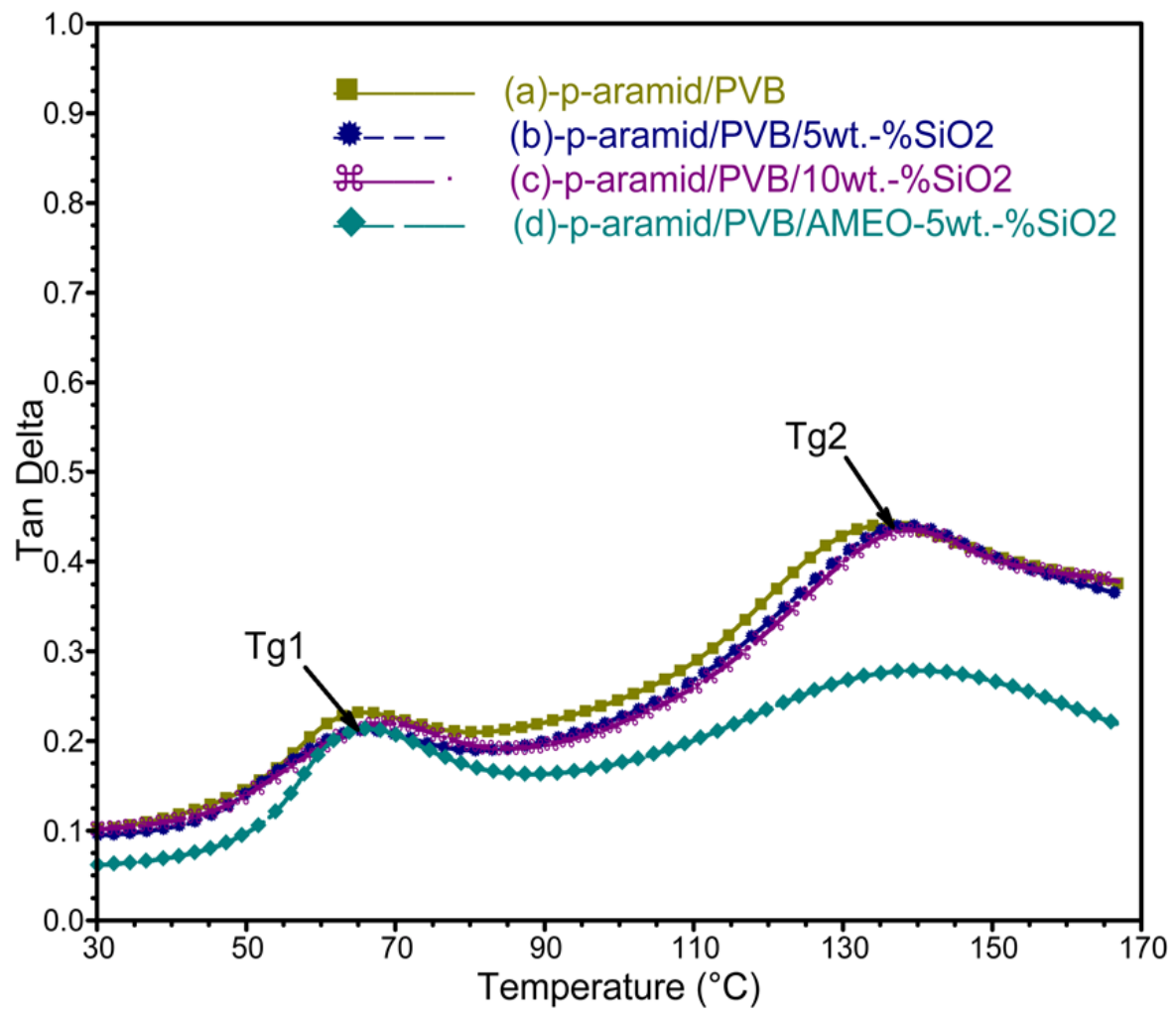

Figure 8-13. The temperature dependences of the damping ratio, Tan Delta of various modified p-aramid fabrics

Table 8-2. DMA results for the modified $p$-aramid fabric composites $(\operatorname{method} b)$

\begin{tabular}{|c|c|c|c|c|c|}
\hline Sample & $\begin{array}{c}\mathrm{E}^{\prime}(\mathrm{MPa}) \\
\text { at } \\
30^{\circ} \mathrm{C}\end{array}$ & $\begin{array}{l}\mathrm{Tg}_{1} \\
\left({ }^{\circ} \mathrm{C}\right)\end{array}$ & $\begin{array}{l}\mathrm{Tg}_{2} \\
\left({ }^{\circ} \mathrm{C}\right)\end{array}$ & $\begin{array}{c}\text { Tan } \\
\delta_{1}\end{array}$ & $\begin{array}{l}\text { Tan } \\
\delta_{2}\end{array}$ \\
\hline p-aramid/PVB & 1466 & 64.9 & 135.3 & 0.23 & 0.44 \\
\hline p-aramid/PVB/5 wt.- $\% \mathrm{SiO}_{2}$ & 2183 & 65.4 & 137.5 & 0.22 & 0.43 \\
\hline p-aramid/PVB/10 wt.- $\% \mathrm{SiO}_{2}$ & 2024 & 66.1 & 138.5 & 0.22 & 0.43 \\
\hline $\begin{array}{l}\text { p-aramid/PVB/AMEO-5wt.- } \\
\% \mathrm{SiO}_{2}\end{array}$ & 2892 & 67.2 & 140.8 & 0.20 & 0.26 \\
\hline
\end{tabular}




\subsection{Ballistic Structural Performance}

Composite sample which shows the best viscoelastic properties consist of four layers with a low weight and thickness of about $100 \mathrm{~g}$ and $3 \mathrm{~mm}$, respectively (Figure 8-14). Future work will be related to processing of samples with favorable softer feel and properties which yield the desired antiballistic protection.

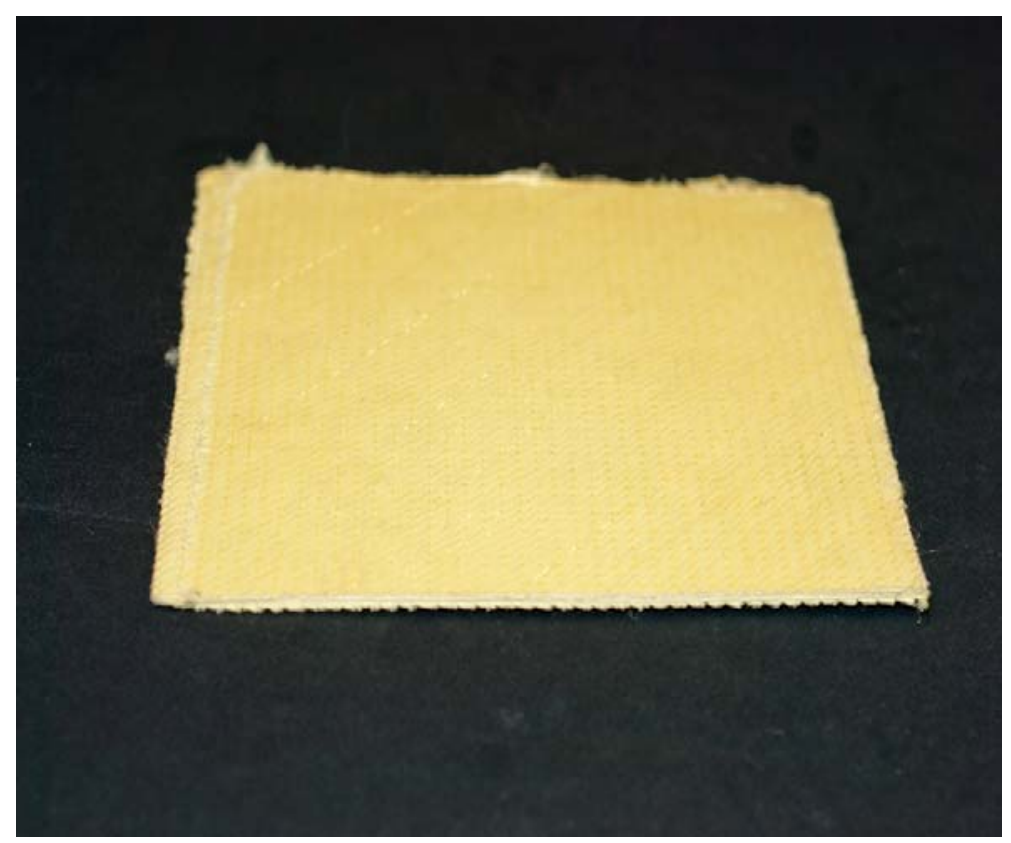

Figure 8-14. Photo of $p$-aramid/PVB/AMEO-5wt.- $\% \mathrm{SiO}_{2}$ fabric composite sample

The ballistic resistance of the targets are evaluated according to the National Institute of Justice Standard NIJ 0101.03 using a clay backing and a 9mm full metal jacketed, 124 grain $(8.0 \mathrm{~g})$ projectile. We notice that the p-aramid fabrics composite with 5 wt.-\% $\%$ SiO2 provide good resistance to penetration by a ballistic projectile u slucaju frontalnog udara (Figure 8-15) sa penetracionom dubinom oko 5mm (Appendix 1). 

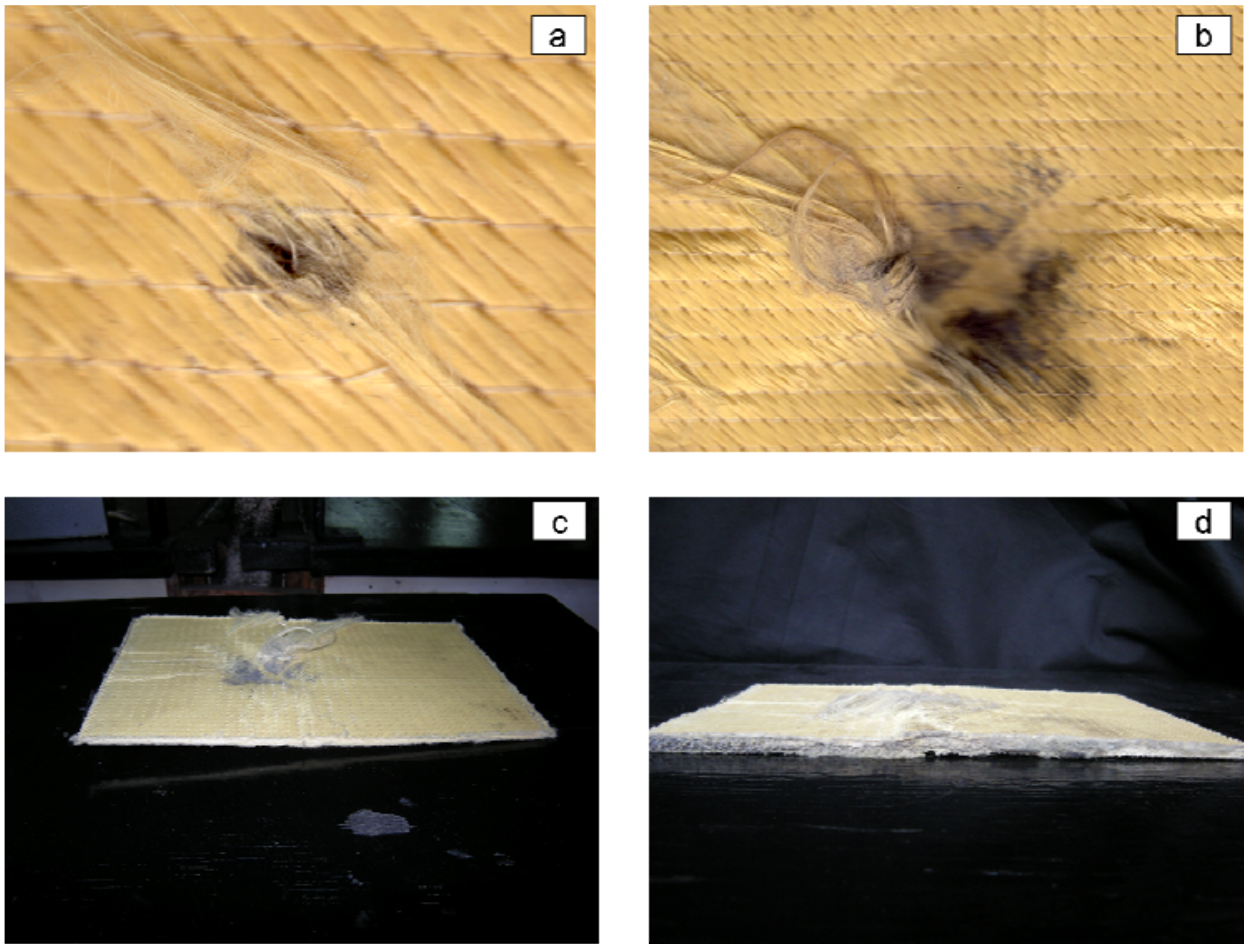

Figure 8-15 Post-test observation of composite laminate damage from after projectile shooting 


\section{Summary And Conclusions}

Nanocomposite technology has now reached the stage where basic research is being applied towards material and process development, aimed at specific products or semifinished materials. A number of new products are appearing on the market (automotive components, sports equipment, consumer goods); and existing processes are being improved with the application of nanocomposite technology and materials. Nanocomposite technology has reached a critical mass and it is likely that many new materials and products will be developed in the next few years.

Literature review of this dissertation is based on the public, accessible, nonclassified information. Keeping this in mind let us see what one may learn from research publications, patents and general web information.

Fibers and fabrics. Polyaramid category has been dominated by Kevlar $^{\circledR}$, s (USA), Twaron ${ }^{\circledR}$ s (Japan), and more recently Heracron ${ }^{\circledR}$ (So. Korea). The technology continuously evolves, thus DuPont renews its Kevlar ${ }^{\circledR}$ grades. For ballistic applications KM2 remains the workhorse, with Kevlar $^{\circledR}$ LT and Kevlar ${ }^{\circledR}$ Mark IV being recent additions. The latter grade has been specifically developed for the new headgear. It is noteworthy that in body armor application thicker Heracron ${ }^{\circledR}$ fibers outperformed Kevlar $^{\circledR}$ KM2 at constant areal densities. The Heracron ${ }^{\circledR}$ fibers are stiffer than KM2, what for the headgear application should not make much difference.

Polyolefin category is represented by the gel-spun UHMWPE fibers, Dyneema ${ }^{\circledR}$ from DSM and Spectra $^{\circledR}$ from Honeywell. Innegra ${ }^{\mathrm{TM}} \mathrm{S}$ fibers (introduced by INNegRITYTM in 2007) are inexpensive, highly oriented polypropylene fibers used for police $\&$ military vests $\&$ helmets. Of the three types, the clear winner in the performance category is Dyneema ${ }^{\circledR}$ HB80 with $35 \%$ better performance than Kevlar ${ }^{\circledR}$, in the economy is Innegra ${ }^{\mathrm{TM}}$ in combination with Kevlar $^{\mathbb{R}}$ or Dyneema $^{\circledR}$.

Non-woven textiles (e.g., 1:1 Kevlar $^{\circledR}+$ Spectra $^{\circledR}$ ) have been reported 30\% ballistically more efficient than fabrics. This may be due to their ease to pull out, similar (but to smaller degree) as the one observed for the new unidirectional UD-fabrics. To the non-woven, stitched or needled textile or felt belong materials produced by carding, 
air laying, randomizer roll, cross-lapping, lot merge and/or slurrying. Usually, these are bonded together by needle-punching entanglement of fibers, but may be resinencapsulated, adhesively or thermally bonded, and/or laminated. To this category belong ArmorFelt ${ }^{\mathrm{TM}}$ (50\% p-aramid, 50\% UHMWPE), Kevlar ${ }^{\circledR}$, Twaron ${ }^{\circledR}$, Dyneema ${ }^{\circledR}$ Fraglight, Spectra ${ }^{\circledR}$, Zylon ${ }^{\circledR}$, etc., as well as their blends. The non-woven fabrics are known as ballistic-resistant materials for garments (vests, helmets, body armor and the like) and equipment (shielding, coverings, shrouds, etc.).

Polymeric matrix. Polymers are divided into: (1) commodity, (2) engineering and (3) specialty categories, with cost and performance going in the same order. In combination with fibers or fabrics, polymers from each category have been used for ballistic protection.

There are recent reports about use of polyethylene with Kevlar ${ }^{\circledR}$ (immiscible system). On impact the fibers are liberated to deform absorbing more energy.

In this category only polyamides (PA) and their blends were looked at. PA-11, PA-12 and PA-63T may be worth scrutiny. The drawback of PA is their hygroscopicity. Water acts as a plasticizer softening the polymer, increasing chain mobility what may lead to recrystallization and hydrolysis that reduces PA molecular weight. As a result, the property of the composite will vary with season and with time. Evidently, smaller is the number of hygroscopic amide groups, less hygroscopic is the polymer. Of blends, PA/PO type may be of value as these systems have low moisture absorbance and will not solidly bond to aramid fibers.

Because of the cost and low production volume PEEK and PPS and their various blends are interesting. They are high temperature polymers with excellent mechanical properties. In addition, on impact PEEK was reported to show strain thickening behavior.

Interphase. Interphase is crucial for the performance of composites. Three methods have been used for its modification: compatibilization, sizing and physical modification. Changes to the interphase may engender either strain thickening (STF) or softening (SSF) fiber behavior. The GF sizing is the best described, but little has been published about sizing of aramid or olefin fibers

There are several reports of a promising application of what may be termed a nanocomposite in body armour. Shear thickening fluids consist of a fluid, containing a 
dispersion of particles. When the fluid is sheared rapidly by an external force it stiffens and resists deformation. When this shear thickening fluid is impregnated into conventional Kevlar ${ }^{\circledR}$ the ability of the material to absorb energy is greatly improved. In one example, the ballistic performance (in terms of absorbed energy) is more than doubled, so that 4layers of Kevlar impregnated with the shear thickening fluid absorbed as much energy 10 layers without the shear thickening fluid. It terms of practical application, this will lead to much more flexible armour with equivalent ballistic protection, and somewhat reduced total weight.

Experimentals reports the preparation of $\mathrm{SiO}_{2}$ and $\mathrm{TiO}_{2}$ /poly (vinyl butyral) nanocomposites with enhanced dynamic mechanical properties. Composites reinforced with colloidal sol silica and titania showed higher mechanical properties than the ones reinforced with non-treated particles. When sol $\mathrm{TiO}_{2}$ particles are used, the highest increase of storage modulus of about $54 \%$ is obtained for $5 \mathrm{wt} \%$ loading, while for sol $\mathrm{SiO}_{2}$, the storage modulus increases with the addition of nanosilica with the largest increase of about $99 \%$ observed for $7 \mathrm{wt} \%$ loading. In addition, titania and silica sol/PVB nanocomposites were introduced within Kevlar/PVB composites and showed remarkable increase of the storage modulus for about 65 and 98\%, respectively. Largest contribution of nanoreinforcements in lowering the glass transition temperature is observed for $5 \mathrm{wt} \%$ loading of $\mathrm{TiO}_{2}$ sol and $7 \mathrm{wt} \%$ of $\mathrm{SiO}_{2}$ sol.

The introduction of silica nanoparticles in the composite of p-aramidpoly(vinyl butyral) leads to significant improvement in the mechanical properties, and the addition of silane coupling agents yielded the maximal value of the storage modulus for the hybrid nanocomposites. The introduction of silane leads to a better dispersion and de-agglomeration $\mathrm{SiO}_{2}$ particles and the formation of chemical bonds between organic and inorganic constituents, multi-axial fabrics with poly(vinyl butyral) and amino-modified $\mathrm{SiO}_{2}$ nanoparticles. From the change in the value of glass transition temperatures of the composite with silane and $\mathrm{SiO}_{2}$, it was concluded that 5 wt. \% modified nanoparticles induced significant mechanical properties. In addition to the improved mechanical properties, the thermal stability of these hybrid materials was also improved.

We has developed of new fabric forms of p-aramid fiber Twaron (Martin ballistic mat) that can be used for body armor composite. It also notes that stiched 
fabrics made of four layers contributes to low weight and thickness (about $100 \mathrm{~g}$ and 3 $\mathrm{mm}$ ) and a softer feel while you get the same protection. Because it only uses $5 \mathrm{wt} .-\%$ $\mathrm{SiO}_{2}$, made possible by a maximum dynamic mechanical and thermal properties at the minimum weight with increased comfort and flexibility.

The hybrid systems can offer possibility to construct ballistic protective systems providing higher protection without sacrificing mobility and comfort. It appears that studies are needed to optimize the performance of ballistic textiles through hybrid laminated systems by the layering of different structures. 
APPENDIX 1:Ballistic Test Results

\begin{tabular}{|c|c|c|c|}
\hline Prvi Partizan & \multicolumn{2}{|c|}{$\begin{array}{c}\text { BALLISTIC TEST REPORTS } \\
\text { 357Magnum FMJ } 10.2 \mathrm{~g}\end{array}$} & $1 / 19 / 2012$ \\
\hline \multicolumn{4}{|c|}{ UNMODIFIED BALLISTIC PLATE } \\
\hline Job & 44.184 & Date/Time Fired & $1 / 19 / 2012 / 8 ; 22 ; 28$ \\
\hline LOT & UM-Merkata & CONTRACT & Sample-1 \\
\hline PROPELLANT LOT & & WEIGHT gr: & \\
\hline SPECIFICATION: & & REQUIREMENTS: & Full \\
\hline CASE LOT: & & BULLET LOT: & \\
\hline FUSE LOT: & & PRIMER LOT; & \\
\hline GUN TYPRE: & Barell & BARREL NO: & HPI 090249 \\
\hline REL HUMUDITY: & $75 \%$ & ATOMS PRESSURE & 1013 bar \\
\hline $\begin{array}{l}\text { ROUND } \\
\text { TEMPERATURE }\end{array}$ & $20 \mathrm{P}^{\circ} \mathrm{PC}$ & & \\
\hline Shot Number & $\begin{array}{l}\text { Velocity } \\
\mathrm{m} / \mathrm{s}\end{array}$ & & \\
\hline 1 & 429.79 & & \\
\hline \multicolumn{4}{|l|}{ Mean } \\
\hline \multicolumn{4}{|l|}{ Standard Deviation } \\
\hline \multicolumn{4}{|l|}{ Maximum } \\
\hline \multicolumn{4}{|l|}{ Minimum } \\
\hline \multicolumn{4}{|l|}{ Max-Min } \\
\hline Correction & 2.72 & & \\
\hline Corr Mean & 427.00 & & \\
\hline
\end{tabular}

BALLISTIC TEST SUPERINTENDENT

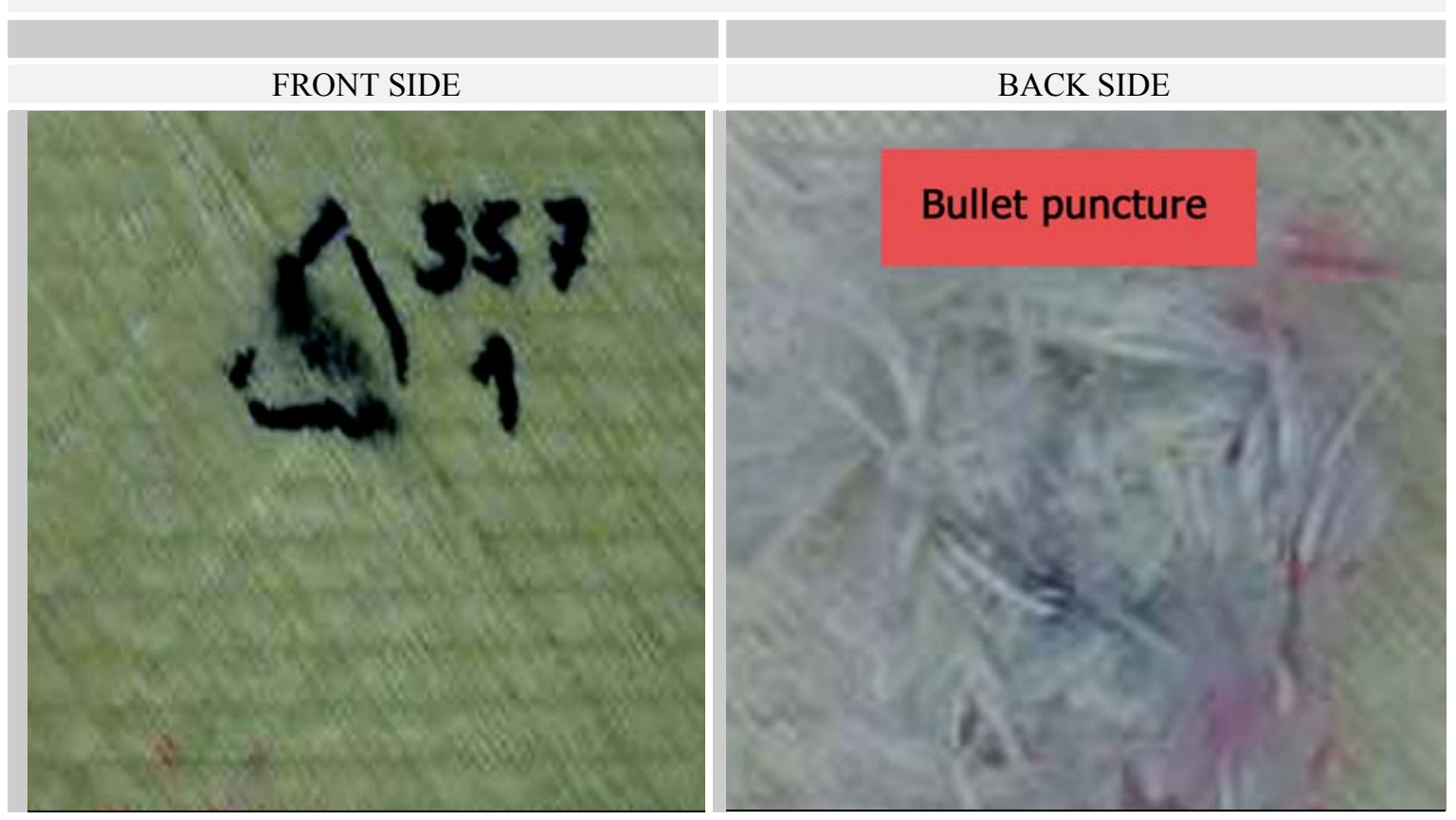




\begin{tabular}{|c|c|c|c|}
\hline PRVI Partizan & \multicolumn{2}{|c|}{$\begin{array}{c}\text { BALLISTIC TEST REPORT } \\
\text { 357Magnum FMJ } 10.2 \mathrm{~g} \\
\end{array}$} & $1 / 19 / 2012$ \\
\hline \multicolumn{4}{|c|}{ NANOMODIFIED BALLISTIC PLATE } \\
\hline Job & 44.184 & Date/Time Fired & $1 / 19 / 2012 / 7: 47: 47$ \\
\hline LOT & UM-Merkata & CONTRACT & Sample-2 \\
\hline PROPELLANT LOT & & WEIGHT gr: & \\
\hline SPECIFICATION: & & REQUIREMENTS: & Full \\
\hline CASE LOT: & & BULLET LOT: & \\
\hline FUSE LOT: & & PRIMER LOT; & \\
\hline GUN TYPRE: & Barell & BARREL NO: & HPI 090249 \\
\hline REL HUMUDITY: & $75 \%$ & ATOMS PRESSURE & 1013 bar \\
\hline ROUND TEMPERATURE & $20 \mathrm{P}^{\circ} \mathrm{PC}$ & & \\
\hline Shot Number & $\begin{array}{c}\text { Velocity } \\
\mathrm{m} / \mathrm{s}\end{array}$ & Number at plate & \\
\hline 1 & 431.64 & 2 & \\
\hline 2 & 434.62 & 3 & \\
\hline 3 & 418.52 & 4 & \\
\hline Mean & 428.26 & & \\
\hline Standard Deviation & 8.57 & & \\
\hline Maximum & 434.62 & & \\
\hline Minimum & 418.52 & & \\
\hline Max-Min & 16.10 & & \\
\hline Correction & 3.26 & & \\
\hline Corr Mean & 425.00 & & \\
\hline
\end{tabular}

BALLISTIC TEST SUPERINTENDENT
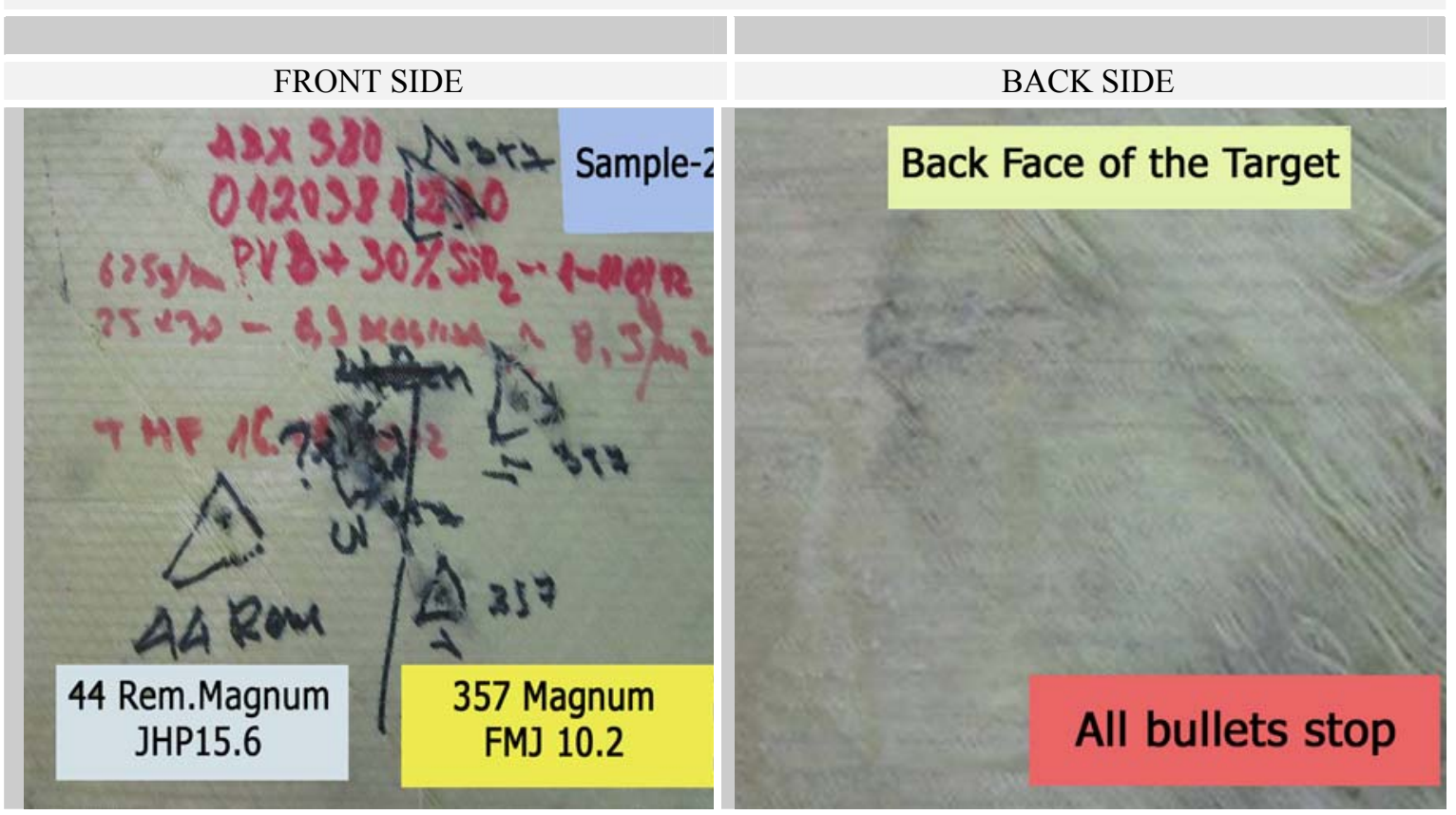


\begin{tabular}{|c|c|c|c|}
\hline PRVI Partizan & \multicolumn{2}{|c|}{$\begin{array}{l}\text { BALLISTIC TEST REPORT } \\
44 \text { Rem.Magnum JHP15.6g }\end{array}$} & $1 / 19 / 2012$ \\
\hline \multicolumn{4}{|c|}{ NANOMODIFIED BALLISTIC PLATE } \\
\hline Job & 44.184 & Date/Time Fired & $1 / 19 / 2012 / 8: 22: 28$ \\
\hline LOT & UM-Merkata & CONTRACT & Sample-2 \\
\hline PROPELLANT LOT & & WEIGHT gr: & \\
\hline SPECIFICATION: & & REQUIREMENTS: & Full \\
\hline CASE LOT: & & BULLET LOT: & \\
\hline FUSE LOT: & & PRIMER LOT; & \\
\hline GUN TYPRE: & Barell & BARREL NO: & HPI 090249 \\
\hline REL HUMUDITY: & $75 \%$ & ATOMS PRESSURE & 1013 bar \\
\hline ROUND TEMPERATURE & $20 \mathrm{P}^{\circ} \mathrm{PC}$ & & \\
\hline Shot Number & $\begin{array}{l}\text { Velocity } \\
\mathrm{m} / \mathrm{s}\end{array}$ & & \\
\hline 1 & 429.79 & & \\
\hline \multicolumn{4}{|l|}{ Mean } \\
\hline \multicolumn{4}{|l|}{ Standard Deviation } \\
\hline \multicolumn{4}{|l|}{ Maximum } \\
\hline \multicolumn{4}{|l|}{ Minimum } \\
\hline \multicolumn{4}{|l|}{ Max-Min } \\
\hline Correction & 2.72 & & \\
\hline Corr Mean & 427.00 & & \\
\hline
\end{tabular}

BALLISTIC TEST SUPERINTENDENT
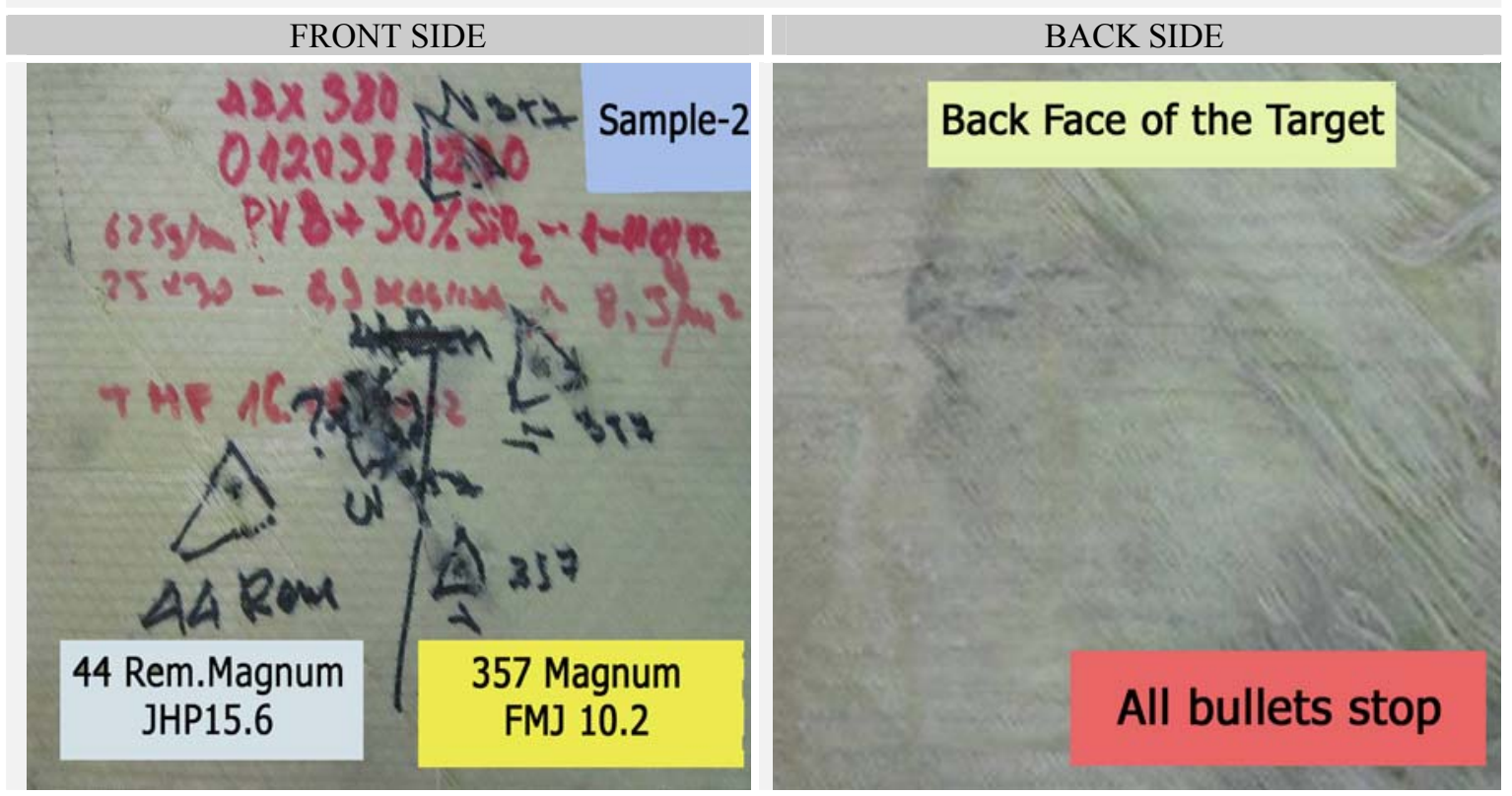


\section{Biografski podaci o kandidatu}

Mr Abdolghane M. Torki rođen je 10. 08. 1965. godine u Tripoliju. Diplomirao je na Hemijskom fakultetu (Alfateh University) u Tripoliju, 1989. godine. Magistarske studije završio je 2000. godine na Pekinškom Univerzitetu aeronautike i astronautike, Beijing University of Aeronautics and Astrnautics-BUAA, u oblasti polimernih kompozitnih materijala. Magistarsku tezu pod nazivom: "Behavior of the Hybrid Composites under Sharpy Impact and Ballistic Impact", odbranio je 28.03.2003. Od 1989. godine zaposlen je u Tehničko-istraživačkom centru u Tripoliju i radi kao hemičar na anlizama kontrole kvaliteta. 
Прилог 1.

\section{Изјава о ауторству}

Потписани-а Abdolghane M. Hussen Torki

број индекса

\section{Изјављујем}

да је докторска дисертација под насловом

"Dinamičko-mehanička svojstva hibridnih nanokompozitnih materijala" ("Dynamic Mechanical Properties Of Hybrid Nanocomposites Materials")

резултат сопственог истраживачког рада,

- да предложена дисертација у целини ни у деловима није била предложена за добијање било које дипломе према студијским програмима других високошколских установа,

- да су резултати коректно наведени и

- да нисам кршио/ла ауторска права и користио интелектуалну својину других лица.

У Београду, 24.05.2012.

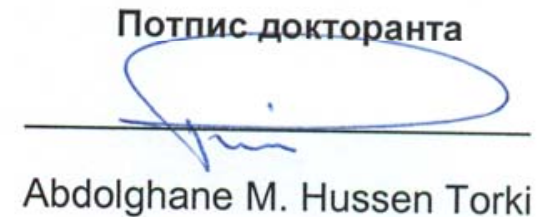


Прилог 2.

\section{Изјава о истоветности штампане и електронске верзије докторског рада}

Име и презиме аутора Abdolghane M. Hussen Torki

Број индекса

Студијски програм Хемија и хемијска технологија

Наслов рада "Dinamičko-mehanička svojstva hibridnih nanokompozitnih materijala" ("Dynamic Mechanical Properties Of Hybrid Nanocomposites

Ментор Др Радослав Алексић Ред. проф.

Потписани/а

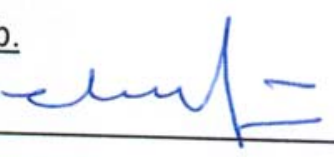

Изјављујем да је штампана верзија мог докторског рада истоветна електронској верзији коју сам предао/ла за објављивање на порталу Дигиталног репозиторијума Универзитета у Београду.

Дозвољавам да се објаве моји лични подаци везани за добијање академског звања доктора наука, као што су име и презиме, година и место рођења и датум
одбране рада.

Ови лични подаци могу се објавити на мрежним страницама дигиталне библиотеке, у електронском каталогу и у публикацијама Универзитета у Београду.

\section{Потпис докторанта}

У Београду, 24.05.2012.

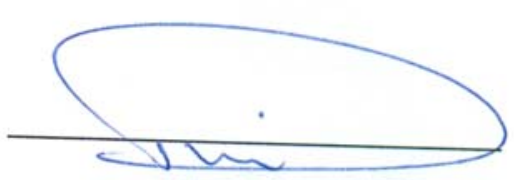

Abdolghane M. Hussen Torki 
Прилог 3.

\section{Изјава о коришћењу}

Овлашћујем Универзитетску библиотеку „Светозар Марковић“ да у Дигитални репозиторијум Универзитета у Београду унесе моју докторску дисертацију под насловом:

"Dinamičko-mehanička svojstva hibridnih nanokompozitnih materijala" ("Dynamic Mechanical Properties Of Hybrid Nanocomposites Materials")

која је моје ауторско дело.

Дисертацију са свим прилозима предао/ла сам у електронском формату погодном за трајно архивирање.

Моју докторску дисертацију похрањену у Дигитални репозиторијум Универзитета у Београду могу да користе сви који поштују одредбе садржане у одабраном типу лиценце Креативне заједнице (Creative Commons) за коју сам се одлучио/ла.

1. Ауторство

2. Ауторство - некомерцијално

3. Ауторство - некомерцијално - без прераде

4. Ауторство - некомерцијално - делити под истим условима

5. Ауторство - без прераде

6. Ауторство - делити под истим условима

(Молимо да заокружите само једну од шест понуђених лиценци, кратак опис лиценци дат је на полеђини листа).

Потпис докторанта

У Београду, 24.05.2012.

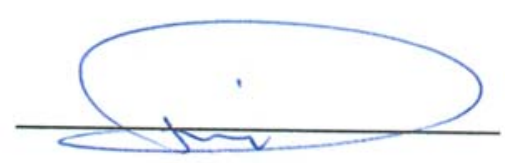

Abdolghane M. Hussen Torki 


\section{REFERENCES}

${ }^{1}$ Department of Justice. 2008. Ballistic Resistance of Body Armor, NIJ Standard-0101.06. Available online at http://www.ncjrs.gov/pdffiles1/nij/223054.pdf. Last accessed April 15, 2011.

2 Committee on Opportunities in Protection Materials Science and Technology for Future Army Applications; National Research Council Opportunities in Protection Materials Science and Technology for Future Army Applications, http://www.nap.edu/catalog.php?record_id=13157

${ }^{3}$ Department of Defense. 1997. Department of Defense Test Method Standard: V50 Ballistic Test for Armor, MIL-STD-662F, December 18. Aberdeen Proving Ground, Md.: U.S. Army Research Laboratory.

${ }^{4}$ Philip Cunniff, U.S. Army Natick Soldier Research, Development and Engineering Center, "Fiber research for soldier protection," presentation to the committee, March 10, 2010.

${ }^{5}$ Montgomery, J.S., and E.S. Chin. 2004. Protecting the future force: A new generation of metallic armors leads the way. AMPTIAC Quarterly 8(4): 15-20.

${ }^{6}$ Inspector General, Department of Defense. 2009. DoD Testing Requirements for Body Armor. Report No. D-009-047, January 29. Available online at http://www.dtic.mil/cgibin/GetTRDoc?AD=ADA499208\&Location=U2\&doc=GetTRDoc.pdf. Last accessed April 29, 2011.

${ }^{7}$ U.S. Army. 2010. Interceptor Body Armor (IBA) brochure, October. Available online at https://peosoldier.army.mil/FactSheets/PMSPIE/ SPIE_SPE_IBA.pdf. Last accessed April 29, 2011.

${ }^{8}$ DoD Inspector General. 2009. DoD Testing Requirements for Body Armor. Report No. D-2009-047, January 29. Available online at http://www.dtic.mil/cgibin/GetTRDoc?AD=ADA499208\&Location $=U 2 \& d o c=$ GetTRDoc.pdf. Last accessed April 29, 2011.

${ }^{9}$ Lord and Mohamed, Weaving: Conversion of Yarns to Fabric, Merrow (1982), pages 141-143:

${ }^{10}$ M. Colakoglu, O. Soykasap, T. Özek, Experimental and numerical investigations on the ballistic performance of polymer matrix composites used in armor design, Appl. Compos. Mater., 14,47-58 (2007).

${ }^{11}$ Utracki, Leszek, Rigid ballistic composites (Review of literature), http://nparc.cisti-icist.nrccnrc.gc.ca/npsi/ctrl?action=rtdoc\&an $=16885314 \&$ lang=en

${ }^{12}$ B. A. Cheeseman, R. Jensen, Ch. Hoppel, Protecting the future force: Advanced materials and analysis enable robust composite armor, AMPITAC Quarterly, 8 (4), 37 - 43 (2010).

13 James W. McCauley, Weapons and Materials Research Directorate, Army Research Laboratory (ARL) fellow, ARL, "Armor materials 101-501: Focus on fundamental issues associated with armor ceramics "kinetic energy passive armor," presentation to the committee, March 9, 2010.

14 James W. McCauley, Chief Scientist, Weapons and Materials Research Directorate, Army Research Laboratory (ARL) fellow, ARL, "Armor Materials 101-501: Focus on Fundamental Issues Associated with Armor Ceramics 'Kinetic energy passive armor,'” presentation to the committee on March 9, 2010.

${ }^{15}$ Flory, P. 1956. Phase equilibria in solutions of rod-like particles. Proceedings of the Royal Society of London Series A-Mathematical and Physical Sciences 234(1196): 73-89.

${ }^{16}$ Smith, P., and P. Lemstra. 1980. Ultra-high-strength polyethylene filaments by solution spinning/drawing. Journal of Materials Science 15(2):

17 3Chae, H., and S. Kumar. 2006. Rigid-rod polymeric fibers. Journal of Applied Polymer Science 100(1): 791-802. 
${ }^{18}$ 4Sikkema, D. 1998. Design, synthesis and properties of a novel rigid rod polymer, PIPD or 'M5': High modulus and tenacity fibres with substantial compressive strength. Polymer 39(24): $5981-5986$

19 6Gupta, V., and V. Kothari. 1997. Manufactured Fibre Technology. New York, N.Y.: Chapman and Hall.

${ }^{20} 7$ Koziol, K., J. Vilatela, A. Moisala, M. Motta, P. Cunniff, M. Sennett, and A. Windle. 2007. High-performance carbon nanotube fiber. Science 318(5858): 1892-1895.

${ }^{21}$ Vigolo, B., A. Penicaud, C. Coulon, C. Sauder, R. Pailler, C. Journet, P. Bernier, and P. Poulin. 2000. Macroscopic fibers and ribbons of oriented carbon nanotubes. Science 290(5495): 1331-1334.

${ }^{22}$ Ericson, L., H. Fan, H. Peng, V. Davis, W. Zhou, J. Sulpizio, Y. Wang, R. Booker, J. Vavro, C. Guthy, A. Parra-Vasquez, M. Kim, S. Ramesh, R. Saini, C. Kittrell, G. Lavin, H. Schmidt, W. Adams, W. Billups, M. Pasquali, W-F. Hwang, R. Hauge, J. Fisher, and R. Smalley. 2004. Macroscopic, neat, single-walled carbon nanotube fibers. Science 305(5689): 1447-1450.

${ }^{23}$ Liu, T., and S. Kumar. 2003. Effect of orientation on the modulus of SWNT films and fibers. Nano Letters 3 (5): 647-650.

${ }^{24}$ Chawla, K. 1998. Fibrous Materials. Cambridge, U.K.: Cambridge University Press.

${ }^{25} \mathrm{http}: / /$ www2.dupont.com/Directories/en;US/Products Services Index/Performance Fibers Fa brics/Fibers.html.

${ }^{\frac{6}{26}}$ History of Kevlar from the official DuPont site. (URL: www.heritage.dupont.com) Kevlar The Wonder Material The Lawrence Berkeley National Laboratory is operated by the University of California for the United States Department of Energy. (URL: www.lbl.gov/MicroWorlds/Kevlar/).

${ }^{27}$ J. Kalantar, L. T. Drzal, The bonding mechanism of aramid fibres to epoxy matrices; Part $1 \mathrm{~A}$ review of the literature, J. Mater. Sci., 25, 4186-4193 (1990).

${ }^{28}$ G. Li, C. Zhang, Y. Wang, P. Li, Y. Yu, X. Jia, H. Liu, X. Yang, Z. Xue, S. Ryu, Interface correlation and toughness matching of phosphoric acid functionalized Kevlar fiber and epoxy matrix for filament winding composites, Composites Sci. Technol., 68, 3208-3214 (2008).

${ }^{29}$ S. M. Walsh, B. R. Scott, D. M. Spagnuolo, The development of a hybrid thermoplastic ballistic material with application to helmets, $A R L-T R-3700$, December 2005.

${ }^{30}$ S. L. Goodwin, N. J. Abbott, Kevlar Properties Investigation High Speed Abrasion Resistance, Afwal-Tr-80-3004, February 1978 - January 1980 Final Report 1980.

${ }^{31}$ J. F. Graham, C. McCague, O. L. Warren, P. R. Norton, Spatially resolved nano-mechanical properties of Kevlar-49 fibers, Polymer 41 4761-4764 (2000).

${ }_{32}$ T. J. Mulkern, M. N. Raftenberg, Kevlar KM2 yarn and fabric strength under quasi-static tension, $A R L-T R-2865$, October 2002.

${ }^{33} \mathrm{http}: / / \mathrm{www} 2$. dupont.com/Kevlar/en US/uses apps/helmets.html

34 J. W. Downing, Jr., J. A. Newell, Characterization of Structural Changes in Thermally Enhanced Kevlar-29 Fiber, J. Appl. Polym. Sci., 91, 417-424 (2004).

35 M. Cheng, W. Chen, T. Weerasooriya, Experimental investigation of the transverse mechanical properties of a single Kevlar_ KM2 fiber, Internl. J Solids Structures, 41, 62156232 (2004).

http://www2.dupont.com/Kevlar/en_US/products/life protection/kevlar km2.html; Mechanical Properties of Kevlar ${ }^{\circledR}$ KM2 Single Fibre, J. Eng Materials Technology, April 2005, Volume 127, Issue 2, pp.197-204.

${ }^{37}$ M. N. Raftenberg, M. Scheidler, T. J. Moynihan, C. A. Smith, Plain-Woven, 600-Denier Kevlar KM2 Fabric Under Quasistatic, Uniaxial Tension, ARL-TR-3437 March 2005.

${ }^{38} \mathrm{http} / / /$ www2.dupont.com/Kevlar/en_US/uses apps/helmets.html

39 P. M. Cunniff, M. A. Auerbach, High performance "M5" fiber for ballistics/structural composites; http://web.mit.edu/course/3/3.91/www/slides/cunniff.pdf.

${ }^{40} \mathrm{http}: / /$ www.m5fiber.com/magellan/about m5.htm

${ }^{41}$ Teijin leaflet 2010,Twaron $®$ Ballistic material handbook; ballistics@teijinaramid.com 
${ }^{42} \mathrm{http} / /$ armorco.com/shop/category.aspx?catid=2

${ }^{43}$ www.ikolon.com/eng/index.html

${ }^{44} \mathrm{http}: / /$ www.bis.doc.gov/news/2010/doj03182010.htm

$45 \mathrm{http}: / / \mathrm{www} \cdot h$ excel.com/Markets/Ballistics/

$46 \mathrm{http}: / / \mathrm{www} 2 . \mathrm{dupont} . \mathrm{com} /$ Kevlar/en US/news events/article20090929.html

${ }^{47}$ L. A. Utracki, Introduction to Polymer Blends, Chapter 1 in Polymer Blends Handbook. L. A. Utracki, Ed., Polymer Blends Handbook, Kluwer Academic Pub., Dordrecht (2002).

48 M. Naffakh, A. M. Díez-Pascual, C. Marco, M. A. Gómez, I. Jiménez, Novel MeltProcessable Poly(ether ether ketone)(PEEK)/Inorganic Fullerene-like WS2 Nanoparticles for Critical Applications, J. Phys. Chem. B, 114 (35), 11444-11453 (2010).

${ }^{49}$ M. R. Parvaiz, S. Mohanty, S. K. Nayak, P. A. Mahanwar, Polyetheretherketone (PEEK) Composites Reinforced with Fly Ash and Mica, J. Min. Mater. Charact. Eng., 9(1), 25 - 41 (2010).

50 H. Mark, N.M. Bikales, C. G. Overberger, G. Menges and J. I. Kroschwitz, Eds., Encyclopedia of polymer science and engineering, 2-nd ed., 11, 315 - 489, John Wiley \& Sons, New York (1988).

${ }^{51}$ 147Freeguard, G.F., and D. Marshall. 1980. Bullet-resistant glass: A review of product and process technology. Composites 11(1): 25-32.

52148 See http://www.bayerfilms.com/tpu/content.php?p=security-glaze for more information.

${ }^{53}$ Sarva, S.S., and A.J. Hsieh. 2009. The effect of microstructure on the rate-dependent stressstrain behavior of poly(urethane urea) elastomers. Polymer 50(13): 3007-3015.

${ }^{54}$ Uram, Jr., J.R. 1984. Moisture-Resistant Transparent Mercaptan Compositions. U.S. Patent 4,555,450. Available online at http://www.patents. com/us-4555450.html. Last accessed April $13,2011$.

${ }^{55}$ Zaera, R., S. Sánchez-Sáeza, J.L. Pérez-Castellanosa, and C. Navarro. 2000. Modelling of the adhesive layer in mixed ceramic/metal armours subjected to impact. Composites Part A 31(8): 823-833.

${ }^{56}$ Guichelaar, P. 1977. Acheson process. Pp. 115-128 in Carbide, Nitride and Boride Materials Synthesis and Processing, A.W. Weimer, ed. London, U.K.: Chapman and Hall.

${ }^{57}$ Dunn, D., M. Paquette, H. Easter, and R. Pihlaja. Continuous carbothermal reactor. U.S. Patent 4,983,553, filed December 7, 1989, and issued January 8, 1991, to the Dow Chemical Company, Midland, Mich. 3Henley, J., G. Cochran, D. Dunn, G. Eisman, and A. Weimer.

${ }^{58}$ Henley, J., G. Cochran, D. Dunn, G. Eisman, and A. Weimer. Moving bed process for carbothermally synthesizing nonoxide ceramic powders. U.S. Patent 5,370,854, filed January 8 , 1993, and issued December 6, 1994, to the Dow Chemical Company, Midland, Mich.

${ }^{59}$ Zheng, J., and B. Forslund. 1995. Carbothermal synthesis of aluminum oxynitride (AlON) powder: Influence of starting materials. Journal of the European Ceramic Society 15(11): 10871100 .

${ }^{60}$ Bickmore, C., K. Waldner, D. Treadwell, and R. Laine. 1996. Ultrafine spinel powders by flame spray pyrolysis of a magnesium aluminum double alkoxid. Journal of the American Ceramic Society 79(5): 1419-1423.

${ }^{61}$ Moores, S. 2007. Energy prices prune SiC bloom. Industrial Minerals 475: 28-35.

${ }^{62}$ Guichelaar, P. 1977. Acheson process. Pp. 115-128 in Carbide, Nitride and Boride Materials Synthesis and Processing, A.W. Weimer, ed. London, U.K.: Chapman and Hall.

${ }^{63}$ Poch, W., and A. Dietzel. 1962. Formation of silicon carbide from silica and carbon. Berichte der Deutschen Keramischen Gesellschaft 39(8): 413-426

64 11Choi, H-J., Y-W. Kim, M. Mitomo, T. Nishimura, J-H. Lee, and D-Y. Kim. 2004. Intergranular glassy phase free $\mathrm{SiC}$ ceramics retain strength at $1500^{\circ} \mathrm{C}$. Scripta Materialia $50(9)$ : 1203-1207.

65 12Zhou, Y., K. Hirao, M. Toriyama, Y. Yamauchi, and S. Kanzaki. 2001. Effects of intergranular phase chemistry on the microstructure and mechanical properties of silicon carbide 
ceramics densified with rare-earth oxide and alumina additions. Journal of the American Ceramic Society 84(7): 1642-1644.

${ }^{66}$ Thévenot, F. 1990. Boron carbide-A comprehensive review. Journal of the European Ceramic Society 6(4): 205-255.

${ }^{67}$ Suri, A., C. Subramanian, J. Sonber, and T. Murthy. 2010. Synthesis and consolidation of boron carbide: A review. International Materials Review 55(1): 4-40.

${ }^{6} 17 \mathrm{Scott}$, J. 1964. Arc furnace process for the production of boron carbide. U.S. Patent 3,161,471, filed February 25, 1958, and issued December 15, 1964, to Norton Company, Worcester, Mass.

${ }^{69}$ Rafaniello, W., and W. Moore. 1989. Producing boron carbide. U.S. Patent 4,804,525, filed July 14, 1987, and issued February 14, 1989, to the Dow Chemical Company, Midland, Mich.

${ }^{70}$ G. A. Harpell, I. Palley, S. Kavesh, D. C. Prevorsek, Ballistic-resistant fabric article, US Pat., 4,650,710, March 17, 1987; to Allied Corp.

${ }^{71}$ L. C. Lin, L. G. Wilson, A. Bhatnagar, H. L. Li, High strength composite, US Pat., 5,587,230, December 24, 1996, to AlliedSignal Inc

${ }^{72}$ A. Bhatnagar, B. D. Arvidson, Impact resistant rigid composite and method for manufacture, US Pat., 6,642,159, November 4, 2003, to Honeywell International Inc

${ }^{73}$ H. L. Thomas, Jr., Layered ballistic-resistant material, US Pat., 7,700,503, April 20, 2010.

${ }_{74}^{74}$ M. J., Chiou, Flexible penetration resistant article, US Pat., 7,727,914, June 1, 2010.

75 A. Bhatnagar, D. A. Hurst, B. D. Arvidson, L. L. Wagner, Spaced lightweight composite armor, US Pat. 7,762,175, July 27, 2010.

${ }^{76}$ L. A. Utracki, Clay-containing Polymeric Nanocomposites, book 786 pg, RAPRA, Shawbury, Shrewsbury, Shropshire UK (2004).

${ }^{77}$ G. B. Ramaiah, R. Y. Chennaiah, G. K. Satyanarayanarao, Investigation and modeling on protective textiles using artificial neural networks for defense applications, Mater. Sci. Eng. B, 168, 100-105 (2010).

${ }^{78}$ Y. Wei, A. F. Bower, H. Gao, Enhanced strain-rate sensitivity in fcc nanocrystals due to grainboundary diffusion and sliding, Acta Materialia, 56, 1741-1752 (2008).

${ }_{79}$ S. J. Savage, Defence applications of nanocomposite materials, Swedish Defence Research Agency Report FOI-R-1456-SE, ISSN 1650-1942, December 2004.

${ }^{80}$ G. Thilagavathi, A. S. M. Raja, T. Kannaian, Nanotechnology and protective clothing for defence personnel, Defence Sci. J., 58 (4), 451-459 (2008).

${ }^{81}$ S. Gordeyev, T. Crawley, Protective Materials for Emergency Responders, Security Sector Focus Report, April 2010.

${ }^{82} \mathrm{http} / / / \mathrm{www} . w e i z m a n n . a c .11 / \mathrm{ICS} /$ booklet/20/pdf/reshef tenne.pdf

${ }^{83}$ B. Halford, Inorganic Menagerie - Unusual properties of nanotubes made from inorganic materials offer intriguing possibilities for applications, $C \& E N, \mathbf{8 3}$ (35), 30-33 (2005).

84 K. Mylvaganam, L. C. Zhang, Ballistic resistance capacity of carbon nanotubes, Nanotechnology, 18, 4757014 pp (2007).

${ }^{85}$ M. Abrams, Nanoscale armour, Mech. Eng., 128, 34 -37 (2006).

${ }^{86}$ S. Gordeyev, T. Crawley, Protective Materials for Emergency Responders, Security Sector Focus Report, April 2010.

${ }^{87}$ L. A. Utracki, Clay-containing Polymeric Nanocomposites, book 786 pg, RAPRA, Shawbury, Shrewsbury, Shropshire UK (2004).

${ }^{88}$ L. A. Utracki, "Mechanical properties of clay-containing polymeric nanocomposites", in Handbook of polymer Nanocomposites, Rakesh Gupta, Elliot Kennel and Kwang-Jea Kim, Eds., CRC Press, Boca Raton, FL (2009).

${ }^{89}$ Z. Wang, J. Yuan, Y. Xia, A dynamic Monte-Carlo simulation for unidirectional composites under tensile impact, Compos. Sci. $\mid$ Technol., 58, 487 - 495 (1998).

${ }^{90} \mathrm{~K}$. Binder, Ed., Monte Carlo and molecular dynamics simulations in polymer science, Oxford University Press, New York (1995). 
${ }^{91}$ G. Tanaka, L. A. Goettler, Predicting the binding energy for nylon 6,6/clay nanocomposites by molecular modeling, Polymer, 43, 541-553 (2002).

92 D. Brown, P.Mélé, S. Marceau, N.D. Albérola, A molecular dynamics study of a model nanoparticle embedded in a polymer matrix, Macromolecules, 36, 1395-1406 (2003).

${ }^{93}$ M. Vacatello, Monte Carlo simulations of polymer melts filled with solid nanoparticles, Macromolecules, 34, 1946 (2001).

${ }^{94}$ S. Sen, J.D. Thomin, S. K. Kumar, P. Keblinski, Molecular Underpinnings of the Mechanical Reinforcement in Polymer Nanocomposites, Macromolecules, 40, $4059-4067$ (2007).

${ }^{95}$ G. M. Odegard, T. S. Gates, L. M. Nicholson, K. E. Wise, Equivalent-Continuum Modeling With Application to Carbon Nanotubes, NASA/TM-2002-211454; Equivalent continuum modeling of nano-structured materials, Comp. Sci. Tech., 62, 1869-80 (2002).

96 G M. Odegard, T. C. Clancy, T. S. Gates, Modeling of the mechanical properties of nanoparticle/polymer composites, Polymer, 46, 553-562 (2005).

${ }^{97}$ N. Sheng, M. C. Boyce, D. M. Parks, G. C. Rutledge, J. I. Abes, R. E. Cohen, Multiscale micromechanical modeling of polymer/clay nanocomposites and the effective clay particle, Polymer, 45, 487-506 (2004).

98 K. Hbaieb Q. X., Wang Y.H.I. Chia, B. Cotterell, Modelling stiffness of polymer/clay nanocomposites, Polymer, 48, 901-909 (2007).

${ }^{99} \mathrm{R}$. Talreja, Multi-scale modeling in damage mechanics of composite materials, J. Mater. Sci., 41, 6800-6812 (2006).

${ }^{100}$ Mo Song, L. Chen, Molecular Dynamics Simulation of the Fracture in Polymer-Exfoliated Layered Silicate Nanocomposites, Macromol. Theory Simul., 15, 238-245 (2006).

${ }^{101}$ S. Yadav, E. A. Repetto, G. Ravichandran, M. Ortiz, A computational study of the influence of

thermal softening on ballistic penetration in metals, Internl. J. Impact Eng., 25(8), 787-803 (2001).

${ }^{102} \mathrm{R}$. Talreja, Multi-scale modeling in damage mechanics of composite materials, J. Mater. Sci., 41, 6800-6812 (2006).

${ }^{103} \mathrm{~F}$. R. Jones, A review of interphase formation and design in fibre-reinforced composites, $J$. Adhesion Sci. Technol., 24, 171-202 (2010).

${ }^{104}$ J. Kalantar, L. T. Drzal, The bonding mechanism of aramid fibres to epoxy matrices; Part $1 \mathrm{~A}$ review of the literature, J. Mater. Sci., 25, 4186-4193 (1990).

${ }^{105} \mathrm{Y}$. Wu, G. C. Tesoro, Chemical modification of Kevlar fiber surfaces and of model di-amides, J. Appl. Polym. Sci., 31, 1041 - 1059 (1986).

106 T. K. Lin, S. J. Wu, J. G. Lai, S. S. Shyu, The Effect of chemical treatment on reinforcement/matrix interaction in Kevlar-fiber/bismaleimide composites, Compos Sci Technol., 60, 1873-8 (2000).

${ }^{107}$ G. Li, C. Zhang, Y. Wang, P. Li, Y. Yu, X. Jia, H. Liu, X. Yang, Z. Xue, S. Ryu, Interface correlation and toughness matching of phosphoric acid functionalized Kevlar fiber and epoxy matrix for filament winding composites, Composites Sci. Technol., 68, 3208-3214 (2008).

${ }^{108}$ K. Mason, Sizing up fiber sizings, Compos. Technol., April 2006.

109 M. Tanoglu, S. H. Mcknight, G. R. Palmese, W. Gillespie. Jr., Dynamic stress/strain response of the lnterphase in polymer matrix composites, Polym. Compos., 22 (5), 621 - 635 (2001).

${ }^{110}$ H. C. Tang, T. Nguyen, T.-J. Chuang, J. Chin, J. Lesko, H. F. Wu, Fatigue model for fiberreinforced polymeric composites, J. Mater. Civil Eng., 12 (2) 97 - 104 (2000).

111 J. R. Pelch, J. E. Ritter, A. J. Lesser, T. P. Russell, T. J. Lardner Fatigue resistance of silanebonded epoxy/glass interfaces using neat and rubber-toughened epoxies, J. Mater. Sci., 37, $3269-3276$ (2002).

${ }^{112}$ R. E. Jensen, S. H. McKnight, M. J. Quesenberry, Strength and durability of glass fiber composites treated with multicomponent sizing formulations, ARL-TR-2655 (2002). 
${ }^{113}$ Y. X. Gan, Effect of interface structure on mechanical properties of advanced composite materials, Int. J. Mol. Sci. 10, 5115-5134 (2009).

${ }^{114}$ P. J. de Lange, P. G. Akker, A. J. H. Maas, A. Knoester, H. H. Brongersma, Adhesion activation of Twaron ${ }^{\circledR}$ aramid fibres studied with low-energy ion scattering and $\mathrm{x}$-ray photoelectron spectroscopy, Surface Interface Analysis, 31 (12), 1079 - 1084 (2001)

${ }^{115}$ I. Ahmad, T. S. Chin, C. K. Cheong, A. Jalar and I. Abdullah, Study of Fiber Surface Treatment on Reinforcement/Matrix Interaction in Twaron Fiber/ENR Composites, Am. J.Appl. Sci., (Sp. Issue): 14-20 (2005)

${ }^{117}$ N. A. Siddiqui, M.-L. Sham, B. Z. Tang, A. Munir, J.-K. Kim, Tensile strength of glass fibres with carbon nanotube-epoxy nanocomposite coating, Composites, A40 1606-1614 (2009).

${ }^{118}$ R. J. Zaldivar, J. Nokes, G. L. Steckel, H. I. Kim, B. A. Morgan, The effect of atmospheric plasma treatment on the chemistry, morphology and resultant bonding behavior of a panbased carbon fiber-reinforced epoxy composite, J. Compos. Mater., 44 (2), 137 - 156 (2010).

${ }^{119}$ J. W. Gillespie Jr, L. A. Carlsson, A. J. Smiley, Rate-dependent mode i interlaminar crack growth mechanisms in graphite/epoxy and graphite/PEEK, Compos. Sci. Technol.,28, 1-15 (1987).

${ }^{120}$ P. J. Biermann, J. C. Roberts, R. Reidy, Richard, Impact resistant flexible body device, US Pat. 7,413,809, 19.08.2008.

${ }^{121}$ Shockey, D.A., J.W. Simons, and D.R. Curran. 2010. The damage mechanism route to better armor materials. International Journal of Applied Ceramic Technology 7(5): 566-573.

${ }^{122}$ Wright, S.C., N.A. Fleck, and W.J. Stronge. 1993. Ballistic impact of polycarbonate: An experimental investigation. International Journal of Impact Engineering 13(1): 1-20.

${ }^{123}$ Shockey, D., J. Simons, and D. Curran. The damage mechanism route to better armor materials. International Journal of Applied Ceramic Technology 7(5): 566-573.

124 12Shockey, D.A., D.C. Erlich, and J.W. Simons. 2004. Lightweight Ballistic Protection of Flight-Critical Components on Commercial Aircraft, Part 2: Large-Scale Ballistic Impact Tests and Computational Simulations, DOT/ FAA/AR-04/45,P2. Available online at http://www.tc.faa.gov/its/worldpac/ techrpt/ar04-45p2.pdf. Last accessed April 15, 2011

${ }^{125}$ Shockey, D.A., D.C. Erlich, and J. W. Simons. 2004. Lightweight Ballistic Protection of Flight-Critical Components on Commercial Aircraft, Part 2: Large-Scale Ballistic Impact Tests and Computational Simulations, DOT/FAA/AR-04/45,P2. Available online at http://www.tc.faa.gov/its/worldpac/techrpt/ar04-45p2.pdf. Last accessed April 15, 2011.

${ }^{126}$ Hearle, J.W.S., B. Lomas, and W.D. Cooke. 1998. Atlas of Fibre Fracture and Damage to Textiles. Boca Raton, Fla.: CRC Press.

127 Allen, S.R. 1983. Mechanical and morphological correlations in poly-(p-phenylene benzobisthiazole) fibers. Ph.D. Dissertation. Amherst, Mass.: University of Massachusetts.

${ }^{128}$ Shockey, D.A., J.W. Simons, and D.R. Curran. 2010. The damage mechanism route to better armor materials. International Journal of Applied Ceramic Technology 7(5): 566-573.

129 Cheeseman, B.A., and T.A. Bogetti. 2003. Ballistic impact into fabric and compliant composite laminates. Composite Structures 61(1-2): 161-173

${ }_{130} 105$ Cunniff, P.M. 1992. An analysis of the system effects in woven fabrics under ballistic impact. Textile Research Journal 62(9): 495-509.

131 Grujicic, M., W.C. Bell, G. Arakere, T. He, X. Tie, and B.A. Cheeseman. 2010. Development of a meso-scale material model for ballistic fabric and its use in flexible-armor protection systems. Journal of Materials Engineering and Performance 19(1): 22-39.

${ }^{132}$ Termonia, Y., P. Meakin, and P. Smith. 1986. Theoretical study of the influence of strain rate and temperature on the maximum strength of perfectly ordered and oriented polyethylene. Macromolecules 19(1): 154-159. 
${ }^{133}$ Shim, V., C. Lim, and K. Foo. 2001. Dynamic mechanical properties of fabric armour. International Journal of Impact Engineering 25(1): 1-15.

${ }^{134} \mathrm{Gu}$, B. 2003. Analytical modeling for the ballistic perforation of planar plain-woven fabric target by projectile. Composites Part B: Engineering 34(4): 361-371.

${ }^{135}$ Wang, Y., and Y. Xia. 1998. The effects of strain rate on the mechanical behaviour of kevlar fibre bundles: an experimental and theoretical study. Composites Part A: Applied Science and Manufacturing 29(11): 1411-1415.

${ }^{136}$ Zhou, Y., D. Jiang, and Y. Xia. 2001. Tensile mechanical behavior of T300 and M40J fiber bundles at different strain rate. Journal of Materials Science 36(4): 919-922.

${ }^{137}$ Wang, Y., and Y. Xia. 1999. Experimental and theoretical study on the strain rate and temperature dependence of mechanical behaviour of Kevlar fibre. Composites Part A: Applied Science and Manufacturing 30(11): 1251-1257.

${ }^{138}$ Shockey, D., J. Simons, and D. Elrich. 2001. Improved barriers to turbine engine fragments: interim report III. May, 2001. Available online

http://oai.dtic.mil/oai/oai?verb=getRecord\&metadataPrefix=html\&identifier=ADA392533. Accessed April 5, 2011.

${ }^{139}$ Montgomery, T., P Grady, and C. Tomasino. 1982. The effects of projectile geometry on the performance of ballistic fabrics. Textile Research Journal 52(7): 442-450.

${ }^{140}$ Kirkland, K., T. Tam, and G. Weedon. 1991. New third-generation protective clothing from high-performance polyethylene fiber: From knives to bullets. Pp. 214-237 in High-Tech Fibrous Materials, ACS Symposium Series. American Chemical Society.

${ }^{141}$ Kozey,V. H. Jiang, V. Mehta,and S. Kumar. 1995. Compressive behavior of materials: Part 2. high-performance fibers. Journal of Materials Research 10)4): 1044-1061.

${ }^{142}$ 12Chawla, K. 2002. Fiber fracture: An introduction. Pp. 3-26 in Fiber Fracture. M. Elices and J. Llorca, eds. Oxford, U.K.: Elsevier Science.

143 Carr, D. 1999. Failure mechanisms of yarns subjected to ballistic impact. Journal of Materials Science Letters 18(7): 585-588.

${ }^{144}$ Tan, V., C. Lim, and C. Cheong. 2003. Perforation of high-strength fabric by projectiles of different geometry. International Journal of Impact Engineering 28(2): 207-222.

${ }^{145}$ Lim, C., V. Tan, and C. Cheong. 2002. Perforation of high-strength double-ply fabric system by varying shaped projectiles. International Journal of Impact Engineering 27(6): 577-591.

146 Carr, D. 1999. Failure mechanisms of yarns subjected to ballistic impact. Journal of Materials Science Letters 18(7): 585-588.

${ }^{147}$ Prosser, R., S. Cohen, and S. Cohen. 2000. Heat as a factor in the penetration of cloth ballistic panels by 0.22 caliber projectiles. Textile Research Journal 70(8): 709-722.

${ }^{148}$ Cunniff, P. 1999. Dimensionless parameters for optimization of textile-based body armor systems. Pp. 1303-1310 in Proceedings of the $18^{\text {th }}$ International Symposium on Ballistics, San Antonio, Texas. W.G. Reinecke, ed. Lancaster, Penn.: Technomic.

${ }^{149}$ Rao, Y., and R.J. Farris. 2000. Modeling and experimental study of the influence of twist on the mechanical properties of high-performance fiber yarns. Journal of Applied Polymer Science 77(9): 1938-1949.

${ }^{150}$ Cunniff, P.M. 1992. An analysis of the system effects in woven fabrics under ballistic impact. Textile Research Journal 62(9): 495-509.

${ }^{151}$ Shockey, D.A., D.C. Elrich, and J.W. Simmons. 2001. Improved Barriers to Turbine Engine Fragments: Interim Report III, DOT/FAA/AR-99/8, III. Menlo Park, Calif.: SRI International.

${ }^{152}$ Chitrangad, I., 1993. Hybrid Ballistic Fabric, Patent No. 5,187,003. Available online at http://www.freepatentsonline.com/5187003.pdf. Last accessed April 12, 2011.

${ }^{153}$ Tan, V.B.C., V.P.W. Shim, and X. Zeng. 2005. Modelling crimp in woven fabrics subjected to ballistic impact. International Journal of Impact Engineering 32(1-4): 561-574.

${ }^{154}$ Shockey, D.A., D.C. Elrich, and J.W. Simmons. 2001. Improved Barriers to Turbine Engine Fragments: Interim Report III, DOT/FAA/AR-99/8, III. Menlo Park, Calif.: SRI International. 
${ }^{155}$ 114Cunniff, P.M. 1992. An analysis of the system effects in woven fabrics under ballistic impact. Textile Research Journal 62(9): 495-509.

${ }^{156} 115 \mathrm{Lim}$, C.T., V.B.C. Tan, and C.H. Cheong. 2002. Perforation of highstrength double-ply fabric system by varying shaped projectiles. International Journal of Impact Engineering 27(6): 577-591.

${ }^{157}$ Montgomery, T.G., P.L. Grady, and C. Tomasino. 1982. Effects of projectile geometry on the performance of ballistic fabrics. Textile Research Journal 52(7): 442-450.

${ }^{158}$ Grogan, J., S.A. Tekalur, A. Shukla, A. Bogdanovich, and R.A. Coffelt. 2007. Ballistic resistance of $2 \mathrm{D}$ and $3 \mathrm{D}$ woven sandwich composites. Journal of Sandwich Structures \& Materials 9(3): 283-302.

159 Lim, C.T., V.B.C. Tan, and C.H. Cheong. 2002. Perforation of highstrength double-ply fabric system by varying shaped projectiles. International Journal of Impact Engineering 27(6): 577-591.

${ }^{160}$ Montgomery, T.G., P.L. Grady, and C. Tomasino. 1982. Effects of projectile geometry on the performance of ballistic fabrics. Textile Research Journal 52(7): 442-450.

${ }^{161}$ Prosser, R.A., S.H Cohen, and R.A. Segars. 2000. Heat as a factor in the penetration of cloth ballistic panels by 0.22 caliber projectiles. Textile Research Journal 70: 709-722.

162 Tan, V.B.C., C.T. Lim, and C.H. Cheong. 2003. Perforation of highstrength fabric by projectiles of different geometry. International Journal of Impact Engineering 28(2): 207-222.

${ }_{163}$ Shim, V.P.W., V.B.C Tan, and T.E Tay. 1995. Modelling deformation and damage characteristics of woven fabric under small projectile impact. International Journal of Impact Engineering 16(4): 585-605.

${ }^{164}$ Shockey, D.A., J.W. Simons, and D.C. Erlich. 1999. Improved Barriers to Turbine Engine Fragments: Interim Report I, DOT/FAA/AR-99/8, I.Menlo Park, Calif.: SRI International.

${ }^{165}$ Chitrangad, I., 1993. Hybrid Ballistic Fabric. U.S. Patent 5,187,003. Available online at http://www.freepatentsonline.com/5187003.pdf. Last accessed April 12, 2011.

${ }^{166}$ Zeng, X.S., V.P.W. Shim, and V.B.C. Tan. 2005. Influence of boundary conditions on the ballistic performance of high-strength fabric targets. International Journal of Impact Engineering 32(1-4): 631-642.

${ }_{167}$ Tan, V.B.C., C.T. Lim, and C.H. Cheong. 2003. Perforation of highstrength fabric by projectiles of different geometry. International Journal of Impact Engineering 28(2): 207-222.

${ }_{168}$ Briscoe, B.J., and F. Motamedi. 1992. The ballistic impact characteristics of aramid fabrics: The influence of interface friction. Wear 158 (1-2): 229-247.

169 Duan, Y., M. Keefe, T.A. Bogetti, and B.A. Cheeseman. 2005. Modeling friction effects on the ballistic impact behavior of a single-ply high-strength fabric. International Journal of Impact Engineering 31(8): 996-1012.

${ }^{170}$ Dischler, L. 2001. Bullet Resistant Fabric and Method of Manufacture. U.S. Patent 6,248,676. Available online at http://www.google.com/patents/ about?id=nGsIAAAAEBAJ\&dq=MartinElectronics\&ie=ISO-8859-1. Last accessed April 12, 2011.

${ }^{171}$ 2Naik, N., and A. Doshi. 2008. Ballistic impact behaviour of thick composites: Parametric studies. Composite Structures 82(3): 447-464.

${ }^{172}$ Guoqi, Z., W. Goldsmith, and C.K.H. Dharan. 1992. Penetration of laminated Kevlar by projectiles-I. Experimental investigation. International Journal of Solids and Structures 29(4): $399-420$.

${ }^{173}$ Morye, S., P. Hine, R. Duckett, D. Carr, and I. Ward. 2000. Modelling of the energy absorption by polymer composites upon ballistic impact. Composites Science and Technology 60(14): 2631-2642

${ }^{174}$ Naik, N.K. 2005. Ballistic impact behaviour of woven fabric composites: Parametric studies. Materials, Science and Engineering: A 412(1-2): 104-116.

${ }^{175} \mathrm{Wu}$, E., and L.-C. Chang. 1995. Woven glass/epoxy laminates subject to projectile impact. International Journal of Impact Engineering 16(4): 607-619. 
${ }^{176}$ Naik, N., and K. Reddy. 2002. Delaminated woven fabric composite plates under transverse quasi-static loading: experimental studies. Journal of Reinforced Plastics and Composites 21(10): 869-877.

${ }^{177} \mathrm{Wu}$, E., and L.-C. Chang. 1995. Woven glass/epoxy laminates subject to projectile impact. International Journal of Impact Engineering 16(4): 607-619.

178 Naik, N. 2006. Ballistic impact behaviour of woven fabric composites: Formulation. International Journal of Impact Engineering 32(9): 1521-1552.

${ }^{179}$ Cantwell, W., and J. Morton. 1990. Impact perforation of carbon fibre reinforced plastic. Composites Science and Technology 38(2): 119-141.

${ }^{180}$ Goldsmith, W., C.K.H. Dharan, and H. Chang. 1995. Quasi-static and ballistic perforation of carbon fiber laminates. International Journal of Solids and Structures 32(1): 89-103.

181 Naik, N., and P. Shrirao. 2004. Composite structures under ballistic impact. Composite Structures 66(1-4): 579-590.

${ }^{182}$ Ballistic Resistance of Body Armor NIJ Standard 0101.04. National Institute of Justice. http://www.nlectc.org. June 2001

${ }^{183}$ S. B. Seymour, C. E. Carraher, Polymer Chemistry-An Introduction, 2nd Edition (Marcel Dekker, New York, 1988)

${ }_{184}$ A. R. Tripathy, W. Chen, S. N. Kukureka, W. J. MacKnight, Polymer 44, 1835 (2003).

${ }^{185}$ K. Nakane, T. Kurita, T. Ogihara, N. Ogata, Composites Part B 35, 219 (2004).

${ }^{186}$ A. K. Dhaliwal, J. N. Hay, Thermochim. Acta 391, 245 (2002).

${ }^{187}$ M. García, G. van Vliet, S. Jain, B. A. G. Schrauwen, A. Sarkissov, W. E. van Zyl, B. Boukamp, Rev. Adv. Mater. Sci. 6, 169 (2004).

${ }^{188}$ X. Li, H. L. Cao, S. Gao, F. Y. Pan, L. Q. Weng, S. H. Song, Y. D. Huang, Plast. Rubber Compos. 37, 223 (2008).

${ }^{189}$ I. Živković, P. Perišić, Z. Burzić, P. Uskoković, R. Aleksić, J. Adv. Mater. 37, 23 (2005).

${ }^{190}$ Y.S. Lee, E.D. Wetzel, N.J. Wagner, J. Mater. Sci. 38, 2825 (2003).

${ }^{191}$ H. Mahfuz, F. Clements, V. Rangari, V. Dhanak, G. Beamson, J. Appl. Phys. 105, 064307 (2009).

192 D. Stojanovic, A. Orlovic, S. Markovic, V. Radmilovic, P. S. Uskokovic, R. Aleksic, J. Mater. Sci. 44, 6223 (2009).

${ }^{193}$ J. L. H. Chau, C.-T. Tung, Y-M. Lin, A-K. Li, Mater. Lett. 62, 3416 (2008).

${ }^{194}$ A. Nair, R. L. White, J. Appl. Polym. Sci. 60, 1901 (1996).

${ }^{195}$ D. V. Cunningham, U.S. Patent, 7,407,900 B2 (2008)

${ }^{196}$ B. B. Sauer, U.S. Patent, 7,556,857 B2 (2009).

${ }^{197}$ N. J. Wagner, E. D. Wetzel, U.S. Patent, 7,498,276 B2 (2009).

${ }^{198}$ N. J. Wagner, J. F. Brady, Phys. Today, 62, 27 (2009).

${ }^{199}$ N. J. Wagner, J. Nam, H. Caroline, U.S. Patent, 0093240 A1, (2010).

${ }^{200} \mathrm{http}$ ://dspace.mit.edu/bitstream/handle/1721.1/15021/15231970.pdf

201 M. García, G. van Vliet, S. Jain, B. A. G. Schrauwen, A. Sarkissov, W. E. van Zyl, B. Boukamp, Rev. Adv. Mater. Sci. 6, 169 (2004).

${ }^{202}$ X. Li, H. L. Cao, S. Gao, F. Y. Pan, L. Q. Weng, S. H. Song, Y. D. Huang, Plast. Rubber Compos. 37, 223 (2008)

${ }^{203}$ M. Torki, I. Zivkovic, V. R. Radmilovic, D. B. Stojanovic, V. J. Radojevic, P. S. Uskokovic, R. R. Aleksic, Int. J. Mod. Phys. B, 24, 805 (2010).

${ }^{204}$ Y. S. Lee, E. D. Wetzel, N. J. Wagner, J. Mater. Sci., 38, 2825 (2003).

${ }^{205}$ H. Mahfuz, F. Clements, V. Rangari, V. Dhanak, G. Beamson, J. Appl. Phys., 105, 064307 (2009).

${ }^{206}$ T. A. Hassan, V. K. Rangari, S. Jeelani, Mater. Sci. Eng. A, 527, 2892 (2010).

${ }^{207}$ V. B. C. Tan, T. E. Tay, W. K. Teo, Int. J. Solids Struct., 42, 1561 (2005).

${ }^{208} \mathrm{http}: / /$ www.szbluestar.com.cn/kemira/Mowital\%20Schulung\%20PVB.pdf

${ }^{209}$ www.teijinp-aramid.com 
${ }^{210}$ Dynasylan ${ }^{\circledR}$ Adhesion Promotors, Hüls, Technical Bulletin

${ }^{211}$ A. Gonzalez-Valadez, J. M. Cervantes-Uc, L. Veleva, Polym. Degrad. Stab., 63, 253 (1999)

${ }^{212}$ J. S. Kang, C. Yu, F. Zhang, Iran. Polym. J., 18, 927 (2009).

${ }^{213}$ C. Morterra, M. J. D. Low, Carbon, 23, 525 (1985).

${ }^{214}$ M. Aurilia, F. Piscitelli, L. Sorrentino, M. Lavorgna, S. Iannace, Eur. Polym. J., 47, 925 (2011).

${ }^{215}$ Y. Takahashi, J. Appl. Polym. Sci., 5, 468 (1961). 